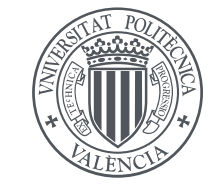

UNIVERSITAT

POLITĖCNICA

DE VALÈNCIA

\title{
Methodology for the optimal management design of water resources system under hydrologic uncertainty
}

\section{Tesis doctoral}

\author{
Presentada por \\ David Haro Monteagudo \\ Directores \\ Abel Solera Solera \\ Joaquín Andreu Álvarez \\ Programa doctoral: \\ Ingeniería Hidráulica y Medio Ambiente
}

Beca de estudios:

FPI MICINN BES-2010-034595

Diciembre 2014 

A Ramón, Ana, Pilar,

Hortensia y Eleuterio

La incertidumbre es una posición incómoda. Pero la certeza es una posición absurda

François Marie Arouet, "Voltaire"

Sin agua, nada somos. Hasta un emperador, privado de agua, se vería pronto reducido a polvo. El agua es el auténtico monarca y todos somos sus esclavos.

Salman Rushdie, La encantadora de Florencia 



\section{Agradecimientos}

En primer lugar a mis directores de tesis, Abel y Joaquín, por brindarme la oportunidad, hace ya más de cinco años, de entrar en el mundo de la investigación. Sin esa llamada telefónica días después de presentar mi proyecto final de carrera todo habría seguido un curso completamente distinto.

Agradecer también al Ministerio de Ciencia e Innovación, primero, y al Ministerio de Economía y Competitividad, después, por la financiación recibida a través de la beca FPI BES-2010-034595 asociada al proyecto INTEGRAME.

Gracias a los revisores de la tesis, Luis Garrote, Bonifacio Fernández y María Máñez por las positivas evaluaciones y por sus sugerencias que ayudaron a mejorar la forma final de la tesis.

A los pececillos que han nadado junto a mí todos estos años en el micro clima de 'La Pecera' (incluidos los sediciosos de 'La Pecera Norte'). A los que están: Andrea, Néstor, Edgar, María, Mario, Coco, Antonio, Héctor, Jesús, Ana y Alberto. Sí, a los peces pequeños también os incluyo aunque acabéis de llegar. Y gracias adicionales Andrea por la revisión del valenciano. Y a los que se fueron: Myky, Melina, Ana, Zohara, Ana Fe, César, Lenin, y Anahí. Por supuesto, no puedo olvidarme de Jessica, Adrián y Javier que, sin ser miembros natos del cardumen, siempre han nadado junto a nosotros.

También quiero darle las gracias a los demás miembros del Grupo de Ingeniería de Recursos Hídricos: Javier Paredes, Carlos Segura, Manuel 
Pulido, Miguel Ángel Pérez por haberme ayudado, de una manera u otra, a lo largo de estos años. También quiero extender este agradecimiento a los miembros de secretaría del Departamento de Ingeniería Hidráulica y Medio Ambiente: Merche, Rosa y Javier, por ayudarme con las gestiones que he tenido que realizar. Perdón también por las molestias ocasionadas, en especial aquellas relacionadas con calentar la comida todos los días a las 13:30, donde entramos toda la marabunta a usar los microondas. Y gracias a Carlos García, Vicente Montes y Diana Pastor, por lo mismo que a los tres anteriores, aunque sin las disculpas del microondas.

Saliendo de la universidad, también es importante agradecer un trocito de esta tesis a otras personas que, en mayor o menor medida, me han ayudado a mantener la línea de flotación durante todo este tiempo.

A quienes me aguantaron en Nebraska seis meses e hicieron que me sintiera como en casa: Cristina, Heather, Ramón, Roy, Carlos, Levy, Luis, Marta, Paloma, Jill, Anna, Erika, Paul... y toda la gente que pude conocer.

Alejandro, gracias por ayudarme con el diseño de la portada. Capote, gracias por venir a Nebraska con Alberto. Y por los gin-tonics. Pilar, gracias por ser un sol. Mario, crack. Dani, padre-abuelo. Javi y Javi, andéis por donde andéis, también me acuerdo de vosotros. Jesús, porque trasciendes el tiempo y el espacio. Olga, por haberme perdonado.

Javi y Carmen (e Inés y Carmén), Sergio y Reyes (y lago), Pablo, María, Carlos, Fran, Alf y Marta (y Carmen), que sois mis amigos de toda la vida, aunque las circunstancias a veces obliguen a que no nos veamos tanto. 
A Jessica, por haber aparecido.

Por último, pero no por ello menos importante, esta tesis ha de agradecerse, y mucho, a mi familia. A mis padres, Ana y José Ramón, todos estos años de apoyo continuado en todas las decisiones que he tomado. $Y$ no sólo me refiero a los últimos cinco años. Por preocuparse por mí tanto que, en comparación, parece que yo no me preocupo por nada. A mi tía Pilar, porque es evidente su influencia en mi evolución académica y personal. Ahora, el 33.3\% de la familia somos doctores, no está nada mal. Y a mis abuelos, Hortensia y Eleuterio, que junto con las tres personas anteriores son un elemento clave de mi vida, pese a que yo pueda ser un algo descastado muchas veces. Os quiero a los cinco.

Gracias a todos. 



\section{Resumen}

Un sistema de gestión de sequías apropiado requiere de la anticipación de los posibles efectos que un episodio de este tipo tenga sobre el sistema de recursos hídricos. Esta tarea sin embargo resulta más complicada de lo que parece. En primer lugar, debido al alto grado de incertidumbre existente en la predicción de variables hidrológicas futuras. Y en segundo, debido al riesgo de sobrerreacción en la activación de medidas de mitigación generando falsa sensación de escasez, o sequía artificial. A este respecto, los planes especiales de sequía proveen de herramientas para la gestión eficiente de situaciones con escasez de recursos y la preparación de cara a futuros eventos. De todos modos, las diferentes estrategias de operación seguidas en cada sistema de recursos hídricos hacen que las herramientas que en algunos casos resultaron altamente útiles no lo sean tanto cuando se aplican en sistemas distintos.

Debido a la falta de tiempo y/o al exceso de confianza en los trabajos realizados por terceros, con excelentes resultados en sus respectivos casos, a veces se cae en el error de implementar metodologías no del todo apropiadas en sistemas con requisitos completamente distintos. El desarrollo y utilización de metodologías generalizadas aplicables a diferentes sistemas y capaces de proporcionar resultados adaptados a cada caso es, por tanto, muy deseable. Este es el caso de las herramientas de modelación de sistemas de recursos hídricos generalizadas. Estas permiten homogeneizar los procesos mientras siguen siendo los suficientemente adaptables para proporcionar resultados apropiados para cada caso de estudio. 
Esta tesis presenta una serie de herramientas destinadas a avanzar en el análisis y comprensión de los sistemas de recursos hídricos, haciendo énfasis en la prevención de sequías y la gestión de riesgos. Las herramientas desarrolladas incluyen: un modelo de optimización generalizado para esquemas de recursos hídricos, con capacidad para la representación detallada de cualquier sistema de recursos hídricos, y una metodología de análisis de riesgo basada en la optimización de Monte Carlo con múltiples series sintéticas. Con estas herramientas es posible incluir tanto la componente superficial como la subterránea del sistema estudiado dentro del proceso de optimización. La optimización está basada en la resolución iterativa de redes de flujo. Se probó la consistencia y eficiencia de diferentes algoritmos de resolución para encontrar un balance entre la velocidad de cálculo, el número de iteraciones, y la consistencia de los resultados, aportando recomendaciones para el uso de cada algoritmo dadas las diferencias entre los mismos.

Las herramientas desarrolladas se aplican en dos casos de estudio reales en la evaluación y posibilidad de complementación de los sistemas de monitorización y alerta temprana de sequías existentes en los mismos. En el primer caso, se propone un enfoque alternativo para la monitorización de la sequía en el sistema de operación anual del río Órbigo (España), complementándolo con la utilización de la metodología de análisis de riesgo. En el segundo caso, las herramientas se emplean en un sistema con una estrategia de operación completamente distinta. Se estudia como el análisis de riesgo de la gestión óptima puede ayudar a la activación anticipada de los escenarios de sequía en los sistemas de los ríos Júcar y Turia, cuya operación es hiperanual. En esta ocasión, el sistema de 
indicadores existente goza de una gran confianza por parte de los usuarios. La metodología de análisis de riesgo es, sin embargo, capaz de anticipar los eventos de sequía con mayor alarma, aspecto que es deseable si se quiere evitar que los episodios en desarrollo vayan a más. En ambos casos se muestra como la evaluación anticipada de las posibles situaciones futuras del sistema permiten una definición confiable de los escenarios de sequía con suficiente antelación para la activación efectiva de medidas de prevención y/o mitigación en caso de ser necesarias.

La utilización de indicadores provenientes de modelos frente a indicadores basados en datos observados es complementaria y ambos deberían utilizarse de forma conjunta para mejorar la gestión preventiva de los sistemas de recursos hídricos. El empleo de modelos de optimización en situaciones de incertidumbre hidrológica es muy apropiado gracias a la no necesidad de definir reglas de gestión para obtener los mejores resultados del sistema, y teniendo en cuenta que las reglas de operación habituales pueden no ser completamente adecuadas en estas ocasiones. 



\section{Resum}

Un sistema de gestió de sequeres apropiat requereix de l'anticipació dels possibles efectes que un episodi d'aquest tipus té sobre el sistema de recursos hídrics. Aquesta tasca resulta més complicada del que sembla. En primer lloc, per l'alt grau d'incertesa existent en la predicció de variables hidrològiques futures. I en segon, a causa del risc de sobrereacció en l'activació de mesures de mitigació generant falsa sensació d'escassesa, o sequera artificial. Referent a això, els plans especials de sequera proveeixen d'eines per a la gestió eficient de situacions amb escassesa de recursos i la preparació de cara a futurs esdeveniments. De tota manera, les diferents estratègies d'operació seguides en cada sistema de recursos hídrics fan que les eines que en alguns casos van resultar altament útils no ho siguen tant quan s'apliquen en sistemes diferents.

A causa de la manca de temps i/o l'excés de confiança en els treballs realitzats per tercers, amb excel-lents resultats en els seus respectius casos, de vegades es cau en l'error d'implementar metodologies no del tot apropiades en sistemes amb requisits completament diferents. El desenvolupament i utilització de metodologies generalitzades aplicables a diferents sistemes i capaços de proporcionar resultats adaptats a cada cas és, per tant, molt desitjable. Aquest és el cas de les eines de modelació de sistemes de recursos hídrics generalitzades. Aquestes permeten homogeneïtzar els processos mentre segueixen sent prou adaptables per a proporcionar resultats apropiats per a cada cas d'estudi.

Aquesta tesi presenta un seguit d'eines destinades a avançar en l'anàlisi i comprensió dels sistemes de recursos hídrics, fent èmfasi en la 
prevenció de sequeres i la gestió de riscos. Les eines desenvolupades inclouen: un model d'optimització generalitzat per esquemes de recursos hídrics, amb capacitat per a la representació detallada de qualsevol sistema de recursos hídrics, i una metodologia d'anàlisi de risc basada en l'optimització de Monte Carlo amb múltiples sèries sintètiques. Amb aquestes eines és possible incloure tant la component superficial com la subterrània del sistema estudiat dins del procés d'optimització. L'optimització està basada en la resolució iterativa de xarxes de flux. Es va provar la consistència i eficiència de diferents algoritmes de resolució per trobar un balanç entre la velocitat de càlcul, el nombre d'iteracions, i la consistència dels resultats, aportant recomanacions per a l'ús de cada algoritme donades les diferències entre els mateixos.

Les eines desenvolupades s'apliquen en dos casos d'estudi reals en I'avaluació i possibilitat de complementació dels sistemes de monitorització i alerta primerenca de sequeres existents en els mateixos. En el primer cas, es proposa un enfocament alternatiu per a la monitorització de la sequera en el sistema d'operació anual del riu Órbigo (Espanya), complementant-lo amb la utilització de la metodologia d'anàlisi de risc. En el segon cas, les eines s'empren en un sistema amb una estratègia d'operació completament diferent. S'estudia com l'anàlisi de risc de la gestió òptima pot ajudar a l'activació anticipada dels escenaris de sequera en els sistemes dels rius Xúquer i Túria, on l'operació és hiperanual. En aquesta ocasió, el sistema d'indicadors existent gaudeix d'una gran confiança per part dels usuaris. La metodologia d'anàlisi de risc és, però, capaç d'anticipar els esdeveniments de sequera amb major alarma, aspecte que és desitjable si es vol evitar que els episodis en desenvolupament vagen a més. En ambdós casos es mostra 
com l'avaluació anticipada de les possibles situacions futures del sistema permeten una definició fiable dels escenaris de sequera amb suficient antelació per a l'activació efectiva de mesures de prevenció i/o mitigació en cas de ser necessàries.

La utilització d'indicadors provinents de models davant indicadors basats en dades observades és complementària i ambdós tipus s'haurien d'utilitzar de forma conjunta per millorar la gestió preventiva dels sistemes de recursos hídrics. L'ús de models d'optimització en situacions d'incertesa hidrològica és molt apropiat gràcies a la no necessitat de definir regles de gestió per obtenir els millors resultats del sistema, i tenint en compte que les regles d'operació habituals poden no ser completament adequades en aquestes ocasions. 



\section{Summary}

A proper drought preventive system management requires anticipating the possible effects that one episode may have on the system. However, this task reveals to be easy to say but harder to do. First, because of the high degree of uncertainty existing in future hydrological variables prediction. And second, because of the high risk of over reacting if the timing for mitigation measures activation is wrong, generating so-called artificial droughts. On this regard, drought plans supply tools to water managers to effectively handle scarce resources situations and preparing for future events. Anyway, the different operation strategies followed in different water resources systems make that the tools that reveal to be useful for some systems are not that effective in others.

Sometimes, due to lack of time and/or excess of confidence in works realized by third parties with good results for their cases, improper methodologies are implemented in systems with completely different requirements. The development and use of generalized methodologies applicable to different systems capable of yielding appropriate results for each case is then desirable. This is the case of generalized water resources systems modeling tools that allow homogenizing processes while still being particularized enough to yield results that suit the requirements of the system under study.

This thesis presents a series of tools aimed to advance in the analysis and understanding of water resources systems, with particular emphasis in drought prevention and risk management. The tools developed include a general optimization model for water resources schemes, capable 
of including a large amount of elements necessary for the creation of a detailed scheme of any resources system, and a risk assessment methodology based on Monte Carlo optimization fed with synthetic stochastic streamflow series. With these tools, it is possible to consider both the surface and groundwater components of the system under study within the optimization process. Optimization is based in iterative resolution of network flows. The consistency and efficiency of different resolution algorithms was tested in order to find a balance between run speed, number of iterations and consistency of results. Recommendations on the use of each algorithm were given due to the differences found between them.

The tools developed were applied to two real case studies in order to assess and complement the existing drought monitoring and early warning systems. In the first case, an alternative drought monitoring approach for the Orbigo River system (Spain), a within-year operated system, was proposed supported by the use of risk assessment methodologies. In the second case, the tools were applied to a system with a completely different operation basis. It was studied how the optimal risk assessment methodology can complement the existing indicators system in the activation of the different drought scenarios at the Jucar and Turia River basins, with an over-year based operation. This time, the existing drought monitoring system is reliable but the newly applied methodology showed that it is capable of anticipating droughts and more alarmingly, something that is not wrong but even desirable in order to prevent episodes develop worse. In both cases, it is shown how anticipated assessment of the possible situation of the system allows a confident definition of drought 
scenarios with sufficient anticipation for the implementation of mitigating measures if necessary.

The use of model-based indicators in front of observed data based ones is complementary and thus they should be used jointly for improved preventive management of water resources systems. The use of optimization modeling during hydrological uncertainty periods is very appropriate due to systems operation rules are often defined for normality periods, and this kind of models do not require the definition of such rules to find the best management of the system. 



\section{General contents}

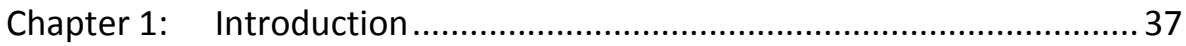

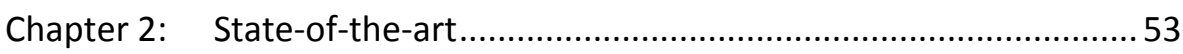

Chapter 3: Advances in NF optimization of WRS ................................. 121

Chapter 4: Application of the new developments ................................. 201

Chapter 5: Summary and conclusions ......................................................259

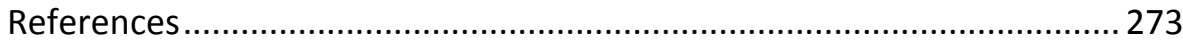

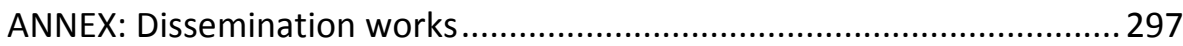

\section{Digital annexes}

Digital Annex A: Sorbe River case of study

Digital Annex B: OPTIGES v3.0 User's Manual

Digital Annex C: Orbigo River Case of Study (data)

Digital Annex D: Jucar-Turia Case of Study (data) 


\section{Table of contents}



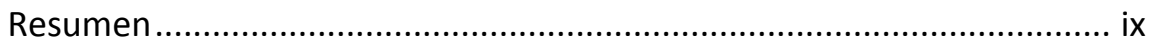

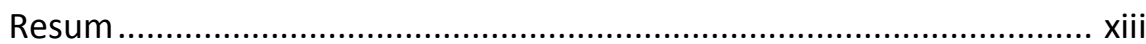

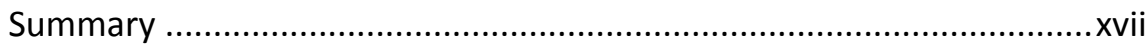

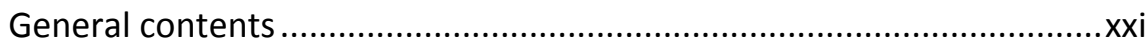

Digital annexes ……......................................................................



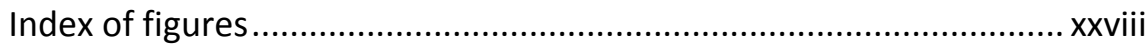

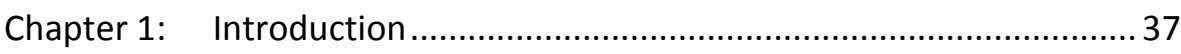

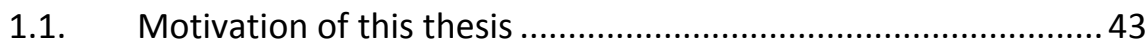



1.3. Description of the contents of this thesis .................................. 45

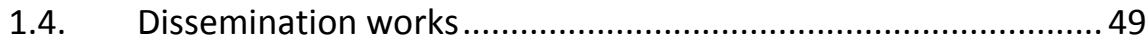

1.4.1. Indexed journal articles ....................................................... 49

1.4.2. Participation in conferences................................................ 50

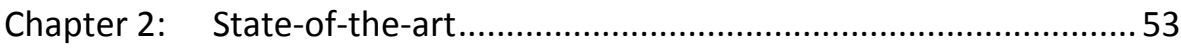

2.1. Drought management and risk assessment in water resources systems 54

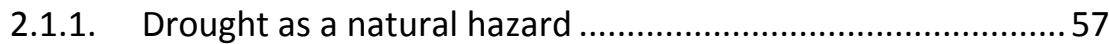

2.1.2. Drought monitoring, forecasting and risk assessment...........60

2.1.3. Planning for drought. Measures for risk and impacts mitigation 66

2.2. Optimization of water resources systems ..................................69






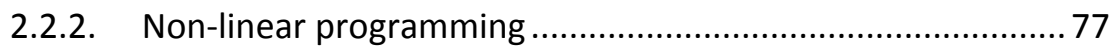

2.2.3. Dynamic programming ...................................................... 79

2.2.4. Computational intelligence (Heuristic optimization) ..............80

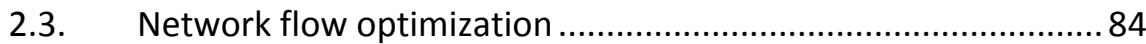

2.3.1. The Minimum Cost Network Flow Problem ..........................87

2.3.2. Algorithms for solving the MCF problem ............................. 89

2.3.3. Application of MCF algorithms in water resources optimization tools 100

2.4. Decision Support Systems for Water Resources Management 104

2.4.1. Role of decision support systems in drought planning and management .................................................................................. 110



Chapter 3: Advances in NF optimization of WRS ................................. 121

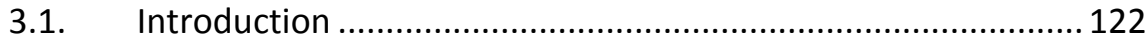

3.2. Network flow optimization and non-linearities. Algorithms, iterations and convergence............................................................... 126

3.2.1. Generalised model formulation and network construction. 127

3.2.2. Introducing non-linear aspects in the network definition.... 129

3.2.3. Solving the minimum cost flow problem.............................. 135

3.2.4. Application to the water resources scheme of the Duero River 136

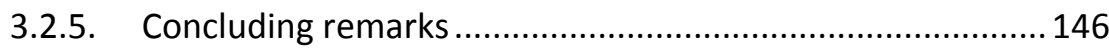

3.3. Incorporation of the conjunctive surface-groundwater component into a multi-period network flow based optimization model 147

3.3.1. New formulation of the generalized optimization model .... 150

3.3.2. Network construction approach for aquifers and design of the




3.3.3. Resolution of the network and setback-stepwise approach for long term optimization horizons. 162

3.3.4. Validation of the results. Application to the Sorbe River case study 164

3.3.5. Concluding remarks. 176

3.4. Assessment of risk with optimal management of water resources systems for decision making support during drought situations 176

3.4.1. Design of a risk assessment process including WRS management optimization model. 179

3.4.2. Application to the Sorbe River case and analysis of the results 185

3.4.3. Conclusive remarks 191

3.5. Incorporation of the new developments into a decision support system shell

3.5.1. Water resources management optimization model OPTIGES 192

3.5.2. Model for risk assessment based in optimal operation of systems OPTIRISK 193

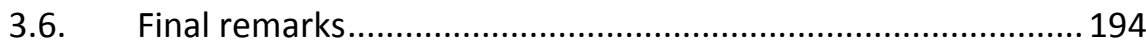

Chapter 4: Application of the new developments .................................. 201

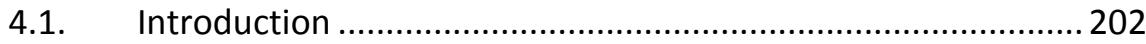

4.2. Case 1: Review of the drought indicators system in the Orbigo

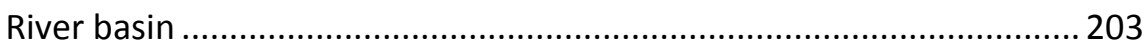

4.2.1. The Orbigo River, a within-year regulated system ...............204

4.2.2. Current drought monitoring and early warning in the Orbigo

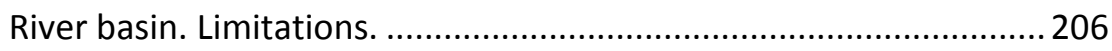

4.2.3. Enhancement of drought preparation with the support of risk assessment methods 
4.3. Case 2: Conjunctive drought risk assessment of the Jucar and Turia River basins ................................................................... 228

4.3.1. The Jucar and Turia River basins .................................... 228

4.3.2. Drought monitoring in the Jucar and Turia River basins ...... 234

4.3.3. Complementary use of drought risk assessment methods and the existing drought indicators system ........................................ 236

4.4. Discussion of the results obtained ..................................... 248

4.4.1. On the cases of study .............................................. 248

4.4.2. On risk based management of water resources systems.... 252

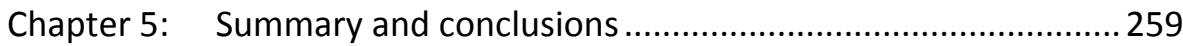

5.1. Summary ................................................................ 259

5.2. Conclusions ................................................................... 262

5.3. Future research lines .................................................... 268

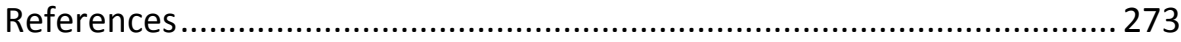

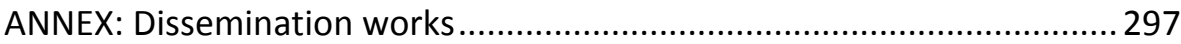

A.1. Indexed journal articles................................................... 297

A.1.1. A model for solving the optimal water allocation problem in river basins with network flow programming when introducing nonlinearities.

297

A.1.2. Methodology for Drought Risk Assessment in Within-year Regulated Reservoir Systems. Application to the Orbigo River System (Spain) 320

A.2. Participation in conferences 345

A.2.1. Incorporating aquifer modeling into a multi-period network flow programming optimization model for water resources management 345

A.2.2. Optimal management of the Jucar River and Turia River basins under uncertain drought conditions 
A.2.3. Current and future drought vulnerability assessment in the Jucar River basin (Spain) . 372 


\section{Index of figures}

Figure 2.1. Example of a water resources system (source: self-elaboration)

Figure 2.2. Implicit stochastic optimization (left) and implicit stochastic optimization (right) methodologies. Source: Labadie (2004). 75 Figure 2.3. Network flow representation of the water resources scheme of figure 2.1 (source: self-elaboration) 86

Figure 3.1. Example system of two reservoirs and two demands with its associated multiperiod network flow scheme (source: Haro et al 2012) .. 129 Figure 3.2. Flow graph of the iterative process in the optimization model (source: Haro et al 2012) 134

Figure 3.3. Duero River basin territory (source: Haro et al 2012). 137

Figure 3.4. Scheme of the Duero River water resources system used for the optimization model developed with AQUATOOL (source: self-elaboration) 138

Figure 3.5. Value of the objective function through iterations 2 to 10 for one year optimization period with $\mathrm{CEV}=4$ (source: Haro et al 2012). 142

Figure 3.6. Value of the convergence criterion and number of iterations needed to reach convergence (source: Haro et al 2012)

Figure 3.7. Network flow representation of an aquifer and its connections with the surface system for an optimization period of $m$ time steps (month in the case of OPTIGES) (source: self-elaboration) 158 Figure 3.8. Flow diagram of the new non-linear calculations routine for OPTIGES including the aquifer (source: self-elaboration)

Figure 3.9. Simplified water resources scheme of the Sorbe River (source: self-elaboration) 166

Figure 3.10. Evolution of the storage volume in the Beleña reservoir before and after the introduction of the Madrid demand (source: self-elaboration)

Figure 3.11. Annual supply deficit to Urban Demand in the Sorbe Water Association before and after the introduction of the Madrid demand (source: self-elaboration) 168 
Figure 3.12. Annual supply deficit to Irrigation Demand in the Sorbe Water Association before and after the introduction of the Madrid demand (source: self-elaboration) 169

Figure 3.13. Annual surface supply to Irrigation Demand in the Sorbe Water Association before and after the introduction of the Madrid demand (source: self-elaboration)

Figure 3.14. Annual groundwater supply to Irrigation Demand in the Sorbe Water Association before and after the introduction of the Madrid demand (source: self-elaboration) 170

Figure 3.15. Evolution of the aquifer strage before and after the introduction of the Madrid demand (source: self-elaboration) 170 Figure 3.16. Annual aquifer discharge from the river before and after the introduction of the Madrid demand. Positive values mean the aquifer is abstracting water from the river bed (source: self-elaboration)

Figure 3.17. Evolution of the stored volume in Beleña reservoir for different optimization steps and setbacks (source: self-elaboration)

Figure 3.18. Irrigation demand shortages in the Sorbe system when considering the groundwater component or not (source: self-elaboration)

Figure 3.19 Urban demand shortages in the Sorbe system when considering the groundwater component or not (source: self-elaboration) 174

Figure 3.20. Madrid demand shortages in the Sorbe system when considering the groundwater component or not (source: self-elaboration) 175

Figure 3.21. Flow chart of the proposed risk assessment methodology (source: self-elaboration)

Figure 3.22. Evolution of the storage level probability in the Beleña Reservoir for a one year risk assessment (source: self-elaboration) 188 Figure 3.23. Evolution of the storage level probability in the Baleña Reservoir for a two years risk assessment (source: self-elaboration) .......189 Figure 3.24. Storage distribution functions in the Beleña reservoir for the month of September 2015 for different anticipation periods (Blues=October; Reds=January; Greens=May) and with different initial conditions. (source: self-elaboration) 190 
Figure 3.25. Storage distribution function in the Beleña reservoir for the month of April 2015 for different anticipation periods (Blues=October; Reds=January) and with different initial conditions. (source: selfelaboration)

Figure 4.1. Location of the Orbigo River basin in the Iberian Peninsula (source: self-elaboration) 205

Figure 4.2. Evolution of the State Index of the Orbigo River basin from October 1999 to September 2013 as obtained with the Drought Plan

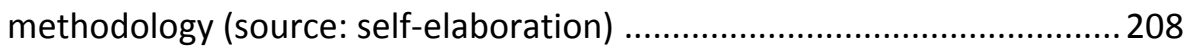
Figure 4.3. Evolution of the State Index of the Orbigo River basin from October 1999 to August 2014 (source: CHD 2014) (source: self-elaboration) 209

Figure 4.4. Historic daily evolution of storage in Barrios de Luna from year 1990-1991 to 2010-2011 (source: self-elaboration)

Figure 4.5. Historic daily evolution of storage in Villameca from year 19901991 to 2010-2011 (source: self-elaboration)

Figure 4.6. Proposed drought scenario thresholds for the state index calculated in Barrios de Luna (source: self-elaboration) 215

Figure 4.7. Proposed drought scenario thresholds for the state index calculated in Villameca (source: self-elaboration).....

Figure 4.8. Evolution of the state index in the Orbigo River basin as calculated with the new thresholds versus the state index calculated as proposed in the drought plans (source: self-elaboration)

Figure 4.9. Scheme of the Orbigo River water resources system developed in AQUATOOL (source: self-elaboration)

Figure 4.10. Storage probability in Barrios de Luna for April 2001 calculated from different previous months (source: self-elaboration)

Figure 4.11. Storage probability in Barrios de Luna for September 2001 calculated from different previous months (source: self-elaboration)......222 Figure 4.12. Storage probability in Barrios de Luna for April 2002 calculated from different previous months (source: self-elaboration) 223

Figure 4.13. Storage probability in Barrios de Luna for September 2002 calculated from different previous months (source: self-elaboration)......224 
Figure 4.14. Storage probability in Villameca for April'01, September'01, April'02 and September'02 (source: self-elaboration). 224

Figure 4.15. Evolution of the state index values in the Orbigo River basin calculated from observed values (black) and with the risk assessment methodology (blue) (source: self-elaboration)

Figure 4.16. Location of the Jucar and Turia River Basins in Iberian Peninsula (source: self-elaboration)

Figure 4.17. Geographical location of Valencia Albufera and level regulation systems (Usaquén Perilla et al., 2012) 232

Figure 4.18. Evolution of the volumes stored in the main reservoirs of the Jucar River basin between October 1990 and September 2010 (source: selfelaboration with data from $\mathrm{CHJ}$ )..... 233 Figure 4.19. Evolution of the volumes stored in the main reservoirs of the Turia River basin between October 1990 and September 2010 (source: selfelaboration with data from $\mathrm{CHJ}$ )...... 233

Figure 4.20. Evolution of the State Index of the Jucar River basin from October 2001 to September 2009 (source: self-elaboration with data provided by $\mathrm{CHJ}$ ). 235

Figure 4.21. Evolution of the State Index of the Turia River basin from October 2001 to September 2009 (source: self-elaboration with data provided by $\mathrm{CHJ}$ ). 235

Figure 4.22. AQUATOOL scheme of the Jucar and Turia water resources systems (source: self-elaboration) 239 Figure 4.23. Evolution of the sum of storages in the main reservoirs of the Jucar River basin (Alarcón, Contreras and Tous) as obtained from simulation with Simges (blue) and observed (red) from 1980 to 2009. (source: selfelaboration). 240

Figure 4.24. Evolution of the sum of storages in the main reservoirs of the Turia River basin (Benageber and Loriguilla) as obtained from simulation with Simges (blue) and observed (red) from 1980 to 2009. (source: selfelaboration) 240

Figure 4.25. Evolution of the volumes stored in the Jucar river basin for different setback-stepwise optimization horizons (source: self-elaboration) 
Figure 4.26. Evolution of the volumes stored in the Turia river basin for different setback-stepwise optimization horizons (source: self-elaboration) 243

Figure 4.27. Evolution of the state index in the Jucar River system calculated from the simulated volumes (blue), from OPTIRISK results (dashed black), and official $\mathrm{CHJ}$ values (black), compared to the drought scenario thresholds (source: self-elaboration) 244

Figure 4.28. Evolution of the state index in the Turia River system calculated from the simulated volumes (blue), from OPTIRISK results (dashed black), and official $\mathrm{CHJ}$ values (black), compared to the drought scenario thresholds (source: self-elaboration) 245

Figure 4.29. Evolution of the state index for the Jucar-Turia Rivers joint system calculated from the simulated volumes (blue), and from OPTIRISK results (dashed black) compared to the drought scenario thresholds (source: self-elaboration) 247 


\section{Index of tables}

Table 3.1. Optimization runs characteristics and results 140

Table 3.2. Total flow values for one year optimization period using different CEV values 145

Table 3.3. Supply to the Madrid demand for different optimization setbackstepwise configurations 173

Table 4.1. Drought scenario thresholds proposed depending on the storage


Table 4.2. Drought scenario thresholds proposed depending on the storage level for Villameca 214 

CHAPTER 1

Introduction 



\section{Chapter 1: Introduction}

Management of natural resources, one of which is water, is a very important activity in the actual world. Availability and quality of water determine, among other important aspects of quality of life and economy, public health levels and agricultural, industrial and energy production. Inside management, planning is one of the most critical tasks. 
In Spain, basin planning is a legal requirement established within the general objectives of achieving the good status and adequate protection of water masses inside a river basin, fulfillment of water demands and equilibrium and harmonization of regional and sectorial development. These objectives must be achieved increasing water availability, protecting its quality, and economizing its use, rationalizing it in harmony with environment and other natural resources (Art 40 of the Consolidated Text of the Spanish Water Law).

To attain these objectives, hydrological planning will employ sustainability criteria in the use of water through integrated management and protection to the long term of resources, preventing water state deterioration, improving of aquatic ecosystems and reducing of pollution. Likewise, hydrological planning should contribute to mitigate the effects of floods and droughts. This work focuses on how hydrological planning and management can contribute to minimize and mitigate the effects of drought.

According to Wilhite and Buchanan-Smith (2005), droughts are recurrent natural phenomena consequences of a deviation in precipitation below expected or normal values that, when extends during a period of time, may cause failures in the capacity of a water resources system to supply the demands derived of human activities and environmental. Drought 'per se' is not a disaster. Whether it is or not will depend on its impact on the system (social, economic and environmental).

The perception of droughts as an event out of normal has made that, historically, these episodes have been dealt with as crisis situations 
during which solutions were adopted as the event developed to mitigate its effects. However, in recent times there has been a change towards a more preventive, or proactive, approach to water resources management so, when drought arrives, its possible effects are the lowest as possible or the situation can be even avoided. The principal reflection in this change of paradigm regarding droughts management is the development of the so called drought plans. These plans are meant to provide appropriate planning tools, including assessment of drought vulnerability, establishment of a drought warning system, and development of programmes of preparedness and mitigation measures oriented toward preventing or reducing economic losses and social and environmental impacts.

It is very difficult to forecast the occurrence of a drought event due to it is a phenomenon that develops slowly and its effects accumulate over time. There is also controversy about the moment in which drought events actually finish, and it usually has to do with the perception on the phenomenon in the affected area. Thus, the beginning and the end of a drought are often determined once the event has completely finished.

Additionally, a vast number of studies predict an increase in the variability of the climatic phenomena (Alderlieste \& van Lanen 2012, Stahl et al. 2010, Sheffield \& Wood 2008, Bates et al. 2008, Bordi et al. 2009), increasing the occurrence of events far from the average. This obviously translates in an increase of drought events, with duration and severity difficult to predict. 
It is evident that facing drought is surrounded by a high level of uncertainty. Logically, the management of a water resources system must consider all this variability when setting measures for drought effects prevention and/or mitigation. Taking into account the anticipation principle, it is necessary to find measures that reduce the risk of failure in the systems instead of alleviating the effects of such possible fail. The use of mathematical models of water resources systems management are of great help in the task of identifying the measures that better help to reduce the risk.

The development of models which support reaching a higher comprehension of a water resources system and its operation is a common practice in the planning process of a water resources system, and serves of great help for the achievement of objectives while respecting the any previously imposed criteria. Moreover, water resources systems modeling provides a way, perhaps the main one, to predict the future behavior of the system or its possible modifications (Loucks 1992). The modeling of water resources systems implies the development of a mathematical or computational framework for describing a particular system and its operation to study, identify and evaluate all the possible solutions to the existing problems in that very system.

The combination of one or several of these models with other essential features such an interactive interface to easy data entry and display, control of model operations, and results extraction is what is considered a Decision Support System Shell (DSSS) as denominated in Andreu et al (2013). The use of participative built Decision Support Systems 
(DSS) in the planning and management of water resources systems has become a common practice in many parts of the world ever since the development of Personal Computers (PCs) and especially the improvement of graphical user interfaces. DSS have been successfully use to reach agreements and common understanding in issues related to the management of water resources. The use of such systems allows developing and using real time management models able to assess the risk of drought, and the effectiveness of proactive and reactive measures applied on regular basis for the management of river basins (Merabtene et al 2002; Pallotino et al 2005; Andreu et al 2009 and 2013). DSSs also permit the monitoring of drought by evaluating the different indicators and drought indices defined for the studied river basin (Haro et al 2014). Additionally, they represent a powerful tool for participatory processes since, as seen in Wilhite et al. (2000), the different stakeholders involved in drought planning have a chance to develop and understanding of one another's various points of view, and to generate collaborative solutions.

When facing a hydrological planning problem, the most usual is having one or more objectives to accomplish under various efficiency measures, or manners of evaluating the achievement of the objectives. Normally, there will be a limited amount of resource and a series of water uses which will compete for it, besides all the different restrictions both physical and environmental. Under this perspective, a water manager will want to know what will be the best flow distribution throughout the system so the benefits for water use are maximized while costs are minimized, and all the demands are properly supplied. This problem is usually called "water allocation problem", and the path to follow will involve defining several 
alternatives and the form of evaluating each of them to finally decide which one of them will be the chosen one. At this point is where an optimization model comes to play to solve the problem.

An optimization model obtains the optimal values of the control variables defined for a certain system (a water resources system in this case), which usually are the circulating flows in it. To do this, the optimization model will obtain the best value (maximum or minimum) of a function which components represent both the control variables, the weight parameters relating them and other general parameters, while respecting a series of restrictions limiting the values selection of the control variables. However, as the mathematical optimization process is usually quite complex, optimization models have had a tendency to make important simplifications of the systems studied, what have made them less detailed than the more extended simulation models and therefore less utilized by water managers (Labadie 2004). On the other hand, continuous advances in computing techniques and computing speeds have made that complex mathematical processes, even though are still laborious, can be solved in less and less time. This makes possible to include more complexities in previous simplistic optimization models so they reach a higher degree of representation, what in the end will make their results closer to real systems.

This thesis explores the possibilities that the use of optimization models offers to preventive drought management of water resources systems from derivation of best management alternatives to filtering of 
alternatives, paying especial attention to their capacity to monitoring and early warning systems support or complementation.

\subsection{Motivation of this thesis}

Prior to the beginning of the development of this thesis, the Water Resources Engineering Research Group at the Universitat Politècnica de València already had a long history of research experience in drought management, development of decision support systems and simulation and optimization models.

Even though there was already an optimization model available for its use under the name OPTIGES (Andreu 1992). This model only considered the optimization of basic aspects of the surface system and already included the possibility to define evaporation from reservoirs and return flows as non-linearities. It was an explicit desire in the group, and other research institutions, of having available a version of the model with enhanced optimization capacities both in computation efficiency and level of detail, especially of the groundwater component of water resources systems. Thus, the first steps of this research were focused to analyze new optimization techniques and algorithms under the perspective of later generalization, and the possibilities of introducing the groundwater component in the already existing model.

Additionally, along the years that this research lasted, the group got involved in several research projects focused in the study of droughts, mostly related to the analysis and reduction of risk and enhancement of resilience of society in front of natural hazards. On this regard, it was 
considered interesting using the new version of the optimization model being developed in the tasks of analysis of risk and early warning. With this philosophy, the chosen path to follow was introducing the optimization model into an existing risk assessment methodology and using it in different cases to test its validity as well as to study different issues related to drought management, especially drought monitoring and early warning systems.

\subsection{Research objectives}

With the above motivation for the development of the research works of included in this thesis, a series of principal and secondary objectives were set.

The first objective is to advance in water resources systems optimization modeling with the development of a new version of a generalized optimization model for complex systems with conjunctive management of surface and groundwater resources. The model will strive to allow the user developing high detailed schemes of the systems under study, paying especial attention to groundwater uses. Additionally, the optimization problem will be approached with iterative network flow programming, being a side objective to find a resolution algorithm that yields stable, consistent results with low execution times.

The next step is approaching the management of drought situations within a water resources system from an optimization basis. Risk assessment is nowadays, as will be shown later, one of the most useful methodologies to evaluate the situation and the possible management 
alternatives for these kind of hazard. Thus, the second objective will involve using the optimization model developed within a risk assessment methodology to establish a working methodology to study management alternatives during such hydrologic uncertainty situations. The approach will make use of Monte Carlo optimization and stochastic analysis to provide useful support to decision making of water managers.

The use of the optimal risk assessment methodology will be combined with a critical revision of the currently used drought indicators systems used by most of river basin district agencies in Spain. It will be applied to two differently operated river basins to demonstrate the necessity of particularized approaches to the drought problem for each river basin, and will show the capacity of optimization driven risk assessment methodologies to support decision making before and during drought events.

It is also a side objective of this thesis implementing the tools developed in the course of the tasks of the research in a DSSS for its further use in future works and projects. The selected DSSS is AQUATOOL (Andreu et al 1996), developed by the Water Resources Engineering Group at UPV for already 25 years, and with a prolonged history of use by several water management related entities both in Spain and internationally.

\subsection{Description of the contents of this thesis}

This document was initially thought to be a compendium of the different publications related to the research work developed during the research phase of this thesis. However, given the complexities related to 
copyright aspects of presenting the original publications as they are, writing a traditional thesis report was the option finally chosen. This makes that complete parts of the text are extracted from the publications that are the result of the research carried out. These parts have been connected to other aspects developed but not published in order to show the whole work done and give it a comfortable and understandable reading format.

In order to give any reader of this text a background on the different aspects developed in this thesis, chapter 2 presents a review of the state-of-the-art in the different fields used to reach the objectives of the thesis namely: drought management and risk assessment of water resources systems, optimization of water resources system, network flow optimization, and decision support systems for water resources planning and management.

Chapter 3 will present the different tools developed under the scope of this thesis. The options for optimization of water systems schemes with a network flow programming approach including non-linearities will be studied in order to find the best algorithm or algorithms to carry out this task efficiently paying attention to the number of iterations and the resolution time. This initial part corresponds mostly with the first publication related to this research in the Journal Water Resources Management in 2012 under the title "A model for solving the optimal water allocation problem in river basins with network flow programming when introducing non-linearities". With the results of the previous study, a generalist model for water resources system will be reformulated including the possibility of modeling both the surface and the groundwater 
components. The resulting model and its initial results were presented in the $10^{\text {th }}$ Congres of Hydrolnformatics held in Hamburg in 2012 with the title "Incorporating Aquifer Modeling Into A Multi-Period Network Flow Programming Optimization Models For Water Resources Management “. This renewed optimization model will be used to create a risk assessment tool based in Monte Carlo optimization using synthetic streamflow series resulting from stochastic modeling of observed ones. Finally, all these development will be included in a decision support system for water resources systems planning and management.

Chapter 4 will serve to show the applicability and usefulness of the tools developed in chapter 3 . They will be applied in two cases of study with different characteristics both in system operation and drought characteristics. The part corresponding to the first case, the Orbigo River, is also mostly extracted from the paper published in Water Resources Management in 2014 under the title "Methodology for drought risk assessment in within-year regulated reservoir systems". The second case of study, the Jucar and Turia River basins, was also presented in two oral communications in conferences. This first one under the name "Optimal management of the Jucar River and Turia River basins under uncertain drought conditions" at the $16^{\text {th }}$ Conference on Water Distribution System Analysis, held in Bari in 2014. The second communication was at the $6^{\text {th }}$ EGU Leonardo Conference HYPER Droughts, held in Prague in 2014, with the title "Current and future drought vulnerability assessment in the Jucar River basin (Spain)". This chapter will also discuss the current approach in Spain to drought forecasting of existing monitoring and early warning 
systems and will propose a new one using the tools developed as main supporting tool.

Chapter 5 will finalize the document offering a summary of the work done and the conclusions extracted from it, part of these conclusions are of course part of the conclusions contained in the papers published. Also, a series of future research and development lines will be presented as proposals for improvement or refinement of the results of the current research.

In the annex of this document are included the author versions of the dissemination works developed under the scope of this thesis and commented above.

In addition to the different chapters that compose the main body of this thesis document, there is a series of digital annexes included in the cd attached to this document that cover principally aspects intimately related to the tasks carried out but which inclusion within the main text would result confusing. These annexes mainly include the data of the different models used as well as the documentation of the tools developed.

Annex A contains the data corresponding to the optimization model of the Sorbe River basin, the synthetic streamflows generation model, and the data for risk assessment analysis.

Annex B includes the user's manual of the new OPTIGES model implemented in the AQUATOOL DSSS as a result of this thesis. 
Annex $\mathrm{C}$ includes the data corresponding to the optimization model of the Orbigo River basin, the synthetic streamflows generation model, and the data for risk assessment analysis.

Annex $\mathrm{D}$ includes the data corresponding to the optimization model of the Jucar-Turia River basins, the synthetic streamflows generation model, and the data for risk assessment analysis.

\subsection{Dissemination works}

As already mentioned before, under the scope of this thesis a series of dissemination works have been developed in the form of indexed journal articles and conference papers and oral presentations. These works have direct relationship with aspects developed in one or several chapters of this document and thus their contents is used in the different chapters that compose this document. At the end of each chapter there is a section gathering the publications that were used or mentioned in its writing.

\subsubsection{Indexed journal articles}

Haro D, Paredes J, Solera A, Andreu J (2012) A model for solving the optimal water allocation problem in river basins with network flow programming when introducing non-linearities. Water Resour Manage 26:4059-4071 (DOI 10.1007/s11269-012-0129-7)

Haro D, Solera S, Paredes J, Andreu J (2014) Methodology for drought risk assessment in within-year regulated reservoir systems. Application to the Orbigo River system (Spain). Water Resour Manag 28 (11); 3801-3814 


\subsubsection{Participation in conferences}

Haro D, Solera A, Paredes J, Andreu J (2012) Incorporating Aquifer Modeling Into A Multi-Period Network Flow Programming Optimization Models For Water Resources Management. In Proceedings of 10th Hydrolnformatics conference, Hamburg, July 2012, ISBN 978-3-941492-45-5

Haro D, Solera A, Pedro-Monzonís M, Andreu J (2014) Optimal management of the Jucar River and Turia River basins under uncertain drought conditions. In Proceedings of the 16th Conference on Water Distribution System Analysis, Bari, July 2014, Procedia Engineering 00 (2014), 000-000

Haro D, Andreu J, Solera A, Paredes J (2014) Current and future drought vulnerability assessment in the Jucar River basin (Spain). Oral presentation in HYPER DROUGHTS: Hydrological, Precipitation, Evaporation, Runoff Droughts. 6th Leonardo Conference, Prague, 2014 


\section{CHAPTER 2}

State-of-the-art 



\section{Chapter 2: State-of-the-art}

The present thesis presents, analyses, and applies a methodology that is mainly related to risk management and assessment in water resources systems during uncertain hydrologic situations, particularly droughts, and to the optimization of the management during such situations. Both topics in which we expect to make an interesting contribution. 
During the development of the research it has also been necessary to pay attention to the following topics: drought characterization and modeling, development and implementation of policies oriented to drought prevention, and development and use of decision support systems

In the following sections we will make a review of the state-of-theart on the different aspects covered by this thesis. We will start with water resources systems optimization and the techniques available, paying special attention to network flow programming in a separate section. Afterwards, we will focus on drought management and risk assessment oriented to river basin management, covering most important issues. Finally, we will devote a section to decision support systems for water resources management.

\subsection{Drought management and risk assessment in water resources systems}

According to Wilhite and Buchanan-Smith (2005), "drought is a natural hazard that differs from other hazards in that it has a slow development, evolves over months or even years, affects large spatial regions, and causes little structural damage". Its beginning and end are often difficult to determine, as well as its severity (Wilhite 1992). Impacts from droughts affect a wide number of sectors, especially economy, environment and society. In recent decades, intense drought events have been observed on all continents with high economic and social costs (Mishra and Singh 2010). Drought forecasting is still a complex task (Bordi and Sutera 2007), and intensity and duration of future droughts remain unknown until the episode has finished. As mentioned in Haro (2014): 
"Water managers confront severe uncertainties within the decision making process, both in the short term (management and operation) and long term (planning), in any water resources system where droughts are very frequent and where water resources are under a massive use."

Because of the difficulty at detecting drought episodes occurrence, and forecasting their intensity and duration, the traditional responses to drought have been reactive, adapting the measures to the severity of impacts as long as they were detected in what is called a crisis management (Haro 2014). This approach is ineffective, poorly coordinated, and untimely; and does little to reduce the risk associated with drought (Wilhite et al. 2000). Because of this, drought management has evolved in recent years towards a more risk-preventive approach. Drought planning must predict what is predictable and establish strategies of prevention and management of the growing drought risks generated within the current climate change dynamics (Arrojo 2007). To reduce drought risk, there must be an understanding of the hazard using climatology, improved operational monitoring, an analysis of vulnerability to understand what people and sectors may be most affected by drought, why these impacts occur, and if these relationships are changing over time (Hayes et al. 2004).

This new risk management based approach to drought management has been expressed in the necessity of developing drought management plans (Wilhite et al. 1996, EC 2000) that provide a dynamic framework for an ongoing set of actions to prepare for, and effectively respond to drought, including periodic reviews of the achievements and priorities; readjustments of goals, means and resources; as well as 
strengthening institutional arrangements, planning, and policy-making mechanisms for drought mitigation. Risk management is generally defined as a proactive approach for coping with risk through planned actions, as opposed to crisis or emergency management. According to Cancelliere et al (2009), "it has the objective of identifying in advance a set of measures oriented to prevent or mitigate consequences of the adverse phenomenon and of implementing these measures."

As in any other aspect of water resources management, active participation processes represent an opportunity to achieve the involvement of all necessary stakeholders and to solve differences between interested parties early enough in the drought management plan process. The importance of public participation in the decision making process for an adequate water scarcity and drought management has been stressed, and drought management plans have been identified as useful tools to achieve this objective (Estrela and Vargas 2012). In the same direction pointed previous publications such as in Wilhite et al (2000) where it is stated that stakeholders must be involved early and continuously in order for there to be fair representation and effective drought management and planning. Public participation processes contribute to achieving the optimum sustainable equilibrium, considering social, economic and environmental aspects and facilitating the continuation, in the long term, of the decision making by consensus (EC 2007). In addition, stakeholder involvement in decision making improves public acceptance of water-management plans, which become more likely to be successful when stakeholders have participated in the design of those plans (Carmona et al. 2013). 
Among all the tasks involved in the successful development of a drought management process, at any scale, there are several aspects, at which public participation becomes not only necessary but also of great interest for its good end. These aspects could be summarized as: a) drought risk and impacts assessment; b) establishment of a monitoring system; c) development of mitigation measures; and d) development of drought prevention oriented policies and their implementation. All these four aspects within the drought management process have in common, to a certain extent, the necessity of developing and using models that allow putting knowledge into common and permit the different stakeholders build a shared vision of the system. At the same time, the use of models in any aspect related to water resources management has revealed as good way to resolve conflicts between stakeholders (Andreu et al 2013). Finally, a model built under the consensus of all the participating parties in the process, and which outcomes are considered valid in any possible scenario, will add legitimacy to all the decisions made based on its results (McIntosh et al 2011).

\subsubsection{Drought as a natural hazard}

Recent analysis of drought forcing climatic variables such as precipitation, temperature, soil moisture, and stream flows (Alderlieste \& van Lanen 2012, Stahl et al. 2010, Sheffield \& Wood 2008, Bates et al. 2008), as well as drought indices and drought characteristics analysis (Bordi et al. 2009, Sheffield \& Wood 2008), coincide that drought episodes will become more frequent and affect larger areas in the future. 
Differences in hydrometeorological variables, socioeconomic factors, and the stochastic nature of water demands in different regions are an obstacle to having a precise definition of drought (Mishra and Singh 2010). Wilhite and Glantz (1985) already identified more than 150 documented definitions of drought, classifying them into four categories:

- Meteorological droughts, defined as abnormally low precipitation over a region for a period of time.

- Agricultural droughts occur when there is a moisture deficit in the soil to meet the growing needs of a particular crop at any stage of growth. Since the amount of water is different for each crop, and can even vary along growth, it is not possible to establish thresholds of valid agricultural drought not even for a geographic area. In areas of rain fed crops, agricultural drought is linked to meteorological drought with a small time lag dependent on the moisture retention capacity of the soil. In irrigated areas, agricultural drought is more linked to hydrological drought.

- Hydrological droughts, related to the decrease in surface and groundwater availability below the average during a period of time in a water resources system and that could threaten the supply to the established demands. Unlike agricultural drought, which occurs shortly after the meteorological, hydrological drought may be delayed for months or a year from the start of the rainfall shortage or not even manifest if the rains return soon. Therefore, the time sequence is: meteorological drought, agricultural drought and then, finally, hydrological drought. The 
ability to manage water resources makes the hydrological drought not rely exclusively upon the flowing flows in rivers and streams, but also the volume of water stored in reservoirs and aquifers, this means the way in which these reserves are managed. Hence the definition is linked to the management system. In regulated systems, when hydrological drought remains several months or years occurs a significant reduction of storage in reservoirs, causing problems to supply water demands on the system. This situation is sometimes referred as operational drought. It manifests itself as a supply deficit. A system resource state suffers drought impacts of various kinds, the main environmental, social, political and economic, which are more pronounced the more severe the drought.

- Socio-economic droughts occur when the water shortage affects people and economic activities. The absence of impacts or their minimization constitutes a management success. To speak of socio-economic drought it is not necessary that a restriction of the water supply occurs, it is sufficient that one economic sector is affected by the decrease in water availability with adverse economic consequences. The growing anthropic pressure on water resources makes that socio-economic droughts occur more often, with increasing economic losses.

Droughts rank first among all natural hazards when measured in terms of the number of people affected and differ from other natural hazards in several ways (Wilhite, 2000). Mishra and Singh (2010) detect four main differences. First, droughts are a creeping phenomenon (Tannehill 
1947). Their temporary and spatial boundaries are difficult to determine as well as their impacts, increasing slowly and accumulating over a considerable period sometimes even further in time than the official termination date. Second, the lack of a universally understood definition of drought that often leads to confusion. Third, unlike other natural disasters such as floods, hurricanes, earthquakes, and tornadoes, drought impacts are normally non-structural and spread over large geographical areas. For this reason, the quantification of the impact and the provision for relief are far more difficult for droughts than for other natural hazards (Wilhite 2000a). Fourth and final, droughts may be triggered or exacerbated by human activities such as bad farming practices, deforestations, groundwater overexploitation, and other activities that can reduce the availability of water within a system. Also a bad management of regulated systems can lead to the occurrence of artificial droughts if the allocation of resources is allocated improperly, either by excess of defect.

\subsubsection{Drought monitoring, forecasting and risk assessment}

The use of monitoring systems and calculation of drought indices and indicators help water managers characterizing droughts and defining risk scenarios. The entrance of a system in each of those scenarios will activate different measures addressed to minimize the possibilities of entering a worse scenario and minimizing the possible effects of the current situation. 


\subsubsection{Drought indices and indicators}

The assessment of drought severity requires the use of an index which fulfils well-known criteria (Tsakiris et al 2013): operational usefulness, physical meaning, sensitivity to a wide range of drought conditions, applicability in all parts of the globe, quick response to changes due to drought and high availability of required data.

Commonly, a drought index is a prime variable for assessing the effect of a drought and defining different drought parameters, which include intensity, duration, severity and spatial extent as defined by Yevjevich (1967) in his theory of runs. A time series of drought indices provides a framework for evaluating drought parameters of interest. It should be noted that a drought variable should be able to quantify the drought for different time scales for which a long time series is essential (Mishra and Singh 2010). To study the general effects of drought and being capable of comparing different regions under similar episodes, the annual scale is often used. Nevertheless, the monitoring of particular drought situations in order to determine its effects in agriculture, drinking water supply or groundwater abstractions will normally require using the monthly or even lower scales (Panu and Sharma 2002).

Generally, drought indices are categorized as meteorological, hydrological, agricultural, or remote sensing-based (Rossi and Cancelliere 2013). Some indices also attempt to combine different data related to different variables (e.g. precipitation, soil, water content) and/or to merge the information from several indices into one value, taking into account also the status of water reserves. Several drought indices have been 
derived in recent decades. Mishra and Singh (2010) made an extensive review of the existing drought indices and analyzed the most common used ones more in depth namely Standardized Precipitation Index (McKee et al 1993), Palmer Drought Severity Index (Palmer 1965), Crop Moisture Index (Palmer 1968), Surface Water Supply Index (Shafer and Dezman 1982), and Vegetation Condition Index (Kogan 1995). The National Drought Monitoring Centre at the University of Nebraska-Lincoln also include as major drought indices the Percent of Normal (Willeke et al 1994), Reclamation Drought Index, and Deciles (Gibbs and Maher 1967).

An indicator system is a drought monitoring system that allows the anticipation in the application of mitigation measures for the reduction of socio-economic and environmental impacts of droughts (Estrela and Vargas 2012). According to these authors, an indicator system is formed by basic variables selected at different points in a river basin and is capable of defining the drought status. These variables may include, among others: reservoirs storages, groundwater piezometric levels in aquifers, streamflows, reservoir inflows and precipitation. The weighted combination of several of these variables in selected control points yields an integrated indicator representative of the hydrological status of the basin. Comparing it with historical values representative of the failures or impacts occurred in the basin tests the validity of the indicator. Other authors also refer to drought monitoring systems, as defined above, as early warning systems for their capacity of anticipating the effects that drought may have on the system (Rossi et al 2008). These authors define a series of requisites that these systems must satisfy in order to be reliable: representing the interrelation between meteorological and hydrological components in a 
significant reduction of water availability; making use of real-time data; being able to describe drought conditions in early stages of drought development; provide comparability between other drought events both in time and space; being capable of describing drought impacts in some way; assessing the severity of the ongoing drought in order to support decision making for triggering drought mitigation actions.

Different drought early warning systems have been developed at different spatial scales, but a very small number of such systems are actually operating (Rossi and Cancelliere 2013). The reasons to this is mainly due to the insufficient density of meteorological and hydrological gauging network, to the fact that monitoring processes are usually shared among different agencies with different objectives, and to the lack of universal standards in computing drought indices varying according to the different definitions used to describe the phenomenon (Rossi 2003). Among the currently operating systems can be mentioned the National Drought Mitigation Center (NDMC) of the University of Nebraska-Lincoln, USA; the Bureau of Meteorology and Queensland Department of Natural Resources and Mines, Australia; the Drought Monitoring Centre for Eastern and Southern Africa. In Spain, drought early warning systems have been developed by the national meteorological service (AEMET) and the ministry of agriculture and environment (MAGRAMA).

\subsubsection{Forecasting and Risk assessment}

Drought forecasting is a critical component of drought hydrology that plays a major role in risk management, drought preparedness and mitigation (Mishra and Singh 2011). These authors make a complete review 
in the available methodologies for this task discussing their advantages as well as their limitations. The most common methods to use with hydrometeorological variables are regression analysis; time series analysis; probability models; artificial neural network models; and hybrid models combining the advantages of individual models. All the previous modeling approaches are useful for short-term drought forecasting to a certain extent. For long-term droughts it is necessary to turn to global circulation models and prediction of climatic indices. Despite all the developed research, Mishra and Singh (2011) acknowledge that "there are still great challenges in developing suitable techniques for forecasting the onset and termination points of droughts since one of the deficiencies in mitigating the effects of a drought is the inability to predict drought conditions accurately for months or years in advance". Due to this inaccuracies and uncertainties, drought management relies nowadays in risk assessment.

Risk receives different definitions depending on the discipline, the event under study and the objective of the analysis. There are two main categories risk definitions: the probability of occurrence of an adverse event, and the expected consequences of that event. The first category limits the risk assessment to determining the probability that a hydrological variable exceeds a given threshold or the probability of failure of the system under investigation. The second category goes a step further and includes the expected loss associated to the occurrence of such adverse event.

None of the previous definitions is capable of including all the different consequences related to water shortages when dealing with drought risk in complex water supply systems with an elevate number of 
interactions between their different components (Cancelliere et al 2009). According to Rossi and Cancelliere (2013): “Assessment of water-shortage risk due to drought is a key step within the strategic planning of drought preparedness measures in water supply systems". Additionally, water resources system operators may benefit from risk assessment since it is also a useful tool for the selection between different management strategies.

Traditionally, reliability, resiliency and vulnerability have been the indices used to capture the different performance aspects of water supply systems (Hashimoto et al 1982). Alecci et al (1986) consider that the risk assessment of a water supply system is a problem that is better approached through a set of several indices and analyzing the probability of suffering shortages of different entities. This is due to the many complexities existing within a water resources system such as the stochastic nature of inflows, the high interconnection existing sometimes between the different components of the system, the competition for water by conflicting demands, the definition of what elements are at risk, and the uncertain character of the impacts in different drought episodes.

Risk assessment can be applied both at the planning stage and during the operation of the system. In the first case, risk assessment is useful to define planning alternatives, usually on a long term basis, in order to minimize the occurrence of drought events in the system taking into account its possible evolution in the future (changes in demands and resources availability). This kind of assessment is called unconditioned due to initial state of the system is unimportant since the procedure is oriented to provide information on what could happen at any time during the 
explored planning horizon. On the other hand, risk assessment during the operation of the system is often referred as conditioned risk assessment. With this procedure, the state of the system is evaluated for the short term usually to explore alternative mitigation measures and policies for an ongoing drought episode. The conditional assessment can be adopted for early warning purposes (Cancelliere et al 2009). According to the same authors, since the results of the conditional risk assessment strongly depend on the initial conditions, it follows that the procedure must be repeated as new information becomes available.

Several authors propose drought risk assessment methodologies, both conditioned and unconditioned (Sanchez-Quispe 1999; Andreu and Solera 2006; Andreu et al 2007; Cancelliere et al 2009; Mishra and Singh 2011; Rossi and Cancelliere 2013; Andreu et al 2013). The requirements set by all of them are similar. A drought risk assessment methodology should include stochastic generation of future hydrological variables, forecasting of water uses and demands, monitoring of the current state of the system, and an operation model of the system either simulation or optimization. All these components can be combined for a Monte-Carlo analysis of the system from which risk parameters can be derived.

\subsubsection{Planning for drought. Measures for risk and impacts mitigation}

Traditionally, water resources systems mitigated the effects of droughts by building and operating regulation infrastructures, incorporating new supply sources, and temporary exploitation of aquifers. However, 
these measures were only useful to face droughts in a punctual and shortterm basis in a so-called reactive approach or emergency management.

The new paradigm for droughts, as mentioned above, is the risk management approach. The core of this approach consist of the development of appropriate planning tools, including assessment of drought vulnerability, establishment of a drought warning system, and development of programmes of preparedness and mitigation measures oriented toward preventing or reducing economic losses and social and environmental impacts.

The European Commision establishes that a drought plan should provide a dynamic framework for an ongoing set of actions to prepare for, and effectively respond to drought, including: periodic reviews of the achievements and priorities; readjustment of goals, means and resources; as well as strengthening institutional arrangements, planning, and policymaking mechanisms for drought mitigation (EC 2007).

The definition of mitigation can be summarized in the set of activities or measures orientated to decrease the negative impacts produced by droughts. These include the emergency, preventive, strategic and long-term actions. The measures for mitigation must be taken into account not only by the involved authorities and institutions but also by the users and stakeholders affected in an individual form.

Mitigation measures can be divided into three categories according to the drought severity situation: 
- Strategic measures are oriented to give a response to drought in the medium and long-term basis. These measures have an institutional and infrastructural character, based in legislation and with a high investment cost. They are usually developed during normality situations since these are the most adequate periods of time to plan and prepare the measures that must be activated during lower resources availability periods.

- Tactical measures are short-term responses planned and validated previously in the frame of the drought plan. Their objective is saving resources through management improvements, conjunctive use of surface and groundwater resources, and voluntary water saving at the main units of water use. These measures also include the increase of control and surveillance of drought indicators.

- Emergency measures give response to unexpected or extreme situations. These usually appear when droughts have a longer duration than anticipated or when a catastrophe occurs. Their objective is elongate as much time as possible the available water resources, establishing restrictions to low priority uses or even generalizing restrictions in more advanced phases of drought.

It is also necessary to define the necessary recovery measures to restore the water bodies affected by drought once the episode has finished.

Yevjevich et al (1978) proposed another classification of drought mitigation measures: 
- "Offer oriented measures" try to solve the problems generated by droughts by making a more efficient use of water resources, developing new supply sources and using unconventional practices to increase the available resources.

- "Demand oriented measures" try to make that the existing resources serve the users in the most effective way. They strive to reduce shortages provided legal and economic restrictions allow it. Most of these measures have the objective of decreasing the demand. It is possible to achieve this by imposing supply restrictions or by increasing the efficiency of the water supply systems.

- "Drought impacts minimization measures" apply when offer cannot be increased nor demand can be reduced. These measures include drought forecasting and risk and lose sharing.

\subsection{Optimization of water resources systems}

A system of water resources is understood, from the point of view of its management, as a single or multi-reservoir system consisting of various physical components such as reservoirs, aquifers, canals, tunnels, pipelines, pumping stations, hydroelectric plants, irrigation areas and urban supply systems (demands), and other intangible assets like use priorities and water rights, that is operated to supply water for urban, agricultural and industrial use for the production of hydroelectric power, for flood control and to meet certain environmental requirements without forgetting the needs of enabling navigation or recreational uses. Figure 2.1 shows an 
example of water resources system where there are a reservoir and two demands, all put together by a series of river stretches in which final section there is a requirement of flow due to environmental reasons.

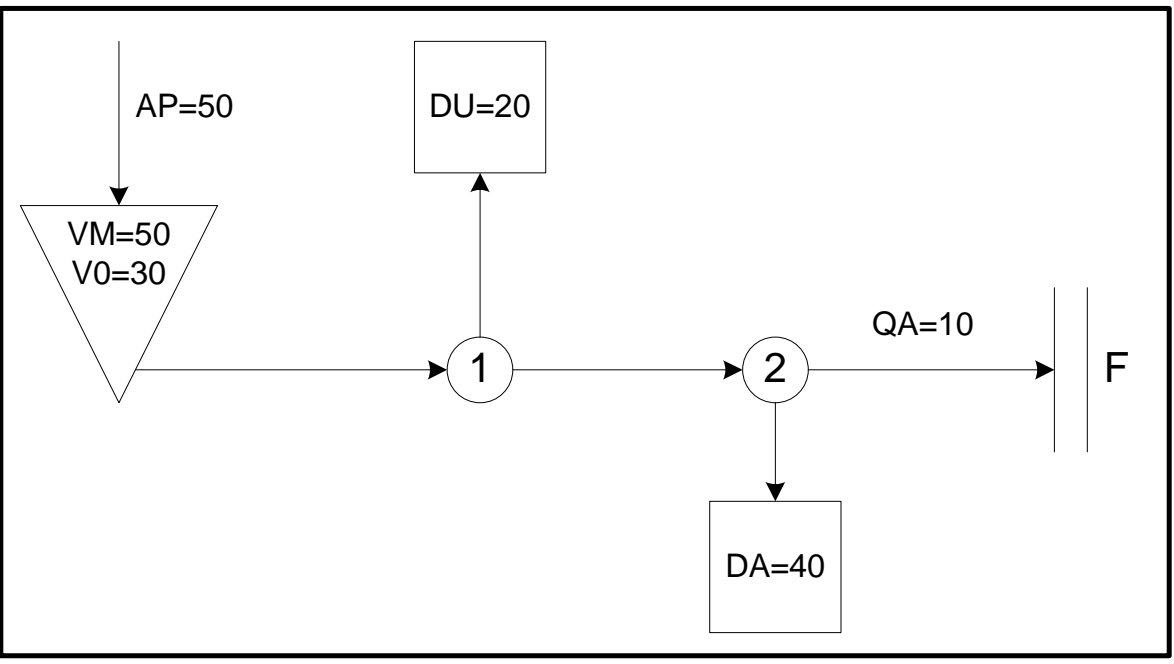

Figure 2.1. Example of a water resources system (source: self-elaboration)

The optimization of a water resources system involves allocating resources, developing flow regulation strategies and reservoir operation rules, and making real-time decisions about which water withdrawals must be done based on the rules of operation defined (Wurbs 1993). The ultimate goal of optimization in any water resources system is to maximize profit, minimize costs, and supply all demands, while the mass balance equation system is satisfied, as well as more specific restrictions (Rani and Moreira 2010).

To achieve these objectives, mathematical modeling and software tools are of invaluable help. Although current simulation models allow us to analyze questions such as "what if ...?" related to different operation 
alternatives, they cannot, however, help us getting what is the best operation strategy for using those alternatives. On the other hand, optimization models have that ability to systematically select the optimal solution, or the family of solutions under a predetermined set of objectives and constraints.

The main task of an optimization model is to obtain the best value (maximum or minimum) of a function whose components represent control variables (or decision variables) as well as different parameters that represent the different weights that may have the previously mentioned variables. This function is called the objective function, and it is the heart of every optimization model (Wurbs 1993). A general formulation of an objective function would be like the following (Labadie 2004):

$$
\max (\text { o min }) \sum_{t=1}^{T} \alpha_{t} f_{t}\left(\boldsymbol{s}_{t}, \boldsymbol{r}_{t}\right)+\alpha_{T+1} \varphi_{T+1}\left(\boldsymbol{s}_{T+1}\right)
$$

where $\boldsymbol{r}_{t}$ is the $\mathrm{n}$-dimensional set of control variables (or decision variables) during period $t$; $\mathrm{T}$ is the optimization horizon; $\boldsymbol{s}_{t}$ represents the system's storage at the beginning of the optimization period $t ; f_{t}\left(\boldsymbol{s}_{t}, \boldsymbol{r}_{t}\right)$ is the objective to be maximized (or minimized); $\varphi_{T+1}\left(\boldsymbol{s}_{T+1}\right)$ represents the future benefits (or costs) beyond the optimization horizon; and $\alpha_{t}$ are the discount factors to determine the present value of future benefits (or costs). This objective function, depending on the variables used, can be linear or non-linear.

The optimization problem does not end with the objective function. Usually, obtaining the values of the control variables also depends of meeting certain restrictions as they come to be fulfilling the equation of 
material balance, and constraints of maximum or minimum flow. Therefore, we must optimize the objective function (maximizing or minimizing it) subject to restrictions that limit the choice of values of the decision variables.

In the example shown in figure 2.1 we could lay out the objective of maximizing the supply to the two different demands and meeting the environmental requirements downstream while maintaining the reservoir storage at the maximum possible volume for future needs. Thus, we can write the following objective function:

$$
\operatorname{Max} \quad a \cdot S D A+b \cdot S D U+c \cdot V
$$

where SDA is the supply to demand DA, SDU is the supply to demand DU and $\mathrm{V}$ is the volume of water stored in the reservoir. Variables $a, b$ and $c$ represent the benefit of one unit water assigned to a determined use or volume stored.

The selection of the values of the decision variables to maximize the objective function above ( $\mathrm{Eq} 2.2$ ) would be limited by the following constraints:

$$
\begin{aligned}
& I_{1}-O_{1}=0 \\
& I_{2}-O_{2}=0 \\
& V 0+A P-O_{R} \leq 50 \\
& Q_{2-F} \geq 10 \\
& S D A \leq 40 \\
& S D U \leq 20
\end{aligned}
$$


These constraints mean that mass balance must be maintained in the nodes (Eq 2.3 and Eq 2.4, where $\mathrm{I}_{\mathrm{i}}$ represent the input to node $\mathrm{i}$ and $\mathrm{O}_{\mathrm{i}}$ represent the output); that the stored volume at each time step cannot be above the maximum storage capacity of the reservoir (Eq 2.5, where $\mathrm{V} 0$ is the initial volume stored in the reservoir, AP is the streamflow input to the reservoir in the month, $O_{R}$ is the output from the reservoir, and 50 represents the capacity or $V_{M}$ ); that the flow at the last stretch of the system must be, at least, equal to the environmental requirement (Eq 2.6, where $Q_{2-F}$ represents the flow from node 2 to the final node); and that there are supply values above which there is no further gain (Eq 2.7 and Eq 2.8).

Of course, such a simple example as the one shown above has an immediate solution. It will not be that obvious when moving to more complex schemes, with more elements and constraints, as well as with longer optimization horizons. It is with those cases, where the optimal solution is not immediate, and there can even be several possibilities, when the water manager must use advanced optimization techniques to allow him to successfully carry out his analysis.

Optimization techniques can be divided into two large families: implicit stochastic optimization (ISO, Figure 2.2a) and explicit stochastic optimization (ESO, Figure 2.2b). The first family is actually formed by deterministic methods that obtain the optimal operation of the system either from historical unregulated hydrological series, if they are long enough to be representative, or from synthetically generated series (one very long series or many short but similar). Even though deterministic 
optimization methods can be used directly due to most of the stochastic aspects of the problem, including the spatial and temporal correlations of the hydrological series, are included implicitly, their major disadvantage of the implicit approach is that optimum operating rules obtained are valid only for the hydrological series employed. Operation rules are often inferred through regression techniques. On the other hand, explicit stochastic optimization methods include, directly in their formulations, the probabilistic description of streamflows instead of deterministic hydrological sequences, as well as for other uncertain parameters of the model. This means that the optimization is performed without the presumption of knowing perfectly what will be the future flows. Additionally, optimum operating rules are derived directly, without the need to subsequently infer from the results of the optimization. However, explicit methods are much more computationally demanding than implicit, and make assumptions that not always can be maintained. 


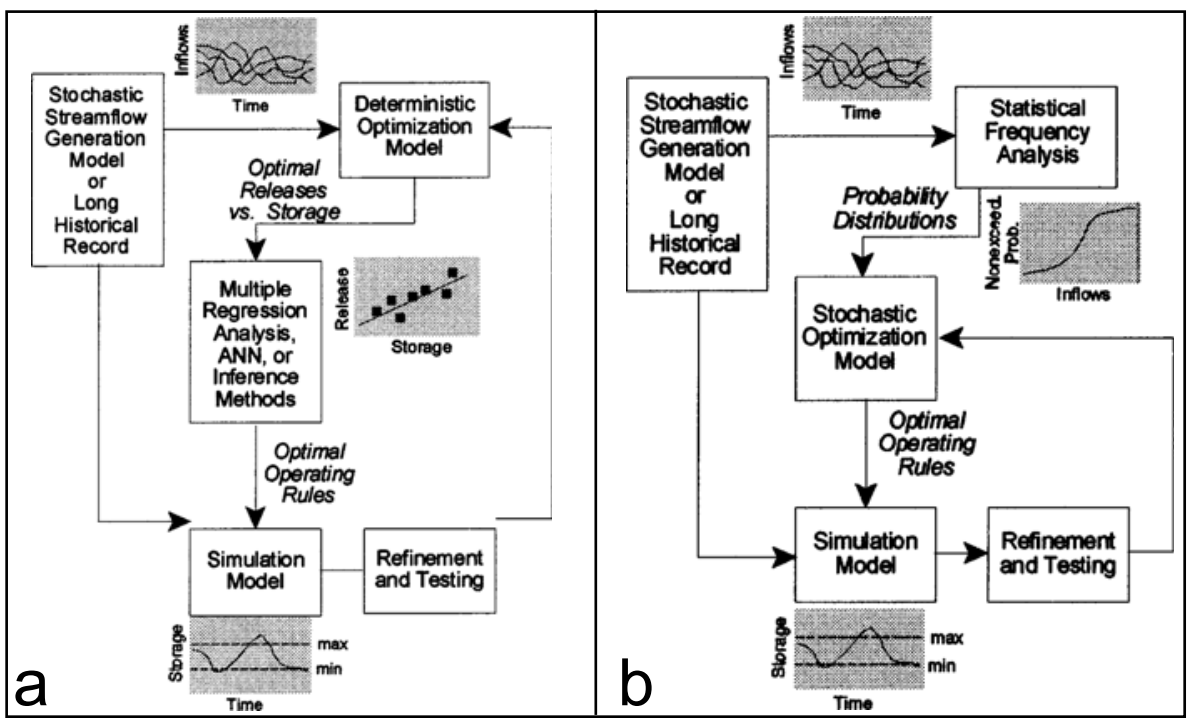

Figure 2.2. Implicit stochastic optimization (left) and implicit stochastic optimization (right) methodologies. Source: Labadie (2004).

In the next subsections, we will discuss, in short, the various techniques that, over recent decades, have been used to solve the problem of optimization of water resource systems. Apart from methodologies encompassed within ISO and ESO families, we will also pay quick attention to the new emerging methods that researches have been using in the recent times to solve the classic problem of the optimal operation of multireservoir systems.

\subsubsection{Linear programming}

Linear programming (LP) is one of the most popular optimization methods applied in modeling of water resources systems optimization problems (Rani and Moreira 2010) since the publication of the SIMPLEX algorithm by Dantzig in 1947. As an implicit stochastic optimization method, 
the most attractive aspect of LP is its flexibility of application to large problems; convergence to a global optimum in a reasonable amount of time; no need to provide initial solutions; the existence of a solid dual theory for sensitivity analysis; and the availability of numerous tools relatively simple to use and created, or adapted, for resolution of linear problems, such as CPLEX (IBM), GAMS (http://www.gams.com) or MATLAB (http://www.mathworks.com) to give some examples. On the other hand, the main disadvantage of using linear programming is that both the objective function and the constraints of the problem must be linear. This, combined with the fact that a lot of aspects of water resources systems have evident nonlinear behaviors, makes necessary to assume a number of simplifications, approximations or iterations, which may result in inaccuracies or excessive size of the problems to be studied.

Linear programming can also be approached from the point of view of probability. As commented above, the deterministic approach assumes that all flows and future random phenomena are known in advance when setting up the problem. A more realistic approach is that the decisions for the current period can be made with enough certainty, but future decisions and their consequences are still random. This is known as Stochastic Linear Programming (SLP). SLP problems can be formulated in two (Lee et al 2006), or more (Lee et al 2008), stages that aim to minimize the cost (or maximize profits) of the first known stage, plus the expected costs (or benefits) of the decisions in a number of future scenarios, each with an associated probability of occurrence. The problem with this procedure is that a large 
number of possible future scenarios result as a consequence, an extremely large linear problem, with the obvious increase in calculation time.

Within LP we can find two particularized techniques like Network Flow Programming (NF) and Interior Point (IP) Method. The first one is considered an efficient form of LP and, since it is one of the main tools in the development of this thesis, will be considered separately in another section. On the other hand, IP algorithm (Karmarkar 1984) is capable of efficiently solving large LP problems.

Literature is full with examples of applications of LP to the optimal operation of water resources systems. (Devi et al 2005; Kondili et al 2010; Alemu et al 2010; Ostadrahimi et al 2011)

Likewise, LP has been used in the development of general watershed simulation models such as WEAP21 (Yates et al 2005). Based on this model, that solves the optimal allocation of resources on a monthly basis using LP, several studies have been carried out as in Levite (2003) where he studied the optimal resource management in Olifante River basin (South Africa) in different scenarios adapted to climate change.

\subsubsection{Non-linear programming}

As already mentioned previously, many water systems cannot be modeled realistically by linearization of its components, and must be approached directly from a non-linear perspective. A particular example of this is the inclusion of hydropower generation in the objective function or the constraints of the problem. 
The most robust and powerful NLP algorithms according to literature are: successive linear programming (SLP); successive quadratic programming (SQP); method of multipliers (MOM); and the generalized reduced gradient method (GRG). All these algorithms require that both the objective function and constraints are differentiable, something that can be problematic sometimes. Still, the explicit calculation of the derivatives is not necessary and the use of automated derivation methods is normally sufficient (Sinha \& Bischof 1998).

Similarly to LP algorithms, many existing general purpose mathematical software tools include several packages and toolkits that allow users to easily solve non-linear problems with several of the above mentioned techniques, e.g. LOQO (Vanderbei 2006), GALAHAD (Gould et al 2003), or MINOS (Murtagh and Saunders 1998).

The major disadvantage of NLP is the high computational requirements of the algorithms, so this technique is often only used implicitly and its explicit extension to stochastic optimization is rarely performed (Labadie 2004). Sun et al (1995) compared the performance of MINOS with a generalized network flow optimization algorithm (EMNet) in a metropolitan water distribution system in California. Although the results of nonlinear programming were adequate, he showed NLP computational requirements are very demanding. Another disadvantage associated with NLP is the possibility of not always reaching a global optimum for the objective function, which leaves these methods to some disadvantage to others who are able to avoid local optima such as LP methods discussed above. Due to the rigorous mathematics involved in NLP, it has not been 
widely used in literature (Singh 2012) with little examples such as the previous one and Arunkumar and Jothiprakash (2012) and Jothiprakash and Arunkumar (2014) for optimizing the hydropower production from a reservoir and from a multi-reservoir system respectively.

\subsubsection{Dynamic programming}

Dynamic programming (DP) is an optimization method for solving multi-stage decision processes. The most attractive characteristic for the application of such methodologies in water resource systems optimization is that a complex multi-stage problem can be decomposed into a series of simpler sub-problems that can be solved one by one recursively (Dasgupta et al., 2006), based on the solution of the previous problem to obtain the solution of the next one.

DP can be used both implicitly and stochastically. When implicit methods are used, the initial state in the next stage is completely determined by the state and the policy decision of the current stage. The probabilistic DP differs from the previous one in that the initial state of the next stage is not completely determined by the state and the decision of the policy in the current state. Instead, there is a probability distribution for what will be the next initial state. However, this probability distribution is still completely determined by the state and the decision of the current state policy.

A generalized DP problem is represented by the large amount of storage required, also referred to as 'the curse of dimensionality' (Bellman \& Dreyfus 1962). To consider all the possibilities, it is necessary to store the 
results of the previous stages. Thus, in big problems, the large number of results will lead to huge data structures. There are methods to previously assess what solutions will be needed to reach the optimal so that you can free up space by discarding the solutions will not be used (Rani \& Moreira 2010).

DP has proved to be a potential tool in developing reservoir operation models in recent years (Singh 2012) and there are several examples of its use in the literature, particularly focused in maximizing hydropower production and water supply (Castelleti 2007; Galelli 2010; Zhang et al 2013; Fayaed et al 2013; Ahmad et al 2014; Li et al 2014; Chang et al 2014; Li et al 2014)

\subsubsection{Computational intelligence (Heuristic optimization)}

All optimization models discussed are so far algorithmic processes. This means that they apply well-structured and converging to a solution processes to quantitative information. In contrast, heuristic methods are based on rules of thumb, previous experience, or several analogies applied to both quantitative and qualitative information. These methods do not guarantee obtaining even local optima, but they strive to find acceptable or satisfactory solutions. Nevertheless, they can often achieve global optimal solutions to problems where traditional methods fail. Computational Intelligence $(\mathrm{Cl})$ makes reference to a fairly wide range of different methodologies. 


\subsubsection{Evolutionary Computation}

Evolutionary Computation (EC) is normally used to overcome the many complexities we can find when facing a water resources system optimization problem. Multiple objectives, non-linearities, uncertainty, etc., that limit analytical optimization methods can be approached with the different techniques developed in this field.

Genetic Algorithms (GA) are based on the mechanisms of natural selection and genetic evolution and are currently the most widely used type of EC techniques within the literature related to the planning and management of water resources systems (Nicklow 2010). Although there is no universal definition, the GA is characterized by the following elements mentioned by various authors (Goldberg 1989; Koza 1992; Michalewicz 1999; Nicklow 2010): (1) generation of an initial population of potential solutions, each identified as a chromosome; (2) evaluation of the objective function for each initial solution and arrangement of chromosomes by their fitness; (3) a process of chromosomes selection, based on the above order, to participate in a process of reproduction, where information from the combination of two or more pairs of "parent" solutions generate new "son" solutions; and (4) application of some degree of mutation in the new solutions to maintain diversity and prevent premature convergence to global optima. The elements described represent techniques inspired by biology such as inheritance, mutation, selection and crossover, to achieve the optimal value of the problem. All items described are repeated in successive generations until a suitable solution is reached. This way we that each new generation has better features than the previous one, emulating 
the biological process of survival of the fittest. Rani et al (2013) made a review of the applications of GA to water resources systems, paying special attention to optimal reservoir operation. Additionally, we can find several examples of application of GA to reservoirs operation optimization in the last years such as Hinçal et al (2011); Louati et al 2011; Wang et al (2011); Arunkumar and Jothiprakash (2013); Kumphon (2013); Lerma et al (2013); and Peralta et al (2014).

Particle Swarm Optimization (PSO) is a population (swarm) based stochastic search technique that simulates the social behavior of birds flocking or fish schooling. First proposed by Kennedy and Eberhart (1995), within PSO algorithms every solution is a bird of the flock and it has individual learning and social learning from the other solutions towards a common destination. The first approach of this technique for reservoir operation optimization was in Kumar and Reddy (2007) and Reddy and Kummar (2007) where they applied different PSO algorithms to a multiobjective reservoir problem. These technique has become kind of popular in the last years, with several applications recorded in literature (Ostadrahimi et al 2011; Afshar 2012; Guo et al 2013; Zhang et al 2014).

Other EC strategies considered in literature are Simulated Annealing ( $S A)$, a stochastic search technique that mimics the annealing procedure in physics (Kirkpatrick et al 1983); Tabu Search (TS), similar to the previous technique, with the capacity of avoiding entrapment in local optima but with little application in reservoir systems (Rani and Moreira 2010); Ant Colony Optimization (ACO) is based in the natural technique of ants to find the shortest distance from their colony to food sources (Dorigo 
and Stützle 2004) with little applications to water resources problems in the last years; and Honey Bees Mating Optimization (HBMO) is another swarm optimization technique based in the mating of real honey bees for the operation of single reservoir systems (Haddad et al 2006).

Finally, Ahmad (2014) proposes the exploration of newly developed optimization methods for other disciplines in the operation of reservoir systems. Artificial Bee Colony $(A B C)$ is a new bee swarm algorithm that simulates the foraging behavior of the bee and the food is regarded as the solution (Karaboga 2009). Gravitational Search Algorithm (GSA) (Rashedi et al 2009) is based on the Newton Law of gravity and mass interaction.

\subsubsection{Artificial Neural Networks}

Artificial Neural Networks (ANN), although not classified as an optimization method per se, may be useful as a tool of multiple regression analysis to determine optimum operating rules from the results of ISO methods as an alternative to classical regression methods (Chaves and Chang 2008; Fayaed et al 2013; Kumar et al 2013; Dariane et al 2014). ANN base their performance in a parallelism with the human brain and multiple interrelationships of its neurons so that a single neuron cannot do a great job by itself, but many massively interconnected neurons can capture the dynamics of very complex processes. A complete development of this technique can be found in ASCE (2000) and Govindaraju (2000), where the performance of ANN and its applications in the field of water resources is explained. 


\subsubsection{Fuzzy logic}

Fuzzy Logic (FL), initially enuntiated by Zadeh (1965), emerges as a tool to deal with problems in which the decision parameters are uncertain, imprecise or based on qualitative aspects. Instead of using complex equations, FL uses linguistic descriptions to define the relationship between inputs and outputs (Rani and Moreira 2010). Thus, a reservoir may be full or empty ( 0 or 1$)$, but it is unclear when passing from one state to another, it could also be said to be full when it is $90 \%$ full or nearly empty when it is $10 \%$. Fuzzy sets can transform linguistic descriptions in numeric forms used for making subsequent decisions.

In the field of water resources engineering $\mathrm{FL}$ is used, for example, as a substitute for regression techniques to infer rules of optimal operation of reservoirs (Mousavi 2007; Kumar et al 2013; Safavi et al 2013), or to determine a single reservoir with hydroelectric power generation depending on the inputs and the state of the reservoir (Moeini 2011).

\subsection{Network flow optimization}

Network flow optimization (NFO) is a tool of wide application in many areas of science and engineering. The schematic similarity of a great variety of systems, such as telecommunications networks, power grids or water systems themselves, with the very definition of a network flow makes that these particular optimization technique is chosen to solve the problems associated with optimal flow distribution through the studied systems. 
For example, the diagram presented in Figure 2.1 can be translated into a network of nodes and arcs as shown in Figure 2.3. Nodes represent points of convergence or divergence of the system, and the arcs represent the outputs of the reservoirs, flows through pipelines, storage, evaporation, etc. Each arc is defined by the source node, the end node, the upper and lower limits of flow through it and the cost (or benefit) associated to the allocation of one unit of flow to that arc. 


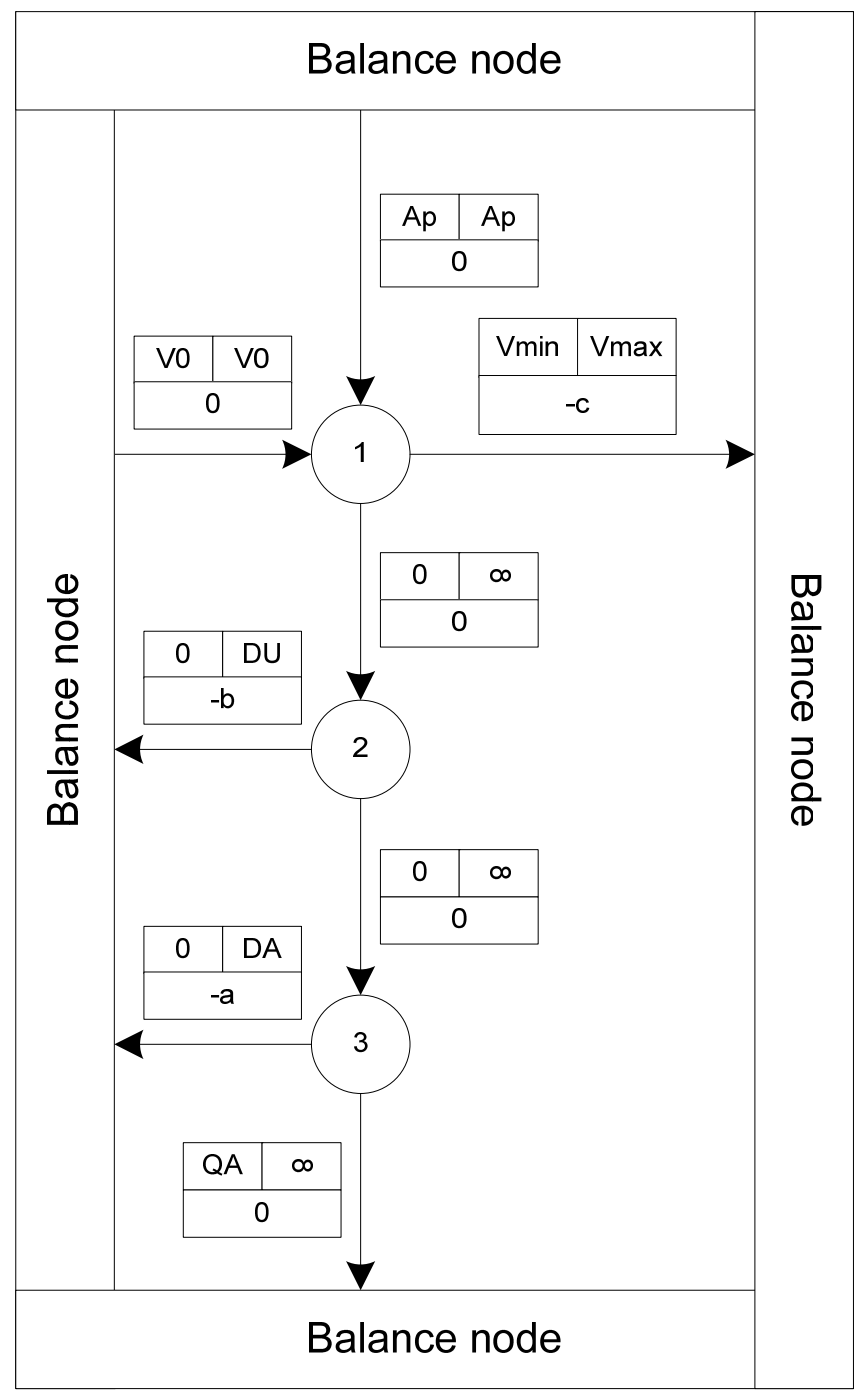

Figure 2.3. Network flow representation of the water resources scheme of figure 2.1 (source: self-elaboration)

NFO is a form of LP that exploits the particular spatial distribution of most of water resources systems to find the optimal resources allocation employing highly efficient algorithms. 
Using NFO has the same advantages as those of LP: (1) the flexibility of this technique to be efficiently used in problems with a considerable size; (2) convergence to a global optimum; (3) no need of an initial solution by the user; and (4) the development of an effective dual theory for the sensitivity analysis. To these, we must add that the specific configuration of a network flow, easily representable in matrix structure, allows very efficient handling of the information contained therein.

Of course, this methodology is not exempt of some problems. As is the case of LP, NFO requires that the relations between the different elements of the system are linear. This is a problem, since a lot of processes and relationships occurring in a water resources system are highly nonlinear, such as evaporation, which depends on the stored volume, or the returns of the demands, which are proportional to volume supplied in each time step. Still, several authors (Fredericks, 1998) have shown that these issues can be solved by iteratively solving the purely linear flow network. Additionally, some authors have developed algorithms that solve networks with gains in arcs and nodes. Solving such networks usually requires more computational effort but less iteration, compared with an algorithm solving pure networks, making them generally faster (Sun 1995).

\subsubsection{The Minimum Cost Network Flow Problem}

From finding the shortest path to complete a route between different towns to what is the maximum flow that can circulate through a pipe grid, the problems that can be solved NFO, selecting the most appropriate algorithm for each case, are many and varied (Ahuja et al 1993; Bazaraa and Jarvis 1977). Several of these problems are particular cases of 
the most general problem known as Minimum Cost Flow problem (MCF). This problem is defined as follows (Ahuja et al 1993):

Let $G=(N, A)$ be a directed network consisting of a set $\mathrm{N}$ of nodes and a set $\mathrm{A}$ of $\mathrm{m}$-directed $\operatorname{arcs}$. Each $\operatorname{arc}(i, j) \in A$ has an associated cost $C_{i j}$ that denotes the cost per unit flow on that arc. Moreover, we associate to each $\operatorname{arc}(i, j) \in A$ a upper $\operatorname{limit} u_{i j}$, that represents the maximum flow capacity of that arch, and a lower limit $l_{i j}$, representing the minimum flow that must traverse the arc. We also associate to each node $i \in N$ an integer value $b_{i}$ representing its supply / demand. If $b_{i}>0$, the node $\mathrm{i}$ is a supply node; if $b_{i}<0$, the node $\mathrm{i}$ is a demand; and if $b_{i}=0$, then node $i$ is a transfer node. The decision variables in the MCF problem are the flows in the arcs and we represent the flow through each arc $(i, j) \in A$ as $x_{i j}$. The MCF problem has the mathematical definition of equations 2.9 to 2.11

$$
\begin{aligned}
& \operatorname{Min} \sum_{i=1}^{m} \sum_{j=1}^{m} c_{i j} x_{i j} \\
& \text { s.a. } \sum_{j=1}^{m} x_{i j}-\sum_{k=1}^{m} x_{k i}=b_{i} \quad i=1, \ldots, m \\
& x_{i j} \geq 0 \quad i, j=1, \ldots, m
\end{aligned}
$$

According to Andreu (1992): It is clear that water resources systems, in a schematic way, are equivalent to a network flow (especially in 
the case of surface water systems), as there is in them a number of rivers and canals (arcs) connecting a series of points (nodes) such as reservoirs, intakes, points of conjunction of tributary rivers, etc.., and the water always flows in a predetermined direction. Therefore, it is logical to approach the optimization of a water resources system by solving a MCF problem.

The next section presents some of the algorithms that have been used for water resources systems optimization when approaching the problem a MCF.

\subsubsection{Algorithms for solving the MCF problem}

Solving the MCF problem involves principally the distribution of flows therethrough so the value of the objective function, generally with the form of Eq 2.9, is minimized. In addition, constraints of Eq 2.10 and Eq 2.11 must comply on all nodes and arcs respectively. This is not something that we can do analytically and thus we must resort to an algorithm to solve the problem numerically (Bersetkas and Tseng 1988).

Although the network flow could be solved by a general LP algorithm, it is more advantageous to use the particular structure of the network flow to accelerate convergence to the solution by using a specific network flow algorithm.

Bersetkas and Tseng (1988) divide the algorithms for network flow optimization into 3 categories: (1) primal cost improvement; (2) dual cost improvement; and (3) auction. The first category corresponds to the algorithms that solve the MCF problem from an initial feasible solution and generate a sequence of feasible flow vectors; each with a better cost than 
the previous, until the optimum value of the objective function is reached. The algorithms belonging to the second category are based on the optimization problem related to the original called dual problem, whose variables are named prices. They achieve the best cost by successive construction of dual vector prices. Finally, auction type algorithms solve the network flow by a process reminiscent, in a way, to real auctions. Although they can be considered approximately as processes of dual optimization, actually iterations take into account both prices (dual) and flows (primal), even worsening both in a single iteration, but finally reaching a primal optimal solution. The algorithms presented next are a sample of all the three categories.

\subsubsection{Out-of-Kilter (OOK)}

This algorithm solves the following problem:

$$
\begin{aligned}
& \operatorname{Min} \sum_{i=1}^{m} \sum_{j=1}^{m} c_{i j} x_{i j} \\
& \text { s.a. } \sum_{j=1}^{m} x_{i j}-\sum_{k=1}^{m} x_{k i}=0 \quad i=1, \ldots, n \\
& l_{i j} \leq x_{i j} \leq u_{i j} \quad i, j=1, \ldots, m
\end{aligned}
$$

We must note that, differently to the general MCF problem formulated in Eq 2.9 to Eq 2.11, this problem requires that all the nodes in the network are transfer nodes. Additionally, the flow limits in the arcs must be always positive $l_{i j}, u_{i j} \geq 0$

Formulated by Ford and Fulkerson (1962), the OOK algorithm is one of the most used algorithms in the optimization of conservative network 
flows. Additionally, it is an algorithm commonly included in general network flows textbooks due to the simplicity of exposition (Bazaraa and Jarvis 1977; Jensen and Barnes 1987; Evans 1992; Ahuja et al 1993).

This algorithm belongs to the second category of MCF algorithms. It bases the optimum search strategy in the successive and iterative resolutions of both the primal and dual problems. The search strategy includes the checking of the state of 'synchronization' (In-Kilter) or 'desynchronization' (Out-of-kilter) of each arc in the network and tries to allocate the flow so all the arcs are synchronized.

In a summarized way, the general search scheme of the OOK algorithm is as follows (Bazaraa and Jarvis 1977):

(1) Start with a conservative flow and a feasible solution for the dual problem. Identifying the In-kilter states and calculate the kilter numbers

(2) If the network contains an Out-of-Kilter arc, then the algorithm changes to solve a primal phase of the problem. During this phase, one of the desynchronized arcs is selected and the flow in the arc is changed so no other arcs have their kilter numbers worsened while improving the one in the selected arc.

(3) When it is not possible to improve any other flow in the primal phase, the algorithm builds a new dual solution to recalculate the state of synchronization of al arcs and repeats step (2) if necessary. 
Iterating between steps (2) and (3), the algorithm constructs an optimal solution or determines that there is no feasible solution.

The main advantages of this algorithm can be summarized from Jensen and Barnes (1987):

- The OOK algorithm does not require any particular memory structure to represent the network. The parameters are introduced and stored in arbitrary order lists

- It does not use external parameters. Everything is described in the arcs definition

- The algorithm can be initialized with any set of flows that comply with the flow conservation. Because of this, it results specially usefull to do sensitivity analysis when changing the arcs definition.

Of course, the algorithm has some disadvantages too:

- The use of arcs to specify the flows in the nodes sometimes supposes a high memory requirement.

- Solutions are not necessarily basic. This can result in a slow convergence towards the optimum.

- The search process may require numerous lectures in the arcs list so it is not very computationally efficient for large problems. 


\subsubsection{Relax-IV (RIV)}

This algorithm, presented by Bersetkas (1994), solves the following MCF problem:

$$
\begin{aligned}
& \operatorname{Min} \sum_{i=1}^{m} \sum_{j=1}^{m} c_{i j} x_{i j} \\
& \text { s.a. } \sum_{j=1}^{m} x_{i j}-\sum_{k=1}^{m} x_{k i}=b_{i} \quad i=1, \ldots, m \\
& 0 \leq x_{i j} \leq u_{i j} \quad i, j=1, \ldots, m
\end{aligned}
$$

This problem is the result of making a variables change $x_{i j}=x_{i j}-l_{i j}$ in the original formulation that allows saving storage memory with respect to the OOK algorithm. In this way, the value of $l_{i j}$ is substituted by 0 and, in exchange, we use a shorter array $b(i)$.

Similarly to OOK, RIV is an algorithm belonging to the second family and its search strategy consists in solving iteratively the primal and dual problems. In this case we do not talk about synchronized and desynchronized arcs. The approach of this algorithm is determining whether an arc is active, balanced, or inactive by comparing the difference between the prices (dual problem) associated to each of the nodes at the extrems of each arc and the cost (primal problem) of the flow through them. According to the state of activity of each arc, we define a series of optimality conditions so one primal-dual solution will be optimal if the following conditions are met in all the arcs of the network simultaneously (Bersetkas 1988): 


$$
\begin{aligned}
& x_{i j}=l_{i j} \quad \forall(i, j) / t_{i j}<c_{i j} \text { (the arc is inactive) } \\
& l_{i j} \leq x_{i j} \leq u_{i j} \quad \forall(i, j) / t_{i j}=c_{i j} \text { (the arc is balanced) } \\
& x_{i j}=u_{i j} \quad \forall(i, j) / t_{i j}>c_{i j} \text { (the arc is active) } \\
& d_{i}=0 \quad \forall i \in N \text { (the deficit is cero in all nodes) }
\end{aligned}
$$

being:

$$
t_{i j}=p_{i}-p_{j} \quad \forall(i, j) \in A \text { (tension array) }
$$

The way to reach these conditions consists in iteratively increasing the dual function. The prices array is increased while maintaining the previous conditions for the flow array. The algorithm finalizes the search when the deficit at each node is zero. The increments in the prices array consist in, starting from a single node with a deficit value different than zero, checking if it is possible to improve the dual function if the price associated to the node is increased. If that is not possible, then an incremental flow path is gradually built following a labeling procedure. The main characteristic is that the labeling process stops when the first incremental direction is found instead of doing it for all the nodes. This process is known as relaxation.

RIV is in essence an algorithm similar to OOK. Thus, its advantages are similar with the difference that, since the search process stops when finds the first arc that complies with the ascent conditions, the arcs lists are not so exhaustively read, speeding up the search process. 


\subsubsection{NETFLO (SIMPLEX)}

The simplex method for linear programming is a very efficient algorithm for solving linear constrained optimization problems. Given that network flows are a particular case of linear programming, it is expectable that the simplex method is an attractive alternative for their resolution. However, the general method is not competitive in front of other algorithms specially designed to take advantage of network flows structure (Ahuja et al 1993).

NETFLO is the name given to the implementation of the simplex algorithm for network flows formulated by Kennington and Helgason (1980) and solves the problem formulated in equations 2.9 to 2.11 . It belongs to the first family of algorithms and is based in the successive increase of the flow vector until reaching the optimum in the objective function. It does so by obtaining a kind of solutions called spanning trees. In these solutions, the flow in the branches of the network that do not belong to the spanning tree are set to zero or to their maximum capacity. The optimal solution is found by advancing from one solution to another generating a feasible tree. The cost of each flows array cannot be lower than in the previous step. Each iteration operates as following (Bersetkas 1998):

(1) A new arc is added to the tree so a single cycle with negative cost is created. The entering arc is selected according to its cost.

(2) Flow is allocated in the cycle. As much as posible without violating feasibility.

(3) One of the arcs in the cycle is discarded, generating a new tree to be used in the next iteration. The discarded arc is chosen 
among those in the cycle that with a lesser contribution to flow increase.

\subsubsection{Generalized Network Algorithms (EMNET y NETPD)}

The kind of algorithms presented next solves a network flow problem slightly different to the previous. A network with gains is a network flow that, apart from the parameters normally associated to each arc in a normal network flow, also includes a multiplier term $\mu_{i j}>0$. In this way, the problem to be solved looks like follows (Jensen and Barnes 1987):

$$
\begin{aligned}
& \operatorname{Min} \sum_{i=1}^{m} \sum_{j=1}^{m} c_{i j} x_{i j} \\
& \text { s.a. } \sum_{j=1}^{m} x_{i j}-\sum_{k=1}^{m} \mu_{i j} x_{k i}=b_{i} \quad i=1, \ldots \\
& 0 \leq x_{i j} \leq u_{i j} \quad i, j=1, \ldots, m
\end{aligned}
$$

We assume that $\mu_{i j}$ is a rational number that can expressed as $\mu_{i j}=p_{i j} / q_{i j}$, where $p_{i j}$ and $q_{i j}$ are two integer numbers. When we allocate one unit flow to $\operatorname{arc}(i, j), \mu_{i j}$ units reach node j. If $\mu_{i j}<1$, we have a losing arc. If $\mu_{i j}>1$, we have a gaining arc.

We must take into account that the capacity $u_{i j}$ of the arc is an upper limit for the flow sent from node $i$ and not for the flow reaching node j. In a similar way, $c_{i j}$ is the cost per unit flow allocated to the arc at node $\mathrm{i}$ and not the cost per unit flow reaching node j. Minimum flows are solved in the same way as done in the formulation of RIV algorithm. 
The solution of this problem can be done in a similar way to the previously shown problems by adapting the algorithms. Ahuja et al (1993) and Jensen and Barnes (1987) developed adaptation of primal algorithms (simplex) to solve the MCF problem in generalized network flows.

EMNET (McBride 1985) is the name for the implementation of a simplex type algorithm to solve a generalized network flow problem. The general strategy is divided in three phases. In the first phase (0), a pure network flow is solved, removing the complicated aspects, what allows obtaining an approximate and efficient solution. In the next phase (1), the complex aspects are introduced in the network again and a feasible solution is obtained from the previous one. Finally, the last phase (2) consists in iteratively changing the flows, like in the simplex algorithm explained before, until reaching the optimal value of the objective function.

NETPD (Curet 1994) is an implementation of a primal-dual algorithm. The search process is similar to the one used by OOK and RIV. In fact, it is a mix of both methodologies. On the one side the feasibility of solutions is maintained during the primal phase (OOK), but the amount of work necessary to determine what dual variable must be ascended is reduced like in RIV.

An interesting aspect of the algorithms developed for generalized network flows is the possibility of solving pure network flows without the need of any change in the code or in the input data. 


\subsubsection{Other algorithms}

Apart from the algorithms presented in a detailed form, there are others that allow solving the MCF problema that were not dealt with more in depth either because to their similarity to the ones presented first or being less frequent in literatura. Examples of these algorithms are RNET (Grigoriadis and Hsu 1978), NEPSA (Paparrizos et al 2009), and more recently there has been an implementation of different MCF algorithms in the C++ network optimization library LEMON (Dezso et al 2011). Sifarelas (2013) and Kiraly and Kovac (2012) make an extensive review of existing MCF algorithms including the ones described above and their evolution through time.

\subsubsection{Comparisons between algorithms}

In order to develop an optimization model based in the resolution of the MCF problem, it is interesting to know which algorithm or family of algorithms is the most efficient among all the available ones. This section makes a summary of the results appeared in scientific literature regarding network flow optimization. An important characteristic of most of comparisons present in literature is the common use of the aleatory network generator NETGEN (Klingman et al 1974). This ensures certain similarity in the results obtained by the different authors, although it must be taken into account that the configuration of hardware used to carry out each study changes with time and will normally be more efficient in more recent researches. 
A good part of authors (Bersetkas 1985, 1988 and 1994; Kuczera 1993; Rani and Moreira 2010) coincide in that codes based in the relaxation method (RIV and previous implementations) are generally more efficient than other algorithms, solving problems up to several orders of magnitude faster. Bersetkas (1985) compared the performance of OOK, one of the initial versions of RELAX and RNET (a simplex based algorithm like NETFLO), showing that OOK is nowaday relatively outdated compared to the other two. Curet (1998) concluded that RIV that more efficiently solves NETGEN problems. Kuczera (1993) compared the performance of NETFLO and RIV for optimizing a water distribution network with reservoirs and demands. In this case, RIV was from twice to seven times more efficient in the network resolution than NETFLO. Additionally, it showed the importance of the initial solution in the performance of the algorithms.

More recently, Kiraly and Kovacs (2012) compared the performance of several algorithms implemented in LEMON with other implementations in different optimization packages and also RIV. They conclude that some newer developments are capable of outperforming RIV but this later is still very robust in most NETGEN problems, with better performance for large problems.

Regarding generalized networks algorithms, McBride (1985) showed that EMNET is about 5 times faster than a simplex based algorithm. Sun et al (1995) obtained that EMNET was between 11 to 17 times faster than a simplex based algorithm depending on the complexity of the network. Similarly to pure networks, primal-dual family algorithms are generally more efficient than simplex based algorithms (Curet 1994 and 
1998). In the case of using generalized network algorithms to solve pure networks, computation times are very similar in the case of primal-dual codes (Curet 1997 and 1998).

\subsubsection{Application of MCF algorithms in water resources optimization tools}

As commented before, the similarity between a water resources system and a network flow is more than evident. Additionally, the simple and clear formulation of MCF problem allows generalizing this method to almost any system we want to model. For this reason, network flows have been used in the development of both simulation and optimization models (Kuczera 1993; Sun et al 1995; Andreu et al 1996; Khaliquzzaman and Chandler 1997; Hsu and Cheng 2002; Haro et al 2012; Lerma et al 2012).

Additionally, the generalization possibilities of network flows have been of great advantage in the development of general simulation and optimization models such as HEC-PRM (Hydrologic Engineering Center 1990), MODSIM (Labadie 2000), SIMGES (Andreu et al 2007), and WATHNET (Kuczera 1997).

\subsubsection{The OPTIGES model}

The OPTIGES model (Andreu 1992) is an optimization model developed since 1987 by the Water Resources Engineering Research Group, currently integrated in the Institute of Water and Environmental Engineering of the Technical University of Valencia. It is a genera software tool for the development and optimization of water resources schemes. 
The model is integrated in the Decision Support System Shell AQUATOOL (Andreu et al 1996)

The use of OPTIGES requires the prior design of a simplified scheme of the water resources system to be studied. In this scheme there msut be the elements that conform the system that basically are conductions (natural and artificial); nodes (confluences, diversion and storage); hydrologic inflows; and demand units. The user provides the program with the spatial configuration of the system as well as with its physical characteristics, resources and demands data, and a set of system priorities that define the criteria of environmental flows and demands satisfaction.

The working time scale is monthly and allows running optimization horizons of one year or larger. The model yields the optimal water allocation according to the objective function Eq 2.26, showing the results relative to water storage in reservoirs, circulating flows, demands supply and deficit, and reliability values.

$$
\min \sum_{t=1}^{N \cdot 12}\left[\sum_{i=1}^{n_{c}} \sum_{j=1}^{n_{i}} \alpha_{i, j} d_{i, j, t}+\sum_{i=1}^{n_{d}} \sum_{j=1}^{n_{i \cdot}} \beta_{i, j} d_{i, j, t}^{\prime}\right]-\sum_{i=1}^{n_{e}} \delta_{i} v_{i, N \cdot 12}
$$

where,

- $n_{c}$ is the number of conductions in the scheme, each one with its mínimum flow requirements divided into $n_{i}$ supply levels.

- $\quad n_{d}$ is the number of demand in the scheme, each one with its demand values divided into $n_{i^{\prime}}$ supply levels.

- $n_{e}$ is the number of reservoirs in the system. 
- $\alpha_{i, j}$ is the cost assigned to deficit $d_{i, j, t}$ of supply level $j$ of the minimum flow of conduction $i$ in month $t$.

- $\quad \beta_{i, j}$ is the cost assigned to deficit $d^{\prime}{ }_{i, j, t}$ of supply level $j$ of demand $\mathrm{i}$ in month $\mathrm{t}$.

The objective function is linear and strives to minimize the weighted sum of déficits of environmental flows and supply déficit to demads while maximizing the stored volume in reservoirs at the end of the optimization period. The weights/costs are given by expressions that reflect the priorities assigned by the user to each environmental flow, demand and reservoir.

Eq 2.26 is a rewriting of Eq 2.9 according to the allocated costs of flow in the different arcs of the network generated by OPTIGES. Given that constraints are also linear like in equations 2.10 and 2.11, the algorithm OOK is used to solve the MCF problem.

Currently, the OPTIGES model allows considering in the optimization process two aspects of nonlinear character, evaporation in reservoirs and return flows from demands. The introduction of these two aspects is done by iterative resolution of the network flow and modification of its parameters similarly to what proposed Fredericks (1998). The MCF problem is solved until reaching convergence or until reaching a maximum number of iterations.

The OPTIGES model has been applied to the development of Spanish river basins plans. It was used to elaborate the "Temporary Scheme of Important Issues" of the Segura River basin demarcation (DHS 2008). 
Another application can be found in the "White Book of Water in Spain", where the "Hydrologic Research Center" of the "Public Works Research and Experiments Center" developed a simplified optimization model of the whole Spanish hydraulic system (MMA 2000).

OPTIGES is a model that can run very long optimization horizons, as long as the data available. Of course, the longer the optimization period is, the larger the size of the network to be solved, with the obvious associated increase in computational cost. Also, the number of elements included in the scheme increases the size of the network. All this required the development of simplified schemes that were far away from reality. Additionally, the introduction of iterative solution of non-linear aspects increases the number of times the network must be solved. This resulted in a dead -end. On the one side the models developed were little representative due to the lack of modeling elements, while on the other one, the introduction of new elements would increase the execution time of the algorithm to prohibitive times.

To overcome this hindrance, it is obvious that increasing the calculation capacity of the model is the most adequate solution so it takes less time to solve each iteration. Once this is achieved, introducing new elements in OPTIGES such as aquifers and hydroelectric production should be almost mandatory. 


\subsection{Decision Support Systems for Water Resources Management}

Management of water resources is a task that requires many different data and approaches to be effective. A water resources engineer working in a given system will often want to get as much information as possible about the system trying to be as close as possible to reality. The problem is that reality is always much more complex than it can be approximated. Problems in the real world are much larger, more complex; less structured and require human judgment and greater effort. Moreover, society demands that decisions are made considering an integrated view of the system under study. This includes, not only allocating the resources between the different uses but also considering aspects such as water quality; cost-benefit analysis of actions; and economic, social, and environmental impact assessment of management policies. Therefore, instruments that help to assess the present situation and assist in the development and evaluation of solutions may be important. Because of the inherent complexity of the dynamics of a system and the social and physical interrelationships that characterize environmental problems, Van Daalen et al. (2002), conclude that computer models are very appropriate for supporting environmental policy as they can provide insight in this complexity that cannot be obtained by other means.

Two types of support can be distinguished; support of operational management and support of strategic policymaking and planning (Gourbesville 2008). A second distinction is between support systems for monitoring, data collection and processing, oriented towards making facts 
and figures about the 'as is' situation available; and tools and systems to support decision-making with a view to the future, typically oriented to the 'ex-ante' identification, analysis and evaluation of alternative allocations, policies or plans (Mostert et al 1999). In fact all the mentioned elements can be synthesized in the so-called concept of decision support system (DSS).

A decision support system (DSS) is a computer information system that tries to help a manager to make a decision. Turban and Aronson (1995) define it as "an interactive, flexible, and adaptable computer-based information system, especially developed for supporting the solution of a non-structured management problem for improved decision-making. It utilizes data, provides an easy-to-use interface, and allows for the decision maker's own insights". They can support the analysis of the present status or provide predictions for the future (Gourbesville 2008). Moreover, they can support discussions, stimulate learning, contribute to institutional capacity building, and store data and models (De Kok et al 2009). They are also viewed as valuable for participation processes (Voinov 2008; Andreu et al 2009 and 2013; Carmona et al 2013).

For over 40 years, researchers and technicians in information systems have been devoted to the development of DSS (Hosack et al 2012). Such is the range of systems, tools and techniques covered by these systems that virtually any computer program, with interactive interfaces, that can help a manager to make decisions could be considered a DSS. There are several classifications for DSS in literature. Haettenschwiler (1999) suggests three categories: passive, active, and cooperative DSS. 
Passive DSS aid in the process of decision making but cannot make a decision, or suggesting a series of decisions, by themselves. Active DSS are capable of this latter. Finally, cooperative DSS allow the refinement of the suggested decisions and their later validation in an iterative process. Another classification provided by Power (2002) states that DSS could be divided according to the kind of assistance they provide to the managers into communication-driven, data-driven, document-driven, knowledgedriven or model-driven. A communication-driven DSS supports more than one person working on a shared task. Data-driven DSS allow accessing to and manipulating time series of data. Document-driven DSS permits working with unstructured data in several electronic formats. A knowledgedriven DSS provides specialized problem solving expertise stored as facts, rules, procedures, or in similar structures. Finally, model-driven DSS makes use of models of any kind capable of yielding new results from the manipulation and introduction of data.

All kinds of DSS help managers to answer relevant questions with regard to a decision making situation. These questions to be answered can be complex and sophisticated or simple and simplified. A DSS can be useful only for decision making to the operative level, or can be used to make strategic decisions on the long term. Each DSS has a defined purpose and the aspects or topics included in its data base, the considered variables, the data series available, and the tools to retrieve and analyze them determine the questions that can be answered and the decisions that can be made.

The design and capabilities of the DSS will influence the validity and usefulness of its results for the decision that we want to make. Validity can 
be defined quite broadly. McNie (2007) recalls the validity of a DSS by the usefulness of the information that it is capable of providing (fit for purpose, accessible and user-friendly). This in turn requires that the information is perceived as valid. Junier and Mostert (2014) view validity as the ability of a model to represent reality correctly. They defend that validity, just like usefulness, is not just determined by technical parameters, but also by the perceptions of those who work with a model or DSS, both developers and users. Validity of a DSS can be compromised for many different reasons. Volk et al (2010) compared four DSSs for river basin management. Although all four were seen as relatively successful, they share a number of shortcomings: limited technical quality (such as insufficient data, model integration, and uncertainty propagation), insufficient involvement of stakeholders, and lack of insight in the specific wants and needs of the endusers.

Also important for the use of DSSs is trust in the outcomes of the instruments. One of the criteria for useful information that McNie (2007) refers to, is credibility: information needs to be accurate, valid and of high quality. Also, a solid scientific basis and providing sensitivity and statistical analyses can improve trust in DSS results (Borowski and Hare 2007). Moreover, the degree of uncertainty and how uncertainty is represented are important factors contributing to trust in the quality of information provided (Maxim and Van der Sluijs 2011).

The development process itself can help to create trust. Bots et al (2011) note that a model can be rejected completely when its validity is contested. Involvement of stakeholders in the development process 
increases transparency, and determines the 'rules of the game', that is to agree beforehand on how to use models in the decision-making process (McIntosh et al 2011). Giupponi and Sgobbi (2013) also acknowledge as ingredients for the success of a DSS the early involvement of end-users and the flexibility of the tools in considering their needs.

Stakeholder involvement in the development process is in fact a common recommendation for improving use (Mysiak et al 2005; Jakeman et al 2006; Voinov and Gaddis 2008; Andreu et al 2009; Giupponi and Sgobbi 2013). So much so that a field of participatory (or 'collaborative') modelling has developed, in which users are actively involved in developing the model itself (Evers et al 2012; Hare et al 2003; Hoppenbrouwers and Rouwette 2012). Borowski and Hare (2005), however, point out that water managers are reluctant to spend much time on participation. McIntosh et al (2011), in addition, state that from a developers' point of view, the cost related to intensive participation may drain the resources for development and may therefore endanger other essential elements of DSSs.

A DSS can be developed independently for a particular case or set of similar cases. Examples include the mDSS in the MULINO project (Fassio et al 2005, Giupponi 2007; Mysiak et al 2005) and the Elbe DSS (De Kok et al 2009; Lautenbach et al 2009), both of which were developed to support the implementation of the WFD. Another possibility is that the DSS is developed with a generalized tool; also known as Decision Support System Shell (DSSS), reducing the need to invest time and money in developing user interfaces, algorithms, writing and debugging of code, and testing of specific programs. The general trend in recent times has been changed to 
use more specific generalized models (Wurbs, 2005). Some examples of DSSS for water resources systems planning and management existing nowadays are MODSIM (Labadie 2005); CALSIM (Draper et al 2004); WEAP21 (Yates et al 2005a and 2005b); MIKE Basin (DHI 2014); IQQM (Simons et al 1996); REALM (Victoria DEPI); Ribasim (Deltares); RiverWare (Zagona et al 2005); Waterware (Jamieson and Fedra 1996); IRAS (Loucks et al 1995); AQUATOOL (Andreu et al 1996); and HEC-ResSim (Klipsch and Hurst 2007). All of them have in common that they are a set of interactive computer programs, based on a graphical interface, incorporating mathematical optimization and simulation models, sometimes combined with other qualitative models, all of which is designed to allow answer questions or issues related to planning a water resources system.

Nowadays, almost everyone involved, in one way or another, in planning and management of water resources relies on the information derived from models (Loucks, 1995). Many authors discuss how DSSs and other modelling tools can contribute to environmental policy (Fassio et al 2005; Mysiak et al 2005; Jakeman et al 2006; Gourbesville 2008; Eden 2011). So, on the one hand there is support for the notion that when problems are complex, modelling tools in general or more specifically DSSs can be useful. On the other hand several authors also comment on the limited use of DSSs (Borowski and Hare 2005; Gourbesville 2008; McIntosh et al 2011; Van Delden et al 2011; Giupponi and Sgobbi 2013). For example, for Van Delden et al (2011), some of these limitations are lack of transparency sometimes, inflexibility and a focus on technical capabilities rather than on real planning systems. Also, a lack of training by end-users and not setting the rules of the game beforehand may result in the failure 
of the DSS. A DSS needs to correspond with the perceptions, experiences and operational procedures of policy and decision makers and should enhance, or support, existing practices rather than replace them. It is also necessary to remember that a DSS is only capable of answering the questions for what it was created and trying to go beyond that will definitely yield disappointing results.

Technically speaking, there are three vital elements for the success of a DSS: the usefulness of the instrument itself (fit for purpose, ease of use), the knowledge base of the model (replication of reality), and the data available for the processing. Jakeman et al (2006) present a 10 step iterative process for the technical development and evaluation of such a DSS. McIntosh et al (2011) review the literature regarding user interfacing, usability and the embedding of models into DSSs. They consider of special importance topics as ease of use, usefulness, trust and credibility, promoting acceptance, and starting simple and small. Several case studies on the development of DSS exist, mostly written by the developers themselves (Andreu et al 2009; Alemu et al 2010; Coelho et al 2012; Klauer et al 2012; Carmona et al 2013).

\subsubsection{Role of decision support systems in drought planning and management}

Drought planning requires preliminary identification and analysis of the risks associated to the occurrence of this natural phenomenon. Additionally, the mitigation measures within a drought prevention strategy need a study within the context of the system so the managers select the ones that yield best cost/effectiveness relation (Haro 2014). To carry out 
these tasks, software tools efficiently integrated within a decision support system (DSS) are of great help in order to enhance the capabilities of decision makers (Rossi et al 2008). The use of such systems allows developing and using real time management models able to assess the risk of drought, and the effectiveness of proactive and reactive measures applied on regular basis for the management of river basins (Merabtene et al 2002; Pallotino et al 2005; Andreu et al 2009 and 2013). DSSs also permit the monitoring of drought by evaluating the different indicators and drought indices defined for the studied river basin. Additionally, they represent a powerful tool for participatory processes since, as seen in Wilhite et al. (2000) and Andreu et al (2009), the different stakeholders involved in drought planning have a chance to develop and understanding of one another's various points of view, and to generate collaborative solutions. A DSS is the common platform that the different stakeholders can use to show their proposals and understand how these would affect the rest of the participants. The whole modeling process especially when all the interested parties collaborate in its development helps building common knowledge and shared vision on the system (Haro 2014).

\subsection{Final remarks}

Droughts are an increasing concern in most of river basin systems, particularly in those with delicate balance between resources availability and uses (water scarcity). The change of drought management paradigm from reactive to proactive requires continuous surveillance of the situation of the system so the appropriate mitigation measures can be activated in time. However, drought monitoring systems are only capable of 
determining the current status of the system with regard the historic records. They are only reliable if the developing drought episode is analogous to previous events, but no drought is identical to another. Therefore, risk assement methodologies appear like a relatively reliable approach to complement monitoring systems in the task of detecting and forecasting the possible effects of a drought episode and to activate mitigation and risk reduction measures (early warning system).

Risk assessment methodologies for river basins operation (shortterm), as proposed in literature, normally account for the use of a simulation model to assess the effects of possible future hydrologic scenarios and of the possible measures defined for drought mitigation and risk reduction. Therefore, risk assessment results will yield probability distributions of the possible state of the system during the period of study according to the operation rules defined during the planning phase for normality situations. However, droughts are not normal aspects in the operation of water resources systems. Thus, the operation rules defined for normality situations probably are not the most appropriate to manage the system in exceptional moments. The problem is that operation rules are often the result of in-depth studies of the basin as well as of long negotiation processes between stakeholders and water managers. Setting new rules during the development of possible emergency situations can be highly inefficient and consumes time and resources that would rather use in more important issues.

Optimization models allow obtaining the best management of the system for a hydrologic scenario without the need of setting operation 
rules, only the priorities for water allocation between the different uses and their supply objectives. The use of such models in a risk assessment methodology would probably allow defining optimal activation of measures both in time and intensity. Therefore, the development of a generalized optimization model capable of representing the most important aspects of the water resources system, and its use in a risk assessment process would be an interesting alternative, or complement, to traditional drought risk assessment methodologies.

There are few areas of knowledge that have used such as varied optimization methodologies as in the optimization of water resources systems (Labadie, 2004). Andreu (1993) wrote: "If we are able to find a suitable objective function, optimization techniques can provide a suitable framework for the analysis of the system where decision making must be done. This point -finding an objective function-is not easy at all for some problems, for example on issues related to water resources planning. Nor is it easy to fully represent the complexities of the systems to optimize. Therefore, and although we speak in terms such as 'global optimum', in most cases the actual optimization results must be regarded as approximations rather than exact solutions. Thus, the optimization is to be understood as an analysis tool rather than as a process that has to give us the ultimate solution. A good dose of good judgment will be needed in the formulation of problems, as it has to consider the need for a sufficiently realistic representation of the face of the model is tractable optimization resulting system. This requires that whoever wants to successfully use these techniques must learn to: 1) Distinguish the essential features of the system that should be maintained in its representation; and 2) choose the 
optimization techniques that will lead to tractable models for which it has to know the existing techniques and / or adapt them to new situations."

Despite this, there is still a large difference between the theoretical application of optimization methods and their practical application in dayto-day management of water resources systems. Labadie (2004) notes several reasons: (1) the skepticism of many operators compared to the results of the models, relying more on personal experience; (2) both computational and detail limitations of the models make the results not as suitable as the operators would be willing to accept; (3) optimization models are much more demanding mathematically, which makes them more difficult to understand than the simulation models; (4) many optimization models cannot incorporate risk and uncertainty; (5) there are a lot of models to choose from and it is often difficult and even confusing to choose one for each particular application; and (6) some of the methods described cannot be generalized and, therefore, require a particular formulation for each case to be studied. This last reason has been overcome with the development of some generalizable optimization methods. These have helped 'losing the fear' to use optimization models for developing operation rules in individual and multi-reservoir systems.

Along the last two decades, various authors have been regularly reviewing the state of the art in the field of water resources systems optimization (Wurbs 1993; Labadie 2004; Rani and Moreira 2010; Fayaed 2013; Ahmda 2014). These reviews show how the amount of optimization techniques has increased with time, allowing researchers and water managers to approach optimization problems from different perspectives 
and new possibilities. Despite the appearance of new optimization techniques with the passing of time, most of the older (or classical) techniques still prevail and are widely used. This has probably to do mostly with reason 3 for not using optimization methods in practical applications, since many of the new methods have very dense mathematics behind them to fully understand what they are doing. These mathematical problems normally come together with reason 6 , the requirement of particularized formulations for each particular problem when a water manager often works in more than one system at a time. In some cases, reason 2 is still valid despite the increasing computational capacity of personal computers. On the other hand, the oldest methods have benefited of the very past of time. They have become mandatory subjects in many technical education programs so the new engineers and technicians are now familiar with these methods. Additionally, the old methods were very computationally demanding at the time they were developed, but they were still very efficient since their developers acknowledged the technical limitations. Thus, these old efficient methodologies are nowadays capable of solving double size problems in a tiny fraction of what they did with old computers while many modern ones still get lost in thousands of iterations. Celeste and Billib (2009) evaluated the applicability of several reservoir optimization models for the development of rule curves for reservoir operation. They show how ISO and heuristic models outperformed ESO models. However, we saw above that an ESO methodology such as SDP is increasing its presence in literature in the last years for the optimization of reservoirs operation (Singh 2012). This later author also acknowledges the 
application of most of the techniques described in this section for the optimization of different aspects of water resources systems management.

Provided that the objective of this thesis is developing a methodology that allows defining the optimal management of a water resources system during drought situations, and that this methodology is easily translated to any other systems, there is a need for an optimization technique that it is generalizable. With this in mind, network flows seem like the most promising approach to the problem we face. However, with the desire that the methodology proposed yields realistic and usable results, the optimization model developed must allow including most of the important aspects present in a water resources systems. It will be necessary as well to take into account the mentioned problems related to the use of network flows, particularly representativity problems due to the impossibility of introducing non-linearities in the optimization process.

Two possibilities can be considered for the development of a network flow based optimization model. For the first one, it is possible to choose using an efficient pure network algorithm and be confident in surpassing the several non-linearities present in the model by iterative resolution of the MCF problem. The second possibility would be the use of an algorithm for generalized network flows.

In this thesis, the first option will be the one selected. On one side, there is the fact that, even though they have been used for water resources systems optimization, generalized network algorithms are not really abundant in literature, while pure network algorithms are. Additionally, it has not been possible, to the date, finding a publicly available algorithm for 
generalized networks. Finally, the introduction of complex non-linearities in the optimization problem would not prevent the use of iterations even for generalized network algorithms since these only allow considering linear gains in the arcs, and not all the aspects present in a river basin have a linear behavior.

Finally, it has been shown how decision support systems are important tools for the planning and management of water resources systems. They are also very useful in drought management processes, especially in promoting common understanding of the problems faced by the different stakeholders and building trust in the measures and policies defined to mitigate the effects of drought.

The introduction of a tool such as the envisaged for this thesis in a decision support system shell would introduce additional possibilities for the analysis and management of droughts. 



\section{CHAPTER 3}

Advances in network flow optimization modelling of water resources systems 



\section{Chapter 3: Advances in NF optimization of WRS}

This chapter contains parts of some of the articles published along the research phase of the thesis either in indexed journals or conference proceedings. These articles are: 
Journal article: Haro D, Paredes J, Solera A, Andreu J (2012) A model for solving the optimal water allocation problem in river basins with network flow programming when introducing non-linearities. Water Resour Manage 26:4059-4071 (DOI 10.1007/s11269-012-0129-7)

Conference communication: Haro D, Solera A, Paredes J, Andreu J (2012) Incorporating Aquifer Modeling Into A Multi-Period Network Flow Programming Optimization Models For Water Resources Management. In Proceedings of 10th Hydrolnformatics conference, Hamburg, July 2012, ISBN 978-3-941492-45-5

Conference communication: Haro D, Solera A, Pedro-Monzonís M, Andreu J (2014) Optimal management of the Jucar River and Turia River basins under uncertain drought conditions. In Proceedings of the 16th Conference on Water Distribution System Analysis, Bari, July 2014, Procedia Engineering 00 (2014), 000-000

\subsection{Introduction}

For the study of water resources systems is common to use two different approaches, simulation and optimization. The aim of the first one is to simulate in detail the operation of the system with a given management rules, while the purpose of the optimization approach is to find the optimal management of the system and calculate the flow and storage of water in such a situation.

Although it is briefly referred in the previous paragraph, a notable difference between the models and simulation optimization is precisely the level of detail. A simulation model is able to represent many elements 
present in a watershed, while optimization models represent system components with a high level of detail less often. This aspect makes that sometimes the results of optimization models are considered unimportant or even come to distrust them because of their low representation in practice (Labadie 2004). However, the number of authors and other organizations that observed the importance of optimization of water resources systems is not reduced. In the "Libro Blanco del Agua" (MMA 2000) the need to employ optimization models in the development of river basin plans, as well as simulation models, is defended. The review of the state-of-the-art in the previous chapter shows that optimization of water resources systems is not an excluded theme today but which is an ideal field for the application of the most advanced (or recent) optimization techniques as we could see in the previous chapter.

Pure reservoir system simulation models reproduce the performance of a water resources system for given hydrological inflows and operating rules. These models are usually based on mass-balance accounting for obtaining the water volumes circulating through the system. Optimization models determine the values for a set of decision variables that will maximize or minimize an objective function subject to constraints. Still, many optimization models can also be categorized as being "simulation" models in the sense that they are applied in the same manner as conventional simulation models. This means the problem can be formulated in a way that the operation rules of the system are reflected in the model characteristics, so the results will describe what will happen under those predetermined plans. Prescriptive models are those which determine the plan that should be adopted to best satisfy the decision 
criteria (Wurbs 1993). This prescriptive orientation is one of the most important features for water resources systems optimization.

A common technique for the optimization of water resources systems is network flow programming due to the great similarity between them. Furthermore, there are highly efficient algorithms for solving flow networks that result in the optimal allocation of flows through it with low computational load, which is advantageous because the need for optimizing very complex systems for extended periods of time. Added to the above is the special structure of network data flow, simple and organized. It allows easily accessing and modifying all the network elements in a truly efficient way. Another advantage of using network flows for a prescriptive optimization study is that many of the data are repeated every time interval, simplifying the definition of the network.

The use of networks flow, however, is not without limitations. The most important, and that also represents a major problem for the development of complex models that represent a variety of situations, is the inability of the algorithms dealing with nonlinearities, such that certain flows through arcs of the network depends in turn on the flow that runs through other arcs. Still, these limitations can be overcome by iterations (Fredericks 1998). And given the efficiency of the existing network flow algorithms, the application of this methodology is completely viable.

One of the objectives of this thesis is the development of a generalized network flow based optimization model for the management of water resources systems and use it to implement a risk assessment 
methodology to support decision making during periods of strong hydrological uncertainty.

The present chapter presents a series of developments oriented to improve the applicability of optimization modeling to water resources systems management. The first section studies the possible problems to be found when implementing an iterative approach to solve non-linearities in a network flow optimization model. Different network flow algorithms will be tried to solve the complete problem in order to find the most appropriate regarding low computational load due to the amount of iterations required. Based on the results of the first section, the second one will present the formulation of a model for water resources management optimization capable of dealing with both the surface and groundwater system. According to the suggestions extracted from literature, an iterative optimization-simulation approach will be used. The new model is applied to a simple case study to check its validity and applicability to more complex systems. Finally, the optimization model developed will be implemented in a risk assessment methodology for decision support during droughts and uncertain hydrological periods. As well, the methodology will be applied to a simple case of study to check the validity of the obtained results and studying their applicability in drought risk management and mitigation. To facilitate the later user of the new developments, they will be implemented in a Decision Support System Shell so they are available to the general public. 


\subsection{Network flow optimization and non- linearities. Algorithms, iterations and convergence}

With the objective of developing a generalized optimization model for water resources management capable of detailed representation of the most important elements within a river basin, and the desire of using a network flow programming approach, one of the first tasks is finding an efficient algorithm to use it as the core engine of the model. Literature review from the previous chapter suggests that the most interesting algorithm nowadays, despite it is already a few years old, is RELAX IV (Bersetkas 1994). Haro (2011) tested the efficiency of this algorithm against another two in the resolution of some basic network flow problems based in water resources systems schemes. The algorithm commented outperformed by far the other two, becoming a very serious candidate to be the calculation engine of a future complex optimization model.

As mentioned before, the development of a detailed optimization model using the network flow programming approach will need of iterative resolution of the network to overcome the hindrances posed by the several non-linear constraints that such a model will have. However, if the amount of iterations needed to reach a global optimum is very high, we will not be advancing with regard to other optimization techniques. Therefore, we require a network flow algorithm that is stable and also has low sensitivity to small changes in the network definition. 
This section analyses the behavior of three different pure network flow algorithms in the iterative resolution of a water resources system based optimization model with non-linear constraints, evaporation and return flows from demands.

\subsubsection{Generalised model formulation and network construction}

The water resources model chosen is the one developed by Andreu (1992) and optimises the monthly system management for a period of $\mathrm{N}$ years by minimising the following objective function.

$$
\sum_{t=1}^{N \cdot 12}\left[\sum_{i=1}^{n_{c}} \sum_{j=1}^{n_{i}} \alpha_{i, j} \cdot d_{i, j, t}+\sum_{i=1}^{n_{d}} \sum_{j=1}^{n_{i}} \beta_{i, j} \cdot d^{\prime}{ }_{i, j, t}\right]-\sum_{i=1}^{n_{r}} \delta_{i} \cdot V_{i, N \cdot 12}
$$

where:

- $\quad N$ is the number of years in the optimization period

- $\quad t$ is the number of month within each year

- $\quad n_{c}$ is the number of channels in the system, each with its ecological flow requirement divided into $n_{i}$ levels

- $\quad n_{d}$ is the number of consumptive demands in the system, each of them divided into $n_{i^{\prime}}$ demand levels

- $\quad n_{r}$ is the number of reservoirs in the system

- $\quad \alpha_{i, j}$ is the cost assigned to the deficit $d_{i, j, t}$ of the level $j$ of the ecological requirement in channel $i$ in month $t$

- $\quad B_{i, j}$ is the cost assigned to the deficit $d^{\prime}{ }_{i, j, t}$ of the level $j$ of demand $i$ in month $t$ 
- $\quad \delta_{i}$ is the benefit assigned to keeping volume $V_{i, N \cdot 12}$ in reservoir $i$ at the end of the optimization period

This objective function is linear; the model minimises the weighted sum of the deficits in the ecological flows in channels and in the supply to consumptive demands and maximises the stored volume in reservoirs at the end of each optimization period.

The weighting factors are defined as:

$$
\begin{aligned}
& \alpha_{i, j}=K_{\alpha}-p_{i} \cdot K 1-j \cdot K 2 \\
& \beta_{i, j}=K_{\beta}-p_{i}^{\prime} \cdot K 3-j \cdot K 4 \\
& \delta_{j}=1+n_{r}-p^{\prime \prime}{ }_{i}
\end{aligned}
$$

where $K_{\alpha}, K_{\beta}, K 1, K 2, K 3$, and $K 4$ are user defined constants and $p_{i}$, $\mathrm{p}_{\mathrm{i}}^{\prime}$, and $\mathrm{p}^{\prime \prime}{ }_{\mathrm{i}}$ are the assigned priorities for each ecological flow, demand and reservoir, respectively.

The optimization of the previous objective function is subject to the habitual mass balance and flow bound constraints (Ahuja et al 1993).

The construction of the network flow is performed following the work of Kuczera (1993), Braga \& Barbosa (2001). The network is just a multiplication of the system scheme for the $\mathrm{N} \cdot 12$ months comprising the optimization period. The networks for a given month and the following month are linked by carryover arcs representing the stored volume in reservoirs. An example for a system with two reservoirs in series is given in Figure 3.1. 


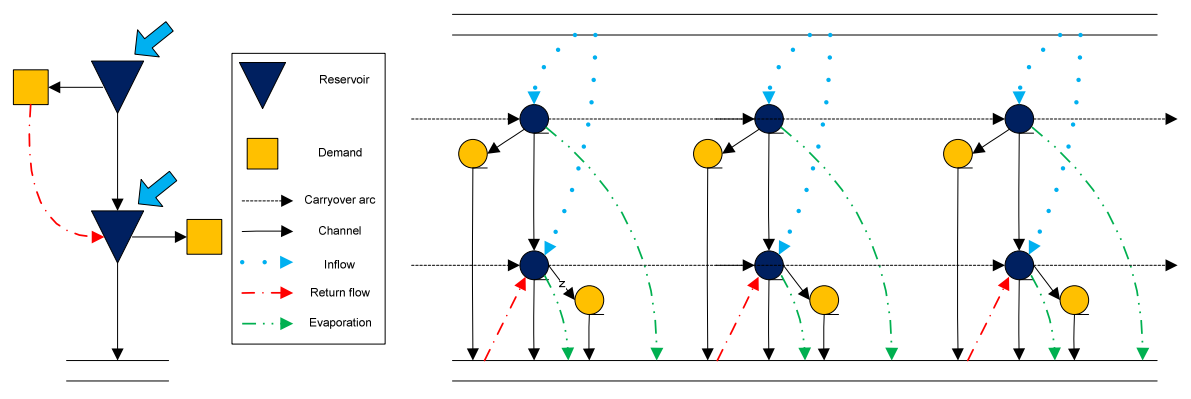

Figure 3.1. Example system of two reservoirs and two demands with its associated multiperiod network flow scheme (source: Haro et al 2012)

\subsubsection{Introducing non-linear aspects in the network definition}

Labadie (2004) described a gap between the theoretical developments of optimization models for reservoir systems and real-world applications. One of the causes of this gap is the simplifications and approximations required to overcome hardware and software limitations. This means that many optimization models do not completely represent or approximate the reality of the systems modelled, with a consequent lack of trust by operators and decision makers. In the case of network flow programming, the linear nature of both the objective function and the constraints makes it difficult to address aspects of the water resources systems that do not have a linear behavior (Haro et al 2012). This is the case for evaporation from reservoirs and return flows, which are two important aspects to be considered when considering a water allocation problem in a resource system. . 
Evaporation is a system loss that can be significant in arid and semiarid climate regions such as in Spain and other Southern European countries. Evaporation has a larger effect for larger water bodies. Evaporation is of particular importance in planning study models where usually only the main and larger reservoirs in the system are included (Haro et al 2012). Not considering evaporation might yield inaccurate resource allocations with mistakenly increased demands. There are also the return flows from consumptive demands. These flows depend on the water use efficiency at the demand site. This means that, in systems with intensive irrigation demands, an important part of the water allocated to their supply will come back to the system somewhere downstream of the intake point. Not accounting for return flows might therefore suggest a false resource deficiency for downstream uses.

Both evaporation from reservoirs and returns from consumptive demands are considered in the generalized model presented in this section. Also called non-network constraints, the problem with using these constraints is that the flows circulating through some arcs in the network are proportional to the flows circulating through different arcs. This proportionality problem is impossible to solve with a common minimum cost flow algorithm because these types of constraints cannot be considered in the calculation process. Different solutions have been considered in the literature for solving this network flow programming problem including generalized network flow algorithms (Sun 1995, Hsu \& Cheng 2001, and Harou 2010), equal flow algorithms (Manca et al 2010), 
and successive solution of the pure network with arc parameters adjusted until convergence (Fredericks et al 1998, llich 1992).

Continuing with the line started by Andreu (1992), the later solution was chosen for handling these two aspects in the generalised model presented in this section. As seen in Labadie (2004), if little iterations are needed to achieve convergence, this process may be more efficient than the other two approaches because inclusion of non-linear conditions usually carries a computational price. The successive solution procedure also allows consideration of conditions where the associated flows do not have a proportional relation with other flows in the system, such as reservoir and channel seepage or aquifer connections.

A critical examination of the appropriateness of using iterations with network flow algorithms to approximate non-network constraints is provided by llich (2009). He concludes that any flow path restrictions that are updated through iterative calls of the network flow solver may fail to deliver reasonable solutions. However, the non-network constraint used as an example in the cited paper was outflow capacity related to reservoir storage. This can be considered an operation rule that is not the type of constraint that would be used in an optimization model. The iterative process is crucial for obtaining the proper model results, and the definitions of the conditions determine how well the model works.

Each of the two non-linear aspects considered in this section add extra arcs to the network. Evaporation from reservoirs adds one arc per month starting at the node representing the corresponding reservoir each month and ending at the balance node; its lower limit is zero and the upper 
limit will be changing through the iterative process. A very low flow cost value is given to the arc so that the maximum flow possible circulates through it and decreases the value of the objective function. Return flows will be considered as hydrological inflows. This means one arc per month will be created between the balance node and the return node in the system. Return flow arcs will not affect the objective function. Moreover, several demands can return to the same point in the system. The corresponding return flow values will be summed in these cases and no extra arcs will be created. The new arcs are also represented in the multiperiod network shown in Figure 3.1.

The flow diagram of the iterative process defined for the generalized model can be seen in Figure 3.2 and works as follows:

- In the first iteration, both evaporation and returns are ignored by setting the upper capacity values of their corresponding arcs to zero and the pure network is solved normally.

- Second, with a first solution of the network, the theoretical evaporation and returns flows are calculated. These values correspond to the evaporation and return values that would occur under the flow conditions calculated in the previous step.

The evaporation for reservoir $i$ is calculated as:

$$
E V_{i, t}=E V R_{i, t} \cdot \frac{S_{i, t-1}+S_{i}}{2}
$$

where $E V R_{i, t}$ is the monthly evaporation rate in month $t$ and $S_{i, t-1}$ and $S_{i, t}$ are the reservoir surface at the beginning and at the 
end of the month, both calculated from the reservoir surface/volume curve.

Return flow from demand $i$ is calculated as:

$$
R_{i, t}=\alpha_{i} \cdot S_{i, t}
$$

where $\alpha_{i}$ is the return fraction from demand $i$, and $S_{i, t}$ is the supply to demand $i$ in month $t$.

- Third, the resulting values for evaporation and return flows are substituted as the upper limits of their corresponding arcs.

- Finally, the calculated evaporation and return values are compared with the values obtained in the previous iteration. If the difference for every arc is lower than the Convergence Error Value (CEV), the process will stop and the last calculated values will be considered correct. If the convergence criterion is not met on some arc, the program will do another iteration to solve the pure network.

The most critical aspect of this iterative process is the CEV. The CEV is initially set to 4 and represents a deviation of 0.04 flow units. This value was chosen during model development as it represented a fairly acceptable deviation value; it also worked well during the previous development of similar models, for instance SIMGES (Andreu et al 1996). However, the value of the CEV affects the number of iterations as well as how "finetuned" the final results are. The relationships among this value, the number of iterations and the results are discussed below. 
The upper and lower limits of evaporation and return arcs are set to zero



Figure 3.2. Flow graph of the iterative process in the optimization model (source: Haro et al 2012) 


\subsubsection{Solving the minimum cost flow problem}

The network flow problem generated from a water resources scheme can be solved with a conventional linear programming algorithm. However, as has been stated before, the special structure of the network facilitates the use of more efficient algorithms which notably reduce the calculation time and allow studying larger problems with numerous variables and restrictions.

The generalized model presented in this section allows for optimization of a water resources scheme with three different, broadly known network flow algorithms: Out-of-Kilter (Ford \& Fulkerson 1962), NETFLO (Kennington \& Helgason 1980), and RELAX-IV (Bersetkas \& Tseng 1994). All three algorithms have been used previously to solve optimization models for water resources systems (Chung et al. 1989; Kuczera 1993; Andreu et al. 1996; Khaliquzzaman \& Chander 1997; Labadie et al 2000; Labadie 2006).

There are several references comparing the performance of the algorithms. Most of the authors (Bersetkas 1985; Bersetkas \& Tseng 1988 and 1994; Kuczera 1993), agree about the superior performance of algorithms based on the relaxation method such as RELAX-IV and previous implementations. These algorithms usually perform faster by up to one order of magnitude than the other minimum cost flow problem algorithms.

All three algorithms are used in the case study below. This was not for studying the best execution time because that had already been studied in Haro (2011). Although the time spent performing calculations is 
important, of more importance are the obtained results. Because each algorithm uses a different methodology to solve the minimum cost flow problem, the optimization results might differ slightly from one algorithm to another. Thus, the performances of the algorithms are studied from a more "operative point of view", checking whether aspects such as the distribution of storage in reservoirs (when more than one exists) make any of the algorithms more or less appropriate for the water allocation task. Moreover, the performance of the algorithms when working in an iterative manner is checked. As the iterative process changes arc capacities, this can be seen as a sensitivity analysis that will affect the number of iterations given a fixed CEV.

\subsubsection{Application to the water resources scheme of the Duero River}

The Duero River basin is a trans-boundary system (Figure 3.3). Of the $97,290 \mathrm{~km} 2$ area of the basin, $81 \%(78,952 \mathrm{~km} 2)$ is in Spain and $19 \%$ $(18,338 \mathrm{~km} 2)$ is in Portugal (CHD, 2008). The climate is continental with a strong Mediterranean character. The mean basin precipitation is approximately $625 \mathrm{~mm} /$ year, resulting in nearly 15,000 million m3/year of available water in the river and aquifers. 


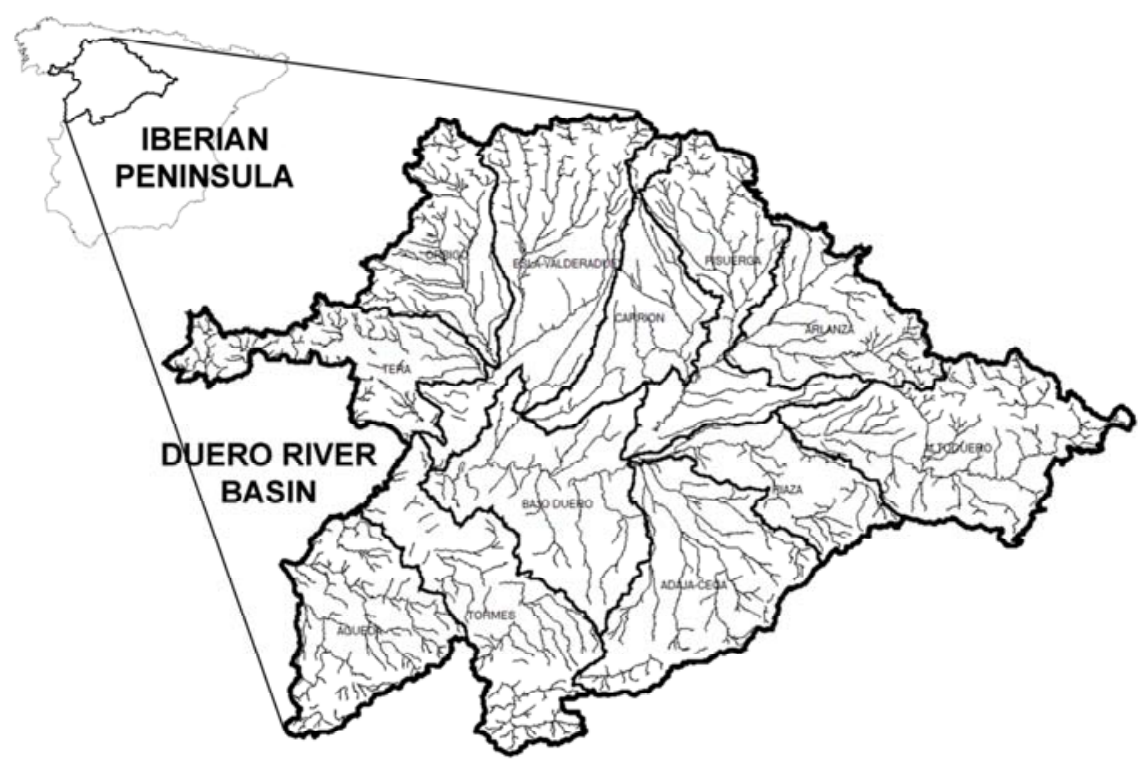

Figure 3.3. Duero River basin territory (source: Haro et al 2012)

Agriculture in the basin includes unirrigated ( 3.5 million ha) and irrigated ( 0.5 million ha) crops. Irrigation is the largest water consumer in the basin, using $80 \%(3,600$ million $\mathrm{m} 3 / \mathrm{yr})$ of the total volume of water consumed. The installed capacity of hydropower is 4,000 MW with an average production of 7,300 $\mathrm{GWh} / \mathrm{yr}$. The urban water demand in the basin is low, with most of the 2.3 million people living in small towns of 1,000 5,000 . To comply with the objectives of supplying agricultural demands and producing energy, the water system has 75 large reservoirs with a total storage capacity of 7,500 million m3. It is divided into 12 subsystems. These subsystems work independently, although complying with management conditions determined by basin policies.

The Duero River basin authority developed a scheme of the system for both simulation and optimization purposes with the DSSS AQUATOOL 
for the development of their latest river basin plan (Figure 3.4). For optimization tasks, the scheme consists of 37 reservoirs (where evaporation is considered), 169 consumptive demands and 49 return points. The Duero River Basin Authority uses optimization for different purposes, namely, developing new operation rules, estimating minimum shortages and maximum surpluses for demand increase studies, or studying the possible effects of climate change independently from actual management. Any of these purposes can be easily achieved with the presented model because its decision variables and constraints are oriented to these goals.

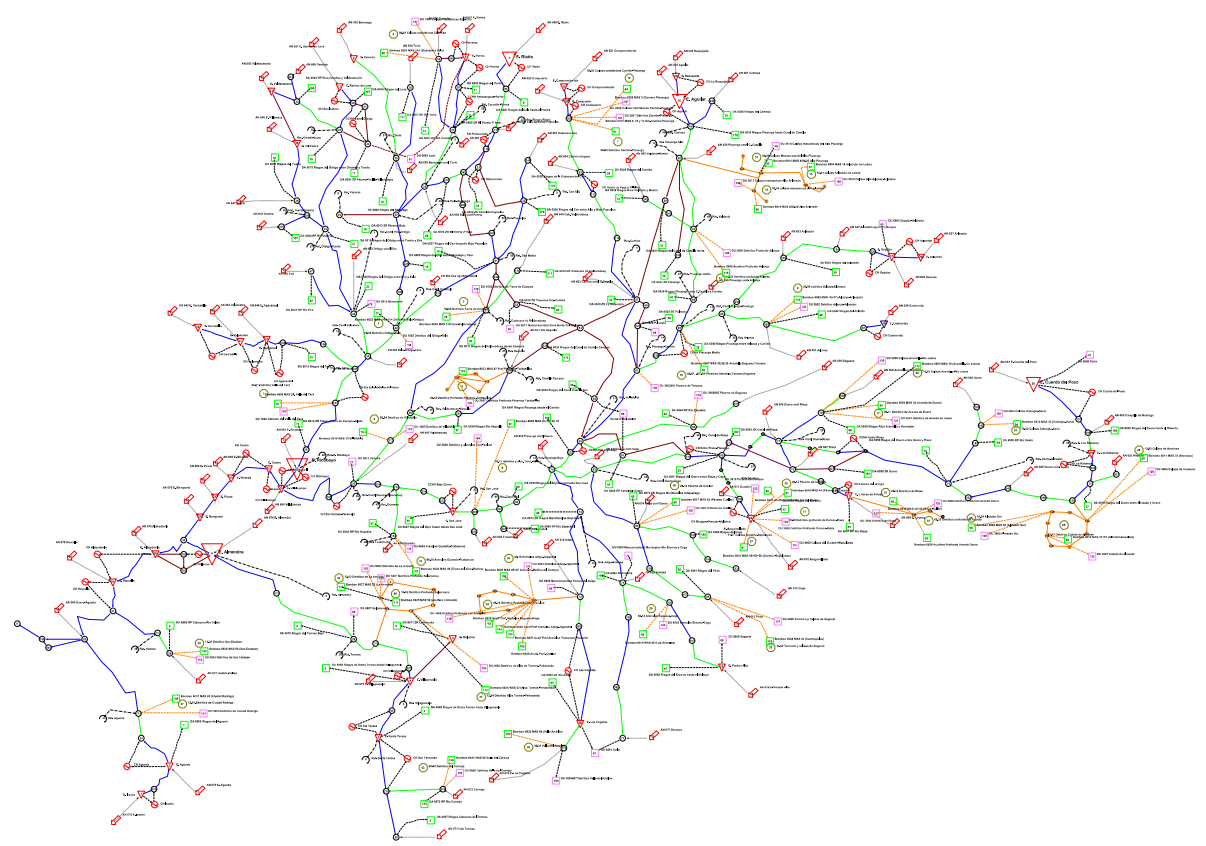

Figure 3.4. Scheme of the Duero River water resources system used for the optimization model developed with AQUATOOL (source: self-elaboration) 
Each of optimization purposes usually has a different modelling time horizon, For example, development of new operation rules requires optimization over long time periods so regression can be applied afterwards, while shortages-surpluses studies are performed for a one or two year time horizon. The optimization period depends very much on the system and the size of its reservoirs. A system with large reservoirs, usually of hyper annual operation, will need longer optimization periods, while systems with small reservoirs that are only suited for fulfilling annual demands will use shorter periods. For the study presented in this section optimization time horizons of one, five, and ten years were used. By doing this it could be shown how the model would perform for some of the different purposes explained before. One year would represent the most immediate operational management of the system; five years would be for short term planning, e.g. demands change; and ten year or longer periods would be used for long-term strategic planning and studying the impact of climate change.

All the runs were performed using an Intel ${ }^{\circledR}$ Core $^{\mathrm{TM}} 2$ Duo CPU E7400 @ $2.80 \mathrm{GHz} 2.80 \mathrm{GHz}$ and $1.74 \mathrm{~GB}$ RAM. Table 3.1 shows a summary of the characteristics and results of the model runs performed for the Duero River system. 
Table 3.1. Optimization runs characteristics and results

\begin{tabular}{|c|c|c|c|}
\hline Optimization Horizon (years) & 1 & 5 & 10 \\
\hline \multicolumn{4}{|l|}{ Size of the network } \\
\hline Arcs & 17965 & 89101 & 178021 \\
\hline Nodes & 6956 & 34220 & 68300 \\
\hline Non-Linear Arcs & 1032 & 5160 & 10320 \\
\hline \multicolumn{4}{|l|}{ Average time per iteration (s) } \\
\hline OOK & 3.089 & 130.187 & 678.919 \\
\hline RLX-IV & 0.184 & 5.221 & 22.571 \\
\hline NF & 0.549 & 11.212 & 44.35 \\
\hline \multicolumn{4}{|l|}{ Number of Iterations } \\
\hline OOK & 3 & 7 & 7 \\
\hline RLX-IV & $>100$ & $>100$ & $>100$ \\
\hline NF & $>100$ & $>100$ & $>100$ \\
\hline \multicolumn{4}{|l|}{ Objective function value } \\
\hline оOK & $-7.204 \cdot 10^{9}$ & $-3.555 \cdot 10^{9}$ & $-7.126 \cdot 10^{9}$ \\
\hline RLX-IV & $-7.205 \cdot 10^{9}$ & $-3.554 \cdot 10^{9}$ & $-7.125 \cdot 10^{9}$ \\
\hline NF & $-7.205 \cdot 10^{9}$ & $-3.562 \cdot 10^{9}$ & $-7.139 \cdot 10^{9}$ \\
\hline
\end{tabular}

It was easy to predict based on the literature that Relax-IV would outperform the other two algorithms because it is approximately 30 times faster than Out-of-Kilter and approximately twice as fast as NETFLO. It was also easy to predict that larger networks would shower larger differences in execution times. However, Table 3.1 shows that there are some small 
differences in the final objective function values and large differences in the number of iterations between the algorithms.

The value of the objective function in the first iteration, when there is no flow through arcs associated with non-linearity, is the same for all three algorithms. The differences in the final value of the objective function are mainly due to the evaporation process and the high cost assigned to evaporation arcs to force that flow through them. The explanation of this effect is as follows. First, when the network is generated, the associated cost for water storage is the same for all reservoirs because the objective is to obtain the best operation of the system. Second, water resource systems are complex systems and most of the time the optimum value of the objective function will not correspond to a single point in the feasible solution space but to a hyper plane in which the objective function has the same value at all points. Finally, each of the algorithms has a different optimum search technique. Therefore, it is possible that, for the same complete flow distribution in the system, the individual storage in some reservoirs is different depending on the algorithm used. Because each reservoir has a different evaporation rate, the calculated evaporation may then also differ depending on the algorithm, which in turn affects the value of the objective function. Table 3.1 shows how the differences are more noticeable for longer optimization periods and that the NETFLO algorithm has larger differences with respect to the other two. This might be explained because Out-of-Kilter and RelaxIV have similar search methodologies that are different from NETFLO, with 
NETFLO being in the simplex method family, while the other two are in the dual ascent methods family.

Despite the differences in the number of iterations, only the Out-ofKilter algorithm was able to converge to a solution in a small number of iterations. The other two algorithms were not able to reach convergence after more than 100 iterations. The objective function in these cases looped between two different values as shown in Figure 3.5 for the case of one year optimization. As has been stated previously, the convergence criterion is that the iterations must stop when the difference between the flow value at every non-linear arc and the new calculated flow value is lower than a certain value of CEV, as seen in Figure 3.2. Depending on the system, the value set as a default CEV might be too low. It must also be taken into account that the optimum of the system will generally not be unique, leading the algorithm to continue yielding similar solutions that are never close enough to meet the convergence criterion, while the value of the objective function oscillates around a central value.

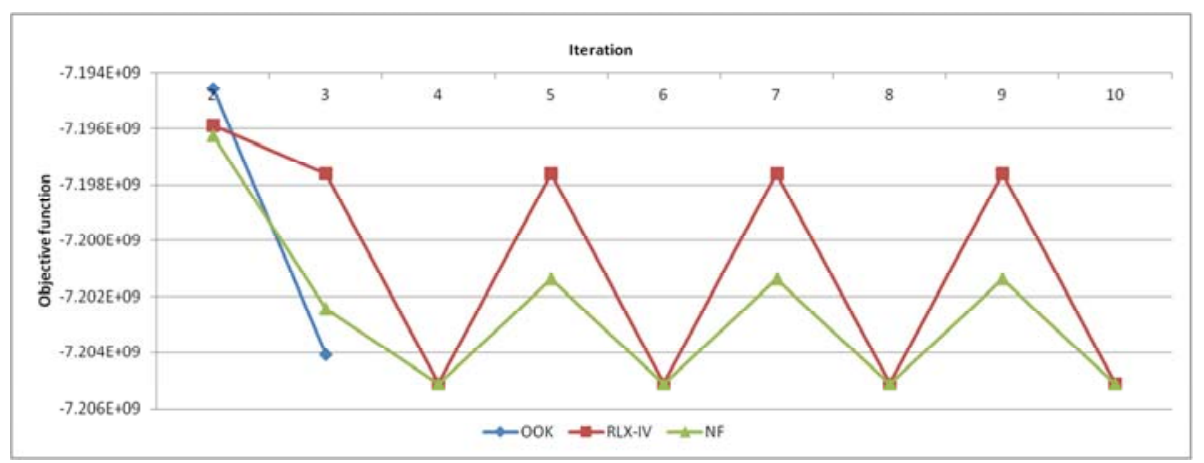

Figure 3.5. Value of the objective function through iterations 2 to 10 for one year optimization period with CEV $=4$ (source: Haro et al 2012) 
The effect on the results from modifying the convergence criterion was examined. The value of the CEV was gradually increased to determine whether the number of iterations was reduced and if that affected the final results. Figure 3.6 shows how increasing the value of the CEV reduces the number of iterations before convergence is reached with the RELAX-IV algorithm. This result is expected. What is more interesting is that the reduction in the number of iterations is not gradual but instead happens in steps. For values of CEV ranging from 4 to 8 , the number of iterations is larger than 200. For CEV values of 9 and 10, the number of iterations performed is reduced to 157; and, for CEV values equal to 11 or higher, the algorithm only needs 3 iterations to reach convergence. The same procedure was performed with the NETFLO algorithm, and the number of iterations was reduced from more than 200 to only 3 for a CEV equal to 15.

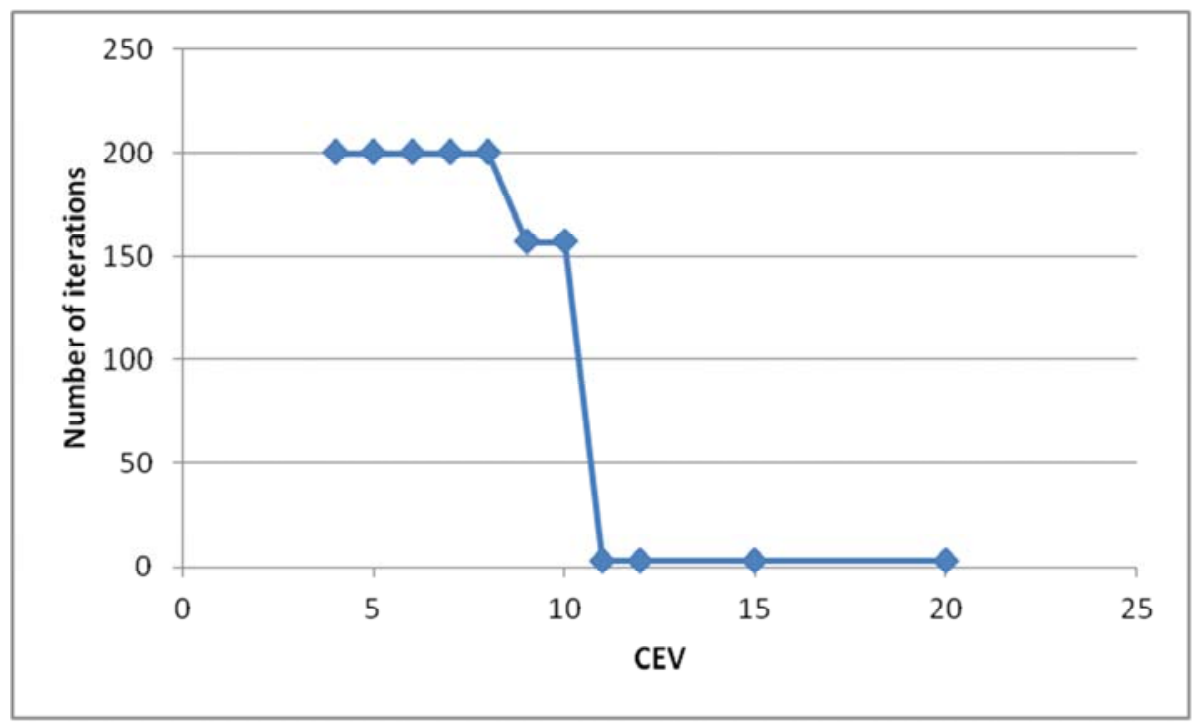

Figure 3.6. Value of the convergence criterion and number of iterations needed to reach convergence (source: Haro et al 2012) 
Table 3.2 shows the results of one year optimization period runs after completing the iterations required for different values of the CEV. As expected, the results for different CEV values do not differ very much from each other. These suggest that the size of the system will directly affect the convergence criteria and will permit defining less restrictive criteria for the larger the systems. This is a logical result because there is less concern about small variations in the numbers with large-scale systems while smaller systems will require more detailed results. The length of the optimization period will also affect the choice of the convergence criteria. 
Table 3.2. Total flow values for one year optimization period using different CEV values

\begin{tabular}{|c|c|c|c|c|c|}
\hline & $\begin{array}{c}\text { OOK } \\
(\mathrm{CEV}=4)\end{array}$ & $\begin{array}{l}\text { RLX-IV } \\
\text { (CEV=4) }\end{array}$ & $\begin{array}{c}\text { RLX-IV } \\
\text { (CEV=11) }\end{array}$ & $\begin{array}{c}\text { NF } \\
(\mathrm{CEV}=4)\end{array}$ & $\begin{array}{c}N F \\
(\mathrm{CEV}=15)\end{array}$ \\
\hline Evaporation (Hm3) & 247.97 & 247.54 & 248.04 & 247.86 & 248.04 \\
\hline Return flows (Hm3) & 1104.26 & 1104.31 & 1104.29 & 1105.03 & 1105.03 \\
\hline Shortages (Hm3) & 627.66 & 627.66 & 627.66 & 627.63 & 627.63 \\
\hline Objective Function & $-7.204 \cdot 109$ & $-7.205 \cdot 109$ & $-7.198 \cdot 109$ & $-7.205 \cdot 109$ & $-7.202 \cdot 109$ \\
\hline
\end{tabular}




\subsubsection{Concluding remarks}

A frequent modelling question is whether it is better to have very detailed, precise results that require a large amount of computation time, or to have a less detailed results that are more immediately available. The response to this question is that it depends on the situation. For a small system with a short time horizon, a more detailed and time-consuming analysis will be necessary, which means an algorithm that is less sensitive to small changes in the problem, e.g. Out-of-Kilter, should be used. Out-ofKilter has been demonstrated to be a quick converging/less sensitive algorithm than the other two and thus it should be used when calculation time is not a constraint. The similarity of the results for differing numbers of iterations and values of the convergence criteria suggests the possibility of simply stopping the iterative process after several cycles. By doing this, large systems with long optimization periods could be solved in relatively short calculation times at the cost of having less fine-tuned results. It would be necessary to determine the point where the objective function starts oscillating and define a rule for stopping given the risk of not having reached pseudo-convergence.

In this section, we have presented a network flow-based optimization model for water resources schemes that consider two nonlinear aspects by solving the network iteratively. The model was applied to the Duero River basin to show its performance at different optimization time horizons. Three different network flow algorithms were used to solve the network problem and to study their performance when confronting an iterative process. As previous studies had already confirmed, RELAX-IV is 
actually the fastest algorithm for solving the pure network problem. However, we detected that it has some problems finding a convergent solution when the network is slightly changed due to iterations. A less time efficient algorithm such as Out-of-Kilter proved more robust for this same task.

The convergence criteria defined for the iterative process strongly influences the number of iterations as well as the results. The modelers then have to decide whether to obtain less accurate results quickly or to wait longer to ensure convergence. An intermediate step that has been proposed is stopping the iterative process once it starts looping between two solutions. In the cases shown, the results did not differ much from each other. Nevertheless, each system studied in the future should be studied from the point of view of convergence. This means finding the convergence criterion which yields the best possible results without a long calculation time. We have given some ideas in this respect, but further investigation is needed to establish more concrete rules to relate the data of the system with the convergence criteria.

\subsection{Incorporation of the conjunctive surface- groundwater component into a multi-period network flow based optimization model}

Global groundwater volume stored beneath the Earth's surface represents 96 percent of the Earth's unfrozen freshwater (Shiklomanov 2003). Groundwater provides useful functions and services to humans and the environment. It feeds springs and streams, supports wetlands, 
maintains land surface stability in areas of unstable ground, and acts as an overall critical water resource serving our water needs.

The IGRAC (International Groundwater Resources Assessment Centre) estimates that about 60 percent of withdrawn groundwater is used to support agriculture in arid and semi-arid climates (IGRAC 2012). Morris et al (2003) report that groundwater systems globally provide 25 to 40 percent of the world's drinking water. Today, half the world's megacities and hundreds of other major cities on all continents rely upon or make significant use of groundwater. Small towns and rural communities particularly rely on it for domestic supplies. Even where groundwater provides lower percentages of total water used, it still can serve local areas with relatively low-cost good-quality water where no other accessible supply exists. Finally, groundwater can bridge water supply gaps during long dry seasons and during droughts.

Therefore, aquifers suppose a very important element in water resources planning and management of many river basins. Thanks to aquifers it is possible to supply, or give additional supply, of numerous demands, being agricultural demands the most favored, especially in surface water shortage periods during which thanks to groundwater pumping many crops can be saved. However, indiscriminate pumping may result in aquifer overexploitation, what would later create several problems for future pumping supply, in rivers connected to the aquifer, and even in zones far from them. Because these reasons, including aquifers in the optimization process is crucial when the groundwater utilization in the studied water resources system has certain entity. Doing this would be 
beneficial allowing, for example, operation rules for pumping from demands or reservoir operation curves taking into account the possibility of additional pumping.

The groundwater component of water resources systems is a key element in the planning of many basins. Therefore, its implementation in the new optimization model was considered necessary.

Singh (2012) devotes a section of his review of optimization modelling applications for water resources management to conjunctive use of surface and groundwater. This same author makes a review of simulation-optimization approaches for conjunctive water use management (Singh 2014). That paper concludes that the optimal conjunctive water management alternatives may not be attained by separate uses of simulation or optimization models and it can only be achieved by the combined applications of simulation and optimization models. This approach can account for the complex water allocation problems and identify the best management policy under a particular set of conditions.

With the results shown in the previous section, we can now address the task of developing a generalized model for water resources optimization with a high degree of detail in system representation. We will take advantage from the combination of efficient network flow algorithms with the iterative approach to introduce the groundwater component of a water resources system in the process of optimizing its management. The introduction of this component will follow an optimization-simulation approach as suggested by literature to obtain the best results. 
This section shows how aquifers, a high complexity element inside many water resources systems, have been introduced in the optimization process of a prescriptive model running under network flow programming. We will present the formulation of the problem and the network construction approach chosen. We will also show the design of the iterative process and finalize with the application of the model to a case study for validation of the results.

\subsubsection{New formulation of the generalized optimization model}

We will base the formulation of the new model used in the previous section. As commented above, we are going to follow a optimizationsimulation approach.

\subsubsection{Objective function}

The optimization of the water resources system for a period of $\mathrm{N}$ years is done by minimizing the function represented in equation 3.7.

$$
\sum_{t=1}^{N \cdot 12}\left[\sum_{i=1}^{n_{c}} T_{C}+\sum_{i=1}^{n_{d}} T_{D}+\sum_{i=1}^{n_{b a}} T_{B A}\right]-\sum_{i=1}^{n_{e}} T_{E}
$$

where:

- $\mathrm{n}_{\mathrm{c}}$ is the number of conductions in the scheme of the system

- $n_{d}$ is the number of demands

- $\mathrm{n}_{\mathrm{ba}}$ is the number of additional pumping infrastructures

- $\quad n_{e}$ is the number of reservoirs 
- $T_{C}$ is the contribution of each conduction with minimum flows defined to the objective function

- $T_{D}$ is the contribution of each demand to the objective function

- $\quad \mathrm{T}_{\mathrm{BA}}$ is the contribution of each additional pumping infrastructure to the objective function

- $\quad \mathrm{T}_{\mathrm{E}}$ is the contribution of each reservoir to the objective function

Subject to the following restrictions:

- The sum of inflows into any node in the network must be the same than the sum of outflows for each month. For reservoir nodes this translates into that the sum of inflows and the volume stored at the beginning of one time step must be equal to the sum of withdrawn water, the infiltration loses, the evaporation loses and the volume stored at the end of the month.

- The flow circulating along one conduction must be lower than its total capacity

- Moreover, all variables must be positive.

3.3.1.2.Contribution of reservoir elements to the objective function

The term $T_{E}$ of the objective function can be expanded as follows:

$$
T_{E}=\sum_{t=1}^{N \cdot 12-1} K_{E} \cdot v_{i, t}+\delta_{i} \cdot v_{i, N \cdot 12}
$$

where $K_{E}$ is a value that can be defined by the user (by default $\left.K_{E}=0\right) ; v_{i, t}$ is the volume stored in reservoir i in month $\mathrm{t} ; \delta_{i}$ is the weight 
assigned to the volume stored in reservoir I at the end of the optimization period $v_{i, N \cdot 12}$. This factor is calculated as shown in equation 3.9.

$$
\delta_{i}=K_{E}+n_{e}-p_{i}^{e}
$$

where; $n_{e}$ is the number of reservoirs existing in the studied water resources scheme; and $p_{i}^{e}$ is the priority assigned to reservoir $i$. This way, reservoirs with a higher number priority are less important than those with a lower priority number.

This term promotes the storage of water in reservoirs during the whole optimization period although the storage facility where this is done results, a priori, unimportant with the exception of the last month of the optimization horizon, when storing water in reservoirs with higher priority benefits more the objective function.

\subsubsection{Contribution of conductions to the objective function}

The term corresponding to conductions, $T_{C}$, has the following formulation:

$$
T_{C}=\sum_{j=1}^{n_{i}} \alpha_{i, j} \cdot d_{i, j, t}+K_{\sigma t} \cdot q_{i, t}
$$

where $n_{i}$ is the number of levels in which it is divided the mínimum flow requirement if the conduction; $\alpha_{i, j}$ is the cost associated to deficit $d_{i, j, t}$ in month $\mathrm{t}$ and minimum flow level $\mathrm{j}$ in conduction $\mathrm{i}$. This cost is calculated as:

$$
\alpha_{i, j}=K_{\alpha}-p_{i}^{c} \cdot K 1-j \cdot K 2
$$


where $K_{\alpha}$ is a user defined value an that is suggested to be 20000 if mínimum flow requirements have absolute priority over demands, or 10000 if their priorities are the same; $p_{i}^{c}$ is the priority assigned to mínimum flow in conduction i with respect to other conductions, following the same priority principle explained for reservoirs; $j$ is the minimum flow level for which $\alpha_{i, j}$ is calculated; finally, K1 y K2 are two internal constants of the model with the value 5 and 200 respectively.

With the first part of the contribution term we promote that minimum flow requirements are met in the networks assigning a very high cost to deficits. Additionally, dividing the minimum flow into levels we make that certain minima are met first in different parts of the system, or distributing the deficit instead of accumulating it in a single conduction. This may represent the importance of meeting some flows more critical than others, or temporary reductions due to water unavailability.

On the other side, $K_{\sigma t}$ is the cost coefficient assigned to flow through conduction $\mathrm{I}$; and $q_{i, t}$ is the flow circulating in that conduction in month $\mathrm{t}$. Most of the times we will not make use of this term, making $K_{\sigma t}=$ 0 . However, it is possible that sometimes the system physical constraints or some management alternatives require that water flows along one conduction and no other. In these particular cases the user can define a small cost coefficient to direct the flow through a particular conduction. 


\subsubsection{Contribution of consumptive demands to the objective} function

Consumptive demands contribute to the objective function through term $T_{D}$ in the form shown in equation 3.12

$$
\begin{aligned}
& T_{D}=\sum_{j=1}^{n_{i \prime}} \beta_{i, j} \cdot d^{\prime}{ }_{i, j, t}+\sum_{k=1}^{n_{t}} \gamma_{i, j} \cdot d^{\prime \prime}{ }_{i, k, t}+\varepsilon_{i} \\
& \text { - } Q_{i, b, t}
\end{aligned}
$$

where $n_{i}$, is the number of supply levels in which demand $i$ is divided; $n_{t}$ is the number of supply sources to demand $\mathrm{i} ; \beta_{i, j}$ is the cost associated to déficit $d_{i, j, t}^{\prime}$ of demand i in month $\mathrm{t}$ and level $\mathrm{j} ; \gamma_{i, j}$ is the cost associated to deficit $d^{\prime \prime}{ }_{i, k, t}$ of demand i in month $\mathrm{t}$ through supply source $\mathrm{k}$; and finally, $\varepsilon_{i}$ is the cost associated to groundwater supply $Q_{i, b, t}$ of demand $i$ in month $t$ with supply level activation $b$.

The three costs are defined by the following equations.

$$
\begin{gathered}
\beta_{i, j}=K_{\beta}-j \cdot K 4 \\
\gamma_{i, k}=-p_{i, k}^{t} \cdot K 3 \\
\varepsilon_{i}=K_{\beta}-p_{i, B} \cdot K 3-\left(n_{i^{\prime}{ }_{i, B}}-1\right) \cdot K 4-2
\end{gathered}
$$

where $K_{\beta}$ is a user defined value although it value is suggested to be 10000; $p_{i, k}^{t}$ is the priority assigned to supply source $\mathrm{k}$ of demand $\mathrm{i}$ with respect to other supply sources to the demand or other demands, following the same priority principle explained for reservoirs and minimum flow requirements; $p_{i, B}$ is the priority assigned to pumping in demand $\mathrm{i} ; n_{i^{\prime}{ }_{i, B}}$ is 
the demand level from which the pumping is activated; $\mathrm{K} 3$ and $\mathrm{K} 4$ are two internal constants of the model with assigned values 5 and 200 respectively.

Similarly to minimum flow requirements, this term promotes the complete supply of demands assigning a cost to the existence of deficits. In this case, there is also a possibility to supply the demand through pumping. Nevertheless, the objective function as defined prioritizes surface supply over groundwater. The user can change this by modifying priority and supply level values of the demand pumping options.

\subsubsection{Contribution of additional pumping to the objective} function

Additional pumping is understood as possible groundwater extractions for their incorporation to the surface system and their use further downstream. The contribution of these elements to the objective function is as shown in equation 3.16.

$$
T_{B A}=\varepsilon_{i} \cdot Q_{i, t}
$$

where $\varepsilon_{i}$ is the same cost assigned to supply pumping in consumptive demands; and $Q_{i, t}$ is the volume pumped in month $\mathrm{t}$.

In a similar way than explained for consumptive demands, surface supply has always more priority than groundwater unless the user modifies the values of priority and supply level conveniently. This way, the model will not extract water from aquifer until it is strictly necessary to supply some use that cannot be met first through surface resources. 


\subsubsection{Network construction approach for aquifers and design of the iterative process}

When considering aquifers in a water resources system, not only their storage capacity must be taken into account but also all the possible relations they may have with the surface system. This means that infiltration from reservoirs and from river bed must be considered, also pumping from demands or for other uses as well as artificial recharges and last but not least the connection between river and aquifer which sometimes exists. Therefore, the inclusion of the groundwater component in the optimization model will require several actions at different levels:

- Water resources system schematization

- Network flow definition

- Iterative process of new non-linear elements

- Aquifer simulation

\subsubsection{Network construction}

Both, the water resources system schematization and the network flow definition are intimately related. We used several of the already available features of the optimization model presented in previous section to build the new one. Therefore, to the existing elements definitions, we included the following new scheme elements and extra options for existing ones:

- Aquifer elements

- Conductions elements, or river reaches, with loses by infiltration 
- Conductions elements, or river reaches, hydraulically connected to the aquifer

- Additional pumping elements

- Artificial recharge elements

- Infiltration from reservoirs

- Pumping supply to consumptive demands

- Infiltration loses from consumptive demands

Each of these new features will require, when defined by the user, the creation of extra arcs in the network flow, what will noticeable enlarge it adding an extra complexity to the resolution process. The network is still built as mentioned in previous section with the addition of the new network definition for aquifers depicted in Figure 3.7. This figure shows the network flow representation chosen for aquifers and their related elements. For clarity purposes, two arcs have been removed, from NBAL to NBENT1 and from NBSAL1 to NBAL, which represent the balance node of the network. The aquifer elements are represented in the figure by nodes $\mathrm{n} 1, \mathrm{n} 2, \ldots, \mathrm{nm}$ and the arcs connecting them. Note that each pair of aquifer nodes is connected by an input and an output arc. These arcs represent either storage or withdrawals since aquifer storage allow us to both saving water for the future or taking it from there for a present use. To make the network algorithms yield the proper results, each of the shown arcs will contribute to the objective function in a different manner so the aquifer balance is also maintained internally. Basically, the arcs representing connections to or from the aquifer will have a very low cost assigned so these flows are always met first. 


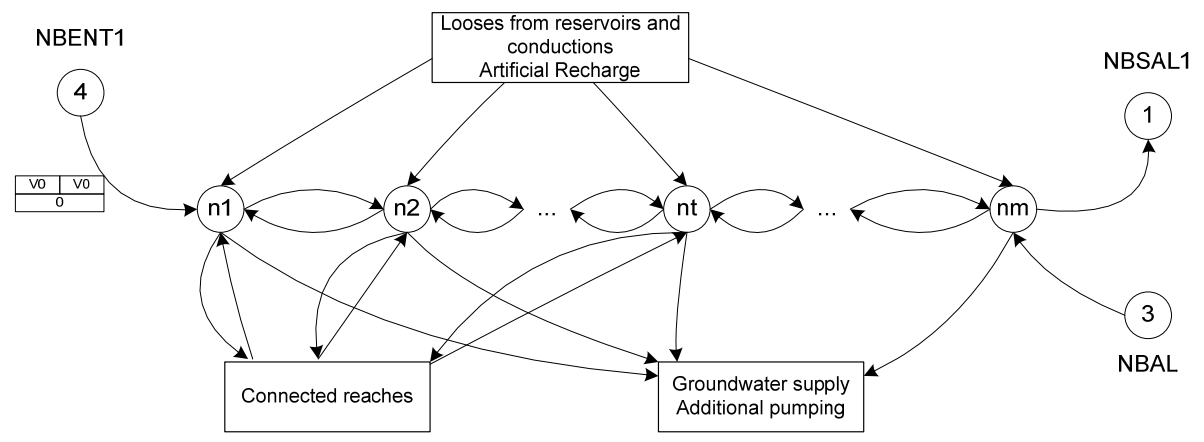

Figure 3.7. Network flow representation of an aquifer and its connections with the surface system for an optimization period of $m$ time steps (month in the case of OPTIGES) (source: self-elaboration)

Several of the newly added features correspond to aspects absolutely non-linear. Thus, as we did in the previous section with the nonlinear aspects considered (evaporation and return flows), we will follow an iterative solution process. All the non-linearities include require that the flow circulating through a certain arc is related in some way to the flow circulating through a different arc. For example, in the case of filtration loses from reservoirs, the circulating flow through the arc connecting the reservoir and the aquifer in one month will be related to the flow representing the stored volume following the infiltration law: $F=a+b V^{c}$, where F represents the infiltration looses flow, $\mathrm{V}$ is the volume stored in the reservoir and $\mathrm{a}, \mathrm{b}$ and $\mathrm{c}$ are three coefficients which must have been defined by the user previously. The same procedure is followed for infiltration looses in conductions. The infiltration loses from consumptive demands depend from the usage and return factors associated to the demands, which must be defined by the user as well. Finally, the hydraulic connection between the aquifer and the river reaches with had been 
included in the scheme will depend on the volume balance of the aquifer with its inputs and outputs, as well as the aquifer type considered. Figure 3.8 shows the flow diagram of the non-linear calculations routine used with the modifications made for aquifer inclusion.

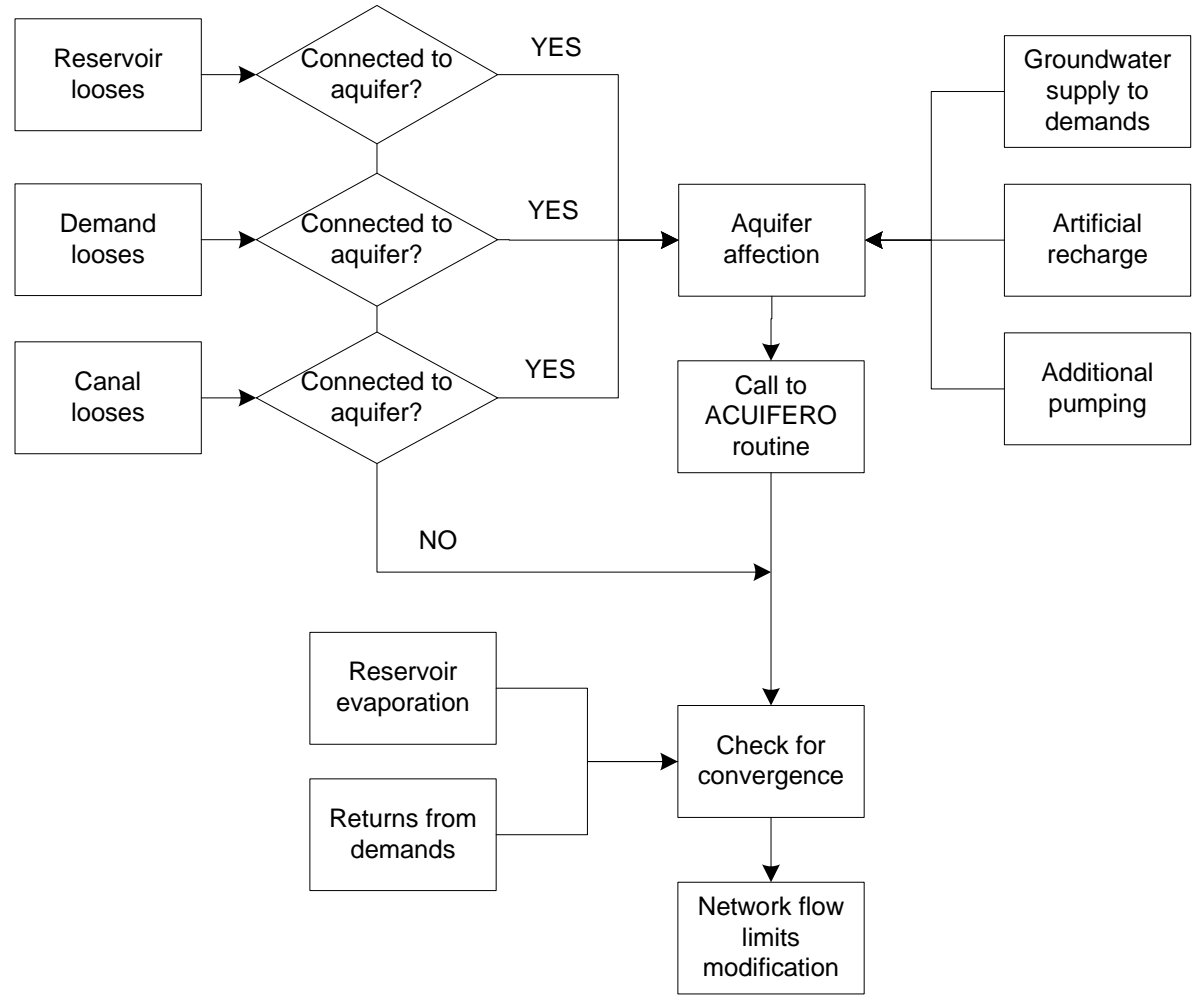

Figure 3.8. Flow diagram of the new non-linear calculations routine for OPTIGES including the aquifer (source: self-elaboration)

\subsubsection{Aquifer simulation}

As we stated at the beginning of this section, the introduction of the groundwater component in the optimization process will follow a optimization-simulation approach. In our case, the pure optimization is 
done exclusively with the water allocation problem of surface resources. The groundwater component of the model is solved with a simulation of the aquifer subject to all the affections due to the surface system management.

As can be seen in Figure 3.8, all the non-linear flows and affections to the aquifer are calculated first and a call is made to a routine with the name ACUIFERO; where the aquifer balance is calculated and the flows circulating between aquifer and hydraulically connected river reaches are obtained. The ACUIFERO routine simulates the aquifer behavior for the whole optimization period according to the kind of aquifer model selected by the user. Currently, the aquifer models available for modeling are:

- Single cell aquifer, corresponds to the classical case of the linear reservoir, this mean an aquifer hydraulically connected to the surface system with a discharge coefficient $\alpha$. The equation governing the aquifer behavior is:

$$
V_{t}=V_{t-1} \cdot e^{-\alpha t}+\frac{R_{t}}{\alpha}\left(1-e^{-\alpha t}\right)
$$

where $V_{t}$ is the volume at the end of month $t$ in function of the volume at the end of the previous month $V_{t-1}$, the discharge coefficient $\alpha$, and the net recharge in month $\mathrm{t} R_{t}$

- Multiple cells aquifer, whose relation with the surface system occurs according to a law represented by several discharge coefficients identified as cells. The volume in each cell at the end of each month is given by equation 3.18.

$$
V_{t}^{i}=V_{t-1}^{i} \cdot e^{-\alpha^{i} t}+\sum_{j} \frac{b_{i j} R_{t}^{j}}{\alpha^{i}}\left(1-e^{-\alpha^{i} t}\right)
$$


where $b_{i j}$ is the distribution coefficient of elemental action $R_{t}^{j}$ for each of the considered cells.

- Deposit aquifer corresponds to a case in which the aquifer is not connected to the surface system and the only interest is obtaining an indicator parameter of its filling or emptying state. This indicator is the stored volume. The only required data to supply are the initial volume and the natural recharge of the aquifer. The volume is then calculated as:

$$
V_{t}=V_{t-1}+R_{t}+R_{N}
$$

where the volume at the end of the month $V_{t}$ is the sum of the volume at the end of the previous month $V_{t-1}$, natural recharge $R_{N}$, and the net effect of external actions in month $R_{t}$

All the discharge values are calculated by hydrologic balance.

The ACUIFERO routine also checks for impossible water withdrawals from river reaches as well as pumping control parameters. The aquifer simulation yields as a result the connection flow between aquifer and river which is the last non-linearity to be calculated. As explained before, the iteration routine checks for convergence in all the affected arcs of the network and reassigns their limits if necessary, triggering a new run of the resolution algorithm.

The previously commented pumping control parameters are rules for groundwater extraction through wells that are defined by the user and depend of the aquifer status (either the volume stored in the aquifer or the volume circulating between river and aquifer). When the value of any of the two aquifer parameters is below certain threshold, the pumping controlled 
by that parameter will stop until the value is again above the defined threshold.

After convergence has been reached for all the non-linearities, the program extracts the results for the complete optimization period and will write average, monthly and annual summaries, as well as create a results file for graphical output.

\subsubsection{Resolution of the network and setback-stepwise approach for long term optimization horizons}

We saw in the previous section that RELAX-IV is a very promising algorithm in term of efficiency. However, we also detected that it has some sensitivity problems when facing the iterative process directed to solve the optimization problem. Given this, we decided to allow the user to choose the algorithm to solve the network between RELAX-IV and Out-of-kilter. On the one side, we have a very efficient algorithm and, on the other, a very robust one.

Additionally, the possibility of consideration of a higher degree of detailed in optimization models also has some drawbacks. The most evident of which is the increase on the size of the network. This larger amount of nodes and arcs within the model is going to directly affect to the running times of the algorithms.

Given that the use of optimization models is often indicated and suggested to carry out the tasks of analysis and alternatives filtering during the planning phase of a water resources system, as well as for the derivation of optimal operation rules, the optimization horizon of the 
models is usually going to be pretty long. This means that the size of the network to be solved will normally be quite big, although it will depend on the system.

Sometimes, due to the nature of the hydrology of the system or the capacity of its infrastructures, the use of long optimization horizons will not be completely necessary. From the operative point of view, there are two general classes of river basin systems: over-year and within-year systems (Vogel \& Bolognese 1995). The latter are characterized by reservoirs that typically run empty the end of each hydrologic year. Such systems are particularly sensitive to seasonal variations in both hydrologic inflows and system yield. Over-year systems do not usually empty by the end of each hydrologic year and are even capable to cope with demands supply and reliability during several campaigns. Such systems are, though, prone to water supply failures (empty reservoirs) during periods of drought that extend over several years. Thus, in the case of the first kind of within-year systems, very long optimization periods are not necessary since optimization only makes sense when the system is within the empty and full state. On the other hand, over-year will require long optimization period to overcome possible periods of scarce resources, although not necessarily the whole data time series available.

In order to make the analysis of the system more dynamic, we have included the possibility of defining setback-stepwise optimizations launches. Stepwise optimization is often used to reduce the size, and thus the running times, of the optimization problem by solving several smaller problems using the final results of the first one as the initial state of the 
next. However, since the objective of the optimization model is minimizing the supply deficits in the different water uses, being reservoir storage a secondary objective at the end of the optimization period, the most common behavior of the models is to empty the reservoirs by the end of the optimization horizon, making the stepwise approach less valid although not necessarily useless. To overcome this hindrance, we allow the user to choose a setback period of the initial step from which the next optimization will start with a slight increase of the amount of steps to solve.

With this, we can speed up the analysis process without compromising the validity of results.

\subsubsection{Validation of the results. Application to the Sorbe River case study}

Once we implemented the new model, and before applying it to more complex cases or other advanced methodologies for the study of water resources systems, we need to test its behavior with a simple case study whose results we can understand and trust. We will use for comparison a simulation model with a series of operating rules already set to obtain the best management results of the model.

\subsubsection{The Sorbe River basin. A simplified optimization approach}

The Sorbe River is the main tributary river on the right margin of the Henares River in the province of Guadalajara (Spain). Born from the union of several streams in the 'Sierra de Pela' near Campisabalos, it begins 
to increase its flow at its junction with the Lillas River at 'Hayedo de Tejera Negra', near Cantalojas. It flows into the Henares at Humanes.

It has a route from north to south, most of it through deep canyons carved into the mountains between the mountains of Ayllon and 'Alto del Rey', used for the construction of the 'Pozo de los Ramos' weir and the Beleña reservoir.

The waters of this river are used for the supply of the city of Madrid, being captured for this purpose from the 'Pozo de los Ramos' weir. Although the city of Madrid has several main supply sources, these are sometimes insufficient to meet all the demand. Thus, it is allowed to withdraw water from the 'Pozo de los Ramos' weir provided that these withdrawals do not affect the other demands downstream. The Beleña reservoir is used to supply drinking water to municipalities and irrigation districts belonging to the Sorbe Water Association, of which the most important are the towns of Guadalajara and 'Alcala de Henares'. The main use of the Beleña Reservoir is supplying urban demands while irrigation demands are mostly supplied from the runoff produced in the intermediate part of the basin, although they can also be supplied from the reservoir. The irrigation demand can also make use of some groundwater extracted from an aquifer that is hydraulically connected to the lower part of the river. This aquifer has a natural recharge due to rainfall infiltration. Additionally, there is a minimum flow requirement for environmental reasons in the last part of the river prior to its junction with the Henares River. Figure 3.9 shows the simplified water resources scheme of the Sorbe River with the main elements present in the basin as described above. Annex $\mathrm{A}$ includes the 
main characteristics of the model as well as the inflow values used for the optimization problem.

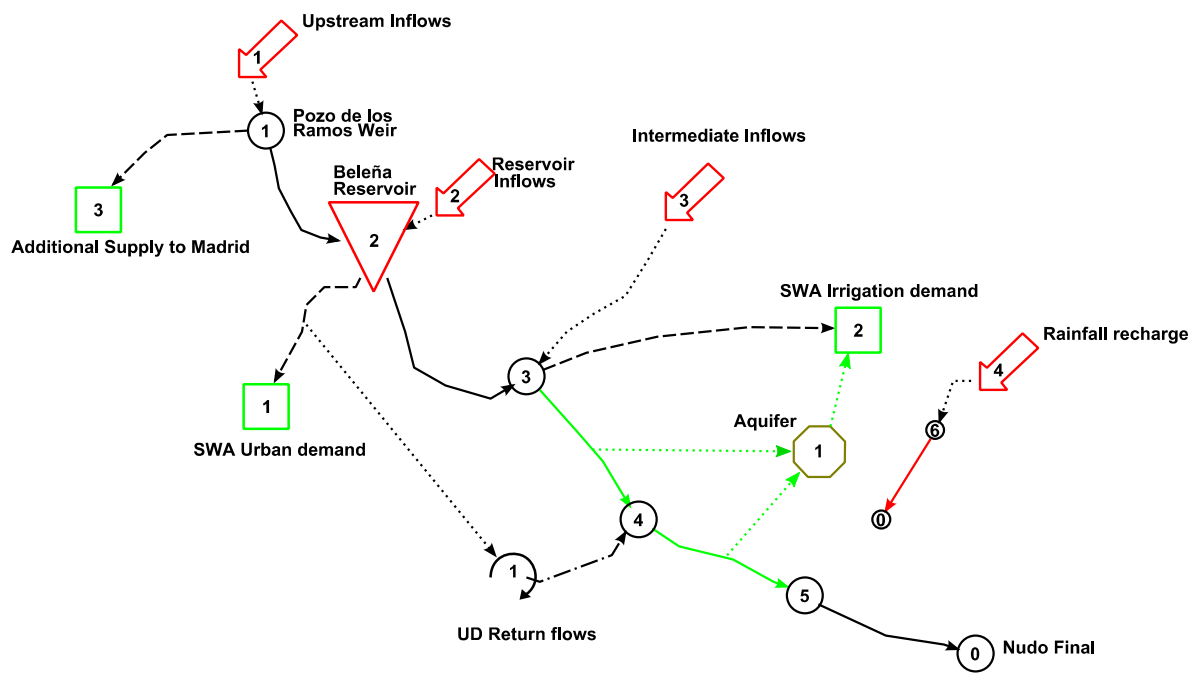

Figure 3.9. Simplified water resources scheme of the Sorbe River (source: self-elaboration)

Therefore, the problem to solve in this basin is obtaining the maximum water supply to the city of Madrid that can be withdrawn from the Sorbe system without affecting the already existing demands or, at least, making this affection as low as possible. Two scenarios were analyzed, one without the existence of the demand to Madrid and another one with it. The optimization horizon was set to 60 years, from October 1940 to September 2000.

Additionally, the modeling possibilities will be studied between the new version of the optimization model and the old one. This, in summary, will show the differences between having or not available groundwater 
supply to the irrigation demand and the connection between the aquifer and the river.

\subsubsection{Results and discussion}

From Figure 3.10 to Figure 3.12 show the behavior of the system in a situation where the additional demand to Madrid is not yet present in the system. Figure 3.10 shows the evolution of the reservoir storage during that period and Figure 3.11 and Figure 3.12 show the annual deficits in the urban and irrigation demands. It is possible to appreciate that the introduction of the new demand will affect the volumes stored in the Beleña reservoir, increasing the risk of suffering supply problems in the future due to a tighter operation of the system.

We can appreciate that the existing demands, despite they already suffer of significant supply problems, are not really affected by the introduction of the new demand. Actually, from 2009 the supply of the water demands of the Sorbe Water Association from the Beleña Reservoir is complemented with transfers from the Alcorlo Reservoir, in the Bornova River an upstream tributary of the Henares River. However, if we look at the distribution of the supply sources in the irrigation demand (Figure 3.13 and Figure 3.14), we can observe how there is a higher need of groundwater abstraction, with the consequent affection of the aquifer and its discharge as can be seen in Figure 3.15 and Figure 3.16 respectively. 




Figure 3.10. Evolution of the storage volume in the Beleña reservoir before and after the introduction of the Madrid demand (source: self-elaboration)

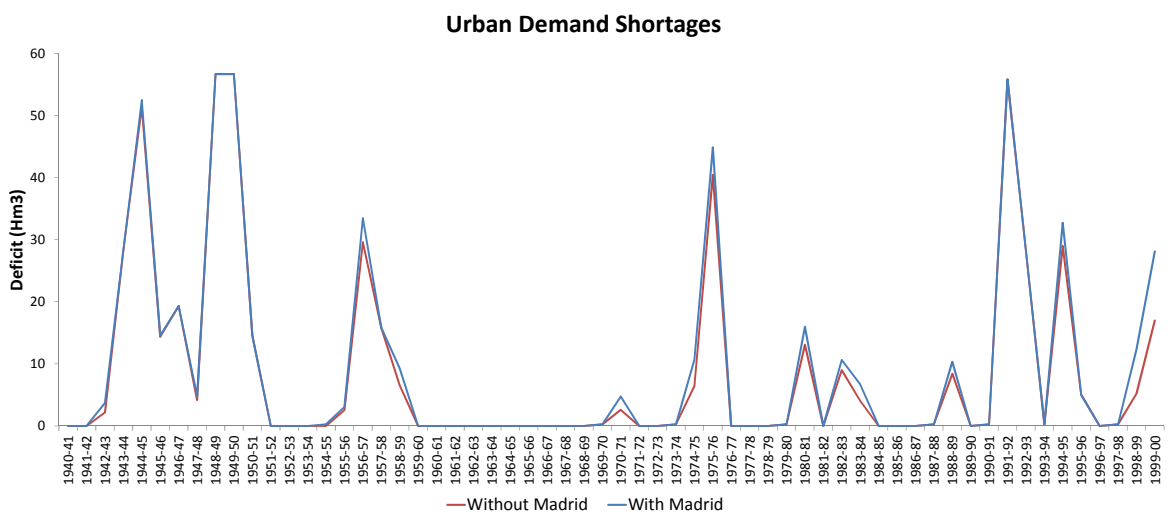

Figure 3.11. Annual supply deficit to Urban Demand in the Sorbe Water Association before and after the introduction of the Madrid demand (source: self-elaboration) 


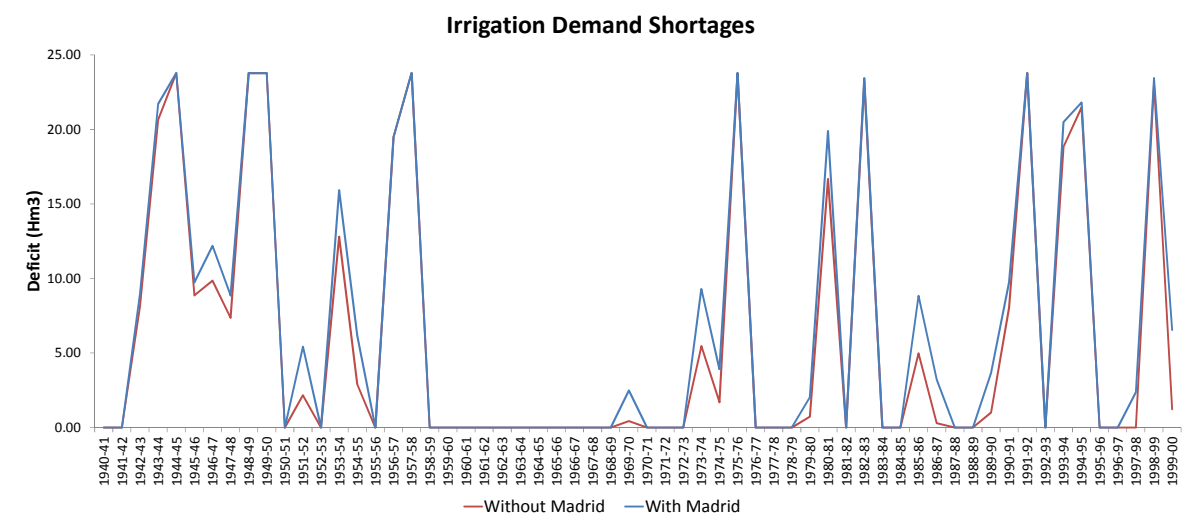

Figure 3.12. Annual supply deficit to Irrigation Demand in the Sorbe Water Association before and after the introduction of the Madrid demand (source: self-elaboration)

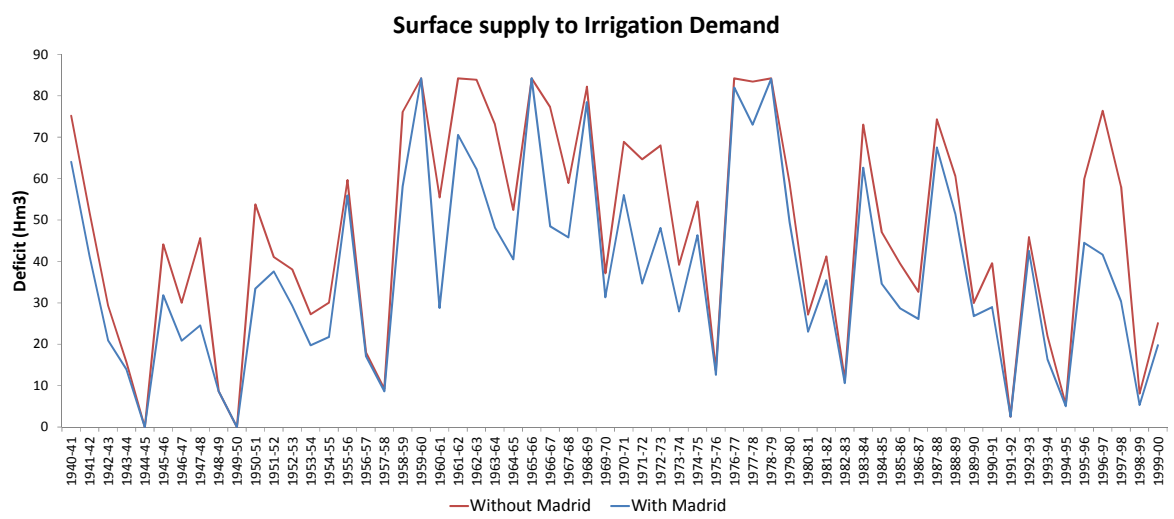

Figure 3.13. Annual surface supply to Irrigation Demand in the Sorbe Water Association before and after the introduction of the Madrid demand (source: self-elaboration) 


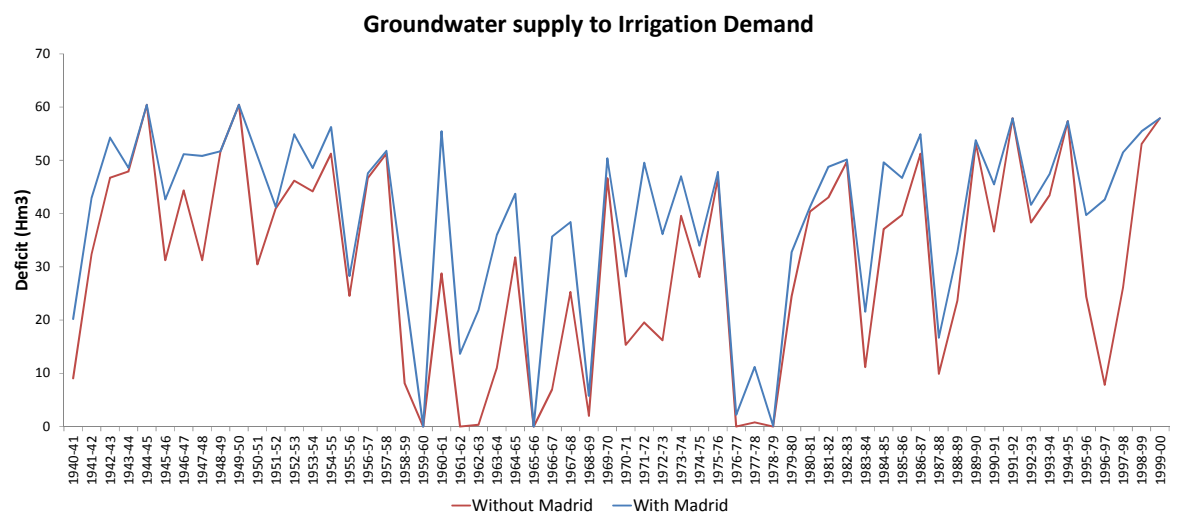

Figure 3.14. Annual groundwater supply to Irrigation Demand in the Sorbe Water Association before and after the introduction of the Madrid demand (source: selfelaboration)

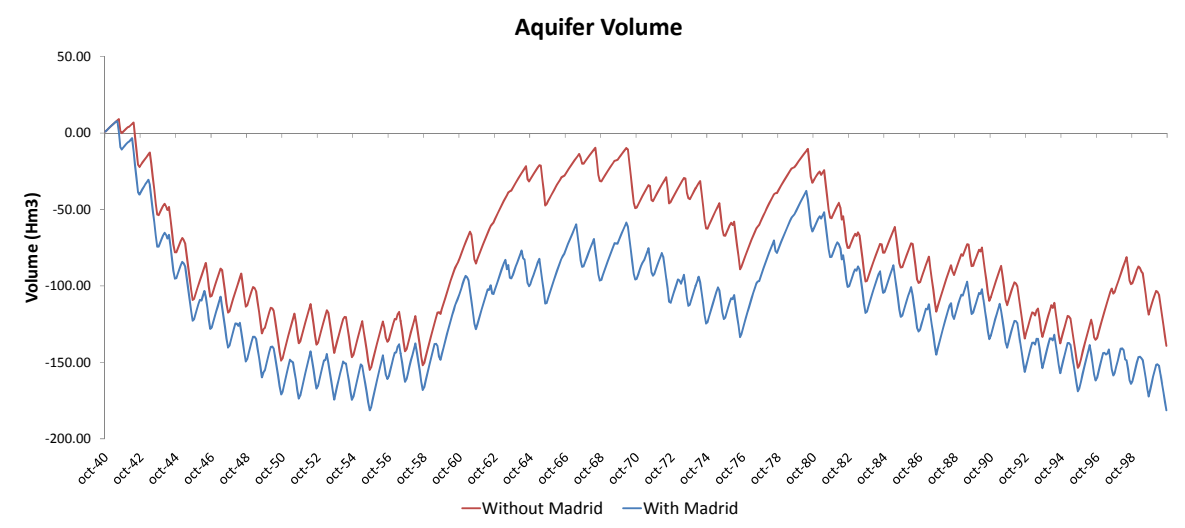

Figure 3.15. Evolution of the aquifer strage before and after the introduction of the Madrid demand (source: self-elaboration) 


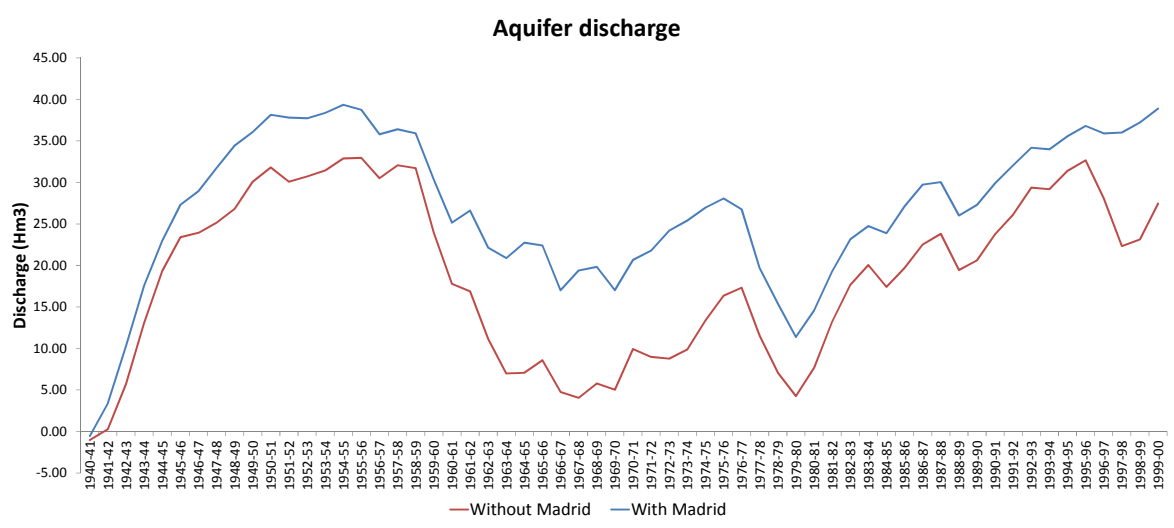

Figure 3.16. Annual aquifer discharge from the river before and after the introduction of the Madrid demand. Positive values mean the aquifer is abstracting water from the river bed (source: self-elaboration)

It is evident that the introduction of the new demand, if we do not want to affect the existing ones in the basin is going to put its pressure directly on the groundwater side of the basin. If there were physical limits to the groundwater abstractions for the irrigation demand (not included in the definition of the problem), the new demand would increase the probability of even reducing the total supply.

Figure 3.10 shows that the basin has mixed operation between within-year and over-year. The most common situation is that the reservoir is empty at the beginning of the year, increases its volume during the autumn and winter months, and empties again during the summer, especially due to the irrigation demand. In particularly good years, the reservoir is capable of storing some water for the following campaign. These makes us think that maybe it is not necessary to use all the 60 years of the horizon in one single optimization, and we can save some calculation 
time by dividing the period into several shorter steps. Figure 3.17 shows the evolution of the stored volume in the Beleña reservoir for several stepwise optimizations ( 60 years at once, 5 years repeated 12 times, 2 years repeated 30 times, and 1 year repeated 60 times), including a setbackstepwise optimization in which the calculation step is 4 years and the initial state of the system is taken from the second one, thus including the other two years in the following 4 year optimization. Only 10 years of the optimization period are shown to better visualization.

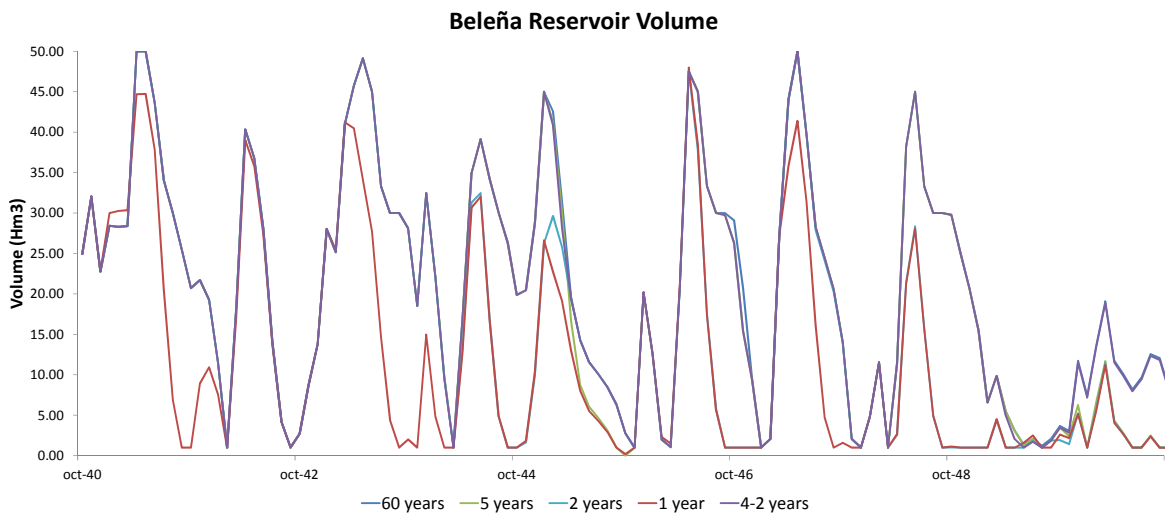

Figure 3.17. Evolution of the stored volume in Beleña reservoir for different optimization steps and setbacks (source: self-elaboration)

The 60 years optimization horizon is the one that achieves higher volumes while, the 1,2 and 5 years do end up emptying the reservoir in certain moments. However, using the setback-stepwise approach, using optimization steps of 4 years and starting the new step with the results at the end of the second year of the previous step, we obtain results very similar to the 60 year optimization option. If we look at the supply results to the demand of Madrid (Table 3.3), we can observe that the maximum 
supply does not change while the average value increases as the optimization steps decrease due to the model tries to use all the available water. However, with the setback configuration, we achieve the same results than with the 60 year approach, with a lower computational cost.

Table 3.3. Supply to the Madrid demand for different optimization setback-stepwise configurations

\begin{tabular}{r|cc}
\hline Optimization steps & Maximum supply & Average supply \\
\hline 60 & 98.49 & 44.51 \\
5 & 98.49 & 45.32 \\
2 & 98.49 & 47.03 \\
1 & 98.49 & 47.92 \\
$4-2$ & 98.49 & 44.51 \\
\hline
\end{tabular}

To finalize with this section, the different results of the modeling possibilities between the new version developed in this thesis and the one existing before are shown. As stated before, the old version of the optimization model did not allow the consideration of the groundwater component of the water resources systems under study, while the new one introduces this possibility.

Figure 3.18, Figure 3.19, and Figure 3.20 show the shortages suffered by the different water demands in the Sorbe system when considering the groundwater component with the new version of the optimization model, and when not considering it as in the previous version. 
It is possible to observe in Figure 3.18 that the possibility of groundwater abstraction from the aquifer is highly benefitial for the irrigation demand, since its shortages if this source of supply did not exist are very high. However, it is possible to observe in Figure 3.19 and Figure 3.20 that shortages in the other demands increase quite dramatically with the consideration of the groundwater component.

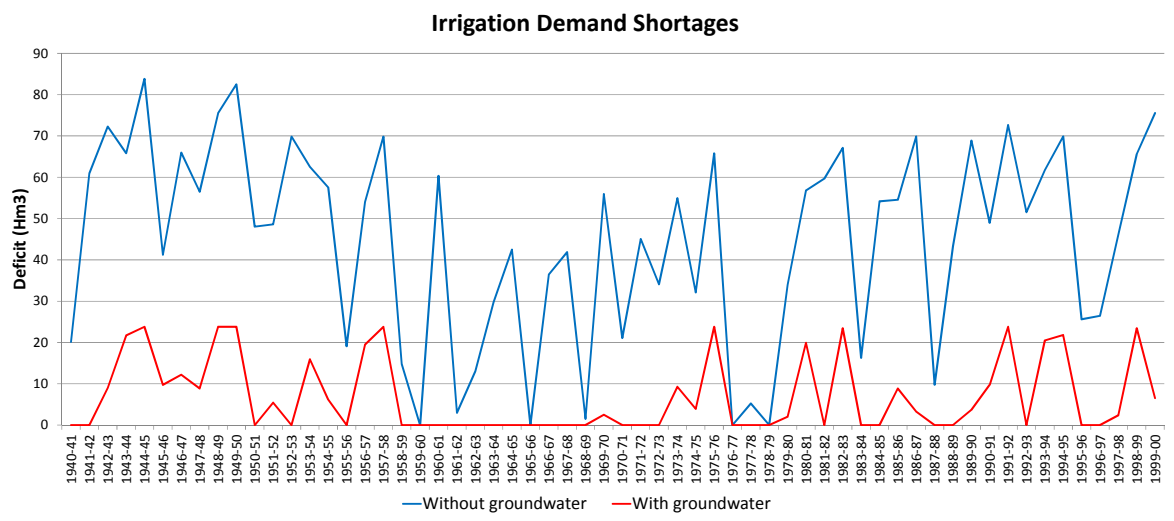

Figure 3.18. Irrigation demand shortages in the Sorbe system when considering the groundwater component or not (source: self-elaboration)

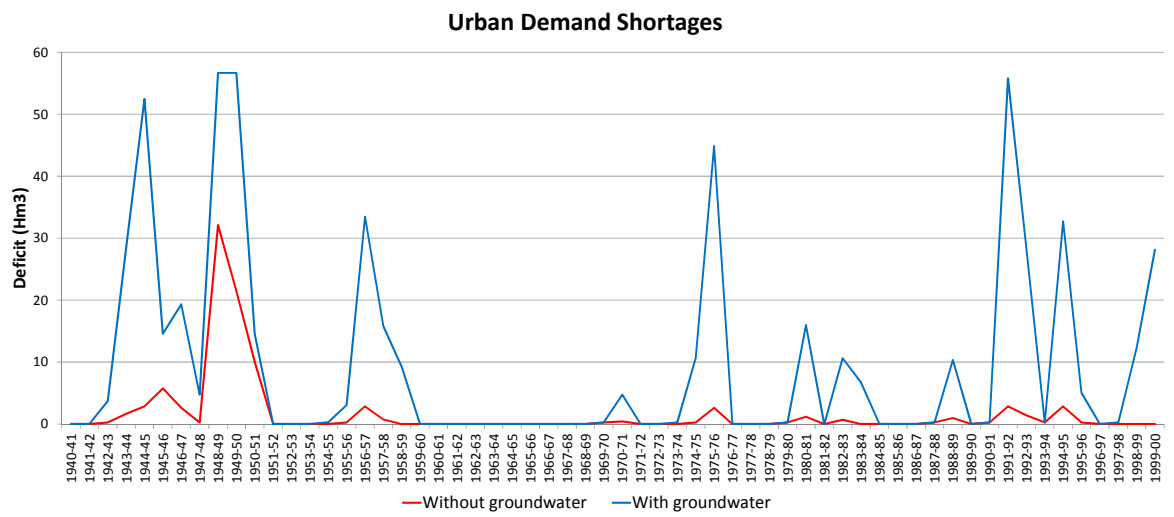

Figure 3.19 Urban demand shortages in the Sorbe system when considering the groundwater component or not (source: self-elaboration) 


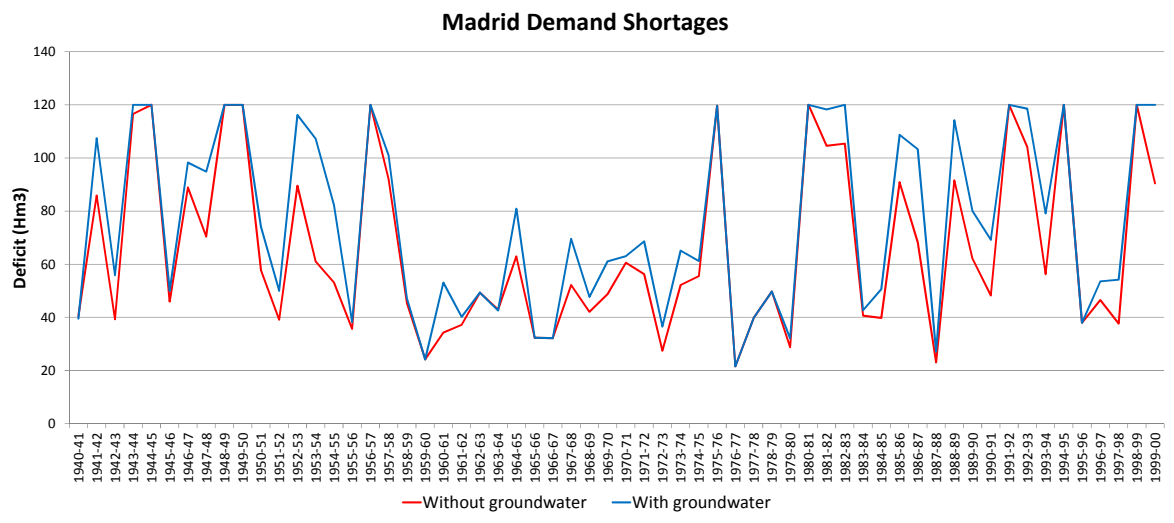

Figure 3.20. Madrid demand shortages in the Sorbe system when considering the groundwater component or not (source: self-elaboration)

The reason to the increase of shortages in urban and Madrid demands is the need for additional reservoir withdrawals to meet environmental requirements at the final stretch of the system. This is due to the groundwater abstractions from the irrigation demand forcing that the river-aquifer connection is towards the aquifer, thus reducing the natural streamflows available in the final part of the system. Since these loses do not exist in the case without aquifer, the resources necessary to alleviate them are available for the other two most priority demands.

Although it might seem that the introduction of the groundwater component is negative for the demands with the highest priorities in the system, it is necessary to observe that the two cases compared are complete different situations result of the limited representation capabilities of the previous version of the optimization model.

The development of a new version capable of representing more aspects existing in water resources systems will allow future users creating more detailed models, eliminating the interpretation and usability 
problems of more simple models that are not capable of covering all the possible complexities.

\subsubsection{Concluding remarks}

We have developed a generalized optimization model for water resources systems management capable of including the groundwater component existing in many systems and that is of great importance for the correct operation for many of them. We did it with network flow programming, using efficient optimization algorithms and surpassing the problem of non-linearities by designing an optimization-simulation iterative process for the calculation of the aquifer evolution.

The results of the validation case study are very satisfactory since the results obtained are the ones that we could expect. Thus, we are confident that this new tool can be applied to other real cases with higher complexity for developing new resources management strategies and rules with positive results.

\subsection{Assessment of risk with optimal management of water resources systems for decision making support during drought situations}

Drought is a major concern for water managers in many regulated river basins throughout the world. Especially at those in which the equilibrium between resources availability and water uses is very fragile, making that deviation below normality compromises the capacity of the 
system to cope with all the demands and environmental requirements. Since droughts are not isolated events but instead they develop over time in what could be considered a creeping behavior, it is very difficult to determine when an episode starts and how long will it last. This lack of knowledge makes difficult both long term and short term decision-making processes.

Because of the difficulty at detecting drought episodes occurrence, and forecasting their intensity and duration, the traditional responses to drought have been reactive, adapting the measures to the severity of impacts as long as they were detected in what is called a crisis management. This approach is ineffective, poorly coordinated, and untimely; and does little to reduce the risk associated with drought (Wilhite et al 2000). Because of this, drought management has evolved in recent years towards a more risk-preventive approach. Drought planning must predict what is predictable and establish strategies of prevention and management of the growing drought risks generated within the current climate change dynamics (Arrojo 2007). To reduce drought risk, there must be an understanding of the hazard using climatology, improved operational monitoring, an analysis of vulnerability to understand what people and sectors may be most affected by drought, why these impacts occur, and if these relationships are changing over time (Hayes et al 2004). This new risk management based approach to drought management has been expressed in the necessity of developing drought management plans (Wilhite 1996) that provide a dynamic framework for an ongoing set of actions to prepare for, and effectively respond to drought, including periodic reviews of the achievements and priorities; readjustments of goals, means and resources; 
as well as strengthening institutional arrangements, planning, and policymaking mechanisms for drought mitigation.

Following a preventive approach in drought management requires advancing, to a certain extent, the possible impacts a drought episode may have on the water resources system. To do this it is necessary both forecasting drought characteristics and assessing their effects on the system. A common methodology is the use of indicator or monitoring systems. As mentioned in the previous chapter, monitoring systems can be composed by different kinds of data. In Spanish river basins, indicator systems are formed by a series of variables that describe the basin drought status and include: reservoir storages, groundwater piezometric levels, streamflows, reservoir inflows and precipitation. The different values taken by the indicator define the drought status. However, these systems are limited to determine current drought situation based on the comparison of present variables values with the variables occurred in the past. This makes that the forecasting capabilities of the indicator systems is low, or even inexistent. Even though they have been calibrated in such a way they can detect developing events similar to past droughts, no drought episode is equal to other and thus it is very unlikely the indicator system is capable of advancing the real consequences of the upcoming event. Therefore, water managers usually rely on risk assessment methodologies to support their decisions oriented to minimize or mitigate the effects of drought.

This section introduces a methodology to assess the best behavior of a water resources system in front an uncertain hydrologic situation, as well as to evaluate the best achievable results for any mitigation option 
managers could envisage. The methodology developed is based in previous works presented in Sanchez-Quispe (1999), Cancelliere et al (2009) and Andreu et al 2013. Their results were successfully used in the management of previous drought episodes in the two systems studied. We now present an evolution of the previous ones introducing an optimization approach what will allow obtaining the best results achievable in the system and the better rules for the application of the mitigation and prevention measures. We will also test the results of the proposed optimization methodology and compare them to the results obtained with a simulation risk assessment approach.

\subsubsection{Design of a risk assessment process including WRS management optimization model}

As commented above, several risk assessment methodologies have been proposed in literature prior to the development of this thesis. All the proposals found in literature make use of simulation models of the system to assess its possible future states based on the operation rules set for it during the planning phase. However, as we stated in the previous chapter, droughts are exceptional situations during which the decisions made during normality periods may not serve to operate the system under higher pressures.

Taking into account the promising results derived from the development of a complete optimization model for water resources management, and the particular advantages of these models with respect 
simulation ones, the application of the new model into a risk assessment methodology seems like a sensible option.

This methodology is summarized in Figure 3.21 and allows evaluating the propensity of the WRS to operative droughts, both on a short and a long-term time scale (from a single campaign to some years depending on the memory of the system). It requires, on a first stage, the identification of the water resources system and its characteristics, both hydrological and physical. From hydrologic characteristics, principally streamflow series, it will be possible to formulate and calibrate a stochastic model with which generating multiple streamflow series equiprobable with the historic series. From the physical characteristics of the system it is possible to develop a scheme that can be later used to run a simulation or an optimization model of the system management. The previously generated series can be used to feed the desired model in multiple runs so multiple different management results of the system are obtained depending on the hydrologic conditions introduced. 


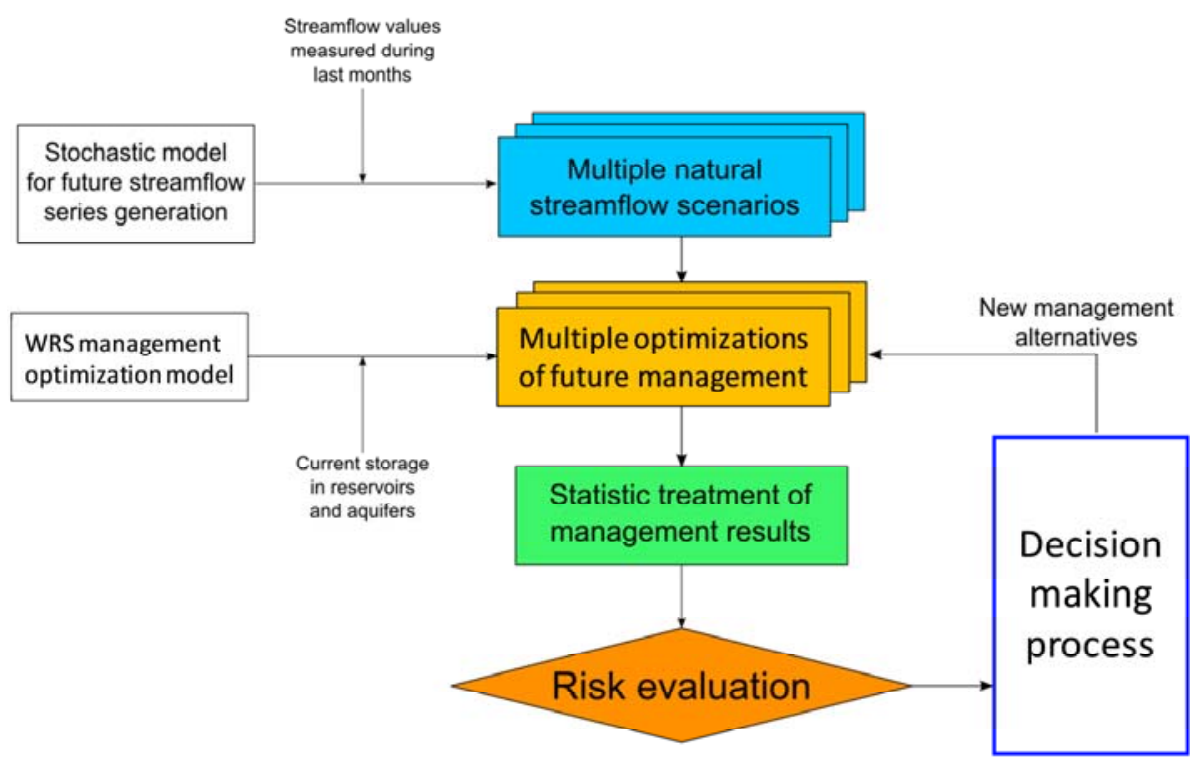

Figure 3.21. Flow chart of the proposed risk assessment methodology (source: selfelaboration)

After the multiple runs are completed, it is possible to calculate several indicators of the basin performance, such as: the probability of suffering a monthly shortfall in the supply to a demand or environmental flow; or the probability of being in a certain storage level at a reservoir in one month.

These values provide an estimation of the risk of operative drought in the forthcoming months. If this risk is high, it will be necessary to take measures to mitigate the effects of the possible drought. However, the methodology is not meant to make decisions by itself but to serve as support to decision makers. 
If the model of the system used is a simulation model, then the results obtained are with regard to the existing, or newly proposed, management rules of the system. On the other hand, by using an optimization model, like we propose now, the results yielded by the analysis will be with regard to the best achievable management of the system resources. This may help decision makers to know what is the best situation they may encounter after the considered period (for example at the end of the irrigation campaign in the summer), and thus to better define operation rules of the system during drought episodes. It will also allow optimizing the timing for additional measures to mitigate drought effects, saving money from their setting and operation costs.

Therefore, to apply this methodology we need a stochastic model for multiple streamflow series generation, an optimization model of the system to study and tools to carry out the probability analyses to obtain management indicators.

\subsubsection{Stochastic generation of streamflow series}

We used MASHWIN (Sánchez-Quispe 1999; Ochoa 2002) tool for the analysis of the streamflow series of the model, the calibration of a stochastic model and generation of multiple conditioned equiprobable series.

On a first stage, MASHWIN allows the user to analyze the series, identifying its main hydrological statistics as well as drought statistics by applying the theory of runs. It is possible to define several thresholds that 
the program will use to identify the duration, intensity and magnitude of the drought episodes associated to the hydrological series under study.

Afterwards, it is possible to calibrate a stochastic model of the streamflow series. The tool permits applying different normalization operations and Fourier analysis of the principal harmonics (that allows reducing the number of parameters later). The tool allows the user choosing among a several autoregressive and moving average model configurations, namely $A R(1), A R(2)$ and $A R M A(1,1)$. Literature on stochastic modeling of streamflow series normally suggests the use of these configurations and not choosing more complex ones. Another possibility provided with MASHWIN is the definition and training of an artificial neural network as an alternative to the autoregressive models (Ochoa 2002).

Finally, the tool permits generating artificial streamflow series either conditioned or unconditioned. The results of this generation are input files for the Montecarlo optimization process.

\subsubsection{Definition of a water resources system management scheme}

The construction of the scheme of the water resources system under study, and that will be later optimized, is done with the graphical interface of the DSSS AQUATOOL (Andreu et al 1996).

AQUATOOL allows the user creating water resources schemes by the combination of different elements that allow representing the reality of the system with as much detail as desired. Among these elements, the user can choose to use channels (natural and artificial, with infiltration loses or 
hydraulically connected to underneath aquifers); nodes (diversion, junctions or storage, representing reservoirs); hydrological inflows to the nodes of the scheme; aquifers, with the possibility of selecting different aquifer models; pumping and artificial groundwater recharge infrastructures; and water demands with their intakes from different supply sources, including the possibility of defining return flows and the node where they are returned to the system. The user supplies the program with the configuration data of the scheme together with the physical data of the elements (for example maximum capacities in channels, or maximum volume storable in reservoirs), the demands data as well as the data used for fixing priorities between scheme elements and for defining guarantee criteria of demands satisfaction and environmental requirements.

\subsubsection{Reservoir storage distribution function as a reliable indicator of the status of the system}

The output of the Montecarlo optimizations of the system consists of multiple series of reservoirs storage and releases, demands supply, aquifers storage, streamflows, etc. The analysis of all those series, or the ones we are most interested in, by means of indices may give us an idea of different features of the analyzed series.

In the case of drought situations, literature proposes the use of different indices in terms of satisfaction of consumptive demands or ecological requirements. These indices usually consider the meeting or not of the requirements from the different water uses and define the state of the system with regard to the probability that there is a failure in supply. The problem with these indicators is that they are only representative of 
one particular water use or set of uses. However, when facing an ongoing drought situation and approaching its management from a risk minimization perspective, we are going to need an indicator that, in some way, summarizes all of what could happen within the basin during the operation phase considered in the risk assessment process. In regulated systems, the evolution of storage in reservoirs is a clear reflection of the operation of the system during the previous period, and their status defines the possibilities of use for the future. Therefore, both reservoir level state probability and storage probability results will reveal as useful indicators of the status of the system with regard to drought and will help in the decision making process by providing information on what can be expected in forthcoming seasons.

In addition to the calculation of the reservoir risk indicators, the risk assessment methodology also provides risk results regarding individual demands (probability of failure per supply level and failure with a given probability), and aquifer status (similar to reservoir results).

\subsubsection{Application to the Sorbe River case and analysis of the results}

In order to test the validity of the new methodology and of its results we are going to apply it to the same case study we used in the previous section, the Sorbe River basin. The system scheme and optimization model used is the same than in the previous section. For the Montecarlo optimization process we decided to use the very historic 
streamflow series and an $A R(1)$ model (the parameters of the stochastic model can be found in annex A).

Risk assessment in a water resources system requires defining a moment in the future in which we want to know the possible status of the system. Depending on the risk results in that particular moment, the decision makers may choose to apply some kind of measure to bring the future situation to more benign chances, stop applying those measure because of the improvement of the situation by itself, or doing nothing since the risk is considered to be assumable.

In the same way, it is necessary to find a moment in which the decisions made as a result of the risk analysis have time to be effective, especially when considering the application of mitigation measures. If measures are activated very late, they will not have the expected effect in the diminishment of risk. On the other hand, if they are activated too early, we may find that we are being over reactive that is also an undesired effect.

We call the difference in time between when the decisions are made and when the risk is assessed 'anticipation period'. Depending on the kind of system we are studying, both the risk assessment moment and the anticipation period will vary. In within-year operated systems such as the one we are looking at in this moment, the most critical moment is the beginning of the summer campaign rather than the end of the hydrologic year. Since reservoirs in within-year operated systems are normally empty by the end of the summer, due to the increased use of water by irrigation demands, and they fill again during the winter months, we cannot consider that an empty reservoir at that moment is representative in terms of 
detecting a drought situation. On the other hand, the availability of water resources at the beginning of the irrigation season can tell us whether the campaign is going to be successful or, on the contrary, there will be shortages. In the case of over-year regulated systems, the definition of the anticipation period is more complex, especially due to the difficulty of autoregressive models for representing trends. However, methodologies such as the proposed can still be useful as complement of the drought monitoring systems.

The length of the analysis defines the size of the network to be solved by the optimization model for each set of streamflow series in the Montecarlo analysis. This, however, may represent a problem due to the nature of optimization. The model is always going to try to optimize the objective function with the water resources available. Thus, if we want to assess the risk in the system under optimal management for one year, we will find that, by the end of the analysis period, the model will empty the reservoir since there are no more years further in time for which to save water. Figure 3.22 shows this for the case of the Sorbe River starting the analysis at the beginning of the hydrological year with a length of one year and 200 unconditioned generated streamflow series. We can observe how the reservoir tends to fill during the months of winter and spring up to approximately the month of April. From that moment, due to the increased water requirements generated by the irrigation demand, the reservoir empties until its minimum volume at the end of the optimization period 




Figure 3.22. Evolution of the storage level probability in the Beleña Reservoir for a one year risk assessment (source: self-elaboration)

Even though the results shown above correspond to an optimal operation of the system, they do not take into account the future needs of the basin. They can still give us an idea of the best achievable results for that particular year but, if we are trying to find proper management options for an ongoing drought management, emptying the reservoirs does not seem a sensible choice.

We can take advantage of the prescriptive capacity of pure optimization and run the model for more than one year. In this way, we can achieve that the management proposed by the model is still optimal, but the option of emptying the reservoirs will be delayed to a future that can be prevented. Figure 3.23 shows the evolution of the storage level probability in the Beleña reservoir for a two years period. 


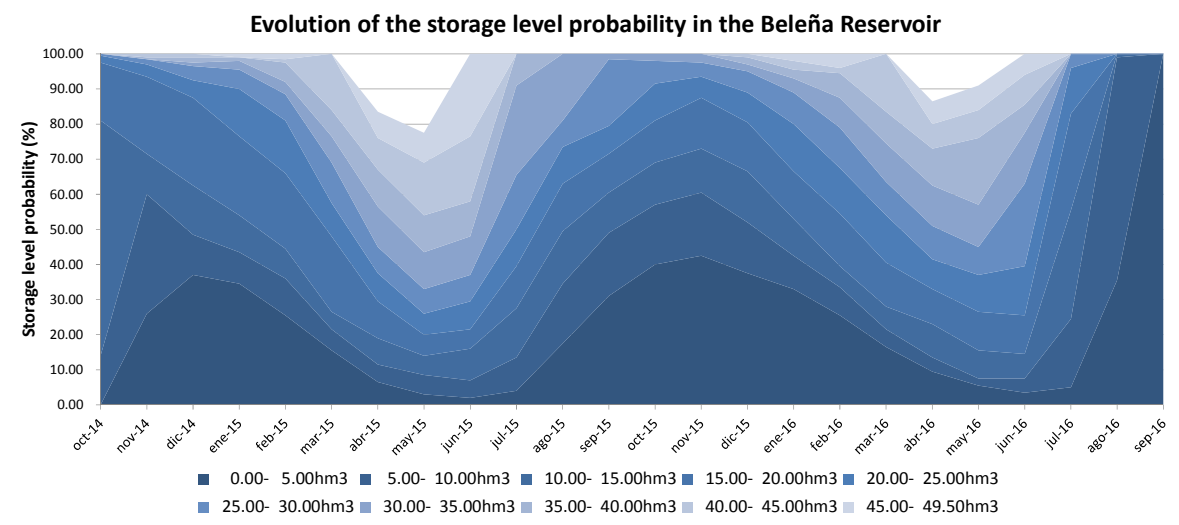

Figure 3.23. Evolution of the storage level probability in the Baleña Reservoir for a two years risk assessment (source: self-elaboration)

In this case we can appreciate that the reservoir still emptiest in the period from May to September, but the model does not deplete de reservoir. The state of the reservoir at the end of April is then going to determine whether the season will be good or not. Figure 3.24 shows the possible storage distribution functions by the end of the hydrological year calculated from different anticipation periods and with varying initial volumes stored in the reservoir. Blue lines correspond to an anticipation period of one year and red lines an anticipation period of 9 months. In both cases, we can see that the situation of the basin is almost the same despite the initial volume considered. However, as we advanced, the situation of the basin is going to be strongly influenced by the situation at the end of April, represented by the green lines. 


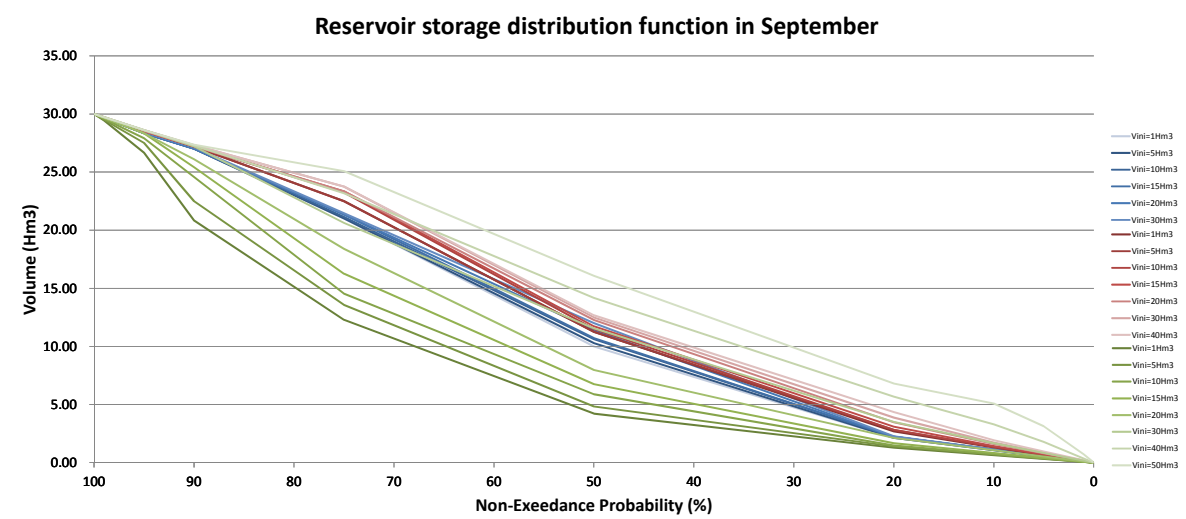

Figure 3.24. Storage distribution functions in the Beleña reservoir for the month of September 2015 for different anticipation periods (Blues=October; Reds=January; Greens=May) and with different initial conditions. (source: self-elaboration)

Therefore, if we consider the volume stored at the end of April as the defining indicator of the future state of the basin (up to September), we can choose to assess the situation of the system in that month as a decision tool to activate proactive measures to improve it. Figure 3.25 shows the different distribution functions obtained for the end of April calculated from October (blue lines) and January (red lines) and with different initial conditions. In this case, the most defining month is less evident, although January seems to have more influence and the distance in time is still enough to consider activating effective measures oriented to reach an appropriate level in the Beleña reservoir by the end of April.

We did not consider the influence of previous hydrologic conditions in this example case study, and only changed the initial storage levels. Although doing this was enough to illustrate the possibilities of the proposed methodology, more complex cases will require detailed study of 
the influence of hydrology together with the influence of the initial storage conditions.

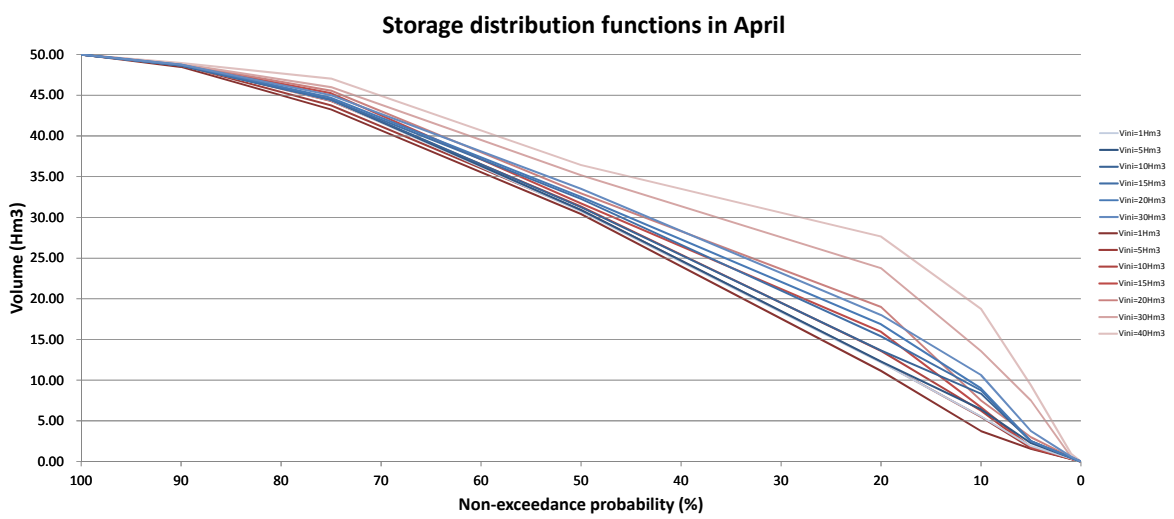

Figure 3.25. Storage distribution function in the Beleña reservoir for the month of April 2015 for different anticipation periods (Blues=October; Reds=January) and with different initial conditions. (source: self-elaboration)

\subsubsection{Conclusive remarks}

We have implemented a methodology for drought risk assessment based on the probabilistic aggregation of optimal management results of a water resources system model when fed with multiple stochastic generated streamflow series.

The methodology has a broad range of applications with regard to drought management and preparation, for example: identification and definition of both measures to reduce the propensity to operative droughts (pro-active measures) and short-term operative drought mitigation measures (reactive measures); design of emergency plans against drought; definition of better indicators to identify the risk of suffering an operative 
drought; and optimizing the implantation of the measures considered to be the most appropriate.

One of the main advantages of the proposed methodology is its capacity for dealing with complex systems, giving an overall picture of the situation in the basin as well as of the individual uses, while most of the previously developed indices are applicable only to a demand or to a group of demands. Thus, the proposed method constitutes an authentic early warning system on the arrival of an operative drought.

\subsection{Incorporation of the new developments into a decision support system shell}

All the developments shown in this chapter were adapted and finally incorporated to the environment of the DSSS AQUATOOL (Andreu et al 1996). This DSS development tool has been in continuous evolution ever since its creation, incorporating new software developments along the years as the result of the works carried out by the Water Resources Engineering Research Group at the Universitat Politecnica de Valencia.

\subsubsection{Water resources management optimization model OPTIGES}

The new version of the optimization model OPTIGES introduces most of the elements definable with the graphic interface of AQUATOOL. Thus, the AQUATOOL database is used to retrieve the system data to build the input files of the model. In the same way, the format of the numerical 
results was adapted to the requirements of the graphics viewer included in the DSSS.

Regarding the internal operation of the model, new variables were defined to include the new features of the model. The input files lecture routine was modified. We also modified the network construction module to include the definitions of the new elements, namely aquifers, conductions with infiltration loses, conductions hydraulically connected to the aquifer, additional pumping, artificial groundwater demands, intakes to demands. Also new additions were made to existing elements (infiltration loses in reservoirs and in demands). As commented before, the iterations routine was modified to include the new non-linearities and a completely new routine for aquifers simulation. Finally, the results retrieval routine was modified to properly identify and read the results from the new network definition.

Annex B includes the user's manual of the new OPTIGES model.

\subsubsection{Model for risk assessment based in optimal operation of systems OPTIRISK}

The risk assessment methodology is included in AQUATOOL under the name of OPTIRISK. In the same way as with OPTIGES, the DSS already includes a risk assessment methodology using the simulation model SIMGES (Solera et al 2007) to carry out the Montecarlo analysis. Thus, the implementation of OPTIRISK is almost immediate doing the appropriate adaptations to the already existing code. 


\subsection{Final remarks}

Proper operation of a water resources system is crucial to maximize the benefits that can be obtained from the use of water. A good, proven efficient method to define the appropriate operating rules for a system is optimization. The evident similarities between a water resources scheme and a network flow model make using this numerical method a fast and easy way for representing and calculating the flows through the system. However, the linear nature of this methodology is problematic when aspects of the water system possess a non-linear behavior.

In this chapter, we showed how an iterative approach is capable of yielding good solutions to the introduction of non-linear aspects in a network flow-based optimization model for water resources schemes. We used the Duero River basin operative scheme to test the performance of the iterative process at different optimization horizons. We used three different network flow algorithms to solve the network flow problem and to study their performance when confronting an iterative process. As previous studies had already confirmed, RELAX-IV is actually the fastest algorithm for solving the single network problem. However, we detected that it has some problems finding a convergent solution when the network is slightly changed due to iterations. A less time efficient algorithm such as Out-ofKilter proved more robust for this same task.

The convergence criteria defined for the iterative process strongly influences the number of iterations as well as the results. The modelers then have to decide whether to obtain less accurate results quickly or to wait longer to ensure convergence. An intermediate step that has been 
proposed is stopping the iterative process once it starts looping between two solutions. In the cases shown, the results did not differ much from each other. Nevertheless, each system studied in the future should be studied from the point of view of convergence. This means finding the convergence criterion which yields the best possible results without a long calculation time. We have given some ideas in this respect, but further investigation is needed to establish more concrete rules to relate the data of the system with the convergence criteria.

Optimization is an important task in water resources planning and management. Thus, it is important that the optimization models, even though they are primarily used for alternatives filtering, show a good degree of detail. This should help to make better decisions on the actions to be studied more in deep. Moreover, water resources systems are becoming more and more complex, and water managers require giving more precise answers to the principal stakeholders' necessities. Therefore, improving the representation of the optimization models being used is a need to be fulfilled in the short term.

After studying the capabilities of the iterative approach to the solution of non-linearities in the network flow problem, we aimed to develop an optimization model capable of including a high degree of detail from the systems studied. The results for simple cases show that the module works fine as the model improves the water availability in the system, reducing the water deficits while it saves surface water for future needs. At the same time, the model makes an efficient use of the aquifer and only extracts water when it is necessary. 
However, the model behavior can still be improved. It has been observed that the model withdraws water from the aquifer in the very months that it is needed. Although this is a logical behavior, it is also interesting the possibility of pumping water before it is needed, so the water stored in the reservoir is saved and, at the same time, during dry periods, when the aquifer recharge is lower, the pressures on it are minor, since the water supplied can come from the superficial storage.

Another aspect to be improved is the behavior of the pumping control parameters. At present, this feature works either allowing groundwater pumping at whole capacity or stopping it completely when the threshold is surpassed. A more optimal solution could be obtained if the pumping capacity could be reduced gradually until the parameter was just at its threshold.

The promising results from the optimization model make it a sensible choice for the implementation of a risk assessment methodology based in optimal operation of the system under risk. As commented before, due to droughts are exceptional situations; the operation of systems suffering a drought episode cannot be done in the same way as during normality periods. Additionally, since no drought is equal to another, deriving particularized operation rules to be applied during drought episodes would not be completely efficient either. Thus, approaching drought management from the optimization point of view seems a promising alternative.

The use of the probability results of the evolution of reservoir storage represents a complete summary of the operation of the whole 
system. Its conjunctive use with existing monitoring systems may serve as an improved drought early warning system combining both the real hydrology of the basin and the optimal operation of the system. 



\section{CHAPTER 4}

Application of the

new developments 



\section{Chapter 4: Application of the new developments}

This chapter contains parts of some of the articles published along the research phase of the thesis either in indexed journals or conference proceedings. These articles are: 
Journal article: Haro D, Solera S, Paredes J, Andreu J (2014) Methodology for drought risk assessment in within-year regulated reservoir systems. Application to the Orbigo River system (Spain). Water Resour Manag 28 (11); 3801-3814

Conference communication: Haro D, Solera A, Pedro-Monzonís M, Andreu J (2014) Optimal management of the Jucar River and Turia River basins under uncertain drought conditions. In Proceedings of the 16th Conference on Water Distribution System Analysis, Bari, July 2014, Procedia Engineering 00 (2014), 000-000

Conference communication: Haro D, Andreu J, Solera A, Paredes J (2014) Current and future drought vulnerability assessment in the Jucar River basin (Spain). In 6th EGU Leonardo 2014, HYPER Droughts, Prague, November 2014

\subsection{Introduction}

The use of monitoring systems and calculation of drought indices and indicators help water managers in defining risk scenarios (Haro et al 2014). The entrance of a system in each of those scenarios will activate different measures addressed to minimize the possibilities of entering a worse scenario and minimizing the possible effects of the current situation. However, this approach often relies in past and current hydrologic 
variables, not taking into account the operation possibilities of the basin for the management of the water resources.

In the previous chapter we presented a series of methodologies oriented to improve the applicability of network flow based optimization models in water resources systems, particularly during situations of uncertain hydrologic conditions such as droughts. The choice of an optimization approach, instead of simulation, may be an interesting option in periods in which the regular operation rules may not be as efficient as expected. In the following sections we are going to apply the methodologies developed before to two cases of study to prove their applicability and usefulness as complementary support to existing monitoring systems and in the development of optimal management options for risk minimization.

\subsection{Case 1: Review of the drought indicators system in the Orbigo River basin}

This section studies the problems for assessing drought risk in within-year operated river basins such as the Orbigo River basin in Spain and how that affects the drought management process, especially due to the high seasonality. We propose complementing the commonly used methodology, particularized for within-year regulated reservoir systems, with the use of future risk results obtained with a Monte Carlo optimization of the future management of the system. We will show the advantages of including the optimal management of the system in a seasonal approach to 
assess drought risk under uncertain hydrology conditions instead of a month-to-month hydrologic approach that does not include it.

\subsubsection{The Orbigo River, a within-year regulated system}

The Orbigo River is a tributary of Esla River at the north-west of the Iberian Peninsula, traversing the provinces of Leon and Zamora, both in the region of Castilla y Leon (Figure 4.1). The total surface drained by this river is of about 5,000 km2, being its length of $162 \mathrm{~km}$. Average precipitation within the basin is of $725 \mathrm{~mm}$ per year and the average potential ETP is 755 $\mathrm{mm}$ per year. Average natural flow is $1,576 \mathrm{hm} 3$ per year composed approximately by surface and groundwater flow in almost the same proportion. Reservoirs in the system have a total regulation capacity circa $373.6 \mathrm{hm} 3$ being the two most important the Barrios de Luna and Villameca reservoirs, both at the headwaters of the system. Water demands reach approximately $466 \mathrm{hm} 3$ per year representing irrigation demand the $96.5 \%$ of the total. The hydroelectricity production does not have a great importance in the basin being limited to some run of the river stations of low capacity. 


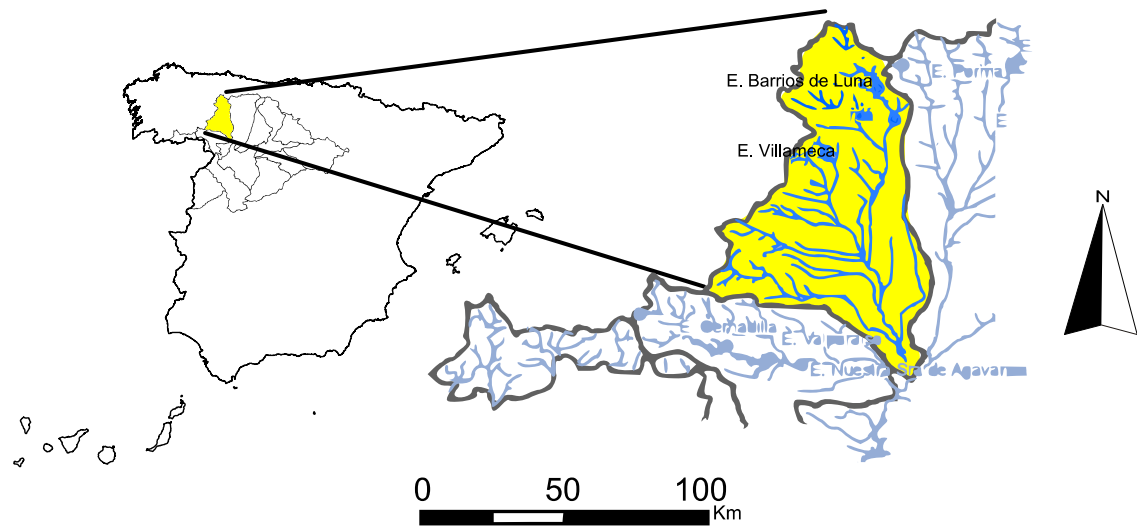

Figure 4.1. Location of the Orbigo River basin in the Iberian Peninsula (source: selfelaboration)

In the case of the Orbigo River, the regulation capacity is quite lower than the amount of resources available, and even lower than the total demand of the system. Reservoirs in the system have an important role in flood prevention and lamination during the rainy seasons in autumn and spring, as well as resource suppliers in the drier months of summer. This makes reservoirs often are empty by the end of the summer and are again at top capacity by the beginning of the irrigation season in a withinyear regulation cycle. In the last times, the Orbigo River basin has suffered several dry spells (CHD 2007). In 1988-1989, irrigation was put to a second plane to ensure urban water supply. Year 1998-1999 was an extremely dry year but a good water distribution saved the irrigation campaign. Finally, in 2001-2002, irrigation campaign had to finish in August due to a bad management of the system that did not allow meeting the supply objectives. 


\subsubsection{Current drought monitoring and early warning in the Orbigo River basin. Limitations.}

One of the objectives of Drought Plans is providing means for anticipation of a possible drought event. For this, it is necessary to establish an early warning system. Spanish basins have adopted a method of drought indicators based in the analysis of historic data that reflect the availability of water in the system. The monitoring system has a hydrologic character since its practical interest lays on its ability to serve as decision-making instrument regarding water resources management in the basin. For each river basin, managers select the indicators that better represent the water resources offer for the different demand units existing in the basin among values of reservoirs storage, piezometric levels, natural streamflows and areal precipitation.

The drought levels in the basin are defined as the weighted sum of the State Index $\left(\mathrm{I}_{\mathrm{e}}\right)$ values of each one of the selected indicators. The value of the State Index $\left(I_{e}\right)$ has the following expression:

$$
\begin{aligned}
& \text { If } V_{i} \geq V_{a v} \rightarrow I_{e}=\frac{1}{2} \cdot\left[1+\frac{V_{i}-V_{a v}}{V_{\text {max }}-V_{a v}}\right] \\
& \text { If } V_{i}<V_{a v} \rightarrow I_{e}=\frac{1}{2} \cdot \frac{V_{i}-V_{\text {min }}}{V_{a v}-V_{\text {min }}}
\end{aligned}
$$

with $V_{i}$ the value of the indicator in the month $i$; $V_{a v}$ the average value of the indicator in the historic series considered; and $\mathrm{V}_{\max }$ and $\mathrm{V}_{\min }$ 
the maximum and minimum values of the indicator in the historic series considered.

The definition of the State Index considers the following criteria:

- Arithmetic average is a robust statistic, as well as simple; so a comparison of the indicator value with the average of the historic series considered will adjust better to the real situation of the selected drought region. Although, it is necessary to take into account the maximum and the minimum historic values.

- It is necessary to homogenize indicators in a dimensionless numeric value capable of quantifying the current situation with respect to the historic, and a quantitative comparison between the different indicators selected.

Drought plans in Spain establish four different levels of drought, or scenarios: normality, pre-alert, alert and emergency (MMA 2007). These levels are determined according to the values of the State Index. The thresholds that define the different levels of the drought status of the system normally are:

- Normality (green): le $\geq 0.5$

- Pre-alert (yellow): $0.5>1 \mathrm{e} \geq 0.3$

- $\quad$ Alert (orange): $\quad 0.3>1 \mathrm{e} \geq 0.1$

- Emergency (red): $0.1>1 \mathrm{e}$

For the Orbigo River basin, the state index is calculated as the weighted sum of the volume stored at the largest reservoir (Barrios de Luna, $w=0.9$ ) and the inflows to the second largest (Villameca, $w=0.1$ ) in the 
Orbigo River basin. Figure 4.2 shows the evolution of $\mathrm{I}_{\mathrm{e}}$ from October 1990 to September 2010. We can observe how the indicator matches the drought periods commented above, 1998-1998 and 2011-2002, plus the more recent drought episode of 2007-2008. Despite it is easy to discern between normality and drought periods when looking at the state index evolution, the change from one scenario to another occurs very quickly to detect the development of a serious drought event in time. It must be noted that the change from normality to emergency occurs in just 4 months and the exit of this situation is equally fast. There is an evident difficulty at determining when the system is under the risk of being in a serious drought threat from the value of its indicator and does not provide enough confidence to define proactive measures.

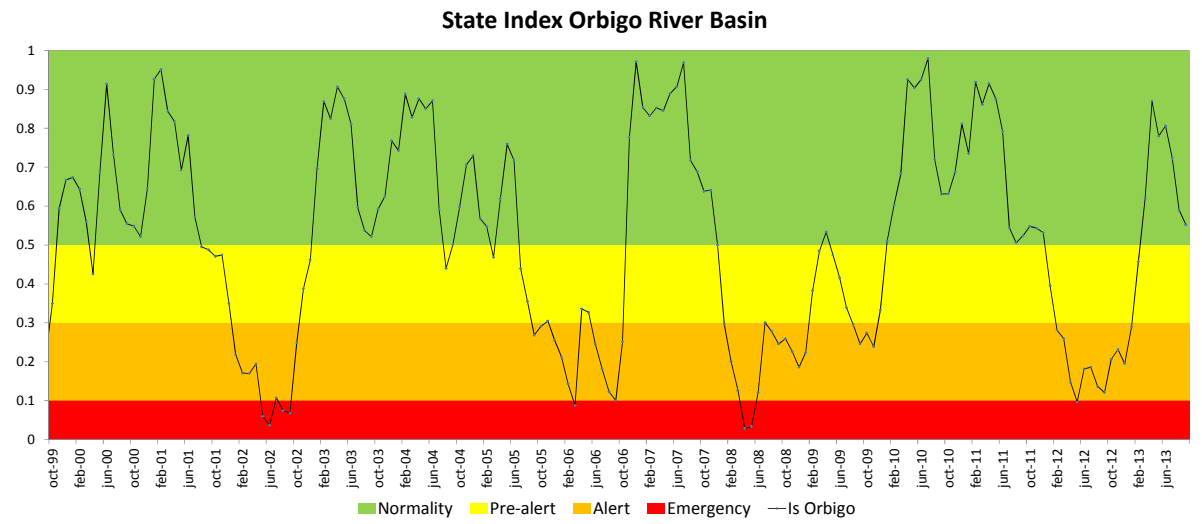

Figure 4.2. Evolution of the State Index of the Orbigo River basin from October 1999 to September 2013 as obtained with the Drought Plan methodology (source: self-elaboration)

Other indicators have been tried but are still not convincing. For example Figure 4.3 shows the State Index for the Orbigo River basin calculated by the Duero River Demarcation Agency using 6 months 
accumulated precipitation and streamflows and the changes still occur very quick as with the previous calculation. Therefore, in the case of systems where seasonality plays an important role in their management, it will be necessary to have additional tools to determine drought risk more accurately.

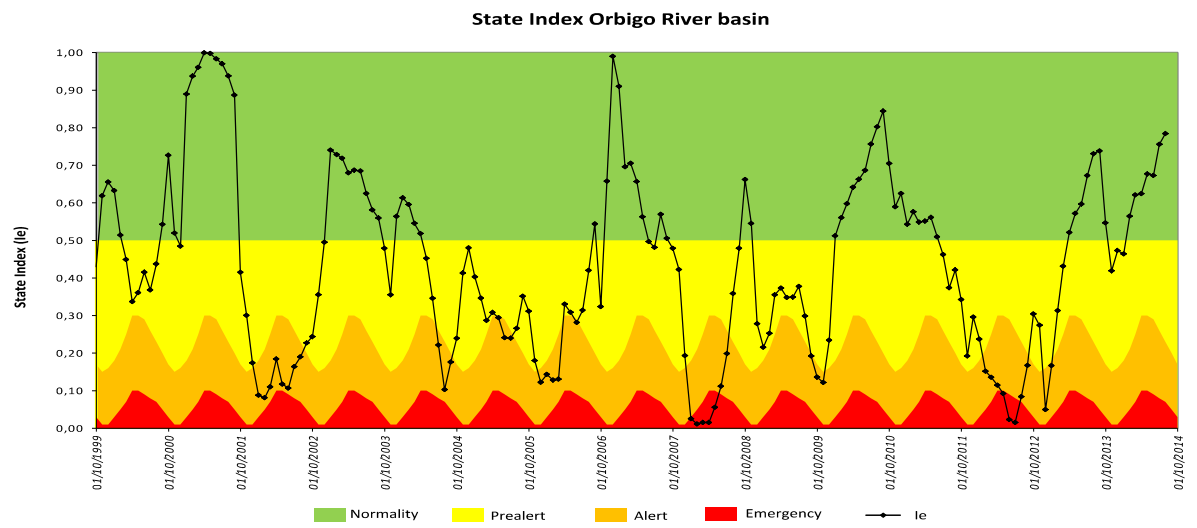

Figure 4.3. Evolution of the State Index of the Orbigo River basin from October 1999 to August 2014 (source: CHD 2014)

Behavior differences of over-year and within-year regulated river basins make necessary using different points of view when approaching management and planning under normal conditions. In the same way, drought situations management should be approached differently too. Failing at detecting and determining the start of a drought episode does not have the same consequences in one kind of system or another. Within-year systems require more immediacy and accuracy because of the rapid changes within them, while over-year systems may allow some delay if conditions are not extremely bad. 


\subsubsection{Enhancement of drought preparation with the support of risk assessment methods}

As seen above, the use of an exclusively hydrologic based index as a mean to detect developing drought episodes in water resources systems with a high seasonality is not completely effective for the means of a preventive management approach. In first place, because it is not possible to compare storage values in reservoirs from one month to another due to the quick fluctuations introduced by the system operation. Normally, the storage levels at the beginning of the irrigation campaign, right after spring rainy season, will have nothing to do with the values at the beginning of autumn, in which reservoirs are usually empty both because of the use of stored water for supply during summer and as flood prevention. Second, the historic data to calculate the state index in reservoirs is very heterogeneous since they contain the variation in time of infrastructures and demands. These conditions are also very likely to change in the future. Finally, the risk in within-year systems is mainly determined by the inflows to reservoirs during the winter and spring seasons. Since the summer and autumn are periods in which reservoirs normally keep low storage levels because of operational and protection issues, the failure in the system will be more likely to happen if there have been a series of dry months during the winter and spring, that are the months in which water is stored. Therefore, a low state index during the months in which the system is supposed to present low storage levels is not representative for the risk assessment in future months. 
Given the limitations of defining the risk of drought in within-year operated system with an indicators system, the risk assessment methodology implemented results an excellent complement to the drought management process. It contains the current situation of demands and infrastructures together with recent data of storage levels and hydrological inflows. This means that all the information, processed separately in the calculation of the system state index, is considered together and it is also possible to include updated information regarding near future changes in the system, while the indicator assumes that management is always going to be similar to the previous one. The results obtained are a straightforward lecture of possible future results that, in the end, is what matters to water managers and allows them to make decisions. The risk assessment methodology perfectly integrates the high seasonality of data since the multiple runs contain that same variability. However, a long-term prediction will always be less reliable than a short-term one, although results evaluation can consider this fact when necessary.

\subsubsection{Proposal of new scenario thresholds}

Regarding the definition of the drought scenario existing in the water resources system, current drought indicator system measures the severity of future drought with regard the conditions in the date of observation. However, this measured severity is going to be different if the observation is done in winter (before the rain season and after the irrigation one), than if it is done by the end of spring or the beginning of summer (the chances of future precipitation are low and the need of water is high). This problem is due to the reality of the system: reservoirs have low 
capacity, they fill during winter and go almost empty in the summer without this being and abnormal situation. It would be a risk situation, if reservoirs were not full by the end of spring.

For a cleared comprehension of the problem, we can look at the historic evolution of the two reservoirs in the system in Figure 4.4 and Figure 4.5.

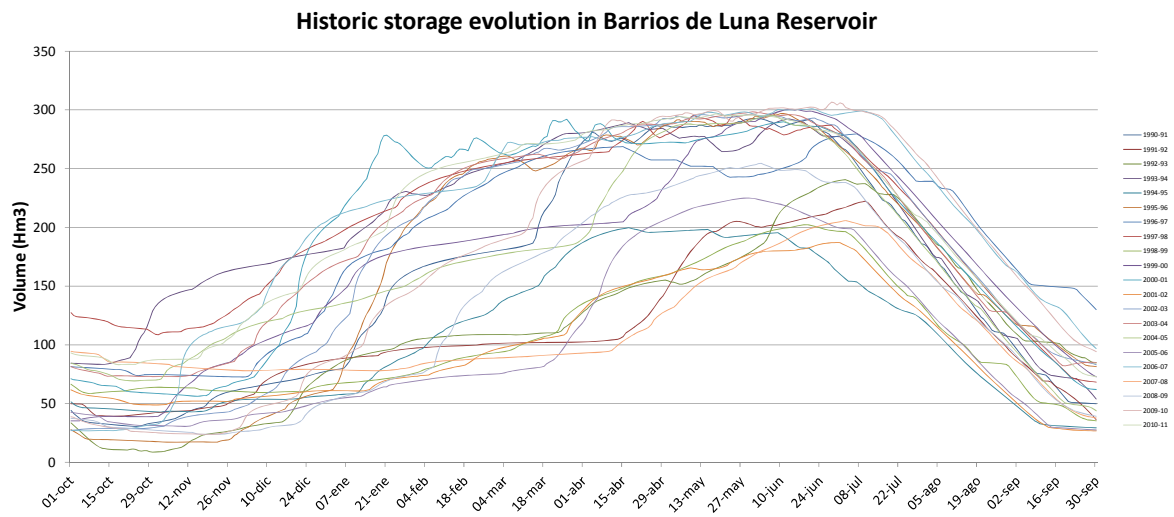

Figure 4.4. Historic daily evolution of storage in Barrios de Luna from year 1990-1991 to 2010-2011 (source: self-elaboration) 


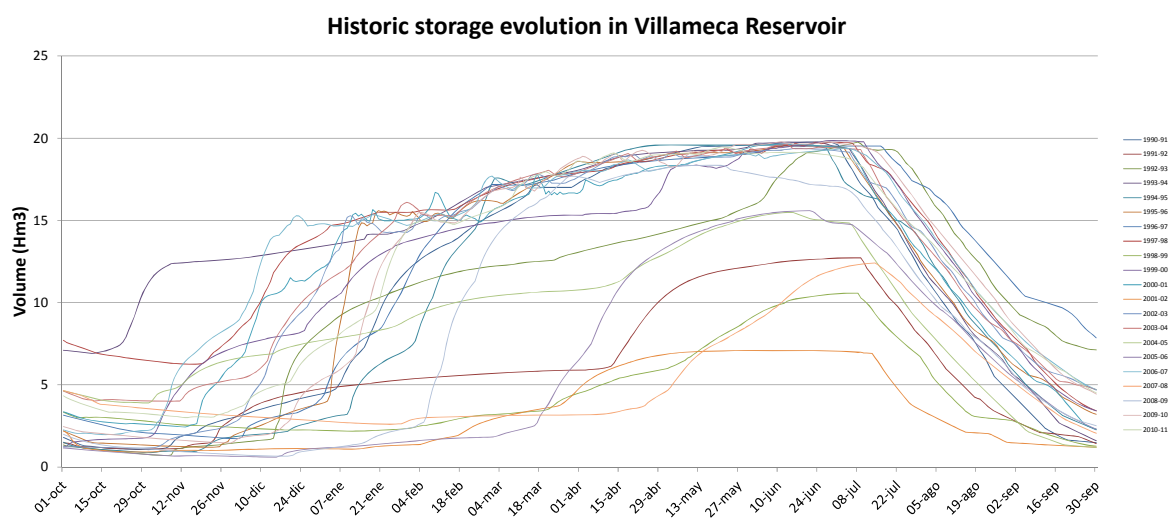

Figure 4.5. Historic daily evolution of storage in Villameca from year 1990-1991 to 20102011 (source: self-elaboration)

In both reservoirs, we can observe that discharges start at the end of June or beginning of July. In normal years reservoirs are full at that moment, but some other not. The years in which the reservoirs are not full before the discharges start, can be considered years with risk. The objective of drought indicators must be anticipating these situations. Apart from exceptional anomalies, reservoirs are usually full by the end of April, sometimes even the end of January. Thus, one of the criteria of the analysis must be the prediction of the reservoir level by this date. Looking at the previous months, it is easily appreciable that storage levels increase in undefined moments between November and January.

A drought indicator based on what is observed in the historical evolutions of reservoirs could have the following definition:

- From October, if reservoir storage is below normality, there is a pre-alert or alert situation depending on the time left until the date in which the reservoir should be full. There would be a 
change to alert if the level is not the expected once reached April.

- From that moment, the alert situation must continue unless there are important precipitations (inflows) that raise the level until the normality situation.

An illustrative table to define the state of the system could be as in Table 4.1 and Table 4.2:

Table 4.1. Drought scenario thresholds proposed depending on the storage level for Barrios de Luna

\begin{tabular}{|r|c|c|c|c|}
\hline Barrios de Luna & Oct-Dec & Jan-Mar & Apr-Jun & Jul-Sep \\
\hline Normality & $\mathrm{V}>100$ & $\mathrm{~V}>250$ & $\mathrm{~V}>250$ & $\mathrm{~V}>250$ \\
\hline Prealert & $\mathrm{V}<100$ & $\begin{array}{c}250>\mathrm{V}> \\
150\end{array}$ & & \\
\hline Alert & & $\mathrm{V}<150$ & $\begin{array}{c}250>\mathrm{V}> \\
200\end{array}$ & $\begin{array}{c}250>\mathrm{V}> \\
200\end{array}$ \\
\hline Emergency & & & $\mathrm{V}<200$ & $\mathrm{~V}<200$ \\
\hline
\end{tabular}

Table 4.2. Drought scenario thresholds proposed depending on the storage level for Villameca

\begin{tabular}{|r|c|c|c|c|}
\hline \multicolumn{1}{|l|}{ Villameca } & Oct-Dec & Jan-Mar & Apr-Jun & Jul-Sep \\
\hline Normality & $\mathrm{V}>5$ & $\mathrm{~V}>15$ & $\mathrm{~V}>18$ & $\mathrm{~V}>18$ \\
\hline Prealert & $\mathrm{V}<5$ & $15>\mathrm{V}>10$ & & \\
\hline Alert & & $\mathrm{V}<10$ & $18>\mathrm{V}>14$ & $18>\mathrm{V}>14$ \\
\hline Emergency & & & $\mathrm{V}<14$ & $\mathrm{~V}<14$ \\
\hline
\end{tabular}


The lecture of these tables cannot be done through the standard indicators since it is different regarding the time of the year. It is not possible either to convert the data into a dimensionless variable as in the classic formulation presented before. A way to produce an equivalent indicator in the range 0-0.1-0.3-0.5-1 would be forcing the equivalence between the threshold values selected and their corresponding dimensionless value. Figure 4.6and Figure 4.7 show a proposal for the monthly state index calculation estimated from the above tables. The values proposed in the tables were relaxed to give a more progressive entry to the different scenarios.

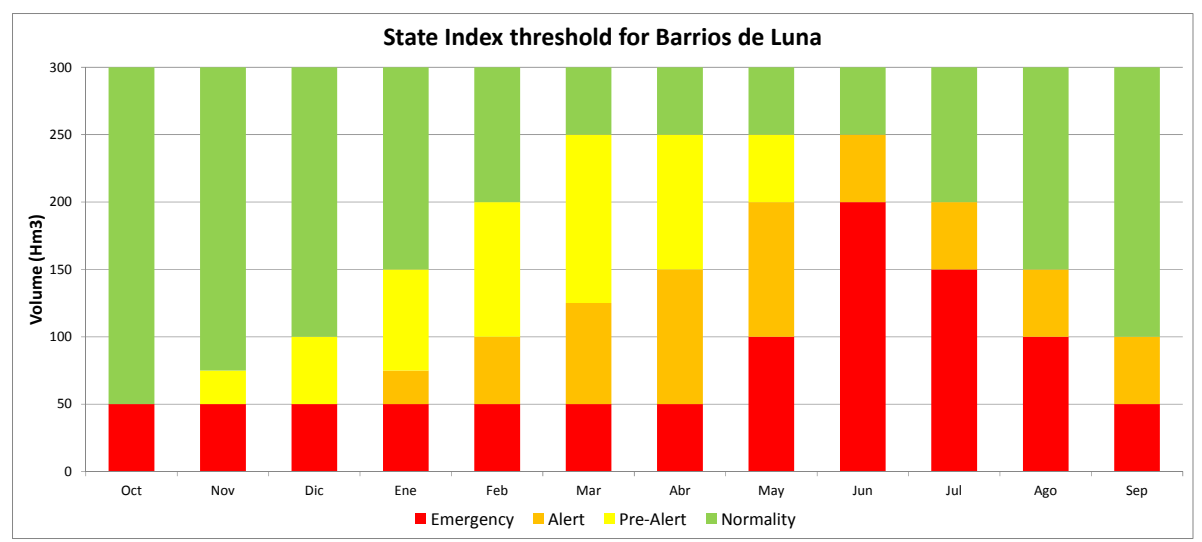

Figure 4.6. Proposed drought scenario thresholds for the state index calculated in Barrios de Luna (source: self-elaboration) 


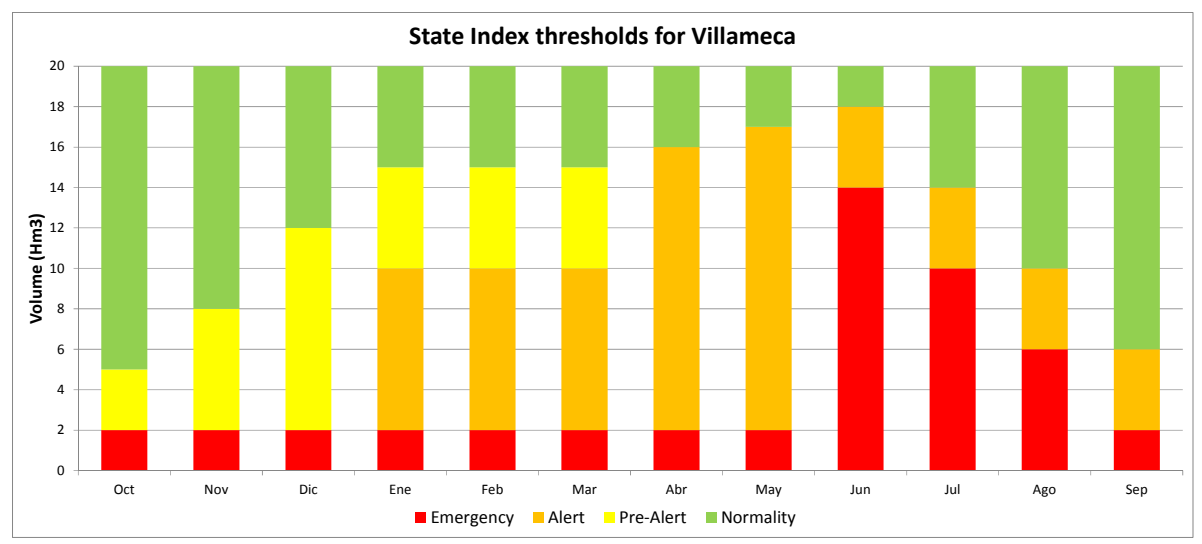

Figure 4.7. Proposed drought scenario thresholds for the state index calculated in Villameca (source: self-elaboration)

Figure 4.8 shows the evolution of the new state index of the Orbigo River basin calculated with the newly proposed thresholds and compared to the one proposed in the drought plan. It is possible to appreciate that it still represents the drought periods occurred during the last part of the $X X$ century and the beginning of XXI similar to the drought plan indicator, making it also valid as a drought indicator. The new index is a bit more conservative, changing into emergency situations that did not reach that status with the drought plan index, for example the period 2004-2006 that only reached alert status. This is not completely bad since during that period the whole Iberian Peninsula suffered an intense drought spell that might have been dampened in some basins by inappropriate indicators. Additionally, it is also appreciable that the new indicator is capable of advancing the changes of scenario, particularly in the worse situations. 
New State Index vs the PES Index in the Orbigo River basin

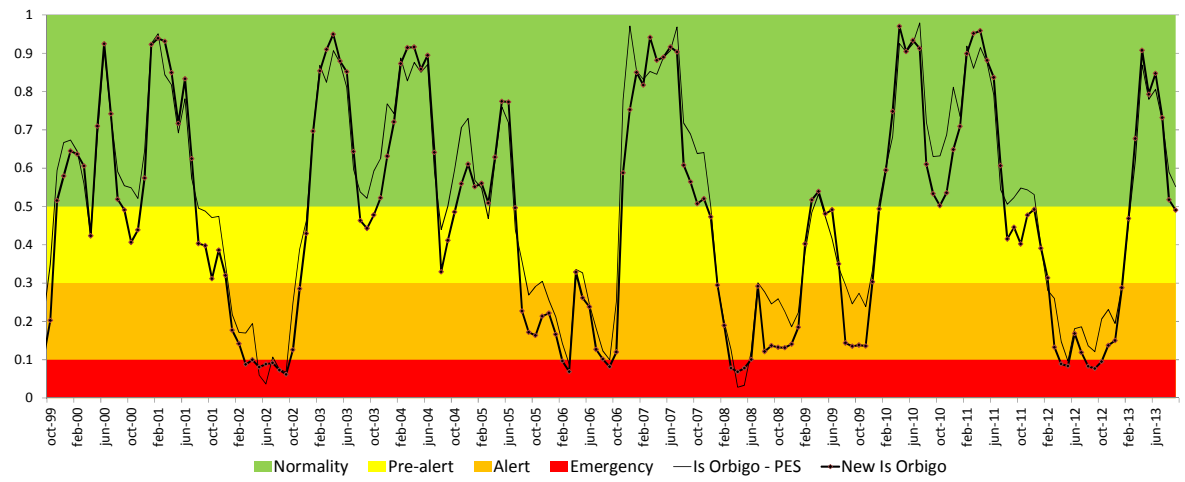

Figure 4.8. Evolution of the state index in the Orbigo River basin as calculated with the new thresholds versus the state index calculated as proposed in the drought plans (source: self-elaboration)

\subsubsection{Indicators forecasting with OPTIRISK}

The use of a risk assessment methodology such as the one proposed could help integrating, improving and standardizing the previously proposed approach with a lecture of results similar to the one done for measured data. The assessment could be done until the next campaign evaluating the state probabilities in reservoirs by the end of the rainy season or the end of the campaign. In dates between October and April we can read the forecasts for the end of April and, from that month, the forecast at the end of the campaign (end of September).

To apply the risk assessment methodology, as defined in the previous chapter, it is necessary a model of the water resources system. The model of the Orbigo River basin was extracted from the larger model of the Esla River developed by the Duero River Demarcation Agency, leaving the scheme shown in Figure 4.9 where the reservoirs of Barrios de Luna and 
Villameca have been highlighted. Annex $\mathrm{C}$ shows the data used to develop the model, including the historic streamflow series. With the later an AR(1) model was calibrated to generate multiple synthetic series. 


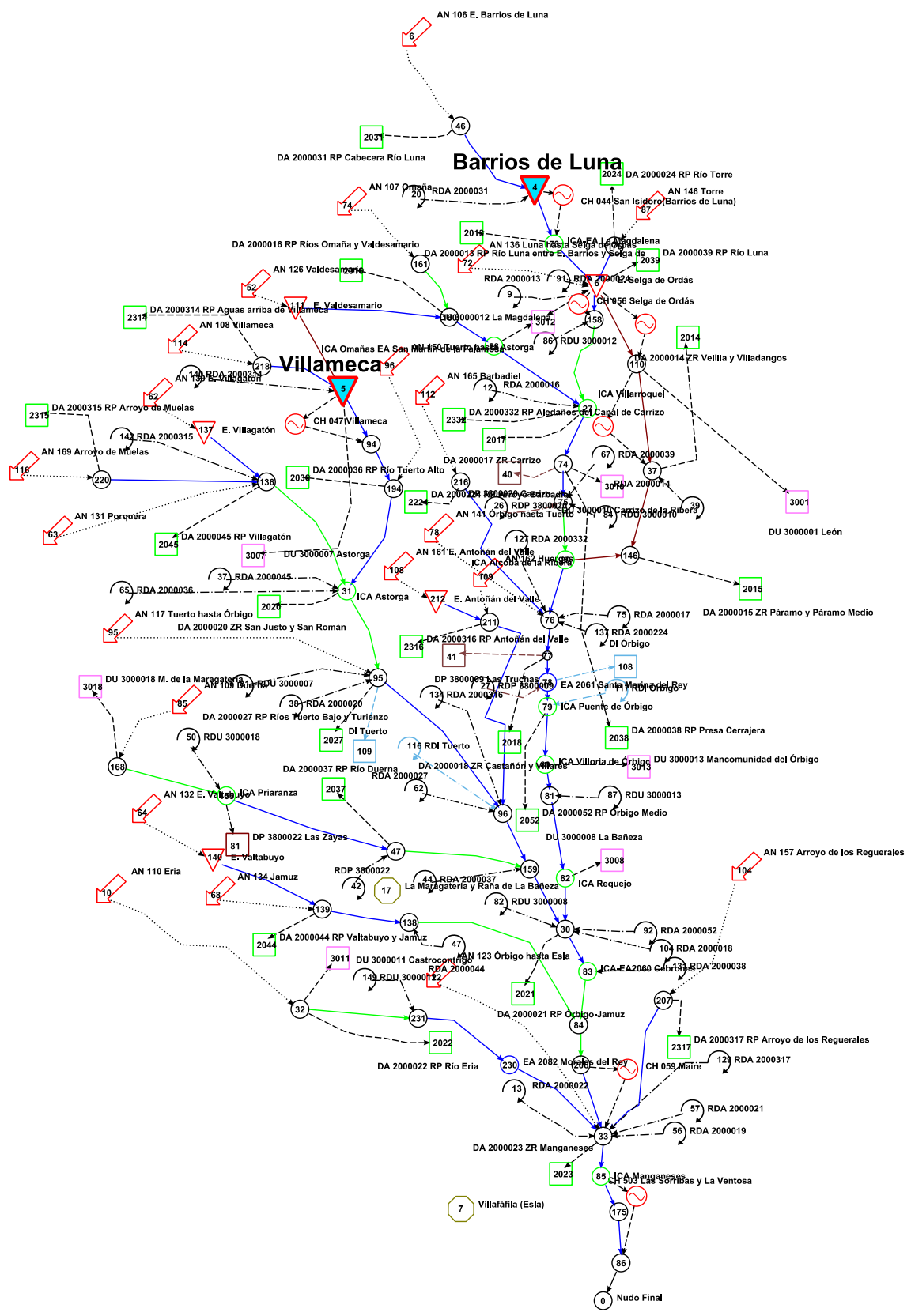

Figure 4.9. Scheme of the Orbigo River water resources system developed in AQUATOOL (source: self-elaboration) 
We made several OPTIRISK runs with the data of the years 2000 to 2002. Historically, hydrologic years 2000-2001 and 2001-2002 were normal and one of the worst respectively. We made runs with initial date each month from October 2000 to September 2002. Synthetic series were generated for each month taking into account the measured streamflows in the previous months. In the same way, initial storage volumes were updated to the final storage value of the corresponding previous month. In the same way, we did it too for the years 2004-2006 and 2012-2014. For each scenario, 2500 series were generated and used.

Unlike the indicators system, that supplies a single state index value according to the current conditions, OPTIRISK provides a probability distribution of the state index value several months in advance. Therefore, the definition of the current drought scenario combining both approaches requires a more detailed analysis. As stated in the previous chapter, we must take into account both risk level and anticipation period to define the drought scenario when using a risk assessment methodology. For the later aspect, we have determined in the previous section that the most important month to define the drought scenario in the Orbigo River system is April. Regarding the other aspect, the acceptable risk level is the point below which system managers will not want to be. This level can be determined either from the analysis of historic situation or agreed between all the stakeholders of the system, although it will usually be a mix of both by means of participatory processes. We defined a risk based scenario definition according to the above tables: 
- If the results obtained before December show a probability higher than $95 \%$ of having the reservoir full, the scenario will be normality. On the contrary, the scenario will be pre-alert.

- If the same occurs from January to April, the scenario will be alert.

- From April, if predictions are to be above the normality level by the end of September, the scenario will be normality. In other case it will be alert.

- If there is a minimal risk of demand supply failure, the scenario will be emergency

In year 2000-2001, Barrios de Luna Reservoir would begin with a pre-alert indication from October'00 to December'00, but it soon changes to normality maintaining like this until the end of the campaign (Figure 4.10). Figure 4.11 shows the situation by the end of the campaign for the same case. It is possible to observe how the initial months of the year also forecast a complete depletion of the reservoir but, from the month of April'01, predictions do not go below $50 \mathrm{Hm}^{3}$. In both cases, it is possible to appreciate that the volume finally stored in the reservoir in the month of study is very close to the anticipated values. 


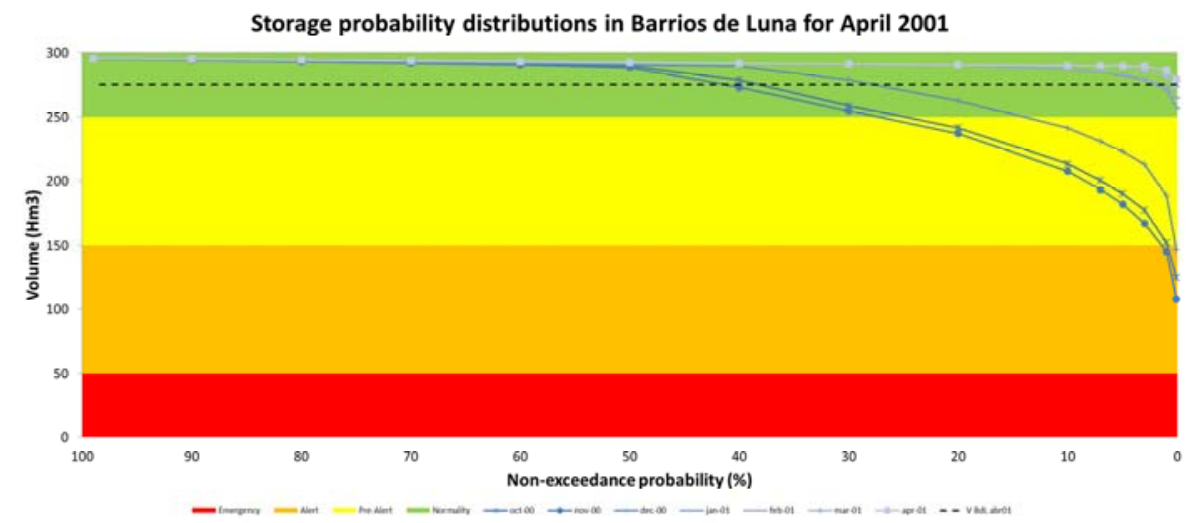

Figure 4.10. Storage probability in Barrios de Luna for April 2001 calculated from different previous months (source: self-elaboration)



Figure 4.11. Storage probability in Barrios de Luna for September 2001 calculated from different previous months (source: self-elaboration)

Figure 4.12shows the predictions for April'02. The predictions from previous year do not show important changes due to they are far in time. However, already in June'01 the chances of low reservoir levels in April'01 start decreasing. In September'01, forecasts indicate a pre-alert situation and continue decreasing after December'01 up to the point that, in 
April'02, there are probabilities for the reservoir even being empty. Thus, the drought scenario would change to alert in May'02. The forecasts for the end of the campaign (Figure 4.13), particularly from the month of April show the high chances of being in a pretty bad situation. Again, the storage value finally reached in the reservoir is among the values forecasted by the risk assessment. This time however, the situation in April'02 ended being better than the predictions from the previous months.

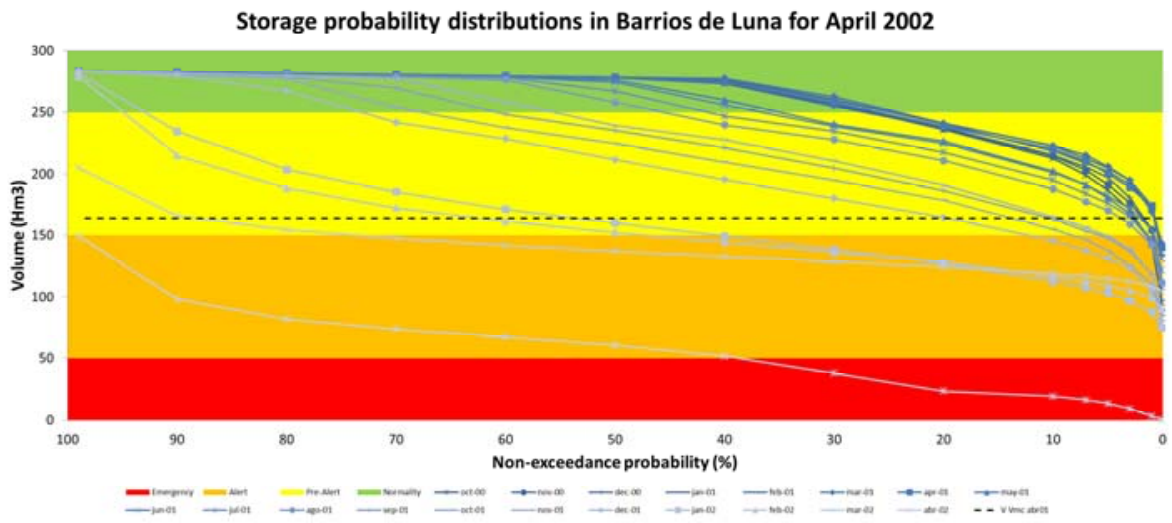

Figure 4.12. Storage probability in Barrios de Luna for April 2002 calculated from different previous months (source: self-elaboration) 


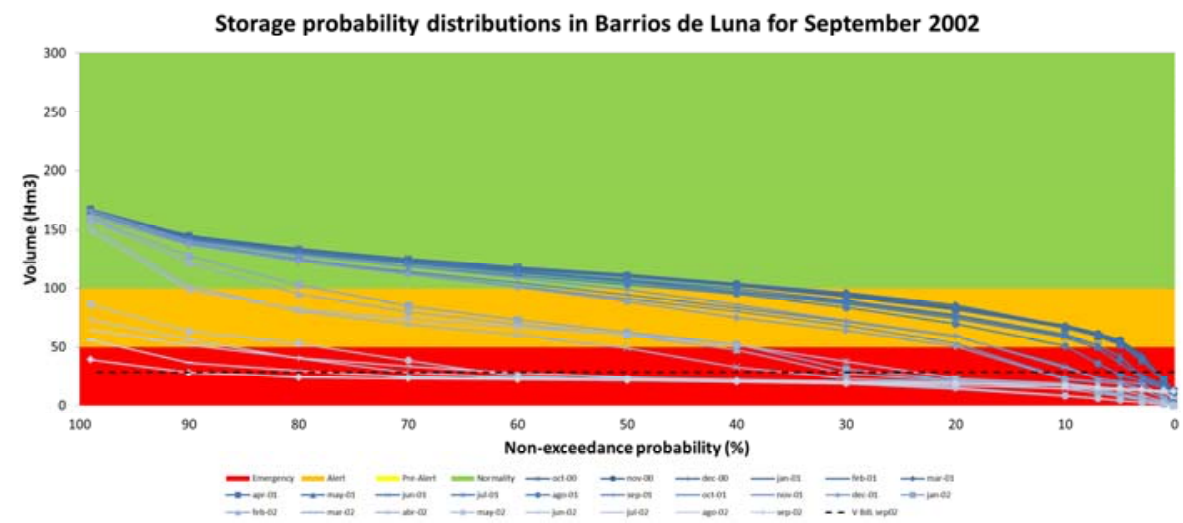

Figure 4.13. Storage probability in Barrios de Luna for September 2002 calculated from different previous months (source: self-elaboration)

Villameca shows a similar evolution (Figure 4.14). Although forecasts for September are lower than what can be deduced from the historic evolution of the reservoir. It is possible that it is due to a higher demand in the model than in reality, aspect that should be refined.


Figure 4.14. Storage probability in Villameca for April'01, September'01, April'02 and September'02 (source: self-elaboration) 
Finally, we can appreciate that the anticipation period as a very important factor for the definition of drought scenarios in the system. In addition, it is possible to see that initial conditions, storage level and hydrologic conditions, play an important role in the final risk level results, although with different effects. None of them has importance for long anticipation periods. Previous hydrologic conditions play an important role in the midterm since the most of the streamflow generates in autumn and spring. In the short term, the most important aspect is the initial storage level in reservoirs, especially because there is almost no streamflow generation during the summer.

\subsubsection{Generalization of the monitoring process based in risk assessment}

According to what we showed in previous paragraphs, we can enunciate a generalized methodology for drought scenarios definition as follows:

Step 1. Analyzing the forecast curves to define a reference probability.

Step 2. Define the reservoirs volume desirable for a normality situation.

Step 3. Determine the time interval in which a situation of lack of normality should change from pre-alert to alert.

Step 4. Identify when the risk of failure is significant to declare the emergency scenario 
Step 5. Translate the volume calculations into a 0-1 dimensionless state index.

Step 1 relates the risk assessment results with reality. In the case of the Orbigo River basin in this section, we can observe in previous figures how the real observed reservoir volumes were closer to the $95 \%$ probability values of the risk results, in average. Therefore, we can use that probability value as reference value for the calculation of the new state index. Step 2 addresses the rank of reservoir storage values that would represent the 10.5 values of a posterior state index. The same applies for step 3, regarding the values between 0.49 and 0.3 corresponding to the pre-alert scenario, and step 4, for the values below 0.3 and above 0.1 representing the alert scenario and thus also the emergency scenario. Step 5 would just mean translating the obtained volume values at the $95 \%$ probability into the $0-1$ values of the state index.

We calculated the evolution of the newly defined indicator in the Orbigo River basin for the period 1990-2010. In each month of the period, a risk assessment analysis run was done using previous month reservoir storages and hydrology as initial constraints. The model was run until the reference month considering the time of the year until April from October and March, and until September from May. The results are presented in Figure 4.15below. 


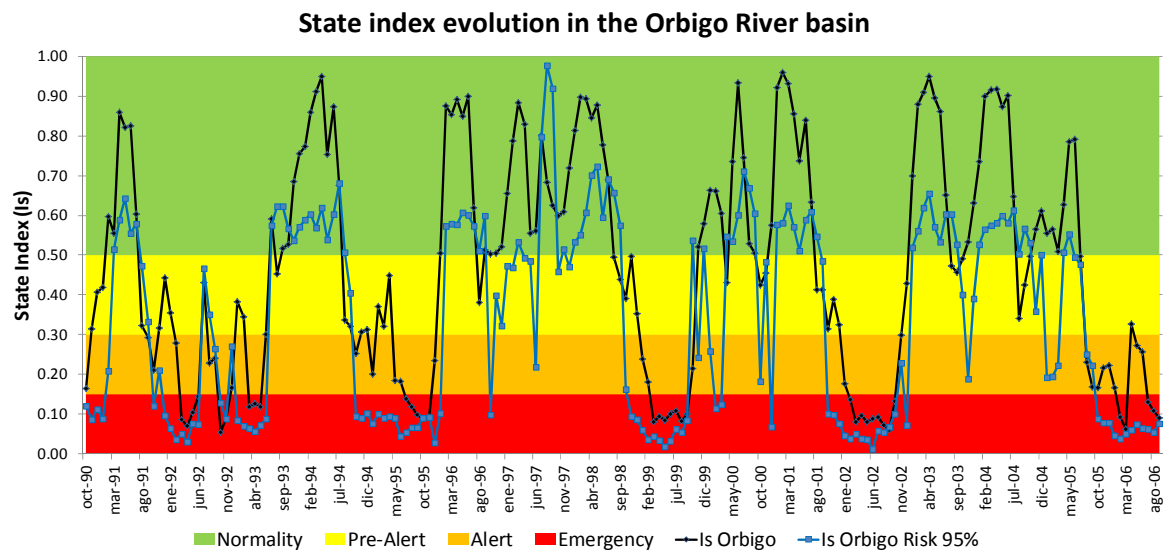

Figure 4.15. Evolution of the state index values in the Orbigo River basin calculated from observed values (black) and with the risk assessment methodology (blue) (source: selfelaboration)

It is possible to appreciate that the index obtained with the risk assessment methodology does not go too high after reaching the normality scenario. This is due to the volumes in September are always low and the index is calculated with the exclusive reference of this month storage values. We can observe that the risk calculated index is capable of anticipating the entrance to drought scenarios some months in advance to the observations based index. However, the transition from normality to emergency is very sudden. This is due to the within-year operation of the system. Anyway, what the values each month show is the possible situation of the basin by the end of the season taking into account the previous hydrologic and storage situation, and this should then alert the managers to implement measures to reduce the risk of reaching such situation. 


\subsection{Case 2: Conjunctive drought risk assessment of the Jucar and Turia River basins}

This section studies the applicability of the developed methodologies in determining the drought status of a water resources system that, different to the previous one, has a strong inertia. We will apply a process similar to the used in the previous section to estimate the value of the drought indicator in the Jucar and Turia River basins.

\subsubsection{The Jucar and Turia River basins}

The Jucar and Turia River Basins are located in the eastern part of the Iberian Peninsula in Spain (see Figure 4.16). These two basins are the main of 9 water exploitation systems in the Jucar River Basin Demarcation (DHJ). In the Valencia coastal plain, where Jucar and Turia Rivers have their final parts, and between both mouths, there is a shallow lake called Albufera, with an associated wetland. Both, the lake and the wetland, represent the nexus of union between both systems, as they depend on return flows from irrigation areas belonging to both basins, and also on groundwater flows from the coastal aquifer beneath the plain (Andreu et al 2009). 




Figure 4.16. Location of the Jucar and Turia River Basins in Iberian Peninsula (source: selfelaboration)

The Jucar River has a length of $497.5 \mathrm{~km}$, traversing the provinces of Teruel, Cuenca, Albacete and Valencia, having its mouth at the Mediterranean Sea. Additionally, this water exploitation system includes the area and services provided by the Jucar-Turia Channel and the littoral sub-basins between the Albufera Lake and around 10 kilometres south from the mouth of the river. It is the most extensive system $(22,261 \mathrm{~km} 2)$ and with more water resources at the Jucar River Basin Agency. On the other hand, the Turia River has a length of $280 \mathrm{~km}$, traversing the provinces of Teruel, Cuenca and Valencia, having its mouth in the city of Valencia at the Mediterranean Sea too. It is the second most extensive system $(6,393 \mathrm{~km} 2)$ and with more water resources at the Jucar River Basin Agency. A brief description of the study area and key issues is presented below, details can be found in Ortega-Reig et al (2014).

Both rivers are an example of a typical Mediterranean river, characterized by a semi-arid climate consisting of irregular rainfall and 
seasonal summer scarcity that occurs when irrigation requirements are at their height (Ortega-Reig et al 2014). Average natural resources reach 1,170 hm3/year for the Jucar River and $295 \mathrm{hm} 3 /$ year for the Turia River. The total population depending on both river basins represents a water demand of $148.5 \mathrm{hm} 3 /$ year and the water demand for irrigated agriculture reaches $833.7 \mathrm{hm} 3 /$ year. The supply to urban areas comes mainly from wells and springs, but Albacete, Sagunto and Valencia metropolitan areas use surface water (Andreu et al 2009).

According to the White Book of Groundwater (CEDEX 1995), the $73 \%$ of the resources in the territory of the $\mathrm{DHJ}$ have a subterranean origin. This percentage increases up to $76 \%$ in the case of the Turia River. All this indicates the great importance that groundwater resources have in the management of these basins. The main aquifers in the region correspond to the Mancha-Oriental aquifer, crucial for the supply of the irrigation demands in the region of Albacete in the Jucar River basin, and the Plana de Valencia Aquifer, very important for the supply of demands in coastal areas of both the Jucar and the Turia Rivers. Apart from the mentioned above, there are other aquifer units of lesser entity along the basins that have minor impact in their management.

Both systems represent one of the most vulnerable areas of the western Mediterranean region, due to high water exploitation indexes, and to environmental and water quality problems when droughts appear. This situation has triggered an increased use of non-conventional resources in recent years, such as reuse of wastewater and drought emergency wells. Also, conjunctive use of surface-ground waters has been historically a very 
important option in the district to provide robustness against droughts. The integrated use of those three kinds of resources was crucial in adapting to the recent drought occurring between 2005 and 2008 (Ortega-Reig et al 2014). This situation is especially important in Turia River Basin where Valencian farmers have been able to integrate groundwater, recycled and traditional surface water use in a single system (Ortega-Reig et al 2014).

From the above, the Albufera Lake represents the nexus of union between both river basins (see Figure 4.17). Their natural and anthropogenic inputs correspond to (Usaquén et al 2012): freshwaters, groundwater contributions through a series of springs called "ullals", direct precipitation on the lake, return flows from irrigation areas belonging to both basins and urban or industrial wastewater treatment outflows. It is noteworthy that agricultural activity, contribute to nearly $60 \%$ of flows into the Albufera ( $\mathrm{CHJ} 2003)$, and the maximum flows are introduced by winter during "la perelloná". Their outputs are: direct evaporation on the lake, agricultural pumping called "rebombeos" and water outflows through three channels or water outlets called "golas" (Pujol, Perellonet and Perelló) (Usaquén et al 2012). Moreover, the biological quality of the lake is heavily damaged. The polluting effects of urban and industrial waste, pesticide use and landfills irreversibly affect aquatic flora, and thus the associated fauna. Currently, the lake is a hypertrophic system due to excessive inputs of allochthonous organic matter and inorganic nutrients. This excess generates a large number of problems, which impact on the lake and are a direct cause of impairment. 


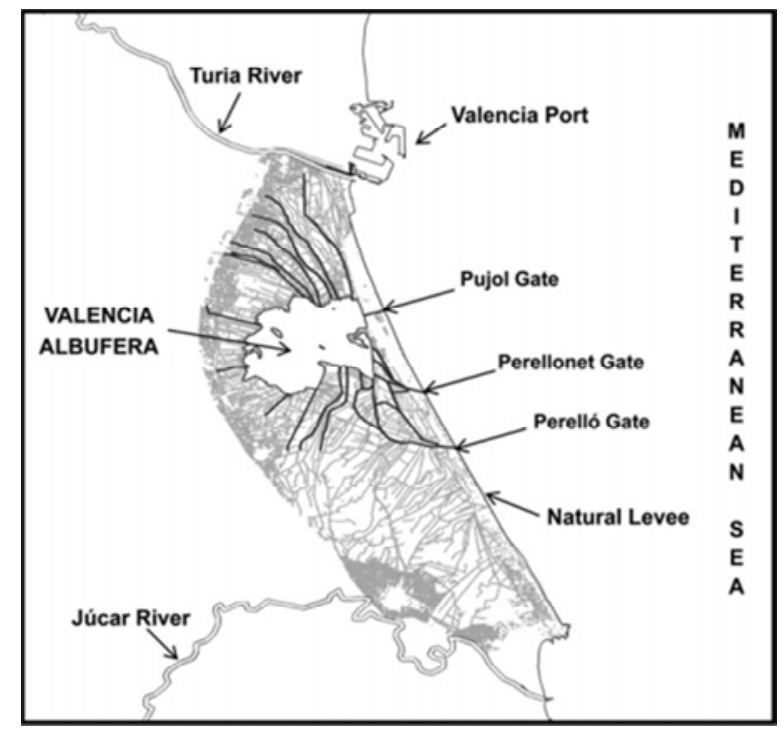

Figure 4.17. Geographical location of Valencia Albufera and level regulation systems (Usaquén Perilla et al., 2012)

The operation of both systems is mainly over-year, especially in the Jucar River basin with the Alarcon and Contreras reservoirs that are capable of storing the highly variable streamflows coming from their upstream subbasins as seen in Figure 4.18). This figure also shows the historical evolution of the third most important reservoir in the Jucar River basin, Tous, although this one is operated under a within-year basis in order to prevent floods in the Valencia Plain after the river leaves is sheer path through the mountains and reaches wider areas. In the same way, the Benageber reservoir in the Turia River also has an over-year operation (Figure 4.19) despite the total capacity of the Turia system is way lower than the Jucar. We can observe how the two systems follow similar periods of emptying and filling mainly due to the headwater of both systems are situated in the 
same geographical area, what is an additional reason their study in a conjunctive way.

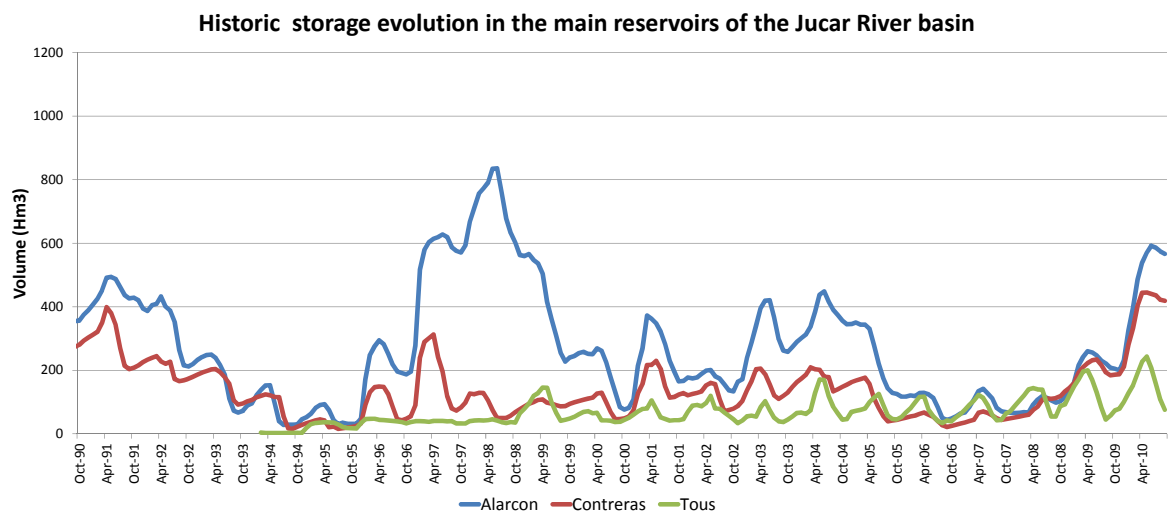

Figure 4.18. Evolution of the volumes stored in the main reservoirs of the Jucar River basin between October 1990 and September 2010 (source: self-elaboration with data from CHJ)

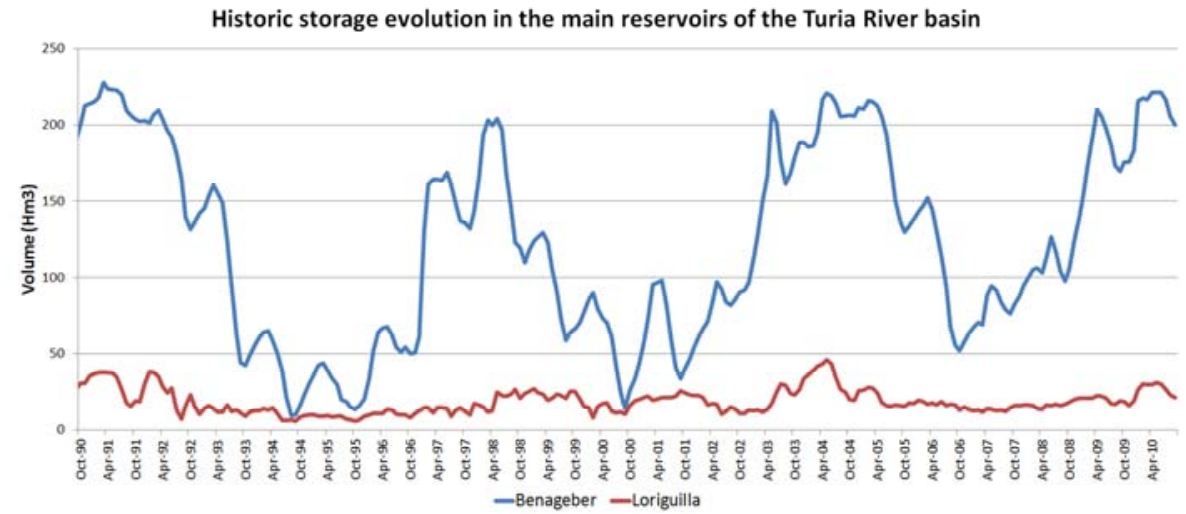

Figure 4.19. Evolution of the volumes stored in the main reservoirs of the Turia River basin between October 1990 and September 2010 (source: self-elaboration with data from CHJ) 


\subsubsection{Drought monitoring in the Jucar and Turia River basins}

The Jucar River District was pioneer in Spain with the implementation of a drought monitoring system based in the selection of several representative indicators along the basin, and their weighted combination to determine a single State Index value from which to evaluate the status of the system according to predefined drought scenario thresholds. All this process is described in the previous section since the state index calculation process described by the Jucar River District Agency was afterwards adopted by most of the other Spanish River District Agencies, with different success as we could see in the first case study with the Orbigo River basin.

In the case of the Jucar and Turia River basins, the state index indicator as defined in the drought plan described in the first case study generates more reliable results than the ones for the Orbigo River basin. Figure 4.20and Figure 4.21show the evolution of the State Index in the Jucar and Turia systems respectively. In both cases, it is possible to appreciate how the entrance in the different drought scenarios is more gradual, with few sudden jumps. This allows a better preventive approach to developing drought episodes, something that would not be possible if the index changed abruptly as we have seen in the previous case study.

The drought monitoring system in the Jucar River Basin District has provided useful information for early warning and action against drought, as well as for risk perception by the public. Yet, in order to manage droughts, a more elaborate and detailed information system is needed to 
better assess the risk and the effectiveness of the measures that can be used to modify the risks, and to mitigate the effects of the drought on both the established uses and on the environment.

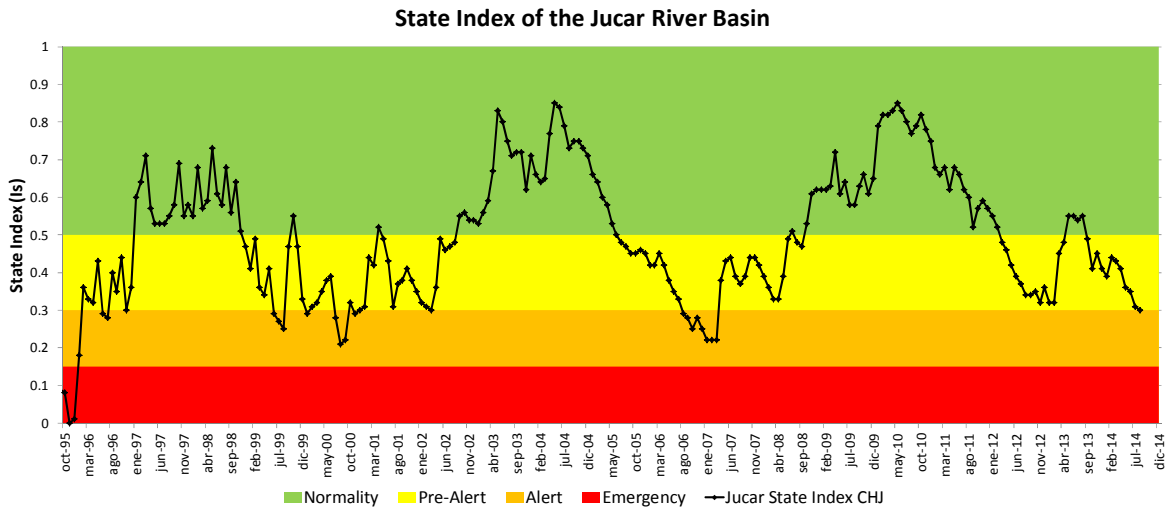

Figure 4.20. Evolution of the State Index of the Jucar River basin from October 2001 to September 2009 (source: self-elaboration with data provided by CHJ)

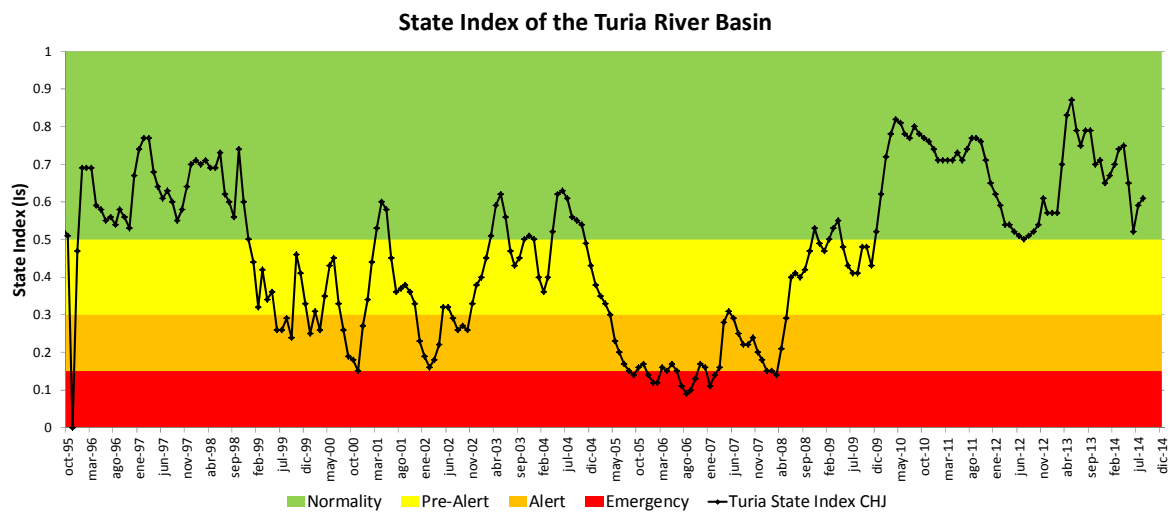

Figure 4.21. Evolution of the State Index of the Turia River basin from October 2001 to September 2009 (source: self-elaboration with data provided by $\mathrm{CHJ}$ ) 


\subsubsection{Complementary use of drought risk assessment methods and the existing drought indicators system}

We are going to apply the risk based monitoring method envisaged at the end of the previous section in the Jucar and Turia River basins. We will analyze more in deep the performance of the risk assessment analysis in front of the current monitoring system results and the possibilities of anticipation so appropriate mitigation measures can be applied in order to minimize the probabilities of evolving in worse scenarios.

We must take into account that this case study represents a completely different situation than the Orbigo River basin. First, the operation of the Jucar and Turia River systems is over-year. That means that the systems are capable of attending their demands for more than one year in a row with their storage capacities almost alone, without depending on the precipitations occurred in the same year. Second, hydrologic droughts in the Jucar River Basin District last several years. This difficults determining when a drought episode really starts since a very good autumn and spring can bring the system to unprecedented storage values but, at the same time, a good year can be followed by several bad ones creating a false sensation of security. Finally and very important, the drought monitoring system in this system works well and is highly trusted by the different actors present in the basin, from its managers to the farmers.

Anyway, as we saw in chapter two, risk assessment methodologies have been successfully used for the management of drought episodes in the Jucar River basin contributing to a better understanding of the system 
and position closeness between the different stakeholders. Thus, introducing a new way to anticipate droughts such as the one proposed here would probably not represent a great impact for the users and managers.

\subsubsection{Development of the risk assessment model}

In order to use the risk assessment methodology proposed in this thesis to the Jucar and Turia River basins case, and as we did with the case of the Orbigo River basin, the first step is developing a model of the water resources system under study. Figure 4.22 below shows the scheme developed with AQUATOOL provided by the Jucar River Basin District Agency $(\mathrm{CHJ})$. In it both the Jucar and the Turia Rivers are represented. It is interesting to observe how they become a conjunctive system by the end of their courses due to part of their flows end up in the Albufera Lake through irrigation uses. Also, the drinking water supply to the city of Valencia is done in a conjunctive basis from the two basins, especially thanks to the Jucar-Turia canal that diverts water from the Jucar River basin to the Turia River.

Taking into account the possibility of aquifer modeling introduced by the newer version of OPTIGES developed in this thesis, the most important aquifers are introduced in the model.

The Mancha-Oriental aquifer is modeled as a multiple cells aquifer with two cells, one for the rapid river discharge and another one for the slow discharge. This aquifer is important due to it is the main water source for irrigation demands in the region and additionally because it has a 
hydraulic connection with the river. Due to water abstractions for irrigation, part of the streamflow in the connected part of the river infiltrates to the aquifer. In periods of low flows, or during drought episodes, there is a risk that this part of the river runs dry. Thus, it is very important to include this aquifer in any model addressed to estimate risks during drought periods since river bed drying is a very serious environmental problem.

The other modeled aquifer is the one located in the Plana of Valencia. This aquifer is used to complement irrigation demands when these cannot be supplied with surface resources. Additionally, it represents one of the inputs to the Albufera Lake and surrounding natural park. During drought episodes, the drought plan of the DHJ includes as a measure the use of additional pumping from this aquifer to substitute the surface resources that irrigation uses give up for the supply of the urban demand of Valencia and its metropolitan area. This aquifer is modeled as a single cell aquifer.

Other aquifers, important for the management of the Jucar and Turia Rivers were also modeled. The filtration aquifers of Contreras and Loriguilla reservoirs delay the incorporation of part of the resources in the basin. These two aquifers are modeled as single cell aquifers as well. 


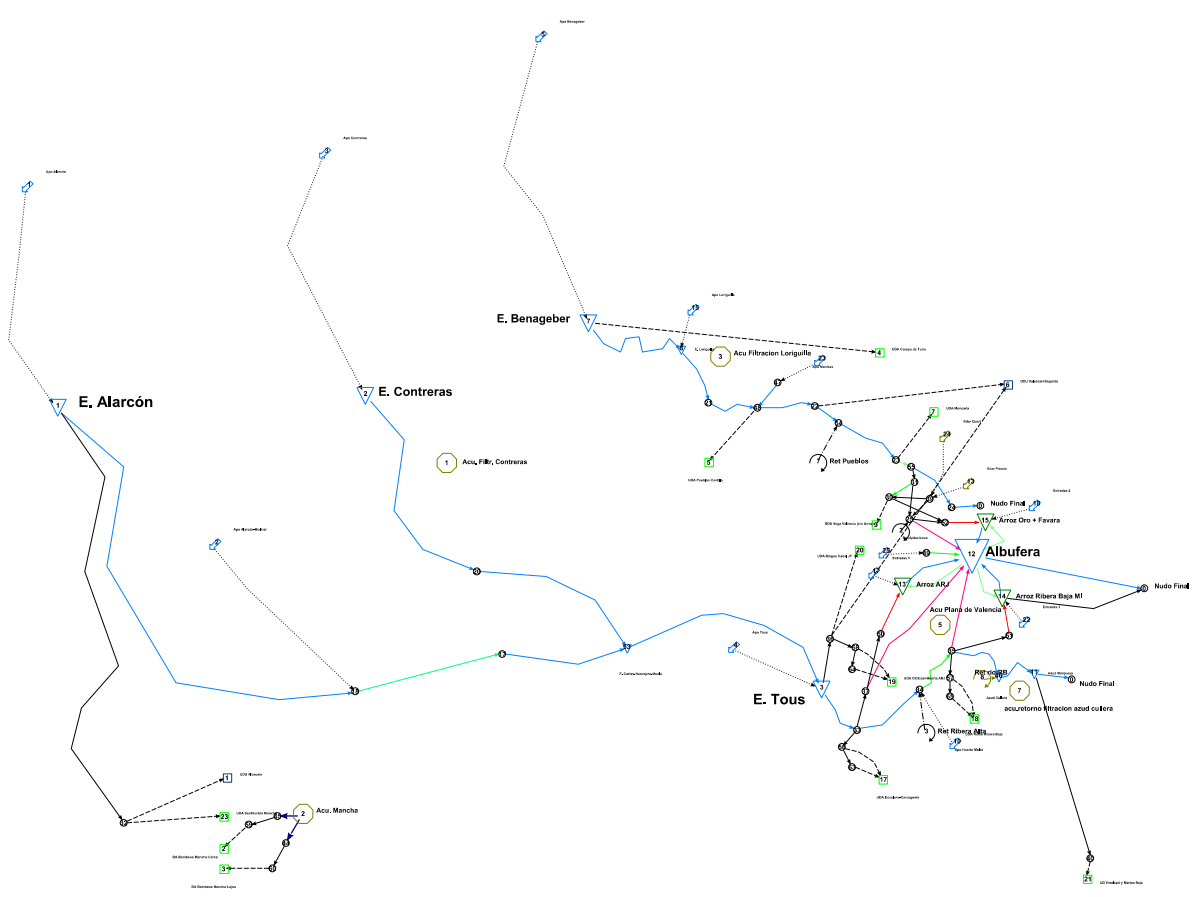

Figure 4.22. AQUATOOL scheme of the Jucar and Turia water resources systems (source: self-elaboration)

The main state indicators in the Jucar and Turia River basins correspond to the sum of the volumes stored in the principal reservoirs of each basin: Alarcón, Contreras and Tous in the Jucar River basin, and Benageber and Loriguilla in the Turia River basin. Figures 4.18 and 4.19 showed the historic evolution of the stored volumes in the two systems respectively. However, the water uses in the Jucar River Basin District have changed over time due to different reasons, e.g. modernization of infrastructures, and reduction of irrigated surface. We will use as reference storage values the ones obtained from the simulation of the system with the new demands and the historic streamflow series, in the same way is done by the $\mathrm{CHJ}$ in their recent River Basin Plan (CHJ 2014). Figure 4.23and 
Figure 4.24show the evolution of the storage volumes in the Jucar and the Turia systems respectively compared to the observed values.

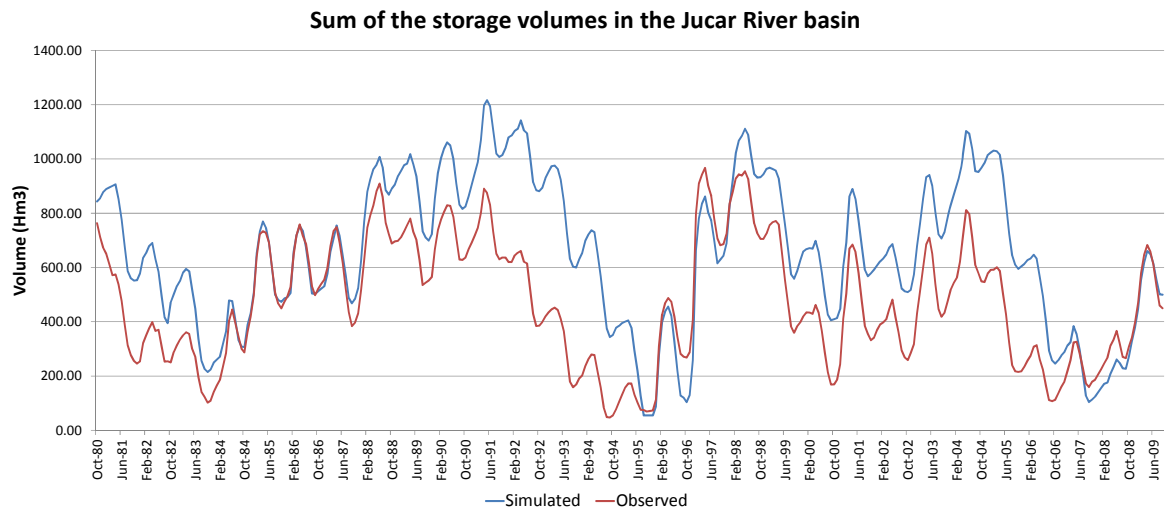

Figure 4.23. Evolution of the sum of storages in the main reservoirs of the Jucar River basin (Alarcón, Contreras and Tous) as obtained from simulation with Simges (blue) and observed (red) from 1980 to 2009. (source: self-elaboration)

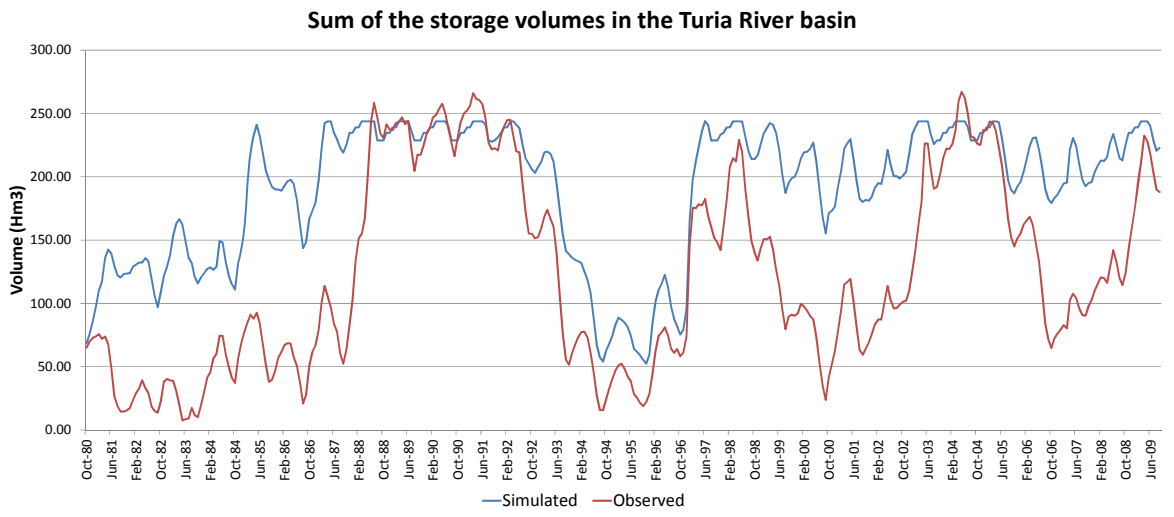

Figure 4.24. Evolution of the sum of storages in the main reservoirs of the Turia River basin (Benageber and Loriguilla) as obtained from simulation with Simges (blue) and observed (red) from 1980 to 2009. (source: self-elaboration) 
It is easy to observe how the more recent demands setup of the basins would have been able of storing more water in reservoirs than in the past, especially in the Turia River basin where the new water assignations in the basin plan are pretty lower than before. Of course, drought situations occurred in the past are still easily observable in the graphs. This is mainly due to some past drought episodes in the Jucar River Basin District last for several years and had an intensity that even decreased demands would have had problems to be met. Anyway, the new envisaged operation of the two systems by the $\mathrm{CHJ}$ has as results larger water availability and thus, it is from the new situation where we must study the occurrence of droughts for an enhanced drought policy in the future.

Regarding the stochastic generation of synthetic streamflow series, we calibrated and used an AR(1) model. 300 series proved enough to yield representative results in the Monte Carlo optimization process. All the data relative to the optimization and streamflows generation models can be found in annex D.

4.3.3.2.State index results using the risk assessment methodology on the optimal management of the system

As we did before, we calculated the evolution of the state index of the main status indicators in the Jucar and Turia River basins with the risk assessment approach developed in this thesis.

The experience in the Jucar River Basin District has revealed that September is the month that better summarizes the situation of the system. This month corresponds to the end of the hydrologic year and it is 
when the water assignments for the next year is done according to the state of the basin. Thus, analyzing what are the possible states of the basin by the end of the hydrologic year is the most appropriate approach for the risk analysis. Additionally, previous experiences with stakeholders and the use of risk assessment methods have developed a common trust in the risk results at the $80 \%$ probability of exceedance $(20 \%$ probability of nonexceedance).

Therefore, we calculated the state index using the resulting volumes in the next September, at the $80 \%$ probability of exceedance, of successive launches of OPTIRISK. Each month, from October 1995, had as initial reservoir volumes variables the volumes at the end of the previous month as simulated. The previous month observed streamflow values are used to generate multiple synthetic streamflow series.

Due to the optimization process tends to empty the reservoirs by the end of the optimization horizon, it would not be wise to set the multiple risk assessment launches for just one year horizon. The inter-drought periods in the Jucar River basin were determined to last around 5 or 6 years (Sanchez-Quispe 1999). Thus, an optimization horizon of 5 years reading the result after the first campaign should be chosen. However, due to the important resources consumption of optimization and the large amount of runs required for the risk assessment, it is advisable to find a shorter optimization horizon that yields similar results. Figure 4.25 shows the resulting volumes in the Jucar River basin main reservoirs for different setback-stepwise optimization horizons. It is possible to observe that a three years horizon extracting the results from the first year yields very 
similar results than the 5 years advised. Then, 3 year optimization horizons will be used in the risk assessment methodology. Results from Turia River basin in Figure 4.26support this decision.

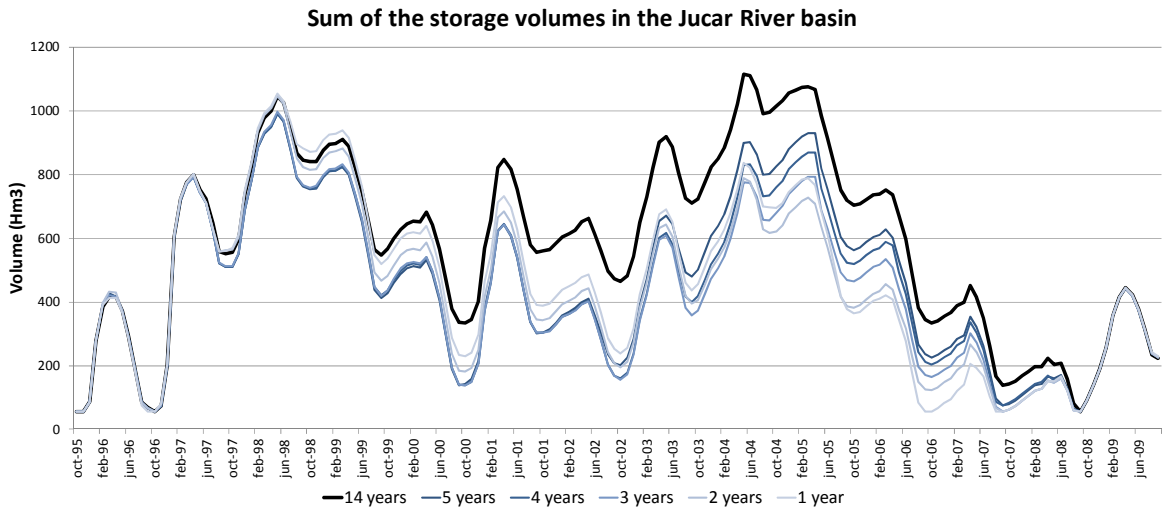

Figure 4.25. Evolution of the volumes stored in the Jucar river basin for different setbackstepwise optimization horizons (source: self-elaboration)

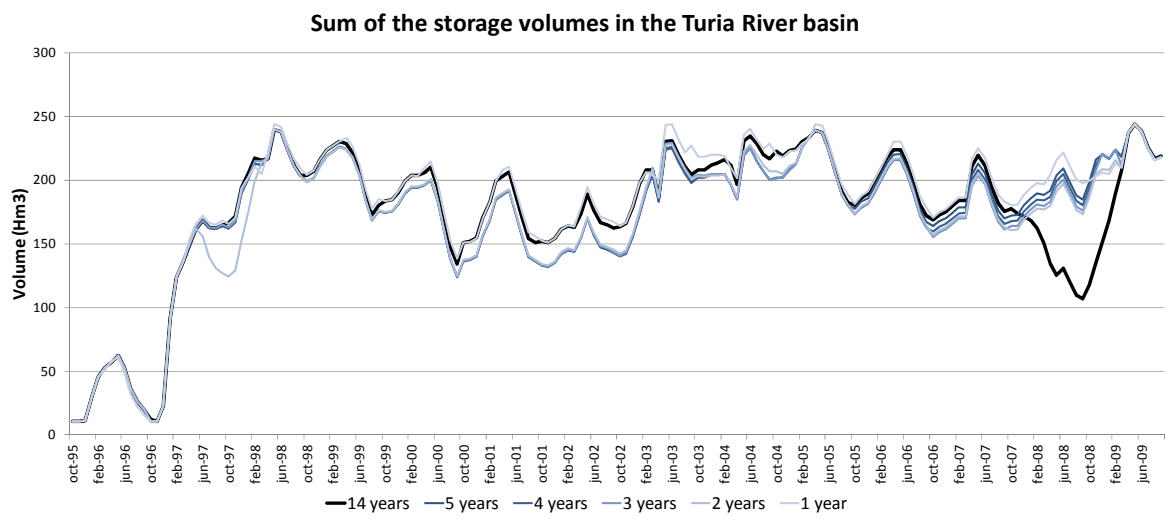

Figure 4.26. Evolution of the volumes stored in the Turia river basin for different setbackstepwise optimization horizons (source: self-elaboration)

The state index formulas presented in equations 4.1 and 4.2 were used to translate volume values into dimensionless $0-1$ values. Figure 4.27 and Figure 4.28show the evolution of the state index in the Jucar and Turia 
systems respectively both calculated from the simulated reservoir volumes, the OPTIRISK volumes, and the one calculated by the $\mathrm{CHJ}$ as the result of the weighted sum of the different indicators selected for each basin. $\mathrm{CHJ}$ indices for both basins include the sum of the volumes stored in their main reservoirs within their corresponding set of indicators, and they have the highest weight in the two cases. This is the reason to include also include the index calculated using only the reservoir volumes.

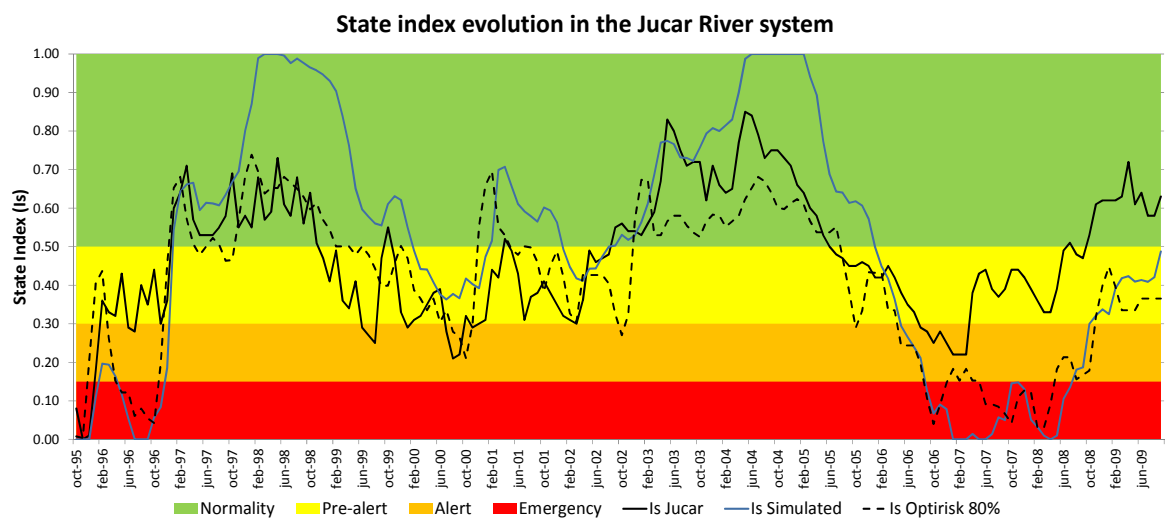

Figure 4.27. Evolution of the state index in the Jucar River system calculated from the simulated volumes (blue), from OPTIRISK results (dashed black), and official CHJ values (black), compared to the drought scenario thresholds (source: self-elaboration) 


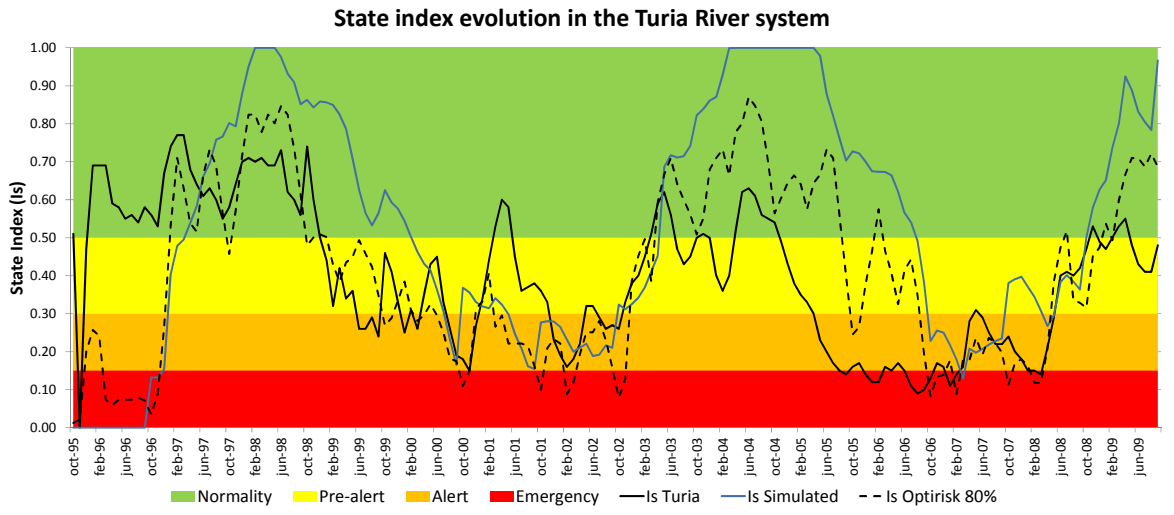

Figure 4.28. Evolution of the state index in the Turia River system calculated from the simulated volumes (blue), from OPTIRISK results (dashed black), and official $\mathrm{CHJ}$ values (black), compared to the drought scenario thresholds (source: self-elaboration)

In the case of the Jucar River, the $\mathrm{CHJ}$ index oscillates between the normality and the alert zones never reaching the emergency status. The index result of the simulated reservoir volumes reaches both 0 and 1 values due to there is only one variable involved and thus there must be 12 zeros and 12 ones corresponding to the minimum and maximum volume value each month respectively (the $\mathrm{CHJ}$ index does not reach those values due to the higher amount of variables involved and the separation in time of the different maxima and minima). Both indices reflect accurately the periods of drought suffered in the Jucar River basin during which the volumes stored in reservoirs had to be almost depleted to attend the different demands in the system. The beginning of the study period (1995-1996) gathers all the zero values due to this part of the series corresponds to the end of the 1992-1995 drought episode in which the reservoirs ended empty and filled with an unprecedented speed shortly after due to the very wet series of years that followed. Afterwards, they slightly touch the alert scenario during the short dry spells of years 1999-2000 and 2001-2002, and 
falls again during 2005 lasting in between emergency and alert values during what was one of the worse drought episodes recorded in the basin. It is remarkable that the $\mathrm{CHJ}$ index reaches the drought scenarios before than the volumes index in year 1999 and this order changes in the entrance to 2005 drought scenario being the $\mathrm{CHJ}$ index the slower one. Finally, the evolution of the index as calculated with OPTIRISK shows a similar behavior with regard to the drought events occurred in the Jucar basin but it is a little more alarming. In general, it anticipates the entrance to the different drought scenarios with respect to the other two indices, and the exit is somehow slower. Additionally, it reaches the emergency scenario more assiduously than the others. This makes of the OPTIRISK risk based monitoring a much more conservative process in the sense that it is capable of triggering the drought scenarios earlier, together with their associated measures.

The reading of the results for the Turia River basin is similar to the one provided above for the Júcar River basin. In this case, it is possible to observe that the values of the state index with an $80 \%$ risk level follow quite consistently the official $\mathrm{CHJ}$ state index values.

4.3.3.3.Conjunctive drought monitoring for the Jucar and Turia River basins

Chapter 10 of the $\mathrm{CHJ}$ drought plan, corresponding to the revision of the last drought event, included within its recommendations for future work the creation of a common indicator for the Jucar and Turia River basins. This is mainly due to, as stated above, the existence of common 
assets between the two rivers, principally the inflows to the Albufera Lake and the drinking water supply to the city of Valencia.

Following the same principles for the two separate river basins, OPTIRISK was used to calculate a state index for the two basins taking as calculation variables the volumes stored in the main reservoirs of the basin at the same time. Figure 4.29 shows the evolution of the state index calculated for both the simulated sum of storage volumes and the predicted ones with OPTIRISK.

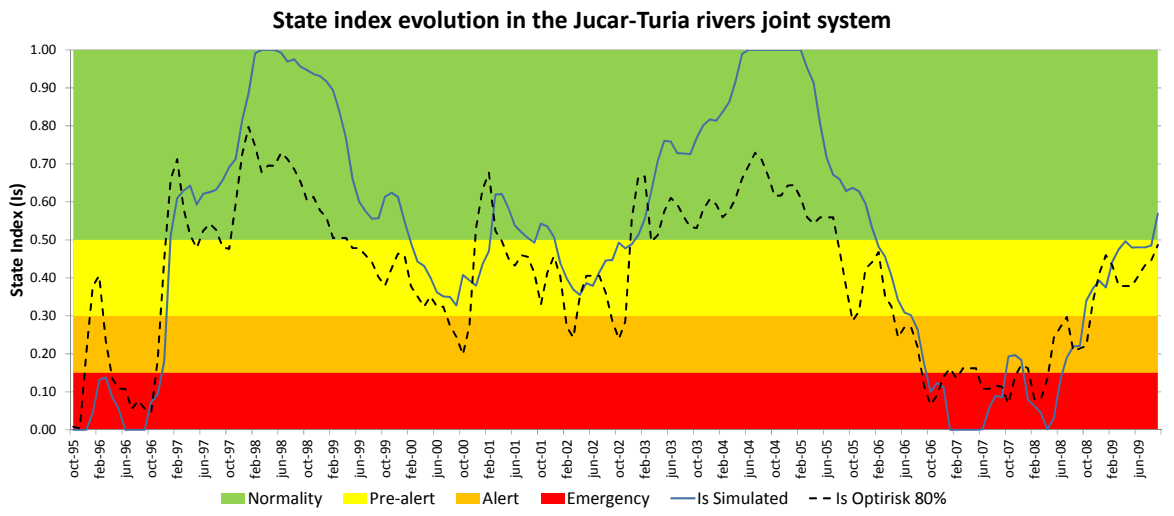

Figure 4.29. Evolution of the state index for the Jucar-Turia Rivers joint system calculated from the simulated volumes (blue), and from OPTIRISK results (dashed black) compared to the drought scenario thresholds (source: self-elaboration)

Due to the higher capacity of the reservoirs in the Jucar River system, the state index calculated for the two systems together resembles very much the one calculated for the first one. Anyway, both systems have suffered the same drought events with different levels of magnitude. 


\subsection{Discussion of the results obtained}

\subsubsection{On the cases of study}

The tools developed in chapter 3 have been applied to two different cases of study with different characteristics, especially from the operational point of view. In the two cases, the optimal risk assessment methodology proposed was used to analyze the existing drought monitoring systems currently used in both systems.

\subsubsection{Case 1: The Órbigo River basin}

This case served to show the difficulties of monitoring systems used in current drought plans to properly anticipating drought risk in within-year operated systems due to their high seasonality.

We have observed that the current indicator system proposed by drought plans in the Orbigo River basin does not really allow anticipating whether there is a risk of suffering a drought situation since the state index oscillates very quickly, making decision making ineffective due to the low confidence in the risk forecasting. Since within-year systems normally end the hydrologic year with low reservoir levels, an indicator system that takes into account all the values of the historic series will always show an important risk of being in a drought situation. The monitoring system currently used does not anticipate the real risk of suffering a severe drought event in many cases. Low state index values do not necessarily mean a high risk of a prolonged drought situation in all cases, especially in within-year 
operated systems, so there is a need for improved monitoring systems (Haro et al 2014).

We showed how in-depth knowledge of the system is necessary, and sometimes enough, to define what can be considered normal and what is considered abnormal within the basin behavior. With a simple approach, we were able to define new thresholds for the system status and observed that these are capable of gathering the information regarding the possible development of a drought event.

Additionally to the definition of new thresholds for the monitoring of drought in the Orbigo River basin, we proposed its complementation with a risk assessment methodology so the future, optimal management of the basin is included in the drought status definition. We showed that it is possible to anticipate to drought scenarios by evaluating the possible future status of the system with different anticipation periods. The application of the proposed methodology, considering different anticipation times and risk levels, improves the determination of the current drought scenario including the real management of the basin and not only hydrologic variables normally considered in monitoring systems (Haro et al 2014). Finally, the methodology presented would also permit assessing the efficacy of the mitigation measures proposed by calculating new risk levels obtained from their application.

We could also appreciate from the results that the longer the simulation period is; the more homogeneous are the results. This is due to the tendency to homogeneity of the synthetic series used, and is a characteristic of ARMA models. This makes this methodology a very 
interesting tool to analyze systems especially up to one year or one year and a half in advance, which are the time periods normally considered in management.

The continuous, updated monitoring of the system using a risk assessment methodology with an appropriate, representative risk level would allow anticipating drought events and implement measures that minimized their effects. We must note, however, that the within-year behavior of the basin under study does not really allow long anticipation periods. Thus, most of the drought management options in the basin will normally fall on the crisis management side rather than on the risk prevention one.

In cases such as the one shown, there is not much space for maneuver after knowing that the reservoirs did not reach the normality volume at the beginning of the campaign. And there is little to do in the months previous to this moment due to the high dependence on climatology for reservoirs filling.

\subsubsection{Case 2: The Jucar and Turia River basins}

We have applied OPTIRISK to the water resources system of the Jucar and Turia River basins in the same way as proposed for the Orbigo River basin. Different to the previous case, the existing drought monitoring system is relied on by both the managers and stakeholders of the $\mathrm{CHJ}$. Thus, there was no need to redefine the drought scenario thresholds.

Still, as in the first case, the application of the risk analysis methodology improves, or complements, the quality of the information of 
the existing system, since it provides estimations of probability that are not obtainable from the more classical indicators described above, complementing them.

The new calculated indices are capable of anticipating the drought events as well as they predict worse situations. This could be seen as bad behavior of the indicator. However, as it will also be discussed below, this behavior not only is not bad but it is even desirable. The optimal risk assessment methodology is taking, for any given month, the possible state of the system at the end of the ongoing hydrologic year. This future state of the system is obtained under the basis of an optimal operation of the system for each of the multiple synthetic streamflow series feeding the Monte Carlo process. Thus, the way to read the state index is: "considering the previous month hydrology, the state of the system in the form of water stored in reservoirs, and the water demands envisaged for the coming months, this will be the drought scenario at the end of the campaign provided that the system is perfectly managed".

With the previous lecture in mind, the manager must understand that, if the hydrologic situation does not improve suddenly, the best scenario is the one provided by the OPTIRISK calculated index. This should then trigger the necessary measures to prevent that situation occurs.

In order to have appropriate results regarding the water uses in the Jucar and Turia River basins, the reservoir volumes used to calculate the new state index were the ones obtained after simulating the system with the historic streamflow series and the most recent envisaged water 
demands from the $\mathrm{CHJ}$ hydrologic plan. If this methodology was to be implemented, the real observed reservoir volumes should be used instead.

In addition to the use of OPTIRISK in the two river basins separately, also a try was done in the search for a common drought indicator for the joint system. Just considering the combined reservoirs storage of both basins, the results reflect that the Jucar River basin has a very high influence due to it has larger capacity. This might disguise a developing of a drought episode in the Turia system as long as the levels in the Jucar system remained in normality. And the same could happen in the opposite direction, a drought developing only in the Jucar system might give the impression to be occurring as well in the Turia system. Even though historically droughts development in both systems have certain correlation due to their headwaters are located in the same geographic region, deeper understanding of the drought development times and the chances of one episode moves from one basin to the other is still necessary.

\subsubsection{On risk based management of water resources systems}

Apart from the particular discussion of the results for the two case studies, the application of the developed methodologies allows discussing other general issues related to management of water resources systems, particularly those with important regulation infrastructures, in situations of hydrologic uncertainty, or droughts. These aspects include drought monitoring and early warning systems, as well as risk assessment methodologies for water resources systems. 
Regarding drought monitoring, existing systems mostly limit to measure a series of climatic and hydrologic variables and calculating several indices that allow determining how is the state of the system in relation to the past, such is the case of the state index used in Spanish drought management plans shown in this chapter. This approach may be useful, if not the only one possible, for some kind of variables and not in all kind of systems. The use of indices based in observation of hydrologic variables and comparison with past data in systems where human activities take place are unable to represent the changes in the system along time. Anthropic actions influence not only river flows themselves with extractions and returns, but also runoff production both surface and subterranean delaying or preventing water reaches streams. Accounting for all of this and translating observed flows in one point to natural regime is often an arduous task not always rewarded with good results. Reservoirs storages represent the epitome of these limitations. In regulated systems, the volume stored in the different reservoirs of the system, or in the most representative, is normally considered a good approximation to the status of the whole system. The comparison between the storage levels at the beginning and the end of the hydrologic year are commonly accepted as a summary of how the campaign has been. However, the volumes stored nowadays are not comparable with the volumes stored ten years ago. Water uses in the system change over time. This makes that the behavior of the system, and thus the storage in reservoirs would be different should the new demands were considered and indices such as the one used by river basin districts cannot reflect that. 
In addition, drought indicators should warn of the risk that a certain situation develops into a worse scenario and not just inform about the current state of the system. Following a drought preventive strategy in a water resources system requires, in a certain sense, a continuous state of vigilance. So that measures addressed to minimize the risk or mitigating the effects of a fully developed drought episode have enough time to operate and be efficient. It is necessary to take into account that measures activation takes some time after the declaration of a new drought scenario. Thus, anticipated slightly more alarming indicators would definitely improve the performance of drought plans.

In the particular case of the state index defined for most of the Spanish drought management plans, we saw that it is not always capable of reflecting the proper state of the system with regard to drought scenarios. Additionally, the parameters used for its calculation are variable with time. This makes that new maximum and minimum values notably change the shape of the indicator evolution. Linked to this, there would be the definition of what is understood as normality and what is not within the system. Should an exceptionally wet period occur, the reservoir storages could reach unprecedented levels that might change the values of the state index giving completely erroneous impressions regarding past drought events, as well as future ones.

Nevertheless, we have observed that, in some cases, such as the one of the Orbigo River basin, the use of indices and even of risk assessment methodologies is not as efficient as could be expected. This is mainly due to the fact that within-year operated systems that rely mostly, 
or even solely, in precipitation-generated resources can only expect to have enough water at the beginning of the campaign, assuming the possible failures of the system if it was a dry year. In such cases, the only approach possible is the crisis management, although predefined measures to activate once it is known that the system will not be able to cope with the water requirements are still necessary and recommended, and thus they should still be considered within the drought plan.

There is a need for appropriate definition of what is considered to be normality in water resources systems in order to be capable of determining when they are in a situation of risk. For this, it is undoubtedly necessary a deep knowledge of the system. As already commented in previous chapters, the use of models both simulation and optimization allow developing knowledge of the system as well as building common understanding on the needs and concerns of the different actors involved in the basin.

This chapter has shown how the application of the developments of this thesis allows overcoming some of the limitations discussed above. The predictions of OPTIRISK improve with respect to the combined indicators of storage, streamflow and precipitation because they include both previous precipitation and storage data. Additionally, they include the information regarding the physical system what allows obtaining its best management options.

In addition, once we define the drought scenario, we can use the same methodology to assess the risk level with the existing management rules to evaluate the changes introduced by the mitigation measures. In this 
way, it is possible to select the best measures for each case and their optimal intensity. 


\section{CHAPTER 5}

Summary and conclusions 



\section{Chapter 5: Summary and} conclusions

\subsection{Summary}

A proper drought preventive system management requires anticipating the possible effects that one episode may have on the system (Haro et al 2014). However, this task reveals to be easy to say but harder to do. First, because of the high degree of uncertainty existing in future hydrological variables prediction. And second, because of the high risk of 
over reacting if the timing for mitigation measures activation is wrong, generating so-called artificial droughts. On this regard, drought plans provide tools to water managers to effectively handle scarce resources situations and preparing for future events. Anyway, the different operation strategies followed in different water resources systems make that the tools that reveal to be useful for some systems are not so effective in others.

Sometimes, due to lack of time and/or excess of confidence in works realized by third parties with good results for their cases, improper methodologies are implemented in systems with completely different requirements. The development and use of generalized methodologies applicable to different systems capable of yielding appropriate results for each case is then desirable. This is the case of generalized water resources systems modeling tools, allowing to homogenize processes while still being particularized enough to yield results that suit the requirements of the system under study.

At the beginning of this document, we set as objective of this thesis the exploration of the possibilities of the use of optimization modeling and risk assessment methodologies for the drought preventive management of water resources systems using a series of side, or intermediate, milestones.

A new version of a general optimization model for water resources schemes was developed. This model is capable of including a large amount of elements necessary for the creation of a detailed scheme of any resources system. Additionally, the new version developed allows modeling both the surface and groundwater components of the system under study, 
as well as their interactions with the surface components, with the use of simplified aquifer models, but representative enough for the usual requirements of optimization models. The optimization process is based in iterative resolution of network flows. The consistency and efficiency of different resolution algorithms was tested in order to find a balance between run speed, number of iterations and consistency of results. Recommendations on the use of each algorithm were given due to the differences found between them.

Afterwards, the model developed was also implemented within a risk assessment methodology based on Monte Carlo optimization fed with synthetic stochastic streamflow series.

The two new tools were included in the AQUATOOL DSSS as new versions of OPTIGES and OPTIRISK, including the design of new user interfaces for data input and management, as well as results display, analysis, and synthesis.

The developments of this thesis were applied to two real case studies in which the drought monitoring and early warning systems were put to test. In the first case, we proposed an alternative drought monitoring approach for within-year operated systems supported by the use of risk assessment methodologies. We have shown how anticipated assessment of the possible situation of the system allows a confident definition of drought scenarios with sufficient anticipation for the implementation of mitigating measures if necessary. In the second case, we applied OPTIRISK to a system with a completely different operation basis. We studied how the optimal risk assessment methodology can complement the existing indicators 
system in the activation of the different drought scenarios at the Jucar and Turia River basins, with an over-year based operation. This time, the existing drought monitoring system is reliable but the newly applied methodology showed that is capable of anticipating droughts and more alarmingly, something that is not wrong but even desirable in order to prevent episodes develop worse.

Finally, a discussion is done on the use of model-based indicators in front of observed data based ones reaching the conclusion that both are complementary and thus they should be used jointly for improved preventive management of water resources systems. It is also discussed the appropriateness of using optimization modeling during hydrological uncertainty periods due to systems operation rules are often defined for normality periods and this kind of models do not require the definition of such rules to find the best management of the system.

\subsection{Conclusions}

Optimization is a useful tool for water resources management often underused due to the modeling limitations and the complexity of some of the techniques used, as well as the computational requirements. This makes that their results fall too far from what can be considered as reliable or understandable. The continuous development in computer hardware allows reducing notably the running times of optimization algorithms what thus opens the door to improve the level of detail introduced in new models. Additionally, the no necessity of defining system operation rules makes optimization models especially useful for handling situations in 
which existing rules are not applicable or less efficient, like during drought events.

Generalization of modeling tools allows approaching many different problems under a same perspective and facilitates the comparison of results between different cases since the underlying processes are common.

The first research objective of this thesis was the development of a new version of the generalized optimization model OPTIGES that allowed increasing the level of detail of future models and using an optimization technique that was easily generalizable and computationally efficient.

Regarding the optimization technique, several options were reviewed and, despite the development of very interesting methodologies in the last times in terms of detail capabilities and computational efficiency, only a few of them allow easy generalization of the processes involved in order to allow developing models representing very different casuistry. Of these, network flows were the ones already used in the existing model. Thus, it was considered a smart choice attaching to this technique and exploring the available algorithms.

The different network flow algorithms present in literature were analyzed. Although generalized network algorithms seemed a promising alternative to pure network algorithms, the abandonment of their further development in some cases made very difficult to locate a fully functional algorithm ready to be used (the implementation of a network algorithm fell out of the scope of this thesis). The only path left at this point was pure 
network algorithms and relying on iterations to solve the non-linear aspects desired for the optimization model. Different available algorithms were analyzed solving the same water resources optimization problem in the search for the most computationally efficient one (something already done in literature before), but this time also the robustness of the final solution was tested when introducing the iterative process to consider non-linear aspects. Iterations slightly change the conditions of the network solved each time. What was found is that some of the most efficient algorithms have trouble to converge to a global optimum during the iterative process. In this case, RELAX IV is a very efficient pure network algorithm compared to the previously used Out-of-Kilter. However, the results of the latter are much more robust when iterations are involved. Both algorithms were finally included as optimizer options for OPTIGES that can be selected by the user depending on the optimization task required. For cases in which the network contains little number of arcs related to non-linearities, RELAXIV is definitely the best option. On the other hand, if the model includes a high number of non-linear elements, then Out-of-kilter is the choice to follow.

A side conclusion, or reflection, to the optimization algorithm topic is related to the mentioned difficulty in locating the very promising, in literature, generalized network algorithms. The problem encountered then was that the person in charge of developing these algorithms had retired some time ago and his line of research had been partially withdrawn and his files been lost within the ocean of information of his former institution. It is a disgrace that promising research lines are given up, and even forgotten, once the scientist in charge of them leaves the institution either 
because of retirement or change of professional situation. It is at least necessary to keep track of the works developed in research institutions so it is easy to retake abandoned lines in the future, detecting that new developing lines have not been opened before, or even recycling methodologies that could be of use in the present or future.

With regard to the introduction of the groundwater component in the optimization options of OPTIGES, there was an important work of design of the network shape of the newly included elements, being aquifers the ones around which orbit the rest of groundwater elements. The final network design considers all the affections to the aquifer during the optimization horizon. Later, these are used to simulate the aquifer and the effect of its discharge flows on the connected river stretches. With the solution adopted, it is possible to include any kind of aquifer model in the optimization models developed. The testing of OPTIGES with the new additions yielded valid results that permit concluding that its use in more complex cases is also possible, including risk assessment methodologies. Additionally, the level of detail reachable with the new version of OPTIGES is an advance towards improving the conception that managers and users have on optimization as a useful modeling technique.

The implementation of the new version of OPTIGES in a risk assessment methodology as a new version of OPTIRISK allows approaching the problem of drought risk assessment and early warning from a different perspective with regard to the previous approaches. The use of an optimization model to obtain the best management of the system in uncertain hydrologic periods such as droughts permits anticipating the 
possible outcomes of these situations without the need of considering the existing operation rules that might result ineffective in these cases.

The application of OPTIRISK for drought monitoring and early warning proposed in the case studies presented here shows the broad range of applications of risk assessment techniques with regard to drought management and preparation, apart from already known applications: identification and definition of both measures to reduce the propensity to operative droughts (pro-active measures) and short-term operative drought mitigation measures (reactive measures); design of emergency plans against drought; definition of better indicators to identify the risk of suffering an operative drought; and optimizing the implantation of the measures considered to be the most appropriate.

One of the main advantages of the tools developed is their capacity for dealing with complex systems, giving an overall picture of the situation in the basin as well as of the individual uses, while most of the previously developed indices are applicable only to a demand or to a group of demands. Thus, the proposed method constitutes an authentic early warning system on the arrival of an operative drought.

Finally, since one drought is no equal to a previous other, just looking at the past to anticipate drought is ineffective. Including future changes in climate and hydrology is mandatory, but also future water demands as well as the possible operation policies of the system is necessary to reach useful and reliable results for an efficient anticipation and preparations for future drought events. 
Finally, with respect to the cases of study analyzed, it is possible to conclude that different operation policies may require as well different approaches with regard to droughts both in the definition of drought thresholds for measures activation, in the variables necessary to measure these thresholds, and the usefulness of the tools to support decision making. This was analyzed in two Spanish river basins that follow similar drought management plans despite their evident differences. OPTIRISK was used in both cases to try and anticipate the possible state of the basin at the end of each hydrologic year and elaborating a drought indicator with these results.

In the first case, the Orbigo River basin, a yearly operated basin was studied. The first aspect observed is that the drought monitoring carried out in this basin is not capable of properly detecting the development of a developing event. It is a highly seasonal basin where the production of water resources depends a lot on the winter and spring precipitations. If these are good, there will not be supply problems during the summer and vice versa. The use of a standardized monitoring methodology (to the national level) does not provide useful nor timely information on the development of drought episodes. A new method based in the observation of the reservoirs levels was developed for this case with interesting, useful results but still insufficient in terms of anticipation. The use of risk assessment did not yield promising results either due to the difficulty of advancing the future status of the system with enough anticipation.

Second, the Jucar and Turia River basins were studied conjunctively. These two basins have an over-year operation basis and drought episodes 
develop over longer periods. The existing monitoring system, with the same philosophy than the one in the other case, does reflect the status of the system in a more appropriate way and holds the confidence of the stakeholders in the basin. The use of OPTIRISK in this case permits anticipating the possible status of the basin with the added value of increased warning. The complementarity of using this together with the existing monitoring system would represent a good early warning system for the two basins.

The analysis of the first case allows concluding too that sometimes proactive approach to drought is very difficult to accomplish. In these cases, the managers may need to opt between an "always ready" policy, which might incur in the consumption of many resources, or just dealing with the hazard when it occurs in a more emergency management approach.

In any case, the use of modeling tools provides insight in the problems of the systems analyzed and permit selecting and discarding options that many times are applied just because they worked somewhere else. This reflects the necessity to treat each case independently instead of generalizing the outcomes of successful experiences.

\subsection{Future research lines}

The thesis work presented in this document hopes to contribute to the advance of water resources management, particularly with regard to drought management in regulated water resources systems. Unfortunately, new answers arise new questions that either cannot be covered in the time of a thesis research or diverge from its main purpose. Thus, in this last 
section, future research lines envisaged from the realization of this thesis are proposed.

Due to the size of systems and the different climatic areas existing within them, drought episodes may have many different causes, or can be dampened by other exceptional occurrences in another part of the basin. For example, a drought at the headwaters of the system might be mitigated by a particularly wet period at the lower part of the basin. It would be interesting to investigate the occurrence of drought episodes at lower scales than the basin and try to correlate them with the failures of the system during historic recorded droughts.

The definition of normality in water resources systems is very sensitive to historic records. Particularly, changes in maximum values may turn what were supposed to be normal situations into risk situations, and risk situations into emergencies. Apart from the necessary knowledge of the system for its proper management, there is a need to determine appropriate thresholds for drought scenarios definition. Additionally, it is necessary to develop new state index calculation methodologies to detach parameters from variables.

The use of ARMA models, even though useful for the medium-short term, is not exempt of limitations for the prediction of future streamflows. Linked to the influence of spatial variability in droughts occurrence in regulated water resources systems, there is a need for advancing in the formulation and calibration of stochastic models introducing exogenous 
variables, such as precipitation in streamflow generation models, in order to improve their predictive capacity.

The hypothesis used for aquifer operation in the models used in this thesis was superposition. It would be interesting to introduce real behavior of aquifers in the calculation of the state index with the risk assessment methodology. Realistically considering the most important water storage bodies within the water system would improve the predictions, especially in systems where the groundwater component is of importance for the meeting of the demands.

Finally, in order to simplify the analysis of the results of the risk assessment for drought monitoring, only the risk level currently used in the Jucar and Turia River basins was explored for the triggering of the different drought scenarios. However, it would be interesting to test different risk levels to find possible combinations depending on the ongoing scenario. 
References 



\section{References}

Afshar MH (2012) Large scale reservoir operation by constrained particle swarm optimization algorithms. J Hydro-environ Res 6:75-87

Ahmad A, El-Shafie A, Razali SFM, Mohamad ZS (2014) Reservoir optimization in water resources: a review. Water resour manag $28,3391-$ 3405 .

Ahuja R, Magnanti T, Orlin J (1993) Network Flows: theory, algorithms and applications. Prentice Hall, New York 
Alderlieste MAA, van Lanen HAJ (2012) Trends in low flow and drought in selected European areas derived from WATCH forcing data and simulated multi-model mean runoff. DROUGHT Technical Report 1

Alecci S, Reitano B, Rossi G (1986) Evaluation of alternatives in management of water resources systems through performance indices. In Proceedings of the International Conference on water Resources Needs and Planning in Drought Prone Areas, Khartoum (Sudan), December 15-17

Alemu ET, Palmer RN, Polebitski A, Meaker B (2010) Decision support system for optimizing reservoir operations using ensemble streamflow predictions. J Water Resour Plan Manag 137, 72-82.

Alter, S.L. Decision Support Systems: Current Practice and Continuing Challenge. Reading, MA: Addison-Wesley, 1980.

Andreu J (1992) Modelo OPTIGES de Optimización de la Gestión de Esquemas de Recursos Hídricos. Manual del programador. Universidad Politécnica de Valencia, Valencia

Andreu J (1992) Modelo OPTIGES de Optimización de la Gestión de Esquemas de Recursos Hídricos. Manual del usuario. Versión 2.0. Universidad Politécnica de Valencia, Valencia

Andreu J, Capilla J, Sanchís E (1991). AQUATOOL: A computer Assited Support System for Water Resources Research Management Including Conjunctive Use, chapter, Decision Support Systems, ed Daniel P. Loucks and João da Costa, Vol. G26, pp 333-335, Springer Verlag, Berlin Heidelberg

Andreu J, Capilla J, Sanchís E (1996). AQUATOOL: a generalized decisión support system for water resources planning and operational management. Journal of Hydrology 177, 269-291

Andreu J, Ferrer-Polo J, Perez MA, Solera A (2009) Decision Support System for Drought Planning and Management in the Jucar River Basin, Spain. 18th World IMACS/MODSIM Congress, Cairns, Australia 
Andreu J, Ferrer-Polo J, Perez MA, Solera A, Paredes-Arquiola J (2013) Drought Planning and Management in the Júcar River Basin, Spain. In: $\mathrm{K}$ Schwabe et al (eds) Drought in Arid and Semi-Arid Regions, 237-249, Springer Science+Business Media, Dordrecht DOI: 10.1007/978-94-0076636-5_13

Andreu J, Pérez MA, Ferrer J, Villalobos A, Paredes J (2007) Drought Management Decision Support System by Means or Risk Analysis Models. In: G Rossi et al. (eds) Methods and Tools for Drought Analysis and Management, 195-216, Springer, Utrecht, Netherlands

Andreu J, Sahuquillo A (1987). Efficient aquifer simulation in complex systems. Journal of Water Resources Planning and Management 113, 110129

Andreu J, Solera A (2006) Methodology for the analysis of drought mitigation measures in water resources systems. In: J Andreu et al (eds) Drought Management and Planning for Water Resources, 133-168, CRC Taylor \& Francis, Boca Raton

Andreu J, Solera A, Capilla J, Ferrer J (2007). Modelo SIMGES para simulación de cuencas. Manual de usuario. Universidad Politécnica de Valencia, España

Andreu J, Solera A, Paredes J (2001) Decision support systems for integrated water resources planning and management. Proceedings of International Conference on Management of Northern River Basins, June 6-8, 2001, Oulu, Finland

Arrojo Agudo P (2007) "Bases para un documento de directrices en material de prevención y gestión de sequías en la planificación hidrológica”, In: La sequía en España. Directrices para minimizer su impacto.Cabrera $E$ and BabianoL (Edt.), ISBN 978-84-690-7328-5, Ministry of Environment of Spain, chapter 1, 29-49, 2007 
Arunkumar R, Jothiprakash V (2012) Optimal Reservoir Operation for Hydropower Generation using Non-linear Programming Model. J I Eng (India): Series A 93, 111-120

Arunkumar R, Jothiprakash $\mathrm{V}$ (2014). Evaluation of a multi-reservoir hydropower system using a simulation model. ISH J Hydrau Eng 20, 177187

ASCE Task Committee. (2000). Artificial neural networks in hydrology. I: Preliminary concepts. J Hydrologic Eng 5, 115-123.

Bates BC, Kundzewicz ZW, Wu S, Palutikof JP (2008) Climate Change and Water. Technical Paper of the Intergovernmental Panel on Climate Change, IPCC Secretariat, Geneva

Bazaraa M, Jarvis J (1977) Linear Programming and Network Flows. John Wiley and Sons Inc, New York

Bazaraa M, Jarvis J (1977) Linear Programming and Network Flows. John Wiley and Sons Inc, New York

Bellman R, Dreyfus S (1962) Applied dynamic programming. Princeton University Press, Princeton

Bersetkas D (1985) A unified framework for primal-dual methods in minimum cost network flows problems. Math Program 32, 125-145

Bersetkas D , Tseng P (1994) RELAX-IV: A Faster Version of the RELAX Code for Solving Minimum Cost Flow Problems. Completion Report under NSFGrant CCR-9103804. Dept. of Electrical Engineering and Computer Science, MIT, Boston

Bersetkas D,Tseng $P$ (1998) The relax codes for linear minimum cost network flow problems. Ann of Oper Res 13, 125-190

Bordi I, Sutera A (2007) Drought monitoring and forecasting at large scale. In: Methods and tools for drought analysis and management.Rossi G, 
Vega T and Bonaccorso B (eds), ISBN 978-1-4020-5923-0, Springer, Dordrecht, Chapter 1, 3-27

Bordi I, Fraedrich K, Sutera A (2009) Observed drought and wetness trends in Europe: an update. Hydrol. Earth Syst. Sci., 13, 1519-1530

Borowski I, Hare M (2007) Exploring the gap between water managers and researchers: difficulties of model-based tools to support practical water management. Water Resour Manag 21, 1049-1074

Bots PW, Bijlsma R, von Korff Y, Van der Fluit N, Wolters H (2011) Supporting the constructive use of existing hydrological models in participatory settings: a set of "rules of the game." Ecol Soc, 16

Braga B, Barbosa PS (2001) Multiobjective real-time reservoir operation with a network flow algorithm. JAWRA 37, 837-852.

Cancelliere A, Nicolosi V, Rossi G (2009) Assessment of drought risk in water supply systems. In: Iglesias A, Cancelliere A, Wilhite D, Garrote L, Cubillo F (eds) Coping with drought risk in agriculture and water supply systems, 93-109, Springer, Utrecht, Netherlands

Carmona G, Varela-Ortega C, Bromley J, 2013, Participatory modeling to support decision making in water management under uncertainty: Two comparative case studies in the Guadiana River basin, Spain. J Environ Manage 128, 400-412

Castelleti A, de Rigo D, Rizzoli AE (2007). Neuro-dynamic programming for designing water reservoir network management policies. Control Eng Pract 15, 1031-1038

Celeste A, Billib M (2010) The Role of Spill and Evaporation in Reservoir Optimization Models. Water Resour Manag 24, 617-628

Celeste, A., Billib, M. (2009) Evaluation of stochastic reservoir operation optimization models. Adv Water Resour 32, 1429-1443 
Chang J, Meng X, Wang Z, Wang X, Huang Q (2014) Optimized cascade reservoir operation considering ice flood control and power generation. J Hydrol 519, 1042-1051.

Chaves P, Chang FJ (2008) Intelligent reservoir operation system based on evolving artificial neural networks. Adv Water Resour 31, 926-936

CHJ, (2003) Contributions to L'Albufera Lake. Supplementary report to the European Investment Bank on the Júcar-Vinalopo. Jucar River Basin District, Valencia, Spain

Chou F, Wu C, Lin C (2006) Simulating Multi-Reservoir Operation Rules by Network Flow Model. ASCE Conf. Proc. 212, 33

Chung F, Archer M, DeVries J (1989) Network Flow Algorithm Applied to California Aqueduct Simulation. J Water Resour Plan Manag 115, 131-147

Coelho AC, Labadie JW, Fontane DG (2012) Multicriteria decision support system for regionalization of integrated water resources management. Water resour manag 26, 1325-1346.

Curet (1997) Applying steepest-edge techniques to a network primal-dual algorithm. Comp Oper Res 24, 601-609

Curet N (1994) An incremental primal-dual method for generalized networks. Comp Oper Res 21, 1051-1059

Curet N (1998) Implementation of a steepest-edge primal-dual simplex method for network linear programs. Ann Oper Res 81, 251-270

van Daalen CE, Dresen L, Janssen MA (2002) The roles of computer models in the environmental policy life cycle. Environ Sci Pol 5, 221-231.

Dariane AB, Karami $F$ (2014) Deriving Hedging Rules of Multi-Reservoir System by Online Evolving Neural Networks. Water Resour Manag, 1-15

Dasgupta S, Papadimitriou C, Vazirani U (2006). Algorithms. McGraw-Hill 
Deka PC, Chandramouli V (2009) Fuzzy Neural Network Modeling of Reservoir Operation. J Water Resour Plan Manag 135, 5-12

Dezso D, Juttner A, Kovacs P, LEMON - an open source C++ graph template library, Electron. Notes Theor. Comput. Sci. 264 (2011) 23-45.

Devi S, Srivastava DK, Mohan C (2005) Optimal Water Allocation for the Transboundary Subernarekha River, India. J Water Resour Plan Manag $131,253-269$

Dorigo M, Stützle T (2004) Ant colony optimization. MIT Press, Cambridge, London, England

Draper A, Munévar A, Reyes E, Parker N, Chung F, Peterson L (2004) CALSIM: Generalized model for reservoir system analysis. Journal of Water Resources Planning and Management, 130(6), 480-489

EC, 2000, Directive 2000/60/EC of the European Parliament and of the Council of 23 October 2000 establishing a framework for Community action in the field of water policy. Official Journal of the European Communities, L327/1

EC, 2000, Directive 2000/60/EC of the European Parliament and of the Council of 23 October 2000 establishing a framework for Community action in the field of water policy. Official Journal of the European Communities, L327/1

EC, 2007, Drought Management Plan Report. Including Agricultural, Drought Indicators and Climate Change Aspects. Office for Official Publications of the European Communities

Eden S (2011) Lessons on the generation of usable science from an assessment of decision support practices. Environ Sci Pol14, 11-19.

Estrela T, Vargas E (2012) Drought Management Plans in the European Union. The Case of Spain. Water Resour Manag 26, 1537-1553 DOI 10.1007/s11269-011-9971-2 
Evans J (1992) Optimization algorithms for networks and graphs. CRC Press

Evers M, Jonoski A, Maksimovič Č, Lange L, Ochoa Rodriguez S, Teklesadik A, ... \& Makropoulos C (2012) Collaborative modelling for active involvement of stakeholders in urban flood risk management. Nat Haz Earth Sys Sci 12, 2821-2842

Fassio A, Giupponi C, Hiederer R, Simota C (2005) A decision support tool for simulating the effects of alternative policies affecting water resources: an application at the European scale. J Hydrol 304, 462-476.

Fayaed SS, El-Shafie A, Jaafar O (2013) Integrated artificial neural network (ANN) and stochastic dynamic programming (SDP) model for optimal release policy. Water resour manag 27, 3679-3696.

Ford L, Fulkerson D (1962) Flows in networks. Princeton University Press, Princeton

Fredericks J, Labadie J, Altenhofen J (1998) Decision Support System for conjunctive Stream-Aquifer Management. J Water Resour Plan Manag $124,69-78$

Galelli S, Soncini-Sessa R (2010) Combining metamodelling and stochastic dynamic programming for the design or reservoir release policies. Environ Model Softw 25, 209-222

Gibbs WJ, JV Maher (1967) Rainfall deciles as drought indicators. Bureau of Meteorology Bulletin No. 48, Commonwealth of Australia, Melbourne

Giupponi C (2007) Decision support systems for implementing the European water framework directive: the MULINO approach. Environ Model Softw 22, 248-258.

Giupponi C, Sgobbi A (2013) Decision Support Systems for Water Resources Management in Developing Countries: Learning from Experiences in Africa. Water 5, 798-818. 
Goldberg DE (1989) Genetic algorithms in search, optimization and machine learning, Addison-Wesley, Reading, Mass

Gourbesville $P$ (2008). Challenges for integrated water resources management. Phys Chem Earth, Parts A/B/C, 33, 284-289.

Gould NIM, Orban D, Toint PL (2003) GALAHAD, a library of thread-safe Fortran 90 packages for large-scale nonlinear optimization. ACM Trans Math Softw 29(4):353-372

Govindaraju RS (2000) Artificial neural networks in hydrology. II: hydrologic applications. J Hydrol Eng 5, 124-137

Grigoriadis MD, Hsu T (1978) RNET. SIGMAP Bulletin.

Guo X, Hu T, Wu C, Zhang T, Lv Y (2013). Multi-objective optimization of the proposed multi-reservoir operating policy using improved NSPSO. Water resour manag $27,2137-2153$

Haddad OB, Afshar A, Marino MA (2006) Honey-bees mating optimization (hbmo) algorithm: A new heuristic approach for water resources optimization. Water Resour Manag 20: 661-680

Haettenschwiler P (1999) Neues anwenderfreundliches Konzept der Entscheidungsunterst, tzung Gutes Entscheiden in Wirtschaft, Politik und Gesellschaft. Zurich, vdf Hochschulverlag AG (1999), pp. 189-208

Hare M, Letcher RA, Jakeman AJ (2003) Participatory modelling in natural resource management: a comparison of four case studies. Integrat Ass, 4(2), 62-72.

Haro D, Paredes J, Solera A, Andreu J (2012) A model for solving the optimal water allocation problem in river basins with network flow programming when introducing non-linearities. Water Resour Manage 26:4059-4071 
Haro D, Solera S, Paredes J, Andreu J (2014) Methodology for drought risk assessment in within-year regulated reservoir systems. Application to the Orbigo River system (Spain). Water Resour Manag 28 (11); 3801-3814

Hashimoto T, Stedinger JR, Loucks DP (1982). Reliability, resiliency, and vulnerability criteria for water resource system performance evaluation. Water resour res $18,14-20$.

Hayes MJ, Wilhelmi OV, Knutson CL (2004) Reducing drought risk: Bridging theory and practice. Nat Hazards Rev 5, 106-113

Hinçal O, Altan-Sakarya AB, Ger AM (2011) Optimization of Multireservoir Systems by Genetic Algorithm. Water Resour Manag 25, 1465-1487

Hoppenbrouwers S, Rouwette E (2012) A dialogue game for analysing group model building: framing collaborative modelling and its facilitation. Int J Organ Des Eng 2, 19-40.

Hosack B, Hall D, Paradice D, Courtney JF (2012) A look toward the future: Decision support systems research is alive and well. J Assoc Inf Sys 13, 3

Hsu NS, Cheng KW (2002) Network flow optimization model for basin-scale water supply planning. J water resour plan manag 128, 102-112.

Hydrologic Engineering Center (1990) HEC-PRM Supplemental programs. HEC, Davis, CA

Ilich N (2009) Limitations of Network Flow algorithms in River Basin Modeling. J Water Resour Plan Manag 135, 48-55

Jakeman AJ, Letcher RA, Norton JP (2006) Ten iterative steps in development and evaluation of environmental models. Environ Model Softw 21, 602-614.

Jamieson D, Fedra K (1996) The WaterWare Decision-Support System for River Basin Planning. 1. Conceptual Design. Journal of Hydrology 177, 163175 
Jensen PA, Barnes JW (1987) Network flow programming. Krieger.

Jothiprakash V, Arunkumar R (2014) Multi-Reservoir Optimization for Hydropower Production using NLP Technique. KSCE J Civil Eng 18 (1); 344354 doi: 10.1007/s12205-014-0352-2

Junier S, Mostert E (2014) A decision support system for the implementation of the Water Framework Directive in the Netherlands: Process, validity and useful information. Environ Sci Pol 40, 49-56.

Karaboga N (2009). A new design method based on artificial bee colony algorithm for digital IIR filters. J Frankl Inst 346, 328-348

Karmarkar N (1984) A new polynomial-time algorithm for linear programming. In Proceedings of the sixteenth annual ACM symposium on Theory of computing (pp. 302-311). ACM

Kennedy J, Eberhart R (1995) Particle swarm optimization, Neural Networks, 1995. Proceedings., IEEE International Conference on, pp. 1942-1948 Vol. 1944

Kennington JL, Helgason RV (1980) Algorithms for Network Programming. John Wiley and Sons, New York

Khaliquzzaman, Chander S (1997) Network Flow Programming Model for Multireservoir Sizing. J Water Resour Plan Manag 123, 15-21

Király Z, Kovács P (2012) Efficient implementations of minimum-cost flow algorithms. arXiv preprint arXiv:1207.6381.

Kirkpatrick S, Gelatt J, Vecchi M (1983) Optimization by simulated annealing. Science 220:671-680

Klingman D, Napier A, Stutz J (1974) NETGEN - A program for Generating Large Scale (Un) Capacited Assignment, Transportation, and Minimum Cost Flow Problems. Manag Sci 20, 814-822 
Klipsch JD, Hurst MB (2007) HEC-ResSim reservoir system simulation user's manual version 3.0. USACE, Davis, CA, 512.

Kogan FN (1995) Droughts of the late 1980s in the United States as derived from NOAA polar-orbiting satellite data. Bulletin of the American Meteorological Society 76(5):655-668

de Kok JL, Kofalk S, Berlekamp J, Hahn B, Wind H (2009) From design to application of a decision-support system for integrated river-basin management. Water resour manag 23, 1781-1811.

Kondili E, Kaldellis JK, Papapostolou C (2010) A novel systemic approach to water resources optimisation in areas with limited water resources. Desalination 250, 297-301.

Koza JR (1992) Genetic programming, MIT Press, Cambridge, Mass.

Kuczera G (1993) Network Linear Programming Codes for Water-Supply Headworks Modeling. J Water Resour Plan Manag 119, 412-417

Kuczera G (1997) Wathnet: Generalised Water Supply Headworks Simulation using Network Linear Programming

Kumar DN, Reddy MJ (2007) Multipurpose reservoir operation using particle swarm optimization. Water Res PI-ASCE 133:192-201

Kumphon B (2013) Genetic Algorithms for Multi-objective Optimization: Application to a Multi-reservoir System in the Chi River Basin, Thailand. Water resour manag 27, 4369-4378.

Labadie J (2004) Optimal Operation of Multireservoir Systems:State-of-theArt Review. J Water Resour Plan Manag 130, 93-111.

Labadie J (2005) MODSIM: River basin management decision support system. In Singh V and Frevert D (eds) Watershed Models, CRC Press, Boca Raton, Florida 
Labadie J, Baldo M, Larson R (2000) MODSIM: Decision support system for river basin management. Documentation and user manual. Dept. Of Civil Engineering, CSU, Fort Collins

Labadie, J. and R. Larson (2007). MODSIM: River basin management decision support system, User Manual, Department of Civil Engineering, Colorado State University, Ft. Collins, CO

Lautenbach S, Berlekamp J, Graf N, Seppelt R, Matthies M (2009) Scenario analysis and management options for sustainable river basin management: application of the Elbe DSS. Environ Model Softw 24, 26-43.

Lerma N, Paredes-Arquiola J, Molina JL, Andreu J (2013) Evolutionary network flow models for obtaining operation rules in multi-reservoir systems. J Hydroinf 16 (1); 33-49

Lévite H, Sally H, Cour J (2003) Testing water demand management scenarios in a water-stressed basin in south Africa: application of the WEAP model. Phys Chem Earth 28, 779-786

Li XJ, Zhang J, Xu LY (2014). An evaluation of ecological losses from hydropower development in Tibet. Ecological Eng.

Li L, Liu P, Rheinheimer DE, Deng C, Zhou Y (2014) Identifying Explicit Formulation of Operating Rules for Multi-Reservoir Systems Using Genetic Programming. Water Resour Manag 28, 1545-1565

Louati MH, Benabdallah S, Lebdi F, Milutin D (2011) Application of a genetic algorithm for the optimization of a complex reservoir system in Tunisia. Water Resour Manag 25:2387-2404

Loucks D (1992) Water Resource Systems Models: Their Role in Planning. Journal of Water Resources Planning and Management 118, 214-223

Loucks D (1995) Developing and implementing decision support systems: A critique and a challenge. Water Resources Bulletin 31, 571-582 
Loucks D, French PN, Taylor MR (1995). IRAS - Interactive River-Aquifer Simulation: Program Description and Operation. Resources Planning Associates, Incorporated, Ithaca, NY, USA.

Loucks DP, French PN, Taylor MR (1995). IRAS - Interactive River-Aquifer Simulation: Program Description and Operation. Resources Planning Associates, Incorporated, Ithaca, NY, USA

Maxim L, van der Sluijs JP (2011) Quality in environmental science for policy: Assessing uncertainty as a component of policy analysis.Environ Sci Pol 14, 482-492.

McBride RD (1985) Solving embedded generalized network problems, Eur J Oper Res 21, 82-92

McEnzie River MIKE BASIN model. DHI Water and Environment (2008)

McIntosh BS, Ascough JC, Twery M, Chew J, Elmahdi A, Haase D, ... \& Voinov A (2011) Environmental decision support systems (EDSS) development Challenges and best practices. Environ Model Softw 26, 1389-1402

McKee TB, Doesken NJ, Kleist J (1993) The relationship of drought frequency and duration to time scales. Preprints, 8th Conference on Applied Climatology, 179-184. January 17-22, Anaheim, California

McNie EC (2007) Reconciling the supply of scientific information with user demands: an analysis of the problem and review of the literature, Environ Sci Pol 10, 17-38

Merabtene T, Kawamura A, Jinno K, Olsson J (2002) Risk assessment for optimal drought management of an integrated water resources system using a genetic algorithm. Hydrol Proc 16, 2189-2208

Michalewicz Z (1999) Genetic algorithms + data structures = evolution programs, 3rd rev. and extended ed. Springer, New York 
MIKE BASIN 2003. Guide to getting started. Tutorial. DHI Water and Environment (2003)

Mishra AK, Singh VP (2010) A Review of drought concepts. J Hydrol 391, 202-216

Mishra AK, Singh VP (2011) Drought Modeling: A Review. J Hydrol 403, 157175

MMA (2008). Confederación Hidrográfica del Duero. Memoria 2008. http://www.chduero.es/Inicio/Publicaciones/tabid/159/Default.aspx. Last accessed 09 March 2011

Moeini R, Afshar A, Afshar MH (2011) Fuzzy rule-based model for hydropower reservoirs operation. Electr Power Energy Syst 33, 171-178

Mostert E, Van Beek E, Bouman NWM, Hey E, Savenije HHG, Thissen, WAH (1999). River basin management and planning. Inkeynote paper for the international workshop on River Basin Management, The Hague (pp. 2729).

Mousavi SJ, Ponnambalam K, Karray F (2007) Inferring operating rules for reservoir operations using fuzzy regression and ANFIS. Fuzzy Set Syst $158,1064-1082$

Murtagh BA, Saunders MA (1998) MINOS 5.5 user's guide. Technical Report-SOL 83-20R. Systems Optimization Laboratory, Department of Operations Research, Stanford University, California

Mysiak J, Giupponi C, Rosato P (2005) Towards the development of a decision support system for water resource management. Environ Model Softw 20, 203-214.

Nicklow J et al (2010) State of the Art for Genetic Algorithms and Beyond in Water Resources Planning and Management. J Water Resour Plan Manag 136, 412-432 
Ochoa JC (2002) Modelo Estocástico de Redes Neuronales para la Síntesis de Caudales Aplicados a la Gestión Probabilística de Sequías. Universitat Politècnica de València, Spain

Ortega-Reig M, Palau-Salvador G, Cascant MJ, Benítez-Buelga J, Badiella D, Trawick P (2014), The integrated use of surface, ground and recycled waste wáter in adapting to drought in the traditional irrigation system of Valencia, Agricultural Water Management, 133; 55-64

Ostadrahimi L, Mariño MA, Afshar A (2011) Multi-reservoir operation rules: Multiswarm PSO-based Optimization Approach. Water Resour Manag 26; 407-427

Pallotino S, Sechi G, Zuddas P (2005) A DSS for water resources management under uncertainty by scenario analysis. Environ Modell Softw 20, 1031-1042

Palmer WC (1965) Meteorological drought. Research Paper No. 45, U.S. Department of Commerce Weather Bureau, Washington, D.C.

Palmer WC (1968) Keeping track of crop moisture conditions, nationwide: The new Crop Moisture Index. Weatherwise 21:156-161

Panu US, Sharma TC (2002) Challenges in drought research: some perspectives and future directions. Hydrol Sci J 47, S19-S30

Paparrizos K, Samaras N, Sifaleras A (2009) An exterior simplex type algorithm for the minimum cost network flow problem. Comput Oper Res 36, 1176-1190.

Peralta RC, Forghani A, Fayad H (2014) Multiobjective genetic algorithm conjunctive use optimization for production, cost, and energy with dynamic return flow. J Hydrol 511, 776-785

Power, D.J.A Brief History of Decision Support Systems. DSSResources.COM, World Wide Web, 
http://DSSResources.COM/history/dsshistory.html, version 4.0, March 10, 2007.

Rani D, Moreira M (2010) Simulation-Optimization Modeling: A Survey and Potential Application in Reservoir Systems Operation. Water Resour Manag 24, 1107-1138

Rani D, Jain SK, Srivastava DK, Perumal M (2013). Genetic Algorithms and Their Applications to Water Resources Systems. Metaheuristics Water, Geotech. Transp. Eng. Elsevier, Oxford, 43-78

Rashedi E, Nezamabadi-Pour H, Saryazdi S (2009). GSA: a gravitational search algorithm. Inform sciences 179, 2232-2248.

REALM User Manuals. Victoria University and Department of Sustainability and Environment http://www.water.vic.gov.au/monitoring/surfacewatermodelling/realm/download_realm_ manuals accedida por última vez en 19 de Julio de 2011

REALM User Manuals. Victoria University and Department of Sustainability and Environment http://www.water.vic.gov.au/monitoring/surfacewatermodelling/realm/download_realm_ manuals accedida por última vez en 19 de Julio de 2011

Reddy MJ, Kumar DN (2007) Optimal reservoir operation for irrigation of multiple crops using elitist-mutated particle swarm optimization. Hydrol Sci J 52:686-701

Ribasim documentation. Delft Hydraulics. http://www.wldelft.nl/soft/ribasim/doc/index.html Accedida por última vez el 19 de Julio de 2011

Ribasim documentation. Delft Hydraulics. http://www.wldelft.nl/soft/ribasim/doc/index.html Accedida por última vez el 19 de Julio de 2011 
Rossi G (2003). Requisites for a drought watch system. In Tools for drought mitigation in Mediterranean Regions (pp. 147-157). Springer Netherlands.

Rossi, G., Nicolosi, V., \& Cancelliere, A. (2008). Recent methods and techniques for managing hydrological droughts. In Drought management: Scientific and technological innovations (Options mediterraneennes, series A, no. 80), pp. 251-265.

Rossi G, Cancelliere A (2013) Managing drought risk in water supply systems in Europe: a review, International Journal of Water Resources Development, 29:2, 272-289, DOI: 10.1080/07900627.2012.713848

Sabet H, Creel C (1994) Network Flow Modeling of Oroville Complex. J Water Resour Plan Manag 117, 301-320

Safavi HR, Chakraei I, Kabiri-Samani A, Golmohammadi MH (2013) Optimal reservoir operation based on conjunctive use of surface water and groundwater using neuro-fuzzy systems. Water Resour Manag 27, 42594275 .

Sanchez-Quispe S (1999) Gestión de Sistemas de Recursos Hídricos con Toma de Decisión Basada en Riesgo. Tesis doctoral. UPV

Sahuquillo A (1983). An eigenvalues numerical technique for solving unsteady linear groundwater models continuously in time. Water Resources Research 19, 87-93

Sechi G, Zuddas P. (2008) Multiperiod Hypergraph Models for Water Systems Optimization. Water Resour Manag 22, 307-320

Shafer BA, Dezman LE (1982) Development of a Surface Water Supply Index (SWSI) to assess the severity of drought conditions in snowpack runoff areas. InProceedings of the Western Snow Conference, pp. 164-175. Colorado State University, Fort Collins, Colorado. 
Sheffield J, Wood EF (2008) Global Trends and Variability in Soil Moisture and Drought Characteristics, 1950-2000, from Observation-Driven Simulations of the Terrestrial Hydrologic Cycle. J Climate 21; 432-458

Sieber J, Purkey D (2011) WEAP: Water Evaluation And Planning System. User Manual. Stockholm Environmental Institute, Somerville, MA

Sifaleras A (2013). Minimum cost network flows: Problems, algorithms, and software. Yugoslav Journal of Operations Research ISSN: 0354-0243 EISSN: 2334-6043, 23(1)

Simons M, Podger G, Cooke R (1996). IQQM - A hydrologyc modeling tool for water resource and salinity management. Environmental Software 11, 185-192

Simons M, Podger G, Cooke R (1996). IQQM - A hydrologyc modeling tool for water resource and salinity management. Environmental Software 11, 185-192

Singh A (2012) An overview of the optimization modelling applications. J Hydrol 466-467, 167-182 doi: 10.1016/j.jhydrol.2012.08.004

Sinha A, Bischof C (1998) Application of automatic differentiation to reservoir design models. J Water Resour Plan Manag 124, 162-167

Solera A, Paredes J, Andreu J (2007). AQUATOOLDMA SSD para planificación de cuencas. Manual de usuario. Universidad Politécnica de Valencia, España

Stahl K, Hisdal H, Hannaford J, Tallaksen LM, van Lanen HAJ, Sauquet E, Demuth S, Fendekova M, Jodar J (2010) Streamflow trends in Europe: evidence from a dataset of near-natural catchments. Hydrol Earth Syst Sc 14, 2367-2382

Sun YH, Yeh W, Hsu NS, Louie P (1995) Generalized Network Algorithm for Water-Supply-System Optimization. J Water Resour Plan Manag 121, 392398 
Tannehill IR (1947). Drought, its causes and effects. Soil Sci, 66, 83

Tsakiris G, Nalbantis I, Vangelis $H$, Verbeiren B, Huysmans $M$, Tychon B, ... \& Batelaan $O$ (2013). A system-based paradigm of drought analysis for operational management. Water Resour Manag, 27, 5281-5297

Turban E, Aronson JE (1995) Decision Support System Pearson Education Asia, 12-16

Usaquén OL, García A, García A, Álvarez C, Revilla JA (2012) Methodology to assess sustainable management of water resources in coastal lagoons with agricultural uses: An application to the Albufera lagoon of Valencia (Eastern Spain), Ecological Indicators, 13; 129-143.

Vanderbei RJ (2006) LOQO user's manual-version 4.05. Princeton University

Volk M, Lautenbach S, van Delden H, Newham LT, Seppelt R (2010) How can we make progress with decision support systems in landscape and river basin management? Lessons learned from a comparative analysis of four different decision support systems. Environ manag 46, 834-849.

Voinov A, Gaddis EJB (2008) Lessons for successful participatory watershed modeling: a perspective from modeling practitioners. Ecol Model 216, 197-207.

Wang K-W, Chang L-C, Chang F-J (2011) Multi-tier interactive genetic algorithms for the optimization of long-term reservoir operation. Adv Water Resour 34:1343-1351

Waterware on-line Manuals. http://www.ess.com.at/MANUALS/WATERWARE/R60reference.html Accessed last on 14th October 2014

Wilhite DA, Glantz, MH (1985). Understanding: the drought phenomenon: the role of definitions. Water Int, 10(3), 111-120. 
Wilhite DA (1992) Drought. In: Encyclopedia of Earth System Science, WA Nierenberg (Editor). Academic Press, Inc., New York, New York, Volumes 1-4

Wilhite DA (1996) A Methodology for Drought Preparedness. Nat Hazards $13,229-252$

Wilhite DA, Hayes MJ, Knutson C, Helm Smith K (2000) Plannign for drought: Moving from crisis to risk management. Journal of the American Water Resources Association 26, 697-710

Wilhite DA (2000a) Drought: A Global Assessment, Vols. 1 and 2. Routledge, New York, 89-104, 1 and 2, Routledge, New York, 129-448.

Wilhite DA, (2000b) Drought as a natural hazard: concepts and definitions. In: Wilhite, D.A. (Ed.), Drought: A Global Assessment, vol. 1. Routledge, New York, 1-18.

Wilhite DA, Buchanan-Smith M (2005) Drought as a natural hazard: understanding the natural and social context. In: Wilhite DA (ed) Drought and water crises: science, technology, and management issues. CRC Press, Boca Raton, FL, pp 3-29

Willeke G, Hosking JRM, Wallis JR, Guttman NB (1994) The National Drought Atlas. Institute for Water Resources Report 94-NDS-4, U.S. Army Corps of Engineers.

Wurbs R (1993) Reservoir-System Simulation and Optimization Models. J Water Resour Plan Manag 119, 455-472

Wurbs R (2005) Modeling river/reservoir system management, water allocation, and supply reliability. J Hydrol 300, 100-113

Xiang L, Tiejian L, Jiahua W, Guagqian W, Yeh WWG (2013) Hydro unit commitment via mixed integer linear programming : A case study of the Three Gorges project, China. IEEE Transactions on Power Systems 29, $1232-1241$ 
Yamout G, El-Fadel M (2005) An Optimization Approach for Multi-Sectoral Water Supply Management in the Greater Beirut Area. Water Resour Manag 19, 791-812

Yates D, Sieber J, Purkey D, Hubert-Lee A (2005) WEAP21 - A Demand-, Priority-, and Preference-Driven Water Planning Model. Part 1: Model Characteristics. Water Int 30, 487-500.

Yates D, Sieber J, Purkey D, Hubert-Lee A (2005) WEAP21 - A Demand-, Priority-, and Preference-Driven Water Planning Model. Part 1: Model Characteristics. Water Int 30, 487-500

Yevjevich V (1965) The application of surplus, deficit and range in hydrology. Colorado State University, Fort Collins, Colorado

Yongdae Lee, Sheung-Kown Kim, and Ick Hwan Ko (2006) Two-Stage Stochastic Linear Programming Model for Coordinated Multi-Reservoir Operation. Operating Reservoirs in Changing Conditions, 400-410. DOI: $10.1061 / 40875(212) 40$

Yongdae Lee, Sheung-Kown Kim, and Ick Hwan Ko (2008) Multistage stochastic linear programming model for daily coordinated multi-reservoir operation. Journal of Hydroinformatics 10(1), 23-27

Zadeh LA (1965) Fuzzy sets. Inform control 8, 338-353

Zagona E, Magee T, Goranflo G, Fulp T, Frevert D, Cotter J (2005) RIVERWARE. In Singh $V$ and Frevert D (eds) Watershed Models, CRC Press, Boca Raton, Florida

Zhang J, Xu L, Yu B, Li X (2014). Environmentally feasible potential for hydropower development regarding environmental constraints. Energy Policy. 
ANNEX

Dissemination

works 



\section{ANNEX: Dissemination works}

\section{A.1. Indexed journal articles}

\section{A.1.1. A model for solving the optimal water allocation problem in river basins with network flow programming when introducing non-linearities.}

Haro, D., Paredes, J., Solera, A. and Andreu, J.

(Published in November 2012 in Water Resources Management)

\section{Abstract}

The allocation of water resources between different users is a traditional problem in many river basins. The objective is to obtain the optimal resource distribution 
and the associated circulating flows through the system. Network flow programming is a common technique for solving this problem. This optimisation procedure has been used many times for developing applications for concrete water systems, as well as for developing complete decision support systems. As long as many aspects of a river basin are not purely linear, the study of nonlinearities will also be of great importance in water resources systems optimisation. This paper presents a generalised model for solving the optimal allocation of water resources in schemes where the objectives are minimising the demand deficits, complying with the required flows in the river and storing water in reservoirs. Evaporation from reservoirs and returns from demands are considered, and an iterative methodology is followed to solve these two non-network constraints. The model was applied to the Duero River basin (Spain). Three different network flow algorithms (Out-of-Kilter, RELAX-IV and NETFLO) were used to solve the allocation problem. Certain convergence issues were detected during the iterative process. There is a need to relate the data from the studied systems with the convergence criterion to be able to find the convergence criterion which yields the best results possible without requiring a long calculation time.

Keywords Network Flows, Optimisation Models, Water Allocation, NonLinearities, Water Resources Management

\section{Introduction}

The optimal management and operation of a water resources system involves allocating resources, developing stream flow regulation strategies and operating rules for reservoirs, and making real-time decisions within the guidelines of the operating rules (Wurbs 1993). The objectives of water resources system optimisation are to maximise benefits, minimise costs, and meet the various water demands, subject to the mass balance equation and other related constraints (Rani \& Moreira 2010).

An optimisation problem consists of obtaining the best value (maximum or minimum) of a function formed by the decision variables for the system and the parameters representing the different weights of the decision variables. This function is called the objective function and is the heart of any optimisation technique (Wurbs 1993). However, an optimisation problem does not end with the objective function. In the case 
of water resources systems, the calculation of the best value for the control variables must comply with a series of restrictions such as the mass balance or maximum and minimum flow limitations.

The water allocation problem has the objective of finding the optimal distribution of the water between different users and uses within a river basin or a similar water resources system. This solution can be used later to solve problems such as drought management, defining the operating rules and environmental flows, and conflict resolution. Many Decision Support Systems for basin management are now focused on solving the water allocation problem (Andreu et al. 1996; Labadie et al. 2000; Wurbs 2005; Yates et al. 2005; Perera et al. 2005).

Labadie (2004) and Rani \& Moreira (2010) reviewed the state-ofthe-art regarding the optimisation techniques used for multi-reservoir systems, which represent the majority of water allocation problems. Both authors said that the most favoured technique for water allocation models has been linear programming. This technique has been used for optimising resources management of whole river basin schemes (Zoltay 2010), developing decision support systems for urban water supply areas (Yamout \& El-Fadel 2005), and optimising irrigation water allocation in complex agricultural schemes (Reca et al. 2001a and 2001b). A reservoir system can be represented as a network of nodes and arcs, where nodes are the points of convergence or diversion and links represent reservoir releases, channel flows, carryover storage, and losses (Labadie 2004). Network flow programming is a computationally efficient form of linear programming and, as was shown by Kuczera (1989), is more suitable than linear programming for solving large multi-reservoir multi-period models. This technique has been used for the joint operation of large multi-reservoir systems (Chou et al. 2006), sizing of multiple reservoirs (Khaliquzzaman \& Chander 1997), and elaboration of hydrological plans (MMA 2000). However, as is the case for linear programming, network flow algorithms require that both the objective function and the problem constraints be linear or linearisable. This means that certain important aspects of water resources systems management such as returns from demands, 
evaporation in reservoirs, or infiltration losses that have highly non-linear behaviours cannot be directly considered in the problem formulation. This problem has been dealt with in three ways: (1) the use of generalised network algorithms to handle networks with gains where arc flows may be adjusted with coefficients other than $-1,0$ or +1 , (Harou et al. 2010, Sun et al. 1995 and Hsu \& Cheng 2002); (2) the successive solution of pure network problems with adjustment of the arc parameters until the results converge to the solution (Fredericks et al 1998); and (3) the use of equal flow algorithms to transfer equal or proportional flows in different arcs of the network as in Manca et al (2010).

This article presents a generalised optimisation model to solve the water allocation problem in water resources schemes with network flow programming. The model formulation takes into account evaporation from reservoirs and returns from demands. An iterative resolution process is presented to overcome the introduction of these two non-network constraints. The methodology is applied to the Duero River basin in Spain. Three well known network flow algorithms are used to solve the problem to investigate which gives the best performance and most efficiently finds the solution when used in an iterative optimisation process.

\section{Tools and methods}

Pure reservoir system simulation models reproduce the performance of a water resources system for given hydrological inflows and operating rules. These models are usually based on mass-balance accounting for obtaining the water volumes circulating through the system. Optimisation models determine the values for a set of decision variables that will maximise or minimise an objective function subject to constraints. Many network flow models can also be categorised as being "simulation" models in the sense that they are applied in the same manner as conventional simulation models. This means the problem can be formulated in a way that the operation rules of the system are reflected in the network characteristics, so the results will describe what will happen under those predetermined plans. However, network flow programming 
also allows the development of models with a more prescriptive orientation. Prescriptive models are those which determine the plan that should be adopted to best satisfy the decision criteria (Wurbs 1993). This prescriptive orientation of network flow programming is its most important feature for water resources systems optimisation. The advantage of using network flows for a prescriptive optimisation study is that many of the data are repeated every time interval, simplifying the definition of the network.

\section{Generalised model formulation and network construction}

The model presented in this paper optimises the monthly system management for a period of $\mathrm{N}$ years by minimising the following objective function.

$$
\sum_{t=1}^{N \cdot 12}\left[\sum_{i=1}^{n_{c}} \sum_{j=1}^{n_{i}} \alpha_{i, j} \cdot d_{i, j, t}+\sum_{i=1}^{n_{d}} \sum_{j=1}^{n_{i \cdot}} \beta_{i, j} \cdot d_{i, j, t}^{\prime}\right]-\sum_{i=1}^{n_{r}} \delta_{i} \cdot V_{i, N \cdot 12}
$$

Where:

- $\quad N$ is the number of years in the optimisation period

- $t$ is the number of month within each year

- $n_{c}$ is the number of channels in the system, each with its ecological flow requirement divided into $n_{i}$ levels

- $\quad n_{d}$ is the number of consumptive demands in the system, each of them divided into $n_{i^{\prime}}$ demand levels

- $\quad n_{r}$ is the number of reservoirs in the system

- $\quad \alpha_{i, j}$ is the cost assigned to the deficit $d_{i, j, t}$ of the level $j$ of the ecological requirement in channel $i$ in month $t$

- $\quad B_{i, j}$ is the cost assigned to the deficit $d^{\prime}{ }_{i, j, t}$ of the level $j$ of demand $i$ in month $t$

- $\quad \delta_{i}$ is the benefit assigned to keeping volume $V_{i, N \cdot 12}$ in reservoir $i$ at the end of the optimisation period 
This objective function is linear; the program minimises the weighted sum of the deficits in the ecological flows in channels and in the supply to consumptive demands and maximises the stored volume in reservoirs at the end of each optimisation period.

The weighting factors are defined as:

$$
\begin{aligned}
& \alpha_{i, j}=K_{\alpha}-p_{i} \cdot K 1-j \cdot K 2 \\
& \beta_{i, j}=K_{\beta}-p_{i}^{\prime} \cdot K 3-j \cdot K 4 \\
& \delta_{j}=1+n_{r}-p^{\prime \prime}{ }_{i}
\end{aligned}
$$

where $\mathrm{K}_{\alpha}, \mathrm{K}_{\beta}, \mathrm{K} 1, \mathrm{~K} 2, \mathrm{~K} 3$, and $\mathrm{K} 4$ are user defined constants and $\mathrm{p}_{\mathrm{i}}$, $p_{i}^{\prime}$, and $p^{\prime \prime}{ }_{i}$ are the assigned priorities for each ecological flow, demand and reservoir, respectively.

The optimisation of the previous objective function is subject to the habitual mass balance and flow bound constraints (Ahuja et al 1993).

The construction of the network flow is performed following the work of Kuczera (1993), Braga \& Barbosa (2001) and Sechi \& Zuddas (2007). The network is just a multiplication of the system scheme for the N.12 months comprising the optimisation period. The networks for a given month and the following month are linked by carryover arcs representing the stored volume in reservoirs. An example for a system with two reservoirs in series is given in figure 1.

\section{Introducing non-linear aspects in the network definition.}

Labadie (2004) described a gap between the theoretical developments of optimisation models for reservoir systems and real-world applications. One of the causes of this gap is the simplifications and approximations required to overcome hardware and software limitations. This means that many optimisation models do not completely represent or approximate the reality of the systems modelled, with a consequent lack of 
trust by operators and decision makers. In the case of network flow programming, the linear nature of both the objective function and the constraints makes it difficult to address aspects of the water resources systems that do not have a linear behaviour. This is the case for evaporation from reservoirs and return flows, which are two important aspects to be considered when considering a water allocation problem in a resource system. .

Evaporation is a system loss that can be significant in arid and semiarid climate regions such as in Spain and other South European countries. Evaporation has a larger effect for larger water bodies. Evaporation is of particular importance in planning study models where usually only the main and larger reservoirs in the system are included. Not considering evaporation might yield inaccurate resource allocations with mistakenly increased demands. There are also the return flows from consumptive demands. These flows depend on the water use efficiency at the demand site. This means that, in systems with intensive irrigation demands, an important part of the water allocated to their supply will come back to the system somewhere downstream of the intake point. Not accounting for return flows might therefore suggest a false resource deficiency for downstream uses.

Both evaporation from reservoirs and returns from consumptive demands are considered in the generalised model presented in this article. Also called non-network constraints, the problem with using these constraints is that the flows circulating through some arcs in the network are proportional to the flows circulating through different arcs. This proportionality problem is impossible to solve with a common minimum cost flow algorithm because these types of constraints cannot be considered in the calculation process. Different solutions have been considered in the literature for solving this network flow programming problem including generalised network flow algorithms (Sun 1995, Hsu \& Cheng 2001, and Harou 2010), equal flow algorithms (Manca et al 2010), 
and successive solution of the pure network with arc parameters adjusted until convergence (Fredericks et al 1998, llich 1992).

Successive solution was used for handling these two aspects in the generalised model presented in this article. As seen in Labadie (2004), if few iterations are needed to achieve convergence, this process may be more efficient than the other two approaches because inclusion of non-linear conditions usually carries a computational price. The successive solution procedure also allows consideration of conditions where the associated flows do not have a proportional relation with other flows in the system, such as reservoir and channel seepage or aquifer connections.

A critical examination of the appropriateness of using iterations with network flow algorithms to approximate non-network constraints is provided by llich (2009). That paper concludes that any flow path restrictions that are updated through iterative calls of the network flow solver may fail to deliver reasonable solutions. However, the non-network constraint used as an example in the cited paper was outflow capacity related to reservoir storage. This can be considered an operation rule that is not the type of constraint that would be used in an optimisation model. The iterative process is crucial for obtaining the proper model results, and the definitions of the conditions determine how well the model works..

Each of the two considered non-linear aspects add extra arcs to the network. Evaporation adds one arc per month starting at the node representing the corresponding reservoir each month and ending at the balance node; its lower limit is zero and the upper limit will be changing through the iterative process. A very low flow cost value is given to the arc so that the maximum flow possible circulates through it and decreases the value of the objective function. Return flows will be considered as hydrological inflows. This means one arc per month will be created between the balance node and the return node in the system. Return flow arcs will not affect the objective function. Moreover, several demands can return to the same point in the system. The corresponding return flow values will be summed in these cases and no extra arcs will be created. The 
new arcs are also represented in the multi-period network shown in figure 1.

The flow diagram of the iterative process defined for the generalised model can be seen in figure 2 and works as follows:

- In the first iteration, both evaporation and returns are ignored by setting the upper capacity values of their corresponding arcs to zero and the pure network is solved normally.

- Second, with a first solution of the network, the theoretical evaporation and returns flows are calculated. These values correspond to the evaporation and return values that would occur under the flow conditions calculated in the previous step.

The evaporation for reservoir $i$ is calculated as:

$$
E V_{i, t}=E V R_{i, t} \cdot \frac{S_{i, t-1}+S_{i, t}}{2}
$$

where $E V R_{i, t}$ is the monthly evaporation rate in month $t$ and $\mathrm{S}_{\mathrm{i}, \mathrm{t}-\mathrm{1}}$ and $\mathrm{S}_{\mathrm{i}, \mathrm{t}}$ are the reservoir surface at the beginning and at the end of the month, both calculated from the reservoir surface/volume curve.

Return flow from demand $i$ is calculated as:

$$
R_{i, t}=\alpha_{i} \cdot S_{i, t}
$$

where $\alpha_{i}$ is the return fraction from demand $i$, and $S_{i, t}$ is the supply to demand $i$ in month $t$.

- Third, the resulting values for evaporation and return flows are substituted as the upper limits of their corresponding arcs.

- Finally, the calculated evaporation and return values are compared with the values obtained in the previous iteration. If the difference for every arc is lower than the Convergence Error Value (CEV), the process will stop and the last calculated values will be considered correct. If the convergence criterion is not met on some arc, the program will do another iteration to solve the pure network. 
The most critical aspect of this iterative process is the CEV. The CEV is initially set to 4 and represents a deviation of 0.04 flow units. This value was chosen during model development as it represented a fairly acceptable deviation value; it also worked well during the previous development of similar models. However, the value of the CEV affects the number of iterations as well as how "fine-tuned" the final results are. The relationships among this value, the number of iterations and the results are discussed below.

\section{Solving the minimum cost flow problem}

The network flow problem generated from a water resources scheme can be solved with a conventional linear programming algorithm. However, as has been stated before, the special structure of the network facilitates the use of more efficient algorithms which notably reduce the calculation time and allow studying larger problems with numerous variables and restrictions.

The generalised model presented in this paper allows for optimisation of a water resources scheme with three different, broadly known network flow algorithms: Out-of-Kilter (Ford \& Fulkerson 1962), NETFLO (Kennington \& Helgason 1980), and RELAX-IV (Bersetkas \& Tseng 1994). All three algorithms have been used previously to solve optimisation models for water resources systems (Chung et al. 1989; Kuczera 1993; Andreu et al. 1996; Khaliquzzaman \& Chander 1997; Labadie et al 2000; Labadie 2006).

There are several references comparing the performance of the algorithms. Most of the authors (Bersetkas 1985; Bersetkas \& Tseng 1988 and 1994; Kuczera 1993), agree about the superior performance of algorithms based on the relaxation method such as RELAX-IV and previous implementations. These algorithms usually perform faster by up to one order of magnitude than the other minimum cost flow problem algorithms.

All three algorithms are used in the case study below. This was not for studying the best execution time because that had already been 
studied. Although the time spent performing calculations is important, of more importance are the obtained results. Because each algorithm uses a different methodology to solve the minimum cost flow problem, the optimisation results might differ slightly from one algorithm to another. Thus, the performances of the algorithms are studied from a more "operative point of view", checking whether aspects such as the distribution of storage in reservoirs (when more than one exists) make any of the algorithms more or less appropriate for the water allocation task. Moreover, the performance of the algorithms when working in an iterative manner is checked. As the iterative process changes arc capacities, this can be seen as a sensitivity analysis that will affect the number of iterations given a fixed CEV.

\section{The Duero River case study}

The Duero River basin is a trans-boundary system (figure 3). Of the $97,290 \mathrm{~km}^{2}$ area of the basin, $81 \%\left(78,952 \mathrm{~km}^{2}\right)$ is in Spain and $19 \%(18,338$ $\mathrm{km}^{2}$ ) is in Portugal (CHD, 2008). The climate is continental with a strong Mediterranean character. The mean basin precipitation is approximately $625 \mathrm{~mm} /$ year, resulting in nearly 15,000 million $\mathrm{m}^{3} /$ year of available water in the river and aquifers.

Agriculture in the basin includes unirrigated ( 3.5 million ha) and irrigated ( 0.5 million ha) crops. Irrigation is the largest water consumer in the basin, using $80 \%\left(3,600\right.$ million $\left.\mathrm{m}^{3} / \mathrm{yr}\right)$ of the total volume of water consumed. The installed capacity of hydropower is 4,000 MW with an average production of 7,300 $\mathrm{GWh} / \mathrm{yr}$. The urban water demand in the basin is low, with most of the 2.3 million people living in small towns of 1,0005,000 . To comply with the objectives of supplying agricultural demands and producing energy, the water system has 75 large reservoirs with a total storage capacity of 7,500 million $\mathrm{m}^{3}$. It is divided into 12 subsystems. These subsystems work independently, although complying with management conditions determined by basin policies. 
The Duero River basin authority developed a scheme of the system for both simulation and optimisation purposes. For optimisation tasks, the scheme consists of 37 reservoirs (where evaporation is considered), 169 consumptive demands and 49 return points. The Duero River Basin Authority uses optimisation for different purposes, namely, developing new operation rules, estimating minimum shortages and maximum surpluses for demand increase studies, or studying the possible effects of climate change independently from actual management. Any of these purposes can be easily achieved with the presented model because its decision variables and constraints are oriented to these goals.

Each of optimisation purposes usually has a different modelling time horizon, For example, development of new operation rules requires optimisation over long time periods so regression can be applied afterwards, while shortages-surpluses studies are performed for a one or two year time horizon. The optimisation period depends very much on the system and the size of its reservoirs. A system with large reservoirs, usually of hyper annual operation, will need longer optimisation periods, while systems with small reservoirs that are only suited for fulfilling annual demands will use shorter periods. For the study presented in this paper optimisation time horizons of one, five, and ten years were used. . By doing this it could be shown how the model would perform for some of the different purposes explained before. One year would represent the most immediate operational management of the system; five years would be for short term planning, e.g. demands change; and ten year or longer periods would be used for long-term strategic planning and studying the impact of climate change.

\section{Results and discussion}

All the runs were performed using an Intel ${ }^{\circledR}$ Core $^{\mathrm{TM}} 2$ Duo CPU E7400 @ $2.80 \mathrm{GHz} 2.80 \mathrm{GHz}$ and $1.74 \mathrm{~GB}$ RAM. Table 1 shows a summary of the characteristics and results of the model runs performed for the Duero River system. 
It was easy to predict based on the literature that Relax-IV would outperform the other two algorithms because it is approximately 30 times faster than Out-of-Kilter and approximately twice as fast as NETFLO. It was also easy to predict that larger networks would shower larger differences in execution times. However, table 1 shows that there are some small differences in the final objective function values and large differences in the number of iterations between the algorithms.

The value of the objective function in the first iteration, when there is no flow through arcs associated with nonlinearity, is the same for all three algorithms. The differences in the final value of the objective function are mainly due to the evaporation process and the high cost assigned to evaporation arcs to force that flow through them. The explanation of this effect is as follows. First, when the network is generated, the associated cost for water storage is the same for all reservoirs because the objective is to obtain the best operation of the system. Second, water resource systems are complex systems and most of the time the optimum value of the objective function will not correspond to a single point in the feasible solution space but to a hyper plane in which the objective function has the same value at all points. Finally, each of the algorithms has a different optimum search technique. Therefore, it is possible that, for the same complete flow distribution in the system, the individual storage in some reservoirs is different depending on the algorithm used. Because each reservoir has a different evaporation rate, the calculated evaporation may then also differ depending on the algorithm, which in turn affects the value of the objective function. Table 1 shows how the differences are more noticeable for longer optimisation periods and that the NETFLO algorithm has larger differences with respect to the other two. This might be explained because Out-of-Kilter and RelaxIV have similar search methodologies that are different from NETFLO, with NETFLO being in the simplex method family, while the other two are in the dual ascent methods family.

Despite the differences in the number of iterations, only the Out-ofKilter algorithm was able to converge to a solution in a small number of 
iterations. The other two algorithms were not able to reach convergence after more than 100 iterations. The objective function in these cases looped between two different values as shown in figure 4 for the case of one year optimisation. As has been stated previously, the convergence criterion is that the iterations must stop when the difference between the flow value at every non-linear arc and the new calculated flow value is lower than a certain value of CEV, as seen in figure 2. Depending on the system, the value set as a default CEV might be too low. It must also be taken into account that the optimum of the system will generally not be unique, leading the algorithm to continue yielding similar solutions that are never close enough to meet the convergence criterion, while the value of the objective function oscillates around a central value.

The effect on the results from modifying the convergence criterion was examined. The value of the CEV was gradually increased to determine whether the number of iterations was reduced and if that affected the final results. Figure 5 shows how increasing the value of the CEV reduces the number of iterations before convergence is reached with the RELAX-IV algorithm. This result is expected. What is more interesting is that the reduction in the number of iterations is not gradual but instead happens in steps. For values of CEV ranging from 4 to 8 , the number of iterations is larger than 200. For CEV values of 9 and 10, the number of iterations performed is reduced to 157; and, for CEV values equal to 11 or higher, the algorithm only needs 3 iterations to reach convergence. The same procedure was performed with the NETFLO algorithm, and the number of iterations was reduced from more than 200 to only 3 for a CEV equal to 15.

Table 2 shows the results of one year optimisation period runs after completing the iterations required for different values of the CEV. As expected, the results for different CEV values do not differ very much from each other. These suggest that the size of the system will directly affect the convergence criteria and will permit defining less restrictive criteria for the larger the systems. This is a logical result because there is less concern about small variations in the numbers with large-scale systems while 
smaller systems will require more detailed results. The length of the optimisation period will also affect the choice of the convergence criteria.

A frequent modelling question is whether it is better to have very detailed, precise results that require a large amount of computation time, or to have a less detailed results that are more immediately available. The response to this question is that it depends on the situation. For a small system with a short time horizon, a more detailed and time-consuming analysis will be necessary, which means an algorithm that is less sensitive to small changes in the problem, e.g. Out-of-Kilter, should be used. Out-ofKilter has been demonstrated to be a quick converging/less sensitive algorithm than the other two and thus it should be used when calculation time is not a constraint. . The similarity of the results for differing numbers of iterations and values of the convergence criteria suggests the possibility of simply stopping the iterative process after several cycles. By doing this, large systems with long optimisation periods could be solved in relatively short calculation times at the cost of having less fine-tuned results. It would be necessary to determine the point where the objective function starts oscillating and define a rule for stopping given the risk of not having reached pseudo-convergence.

Future research on the ideas suggested in this paper should involve trying the same process in several different systems so that similar patterns can be found and the general rules can be defined. The authors of this article are working on introducing new non-network constraints such as aquifers into the optimisation process. These additions should be included in a future convergence study of network flow algorithms.

\section{Conclusions}

Proper operation of a water resources system is crucial to maximising the benefits that can be obtained from the use of water. A good, proven efficient method to define the appropriate operating rules for a system is optimisation. The evident similarities between a water resources scheme and a network flow model make using this numerical 
method a fast and easy way for representing and calculating the flows through the system. However, the linear nature of this methodology is problematic when aspects of the water system possess a non-linear behaviour.

In this article, we have presented a network flow-based optimisation model for water resources schemes which considers two nonlinear aspects by solving the network iteratively. The model was applied to the Duero River basin to show its performance at different optimisation time horizons. Three different network flow algorithms were used to solve the network problem and to study their performance when confronting an iterative process. As previous studies had already confirmed, RELAX-IV is actually the fastest algorithm for solving the single network problem. However, we detected that it has some problems finding a convergent solution when the network is slightly changed due to iterations. A less time efficient algorithm such as Out-of-Kilter proved more robust for this same task.

The convergence criteria defined for the iterative process strongly influences the number of iterations as well as the results. The modellers then have to decide whether to obtain less accurate results quickly or to wait longer to ensure convergence. An intermediate step that has been proposed is stopping the iterative process once it starts looping between two solutions. In the cases shown, the results did not differ much from each other. Nevertheless, each system studied in the future should be studied from the point of view of convergence. This means finding the convergence criterion which yields the best possible results without a long calculation time. We have given some ideas in this respect, but further investigation is needed to establish more concrete rules to relate the data of the system with the convergence criteria.

\section{Acknowledgements}

We thank the Spanish Ministry of Economy and Competitivity (Comisión Interministerial de Ciencia y Tecnología, CICYT) for funding the projects 
INTEGRAME (contract CGL2009-11798) and SCARCE (program Consolider-Ingenio 2010, project CSD2009-00065). We also thank the European Commission (Directorate-General for Research \& Innovation) for funding the project DROUGHTR\&SPI (program FP7-ENV-2011, project 282769). And last, but not least, to the Fundación Instituto Euromediterráneo del Agua with the project "Estudio de Adaptaciones varias del modelo de optimización de gestiones de recursos hídricos Optiges".

\section{References}

Ahuja R, Magnanti T, Orlin J (1993) Network Flows: theory, algorithms and applications. Prentice Hall, New York

Andreu J, Capilla J, Sanchís E (1996) AQUATOOL, a generalized decision-support system for water resources planning and operational management. J Hydrol 177, 269-291

Bazaraa M, Jarvis J (1977) Linear Programming and Network Flows. John Wiley and Sons Inc, New York

Bersetkas D (1985) A unified framework for primal-dual methods in minimum cost network flows problems. Math Program 32, 125-145

Bersetkas D, Tseng P (1988) The relax codes for linear minimum cost network flow problems. Ann of Oper Res 13, 125-190

Bersetkas D , Tseng P (1994) RELAX-IV: A Faster Version of the RELAX Code for Solving Minimum Cost Flow Problems. Completion Report under NSFGrant CCR9103804. Dept. of Electrical Engineering and Computer Science, MIT, Boston

Bersetkas D (1998) Network Optimization. Continuous and discrete models. Athena Scientific, Belmont

Celeste A,Billib M (2010) The Role of Spill and Evaporation in Reservoir Optimization Models. Water Resour Manag 24, 617-628

Chou F, Wu C, Lin C (2006) Simulating Multi-Reservoir Operation Rules by Network Flow Model. ASCE Conf. Proc. 212, 33 
Chung F, Archer M, DeVries J (1989) Network Flow Algorithm Applied to California Aqueduct Simulation. J Water Resour Plan Manag 115, 131-147

Ford L, Fulkerson D (1962) Flows in networks. Princeton University Press, Princeton

Fredericks J, Labadie J, Altenhofen J (1998) Decision Support System for conjunctive Stream-Aquifer Management. J Water Resour Plan Manag 124, 69-78

Harou JJ, Medellín-Azuara J, Zhu T et al (2010) Economic consequences of optimized water management for a prolonged, severe drought in California. Water Resour Res 46, W05522

Ilich N (2009) Limitations of Network Flow algorithms in River Basin Modeling. J Water Resour Plan Manag 135, 48-55

Kennington JL, Helgason RV (1980) Algorithms for Network Programming. John Wiley and Sons, New York

Khaliquzzaman, Chander S (1997) Network Flow Programming Model for Multireservoir Sizing. J Water Resour Plan Manag 123, 15-21

Klingman D, Napier A, Stutz J (1974) NETGEN - A program for Generating Large Scale (Un) Capacited Assignment, Transportation, and Minimum Cost Flow Problems. Manag Sci 20, 814-822

Kuczera G (1993) Network Linear Programming Codes for Water-Supply Headworks Modeling. J Water Resour Plan Manag 119, 412-417

Labadie J, Baldo M, Larson R (2000) MODSIM: Decision support system for river basin management. Documentation and user manual. Dept. Of Civil Engineering, CSU, Fort Collins

Labadie J (2004) Optimal Operation of Multireservoir Systems:State-of-the-Art Review. J Water Resour Plan Manag 130, 93-111.

Labadie J (2006) MODSIM: River basin management decision support system. In: Singh W, Frevert D (eds) Watershed Models, CRC, Boca Raton, pp 569-592

MMA (2000) Libro blanco del agua en España. Ministerio de Medio Ambiente, Secretaría general Técnica, Centro de Publicaciones 
MMA (2008) Confederación Hidrográfica del Duero. Memoria 2008. http://www.chduero.es/Inicio/Publicaciones/tabid/159/Default.aspx. Last accessed 25 June 2012

Perera B, James B, Kularathna M (2005) computer software tool REALM for sustainable water allocation and management. J Environ Manag 77, 291-300

Rani D, Moreira M (2010) Simulation-Optimization Modeling: A Survey and Potential Application in Reservoir Systems Operation. Water Resour Manag 24, 1107-1138

Reca J, Roldán J, Alcaide M, López R, Camacho E (2001a) Optimisation model for water allocation in deficit irrigation systems I. Description of the model. Agric Water Manag 48, 103-116

Reca J, Roldán J, Alcaide M, López R, Camacho E (2001b) Optimisation model for water allocation in deficit irrigation systems II. Application to the Bembézar irrigation system. Agric Water Manag 48, 117-132

Sabet H, Creel C (1991a) Network Flow Modeling of Oroville Complex. J Water Resour Plan Manag 117, 301-320

Sabet H, Creel C (1991b) Model Aggregation ffor California state Water Project. J Water Resour Plan Manag 117, 549-565

Sechi G, Zuddas P. (2008) Multiperiod Hypergraph Models for Water Systems Optimization. Water Resour Manag 22, 307-320

Wurbs R (1993) Reservoir-System Simulation and Optimization Models. J Water Resour Plan Manag 119, 455-472

Wurbs R (2005) Modeling river/reservoir system management, water allocation, and supply reliability. J Hydrol 300, 100-113

Yamout G, El-Fadel M (2005) An Optimization Approach for Multi-Sectoral Water Supply Management in the Greater Beirut Area. Water Resour Manag 19, 791-812

Yates D, Sieber J, Purkey D, Hubert-Lee A (2005) WEAP21 - A Demand-, Priority-, and Preference-Driven Water Planning Model. Part 1: Model Characteristics. Water Int 30, 487-500. 
Zoltay V, Vogel R, Kirshen P, Westphal K (2010) Integrated Watershed Management Modeling: Generic Optimization Model Applied to the Ipswich River Basin. J Water Resour Plan Manag 136, 566-575

Table 1 Optimization runs characteristics and results

\begin{tabular}{|c|c|c|c|}
\hline $\begin{array}{r}\text { Optimization Horizon } \\
\text { (years) }\end{array}$ & 1 & 5 & 10 \\
\hline \multicolumn{4}{|l|}{ Size of the network } \\
\hline \multirow[t]{2}{*}{ Arcs } & 17 & 89 & 17 \\
\hline & 965 & 101 & 8021 \\
\hline \multirow[t]{2}{*}{ Nodes } & 69 & 34 & 68 \\
\hline & 56 & 220 & 300 \\
\hline \multirow[t]{2}{*}{ Non-Linear Arcs } & 10 & 51 & 10 \\
\hline & 32 & 60 & 320 \\
\hline \multicolumn{4}{|l|}{$\begin{array}{r}\text { Average time per } \\
\text { iteration (s) }\end{array}$} \\
\hline \multirow[t]{2}{*}{ OOK } & 3.0 & 13 & 67 \\
\hline & 89 & 0.187 & 8.919 \\
\hline \multirow[t]{2}{*}{ RLX-IV } & 0.1 & 5.2 & 22. \\
\hline & 84 & 21 & 571 \\
\hline \multirow[t]{2}{*}{ NF } & 0.5 & 11. & 44. \\
\hline & 49 & 212 & 35 \\
\hline \multicolumn{4}{|l|}{ Number of Iterations } \\
\hline OOK & 3 & 7 & 7 \\
\hline \multirow[t]{2}{*}{ RLX-IV } & $>1$ & $>1$ & $>1$ \\
\hline & 00 & 00 & 00 \\
\hline \multirow[t]{2}{*}{ NF } & $>1$ & $>1$ & $>1$ \\
\hline & 00 & 00 & 00 \\
\hline \multicolumn{4}{|l|}{ Objective function } \\
\hline \multirow[t]{2}{*}{ OOK } & - & - & - \\
\hline & $7.204 \cdot 10^{9}$ & $3.555 \cdot 10^{9}$ & $7.126 \cdot 10^{9}$ \\
\hline \multirow[t]{2}{*}{ RLX-IV } & - & - & - \\
\hline & $7.205 \cdot 10^{9}$ & $3.554 \cdot 10^{9}$ & $7.125 \cdot 10^{9}$ \\
\hline \multirow[t]{2}{*}{ NF } & - & - & - \\
\hline & $7.205 \cdot 10^{9}$ & $3.562 \cdot 10^{9}$ & $7.139 \cdot 10^{9}$ \\
\hline
\end{tabular}


Table 2 Total flow values for one year optimization period using different CEV values

\begin{tabular}{|c|c|c|c|c|c|}
\hline & $\begin{array}{r}00 \\
K(C E V=4)\end{array}$ & $\begin{array}{l}\text { RLX- } \\
\text { IV (CEV=4) }\end{array}$ & $\begin{array}{l}\text { RLX-IV } \\
(\mathrm{CEV}=11)\end{array}$ & $\begin{array}{l}\text { NF } \\
(C E V=4)\end{array}$ & $\begin{array}{r}\mathrm{NF} \\
(\mathrm{CEV}=15)\end{array}$ \\
\hline Evaporation $\left(\mathrm{Mm}^{3}\right)$ & $97^{247 .}$ & $4^{247.5}$ & 248.04 & $7.86^{24}$ & $.04^{248}$ \\
\hline $\begin{array}{l}\text { Return } \\
\text { flows }\left(\mathrm{Mm}^{3}\right)\end{array}$ & $4.26^{110}$ & 31 & $9^{1104.2}$ & $05.03^{11}$ & $5.03^{110}$ \\
\hline$\left(\mathrm{Mm}^{3}\right)^{\text {Shortages }}$ & $66^{627 .}$ & $6^{627.6}$ & 627.66 & $7.63^{62}$ & $.63^{627}$ \\
\hline $\begin{array}{l}\text { Objective } \\
\text { Function }\end{array}$ & $7.204 \cdot 10^{-}$ & $7.205 \cdot 10^{9}$ & $7.198 \cdot 10^{9}$ & $7.205 \cdot 10^{-}$ & $7.202 \cdot 10^{-}$ \\
\hline
\end{tabular}

Fig. 1 Example system of two reservoirs and two demands with its associated multiperiod network flow scheme

Drawn with Microsoft Visio
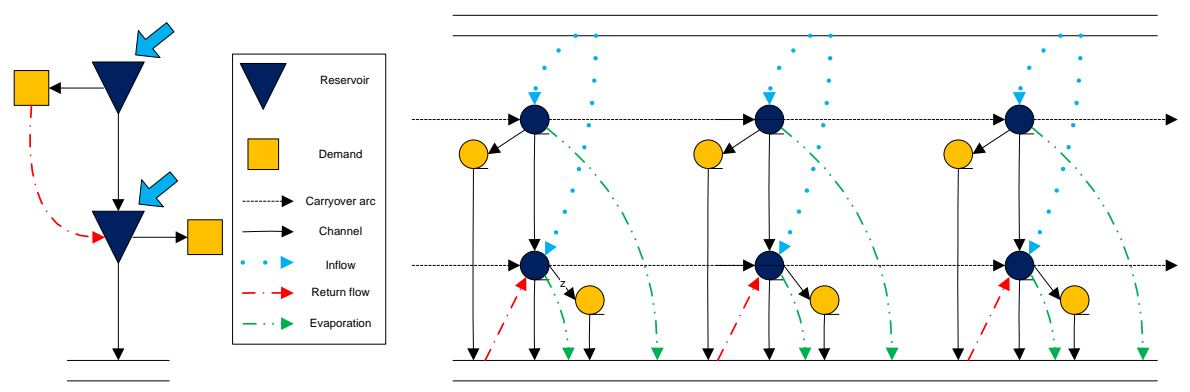
Fig. 2 Flow graph of the iterative process in the optimization model

Drawn with Inkscape




Fig. 3 River Duero basin territory

Provided by CHD, created with INKSCAPE

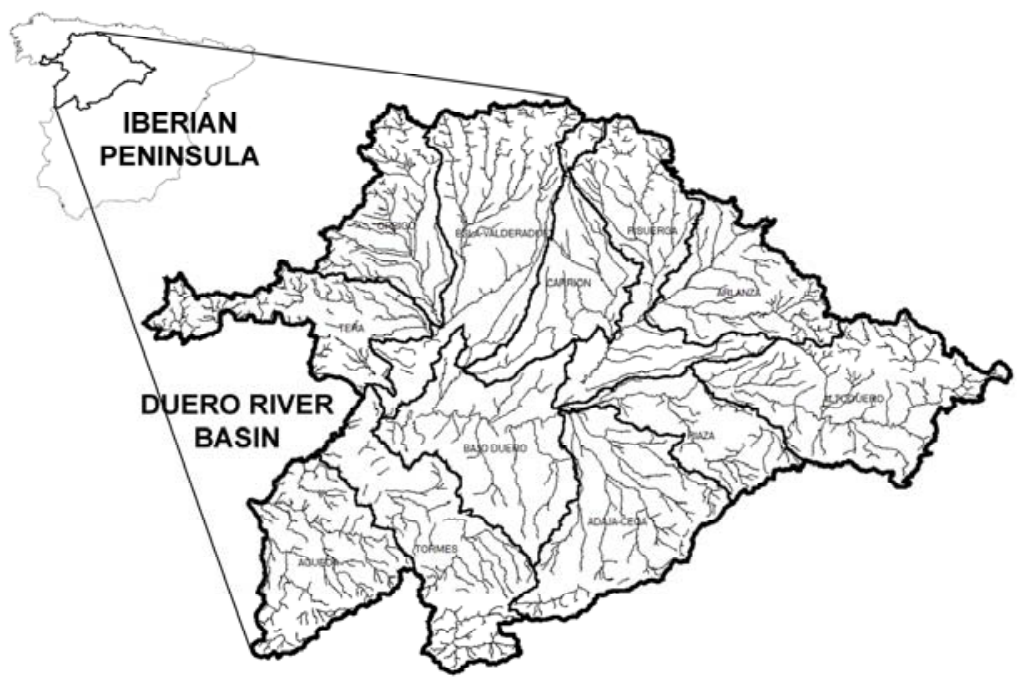

Fig. 4 Value of the objective function through iterations 2 to 10 for one year optimization period with $\mathrm{CEV}=4$

Drawn with MS Office

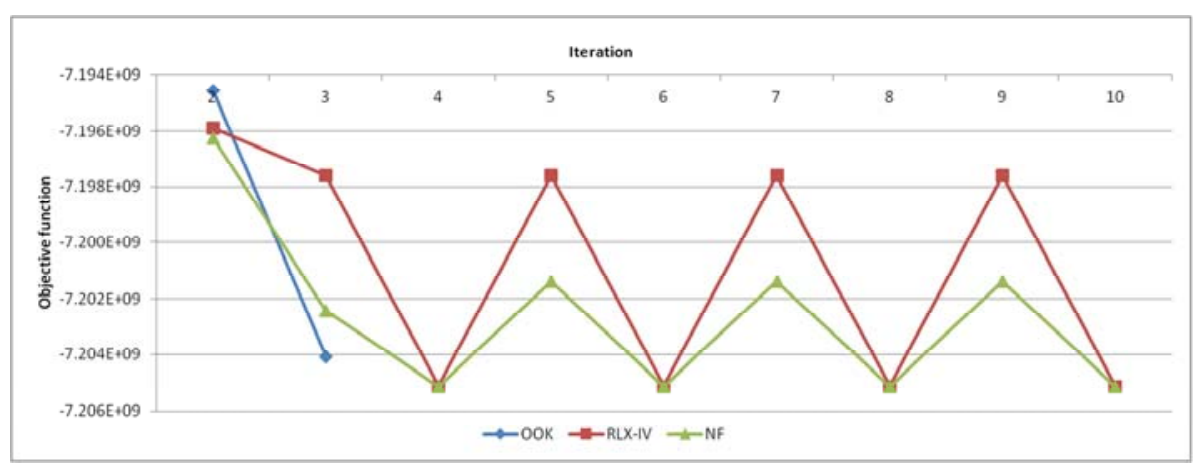


Fig. 5 Value of the convergence criterion and number of iterations needed to reach convergence.

Drawn with MS Office

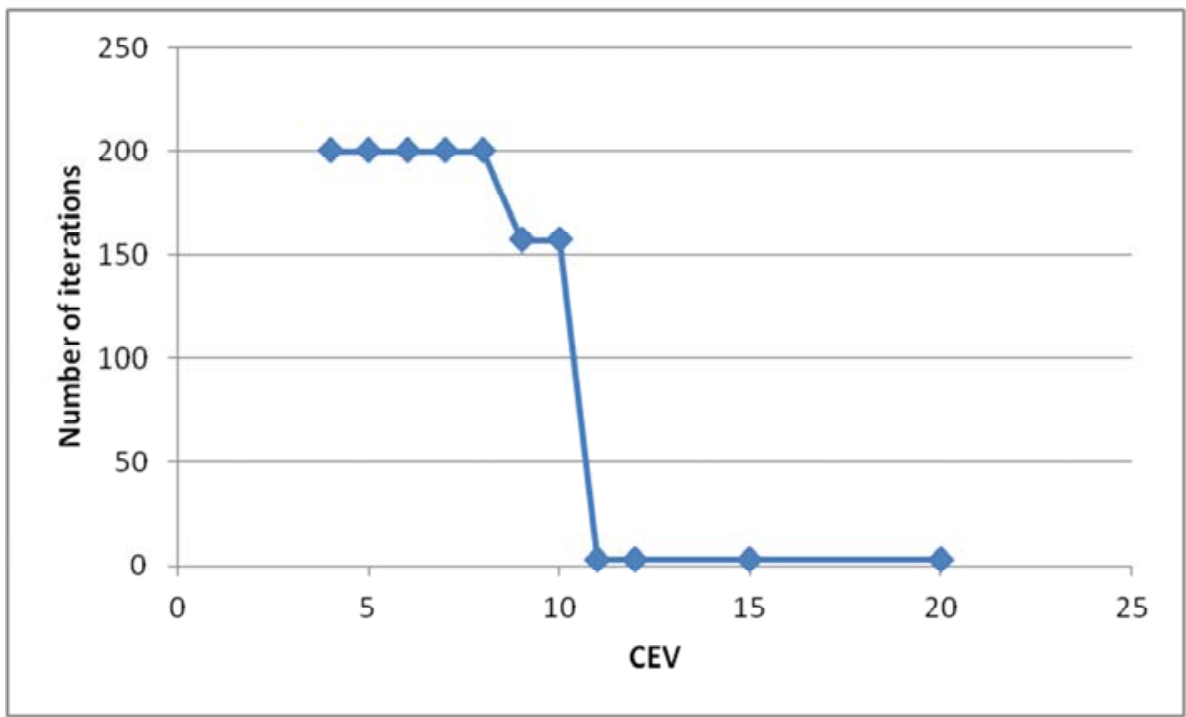

\section{A.1.2. Methodology for Drought Risk Assessment in Within-year Regulated Reservoir Systems. Application to the Orbigo River System (Spain)}

David Haro - Abel Solera - Javier Paredes- Joaquín Andreu

(Published in September 2014 in Water Resources Management)

Abstract: Drought occurrence and its related impacts are a major concern in many river basins throughout the world. In the last years, drought management procedures have moved from a crisis approach towards a more sensitive preparedness approach. Drought plans development has arisen as an effective way of providing measures and actions to manage drought situations. However, due to each river basin has 
different operation characteristics, drought management requires a different approach in order to be efficient. Decision support tools are a great ally of water managers, especially in situations of high water stress and hydrologic uncertainty, allowing them to in-deep analyze the system and finding the best measures to minimize the risk of a system failure. This paper studies the difficulties of only using an indicator system based in current and past data to assess the drought risk in within-year regulated reservoir systems. It proposes the complementary use of a general risk assessment methodology to anticipate the future probable status of the system and defining the current drought scenario. It shows how the complementary use of a monitoring system and a risk assessment decision support system may improve the drought detection process allowing water managers optimizing the selection of mitigation measures and minimizing the probability of overreaction during a drought situation.

Keywords: drought; water resources systems management; risk assessment; decision support system; stochastic multi-scenario analysis

\section{Introduction}

In recent decades, intense drought events have been observed on all continents with high economic and social costs (Mishra and Singh 2010). Drought forecasting is still a complex task (Bordi and Sutera 2007), and intensity and duration of future droughts remain unknown until the episode has finished. Water managers confront severe uncertainties within the decision making process, both in the short term (management and operation) and long term (planning), in any water resources system where droughts are very frequent and where water resources are under a massive use.

Because of the difficulty at detecting drought episodes occurrence, and forecasting their intensity and duration, the traditional responses to drought have been reactive, adapting the measures to the severity of impacts as long as they were detected in what is called a crisis management. This approach is ineffective, poorly coordinated, and untimely; and does little to reduce the risk associated with drought (Wilhite 
et al. 2000). Because of this, drought management has evolved in recent years towards a more risk-preventive approach. Drought planning must predict what is predictable and establish strategies of prevention and management of the growing drought risks generated within the current climate change dynamics (Arrojo 2007). To reduce drought risk, there must be an understanding of the hazard using climatology, improved operational monitoring, an analysis of vulnerability to understand what people and sectors may be most affected by drought, why these impacts occur, and if these relationships are changing over time (Hayes et al. 2004). This new risk management based approach to drought management has been expressed in the necessity of developing drought management plans (Wilhite et al. 1996, EC 2000) that provide a dynamic framework for an ongoing set of actions to prepare for, and effectively respond to drought, including periodic reviews of the achievements and priorities; readjustments of goals, means and resources; as well as strengthening institutional arrangements, planning, and policy-making mechanisms for drought mitigation.

Drought planning requires preliminary identification and analysis of the risks associated to the occurrence of this natural phenomenon. Additionally, the mitigation measures within a drought prevention strategy need a study within the context of the system so the managers select the ones that yield best cost/effectiveness relation. To carry out these tasks, software tools efficiently integrated within a decision support system (DSS) are of great help in order to enhance the capabilities of decision makers (Rossi et al 2006). The use of such systems allows developing and using real time management models able to assess the risk of drought, and the effectiveness of proactive and reactive measures applied on regular basis for the management of river basins (Andreu et al. 2009). DSSs also permit the monitoring of drought by evaluating the different indicators and drought indices defined for the studied river basin. Additionally, they represent a powerful tool for participatory processes since, as seen in Wilhite et al. (2000), the different stakeholders involved in drought planning have a chance to develop and understanding of one another's various points of view, and to generate collaborative solutions. A DSS is the common platform that the different stakeholders can use to show their 
proposals and understand how these would affect the rest of the participants. The whole modeling process especially when all the interested parties collaborate in its development helps building common knowledge and shared vision on the system.

The use of monitoring systems and calculation of drought indices and indicators help water managers defining risk scenarios. The entrance of a system in each of those scenarios will activate different measures addressed to minimize the possibilities of entering a worse scenario and minimizing the possible effects of the current situation. However, this approach may not work as well as expected in water resources systems subject to strong seasonal operation schemes such as within-year reservoir systems. In these cases, relying on the status of the system to start making decisions towards the future of the river basin may result in unnecessary over reaction.

This paper studies the problems for assessing drought risk in withinyear operated river basins and how that affects the drought management process, especially due to the high seasonality. We propose complementing the common used methodology, particularized for within-year regulated reservoir systems, with the use of future risk results obtained by simulating the future behavior of the system in a Monte Carlo approach with multiple equiprobable streamflow series with different anticipation periods. We will show the advantages of including the real management of the system in a seasonal approach to assess drought risk under uncertain hydrology conditions instead of a month-to-month approach that does not include it. We apply the proposed method to the Orbigo River basin in Spain.

\section{Materials and methods}

\section{The Orbigo River basin (Spain)}

The Orbigo River is a tributary of Esla River at the north-west of the Iberian Peninsula, traversing the provinces of Leon and Zamora, both in the region of Castilla y Leon (figure 1). The total surface drained by this river is of about $5,000 \mathrm{~km}^{2}$, being its length of $162 \mathrm{~km}$. Average precipitation within 
the basin is of $725 \mathrm{~mm}$ per year and the average potential ETP is $755 \mathrm{~mm}$ per year. Average natural flow is $1,576 \mathrm{hm}^{3}$ per year composed approximately by surface and groundwater flow in almost the same proportion. Reservoirs in the system have a total regulation capacity circa $373.6 \mathrm{hm}^{3}$ being the two most important the Barrios de Luna and Villameca reservoirs, both at the headwaters of the system. Demands reach approximately $466 \mathrm{hm}^{3}$ per year representing irrigation demand $96.5 \%$ of it. The hydroelectricity production represents a small amount.

As can be perceived, in the case of the Orbigo River, the regulation capacity is quite lower than the amount of resources available, and even lower than the total demand of the system. Reservoirs in the system have an important role in flood prevention and lamination during the rainy seasons in autumn and spring, as well as resource suppliers in the more dry months of summer. This makes reservoirs often are empty at the end of the summer and are full again for the irrigation season in a within-year regulation cycle. In the last times, the Orbigo River basin has suffered several dry spells. In 1988-1989, irrigation was put to a second plane to ensure urban water supply. Year 1998-1999 was an extremely dry year but a good water distribution saved the irrigation campaign. Finally, in 20012002, irrigation campaign had to finish in August due to a bad management of the system.

\section{Current drought monitoring and risk assessment methodology}

Behavior differences of over-year and within-year regulated river basins make necessary using different points of view when approaching management and planning under normal conditions. In the same way, drought situations management should be approached differently too. Failing at detecting and determining the start of a drought episode does not have the same consequences in one kind of system or another. Within-year systems require more immediacy and accuracy because of the rapid changes within them, while over-year systems may allow some delay if conditions are not extremely bad. 
The anticipation in the application of mitigation measures becomes an essential tool for the reduction of socio-economic and environmental impacts of droughts; that is why having a complete indicator system that allows calling an early alert of these extreme events and activate in advance the program of measures established for these emergency situations is crucial (Estrela \& Vargas 2012). An indicator system for a river basin is formed by a series of variables that describe the basin drought status and include reservoir storages, groundwater piezometric levels, streamflows, reservoir inflows and precipitation. The different values taken by the indicator define the drought status and degree of severity. Different monitoring systems were developed worldwide in recent times. Rossi and Cancelliere (2013) and Tsakiris et al (2013) make extensive reviews of the approaches and different methodologies for drought monitoring and risk assessment.

For the case studied, drought plans in Spain establish four different levels of drought: normality, pre-alert, alert and emergency (MMA 2007). These levels are determined according to the monitoring system established at each river basin. The monitoring system has a hydrologic character since its practical interest lays on its ability to serve as decisionmaking instrument regarding water resources management in the basin. For each river basin, managers select the indicators that better represent the water resources offer for the different demand units existing in the basin. These indicators must reflect the resources availability in a homogeneous way and thus, these are selected among reservoirs storage, piezometric levels, natural streamflows and areal precipitation. The drought levels in the basin are defined as the weighted sum of the State Index $\left(\mathrm{I}_{\mathrm{e}}\right)$ values of each of the selected indicators.

The value of the State Index $\left(\mathrm{I}_{\mathrm{e}}\right)$ has the following expression:

$$
\text { If } V_{i} \geq V_{a v} \rightarrow I_{e}=\frac{1}{2} \cdot\left[1+\frac{V_{i}-V_{a v}}{V_{\max }-V_{a v}}\right]
$$




$$
\text { If } V_{i}<V_{a v} \rightarrow I_{e}=\frac{1}{2} \cdot \frac{V_{i}-V_{\min }}{V_{a v}-V_{\min }}
$$

with $V_{i}$ the value of the indicator in the month I; $V_{a v}$ the average value of the indicator in the historic series considered; and $V_{\max }$ and $V_{\min }$ the maximum and minimum values of the indicator in the historic series considered.

The definition of the State Index considers the following criteria:

Arithmetic average is a robust statistic, as well as simple; so a comparison of the indicator value with the average of the historic series considered will adjust better to the real situation of the selected drought region. Although, it is necessary to take into account the maximum and the minimum historic values.

It is necessary to homogenize indicators in a dimensionless numeric value capable of quantifying the current situation with respect to the historic, and a quantitative comparison between the different indicators selected.

The thresholds that define the different levels of the drought status of the system normally are:

$$
\begin{array}{ll}
\text { Normality (green): } & l_{\mathrm{e}} \geq 0.5 \\
\text { Pre-alert (yellow): } & 0.5>\left.\right|_{\mathrm{e}} \geq 0.3 \\
\text { Alert (orange): } & 0.3>\left.\right|_{\mathrm{e}} \geq 0.1 \\
\text { Emergency (red): } & 0.1>\left.\right|_{\mathrm{e}}
\end{array}
$$

For the Orbigo River basin, the state index is calculated as the weighted sum of the volume stored at the largest reservoir (Barrios de Luna, $w=0.9$ ) and the inflows to the second largest (Villameca, $w=0.1$ ) in the Orbigo River basin. Figure 2a shows the evolution of $\mathrm{l}_{\mathrm{e}}$ from October 1996 to September 2010. It is possible to observe how the drought status varies several times within the same year, going from normality to almost 
emergency and back. It is also easy to appreciate that most of the alert and emergency situations occur by the end of the hydrologic year, something that is logic since the operational management of this basin requires the reservoirs to be empty by that time of the year. Therefore, there is an evident difficulty at determining when such a system is in a drought situation from the value of its indicator due to the high seasonality of the system. We recalculated the State Index by using the monthly average, maximum and minimum values for each different month instead of the values of the whole time series (figure $2 \mathrm{~b}$ ). It is easy to appreciate that there is a clear difference between normality and drought periods while they remain at the same periods of time as detected originally (1998/99 and 2001/02). At the same time, drought periods that were less evident (2005/06 and 2007/09) now reveal as important events. Anyway, despite it is easier to discern between normality and drought periods, the change from one scenario to another still occurs very quickly to detect the development of a serious drought event in time. Therefore, in the case of systems where seasonality plays an important role in their management, it will be necessary to have additional tools to determine drought risk more accurately.

\section{The SIMRISK methodology}

Following a preventive approach in drought management requires advancing, to a certain extent, the possible impacts a drought episode may have on the water resources system. To do this it is necessary both forecasting drought characteristics and assessing their effects on the system. For the first part, there are a series of methodologies that have shown their capabilities in the last years: regression, time series analysis, probability models, artificial neural networks and hybrid models. Mishra and Singh (2011) present a more detailed discussion on these techniques. With regard to the second aspect, the forecasted characteristics of future drought events can feed a decision support system that allows assessing the possible effects of future events, for example by optimizing the 
definition of risk indicators (Rossi et al 2012) or assessing the vulnerability of the system (Preziosi et al 2013).

SIMRISK is a generalist methodology that analyses the actual management of a complex water resources systems, anticipates the risk of having problems with future resources availability and allows evaluating and justifying the most appropriate mitigation measures. SIMRISK was initially developed in Sanchez-Quispe (1999) and Sanchez-Quispe et al (2001), and it is implemented in the decision support system shell AQUATOOL (Andreu et al. 1996). Cancelliere et al (2009) also propose a similar methodology.

The analysis process is based in the Monte-Carlo method and consists of generating multiple, future, probable, natural streamflow scenarios for a determined anticipation period, and simulating the system management for each of them according to the objectives and supply criteria decided previously. Each of the simulations will yield different results with regard to the system operation, namely supplies, shortages, reservoir withdrawals, aquifer extractions, environmental flow compliance and hydropower generation. All these results are treated statistically to obtain the risk level at which the system may be in the following months.

Figure 3 shows a scheme that summarizes the methodology in which, starting from the current situation of the system, the decision makers can obtain information about the risks assumed for the future as a consequence of the operation of the system. If the risk level obtained by the actual management of the system cannot be assumed, management alternatives can be studied with the methodology obtaining new risk levels in an iterative process.

\section{Water Resources System management simulation model}

SIMRISK requires information about the status, objectives and a physical definition of the analysed system. The storage levels in reservoirs and aquifers, as well as recent natural streamflow measurements, define the status of the system. The objectives are the demand supplies proposed 
for the following campaigns (one or more, depending on the anticipation period defined) and the reliability accepted for them. Finally, a management simulation model gives the physical description. The model should be capable of representing the real operation of the system with as much detail as possible. The model selected for the implementation of the methodology is SIMGES (Andreu et al. 2007).

SIMGES allows developing simulation models of complex water resources systems in which the user can define regulation and storage elements both superficial and subterranean, water transportation elements either river reaches or manmade, consumptive or non-consumptive demand elements, and withdrawal elements from both surface and groundwater. The model simulates water management at a monthly timescale according to user defined operation rules. Minimum environmental flows can be defined as well as different users priorities for water supply and more complex operation rules. The model calculates the monthly management by translating the system scheme to a network flow in which the solution algorithm determines the circulating flows with an objective function that minimises demands and environmental flows deficits and maximises water storage and hydroelectric production requirements. The results of the model include the evolution of all the relevant variables in monthly and annual level, average values for the whole simulation period as well as the reliability of supply.

\section{Stochastic model for future streamflow series generation}

Using SIMRISK requires a high number of streamflow series that are equiprobable with the historic one. It is thus necessary calibrating and validating some kind of stochastic model from which is possible to generate as many synthetic series as necessary to carry out the analysis process. For the case study of the Orbigo River basin, an autoregressive model of first order, $A R(1)$, resulted enough to generate series that preserved the statistic characteristics of the historic series.

We generate series under a conditioned basis, utilizing as initial values the observed streamflows in the months prior to the generation of 
the synthetic series. The length of the synthetic series will depend, again, on the characteristics of the river basin modeled. However, since conditioned generated series tend to become homogeneous after a certain amount of generations, the most interesting length to analyze will normally be either one or two campaigns in one run. Anyway, the methodology is developed to be used as a complement of the drought monitoring system existing at the basin. Thus, generation of series should be done once a month. In addition, revising the stochastic models to adapt them to possible hydrologic changes is a task that should be done every few years.

\section{Statistic treatment of management results}

The model aggregates the results of the Monte-Carlo simulations of the system with the several generated synthetic series. This aggregation provides probability distributions for reservoirs storage; shortages at consumptive demands; aquifers extractions; and status of drought monitoring indicators. Managers can use these results assess the risk of the basin to be in a drought situation given the current management and the possible effects it would have on the system. This will help the decision makers drawing the different alternatives of management to minimize possible impacts. With this methodology, it is also possible to analyze new management alternatives or mitigation measures to select the most effective ones at reducing the risk.

The methodology is an interesting tool to use with and by stakeholders during public participation processes addressed to find the best management practices for drought risk minimization as seen in Andreu et al (2009).

Application to within-year operated systems (case of the Orbigo River)

As seen before, the use of monthly updated state index as a mean to detect developing drought episodes in water resources systems with a high seasonality is not completely effective for the means of preventive management. In first place, because it is not possible to compare storage 
values in reservoirs from one month to another due to the quick fluctuations introduced by the system operation. Normally, the storage levels at the beginning of the irrigation campaign, right after spring rainy season, will have nothing to do with the values at the beginning of autumn, in which reservoirs are usually empty both because of the use of stored water for supply during summer and as flood prevention. Second, the historic data to calculate the state index in reservoirs is very heterogeneous since they contain the variation in time of infrastructures and demands. These conditions are very likely to change in the future. Finally, the risk in within-year systems is mainly determined by the inflows to reservoirs during the winter and spring seasons. Since the summer and autumn are periods in which reservoirs normally keep low storage levels because of operational and protection issues, the failure in the system will be more likely to happen if there have been a series of dry months during the winter and spring, that are the months in which water is stored. Therefore, a low state index during the months in which the system is supposed to present low storage levels is not representative for the risk assessment in future months.

Given the limitations of defining the risk of drought in within-year operated system with an indicators system, the risk assessment methodology presented above results an excellent complement to the drought management process. It contains the current situation of demands and infrastructures together with recent data of storage levels and hydrological inflows. This means that all the information, processed separately in the calculation of the system state index, is considered together and it is also possible to include updated information regarding near future management information, while the indicator assumes that management is always going to be similar to the previous one. The results obtained are a straightforward lecture of possible future results that, in the end, is what matters to water managers and allows them to make decisions. The risk assessment methodology perfectly integrates the high seasonality of data since the multiple simulations contain that same variability. However, a long-term prediction will always be less reliable than 
a short-term one, although results evaluation can consider this fact when necessary.

Regarding the definition of the drought scenario existing in the water resources system, current drought indicator systems measure the severity of future drought with regard the conditions in the date of observation. However, this measured severity is going to be different if the observation is done in winter (before the rain season and after the irrigation one), than if it is done by the end of spring or the beginning of summer (the chances of future precipitation are low and the need of water is high). If we do a risk calculation for the coming summer during the previous autumn in a within-year operated system such as the Orbigo River, the risk perception will be low. This is due to the probability that a month with high precipitation occurs and changes the whole prediction. Under this assumption, we cannot classify a failure forecast with an anticipation period higher than 6 months as an emergency, but maybe as an alert. Consequently, drought scenarios definition should be according to two factors: risk of failure and anticipation period.

In order to show the usefulness of the SIMRISK methodology regarding drought risk anticipation and effectiveness of measures, we analyzed 24 different scenarios. The scenarios are a combination of initial month of simulations (October, January, April and July); initial storage levels at the basin reservoirs (low and medium); and previous hydrologic conditions (average, dry and minimum). Average hydrologic conditions use as initial streamflows the average streamflow calculated from the historic series; dry conditions correspond to half of previous average conditions; and minimum conditions use as initial inflow the lowest record in the historic series. Each of the scenarios contains 10,000 different synthetic series that span for three consecutive campaigns. The reason to simulate such amount of series is capturing in the probabilistic results all, or the most, of their variability.

\section{Results and discussion}


Regarding the efficiency of the monitoring system, figure 4 shows, for the scenario starting October with low reservoir levels and average hydrologic conditions, the evolution of the system State Index along the three campaigns simulated with the SIMRISK calculated with the complete historic series values as the drought plan proposes (a) and with the alternative month-to-month calculation method (b). Each of the lines corresponds to the values of the state index with a certain probability of non-exceedance. In this way, the lighter blue lines represent the state index values evolution that were not be exceeded the $99 \%$ of the times in the 10000 simulations, and so on until the darker blue line that represents the $10 \%$ probability of non-exceedance. From figure $4 a$, it is possible to observe that the indicator system proposed by the drought plan does not really allow anticipating whether there is a risk of suffering a drought situation since, during the months before the beginning of the irrigation campaign (May), most of the probabilities fall under the normality scenario. Additionally, during the irrigation campaign the state index value drops very quick and makes that the end of the campaign appears to be always in a severe risk of drought. Since within-year systems normally end the hydrologic year with low reservoir levels, an indicator system that takes into account all the values of the historic series will always show an important risk of being in a drought situation. However, if the possible values of the state index are calculated by comparing the indicator values obtained only with the values corresponding to that particular month (figure $4 \mathrm{~b}$ ), it is possible to obtain a better probability distribution in which one can observe that there is a possibility to be in a risk situation even though the storage levels are high. This points out the fact that low state index values do not necessarily mean a high risk of a prolonged drought situation in all cases, especially in within-year operated systems, but there is a need for improved monitoring systems. We can also appreciate from the graph that the longer the simulation period is, the more homogeneous are the results. This is due to the tendency to homogeneity of the synthetic series used, and is a characteristic of ARMA models. This makes this methodology a very interesting tool to analyze systems especially up to one 
year or one year and a half in advance, which are the time periods normally considered in management.

Unlike the indicators system, that supplies a single state index value according to the current conditions, SIMRISK provides a probability distribution of the state index value several months in advance. Therefore, the definition of the current drought scenario combining both approaches requires a more detailed analysis. As stated in the previous section, we must take into account both risk level and anticipation period to define the drought scenario when using the SIMRISK methodology. In first place, there will normally be a level of risk, below which the system managers will not want to be. This level either can be determined from the analysis of historic situation or agreed between all the stakeholders of the system, although it will usually be a mix of both by means of participatory processes. As an initial rule of thumb, the historic distribution at the end of the campaign is a good indicator of what is normal in the system. All the graphs in figure 5 incorporate that historic distribution for comparison with the risk assessment results. The moment of the year selected to analyze the risk situation is the end of the hydrologic year, which coincides with the end of the irrigation campaign. Normally, a situation of normality at this stage will mean that the campaign ended without supply problems. Values below normality will show that there were from minor to larger problems during the previous months. In the case of the Orbigo River basin, it is possible to observe that historic operation of the system has resulted in situations at the end of the campaign below normality the $65 \%$ of the times, below prealert the $36 \%$ of the times, and below alert, thus in emergency situation, the $13.5 \%$ of the times. On average, the system usually has reached the end of the hydrologic year in a situation of pre-alert (a value of the state index of 0.4 for the $50 \%$ probability). We can consider a good thing that the risk assessment shows an average risk level within the limits of the pre-alert scenario at the end of the campaign. If the average risk level is above, it will represent a very good situation and, if it is below it will be necessary to consider a change in the drought scenario. 
On the other hand, we can also consider the anticipation period as a very important factor for the definition of drought scenarios in the system. On this regard, the graphs in figure 5 show the possible status of the basin by the end of the first campaign from four different anticipation periods. As discussed in the previous section, assessing the risk level at the beginning of the hydrologic year does not really allow deriving whether there is a real risk of suffering a severe drought situation. Figure 5a shows that all the scenarios almost match each other and the historic distribution despite initial storage levels and previous hydrological conditions and, in all cases, the $50 \%$ probability risk level falls within the pre-alert scenario boundaries. When observing figure $5 \mathrm{~b}$, for an anticipation period of 9 months, it is already possible to think that there may be some issues by the end of the campaign. However, at that particular moment, only the autumn rains have occurred and it is still possible that spring precipitations change the results. In the case of an anticipation period of 6 months, figure 5c, there are little possibilities of additional inflows to the basin until the end of the campaign but there will be a drastically increase of water use from that moment. The resulting risk levels are already a good measure of the possible situation of the basin at the end of the campaign. It is possible to see that only in the case of medium storage levels and average previous hydrologic conditions the risk is within acceptable levels. This may alert water managers to start taking actions to bring the risk level back to acceptable values with enough time for these measures to be effective. Finally, figure $5 d$ shows what the real risk level will be by the end of the campaign since the three months of the analysis period correspond to the drier and most water intensive use months of the hydrologic year. In addition, by looking at the different graphs in figure 5 , it is possible to appreciate that initial conditions, storage level and hydrologic conditions, play an important role in the final risk level results, although with different effects. None of them has importance for a 12 months anticipation period. Previous hydrologic conditions play an important role in the midterm (figure $5 b$ and $5 c$ ) since the most of the streamflow generates in autumn and spring. In the short term (figure $5 \mathrm{~d}$ ), the most important aspect is the 
initial storage level in reservoirs, especially because there is almost no streamflow generation during the summer.

Therefore, according to what we showed in previous paragraphs, a simple scenario definition method for the Orbigo River system could be as following: If the anticipation period is six or less months, the drought scenario will correspond to the scenario in which the average risk level falls by the end of the campaign. Otherwise, if anticipation period is higher than six months, the drought scenario will correspond to the scenario above the one in which the average risk level falls by the end of the campaign. This means, if we detect an alert scenario with an anticipation period of 6 months, the measures to activate will be the corresponding to that same scenario in the drought plan. However, if that same alert scenario is the result of a 9 months anticipation period, then the measures to activate will correspond to the pre-alert scenario. Anyway, once we define the drought scenario, we can use the same methodology to assess the risk level with the existing management rules to evaluate the changes introduced by the mitigation measures. In this way, it is possible to select the best measures for each case and their optimal intensity.

\section{Conclusions}

A proper drought preventive system management requires anticipating the possible effects that one episode may have on the system. However, this task reveals to be easy to say but harder to do. First, because of the high degree of uncertainty existing in future hydrological variables prediction. And second, because of the high risk of over reacting if the timing for mitigation measures activation is wrong, generating so-called artificial droughts. On this regard, drought plans supply tools to water managers to effectively handle scarce resources situations and preparing for future events. Anyway, the different operation strategies followed in different water resources systems make that the tools that reveal to be useful for some systems are not that effective in others.

This paper shows the difficulties of monitoring systems used in current drought plans to properly anticipating drought risk in within-year 
operated systems due to their high seasonality. The monitoring system currently used does not anticipate the real risk of suffering a severe drought event in many cases. This paper proposes the use of a risk assessment methodology to complement the indicator system so the management of the basin is included in the drought status definition. We show that it is possible to define the current drought scenario by evaluating the possible future status of the system with different anticipation periods. We applied the proposed methodology to the Orbigo River basin, a within-year operated system in the Iberian Peninsula.

The application of the proposed methodology, considering different anticipation times, improves the determination of the current drought scenario including the real management of the basin and not only hydrologic variables normally considered in monitoring systems. Finally, the methodology presented also permits assessing the efficacy of the mitigation measures proposed by calculating new risk levels obtained from their application.

\section{Acknowledgements}

The authors want to thank the Spanish Ministry of Economy and Competitivity (ComisiónInterministerial de Ciencia y Tecnología, CICYT) for funding the projects INTEGRAME (contract CGL2009-11798), NUTEGES (VI Plan Nacional de I+D+i 2008-2011, CGL2012-34978) and SCARCE (program Consolider-Ingenio 2010, project CSD2009-00065). Also thanks to the European Commission (Directorate-General for Research \& Innovation) for funding the projects DROUGHT-R\&SPI (program FP7-ENV-2011, project 282769) and ENHANCE (program FP7-ENV-2012, project 308438). Last but not least to the Confederación Hidrográfica del Duero for providing the data and support to build the models.

\section{References}


Andreu J, Capilla J, Sanchis E (1996) AQUATOOL a generalized decision support system for water resources planning and operational management. J Hydrol 117; 269-291

Andreu J, Solera A, Capilla J, Ferrer J (2007) Modelo SIMGES para simulación de cuencas. Manual de usuario v3.00. ISBN 978-84-8363-170-6, Editorial Universidad Politécnica de Valencia, Valencia

Andreu J, Ferrer-Polo J, Mérez MA, Solera A (2009) "Decision Support system for Drought Planning and Management in the Jucar River Basin, Spain", In 18th World IMACS Congress and MODSIM09 International Congress on Modelling and Simulation. Anderssen RS, Braddock RD and NewhamLTH (Edt) ISBN 978-0-9758400-7-8, Modelling and Simulation Society of Australia and New Zealand and International Association for Mathematics and Computers in Simulation, 2377-2383, July 2009

Arrojo Agudo P (2007) "Bases para un documento de directrices en material de prevención y gestión de sequías en la planificación hidrológica", In: La sequía en España. Directricesparaminimizarsuimpacto.Cabrera $E$ and BabianoL (Edt.), ISBN 978-84-690-7328-5, Ministry of Environment of Spain, chapter 1, 29-49, 2007

Bordi I, Sutera A (2007) "Drought monitoring and forecasting at large scale", In Methods and tools for drought analysis and management.Rossi G, Vega T and Bonaccorso B (Edt.), ISBN 978-1-40205923-0, Springer, Dordrecht, Chapter 1, 3-27

Cancelliere A, Nicolosi V, Rossi G (2009) "Assessment of Drought Risk in Water Supply Systems" in Coping with Drought Risk in Agriculture and Water Supply Systems. Adv Nat Technol Haz 26, 93-109

EC, 2000, Directive 2000/60/EC of theEuropeanParliament and of the Council of 23 October 2000 establishing a frameworkforCommunityaction in thefield of waterpolicy. Official Journal of the European Communities, L327/1 
Estrela T, Vargas E, 2012, Drought Management Plans in theEuropeanUnion. The Case of Spain. Water Resour Manag 26, 1537-1553

García-Ruiz JM, López-Moreno JI, Vicente-Serrano SM, LasantaMartínez

\author{
$\mathrm{T}$, \\ Beguería
}

(2011) Mediterranean water resources in a global change scenario.Earth Sci Rev 105; 121-139

Hayes MJ, Wilhelmi OV, Knutson CL (2004) Reducing Drought Risk: Bridging Theory and Practise. Nat Hazards Rev 5; 106-113

Labadie J (2004) Optimal operation of multi-reservoir systems: state of the art review. J Water Resour Plan Manag 130; 93-111

Mishra AK, Singh VP (2010) A review of drought concepts. J Hydrol 391, 202-216

Mishra AK, Singh VP (2011) Drought modeling - A review. J Hydrol 403, 157-175

MMA, 2007, Plan especial de actuacion en situaciones de alerta y eventual sequia. ConfederacionHidrografica del Duero, Ministerio de MedioAmbiente, Gobierno de España

Preziosi E, Del Bon A, Romano E, Petrangeli AB, Casadei S (2013) Vulnerability to drought of a complex water supply system. The Upper Tiber Basin case study (Central Italy). Water Resour Manag 27, 4655-4678

Rossi G, Cancelliere A, Giuliano G (2006) "Role of decision support system and multicriteria methods for the assessment of drought mitigation measures", In Drought Management and Planning for Water Resources. Andreu J, Rossi G, Vagliasindi F and Vela A (edt.), ISBN 1-56670-672-6, CRC Press (Taylor \& Francis), Boca Raton, Chapter 9, 203-240

Rossi G, Caporali E, Garrote L (2012) Definition of risk indicators for reservoirs management optimization. Water Resour Manag 26, 981-996 
Rossi G, Cancelliere A (2013) Managing drought risk in wter supply systems in Europe: a review. Int J Water Resour D 29, 272-289

Sánchez-Quispe S (1999) Gestión de Sistemas de Recursos Hídricos con Toma de Decisión Basada en Riesgo. Tesis Doctoral. Universidad Politécnica de Valencia

Sánchez-Quispe S, Andreu J, Solera A (2001) Gestión de Recursos Hídricos con Decisiones Basadas en Estimación del Riesgo. Universidad Politécnica de Valencia

Tsakiris G, Nalbantis I, Vangelis H, Verbeiren B, Huysmans M, Tychon B, Jacquemin I, Canters F, Vanderhaegen S, Engelen G, Poelmans L, De Becker P, Batelaan O (2013) A system-based paradigm of drought analysis for operational management. Water Resour Manag 27, 5281-5297

Wilhite DA, 1996, A MethodologyforDroughtPreparedness. Nat Hazards 13, 229-252

Wilhite D, Hayes MJ, Knutson C, Helm Smith K (2000) Plannign for drought: Moving from crisis to risk management. J Am Water Resour As 26, 697-710 


\section{Figures}

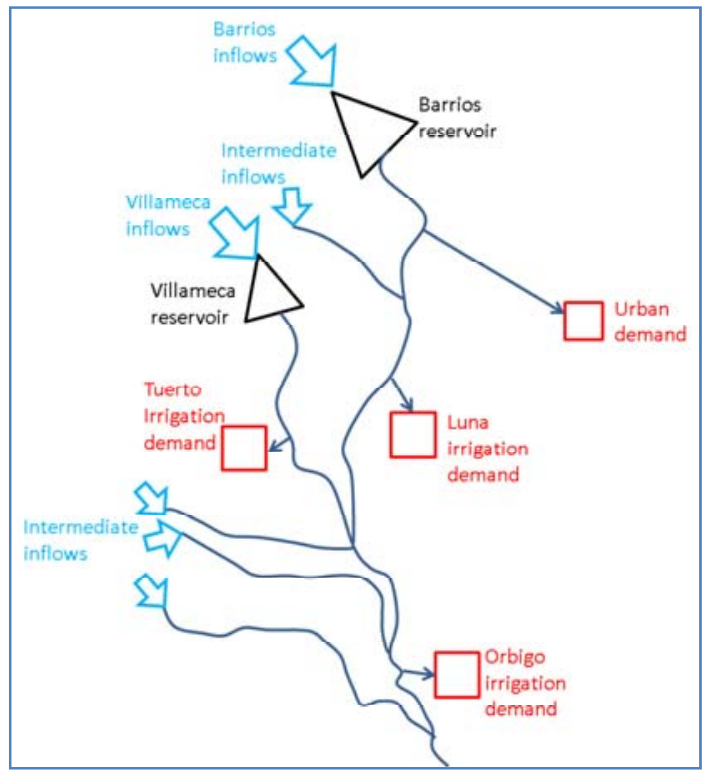

Figure 1. Scheme view of the Orbigo River basin 
State Index for Orbigo River basin for the period 1996/97 to 2009/10

a) Current methodology

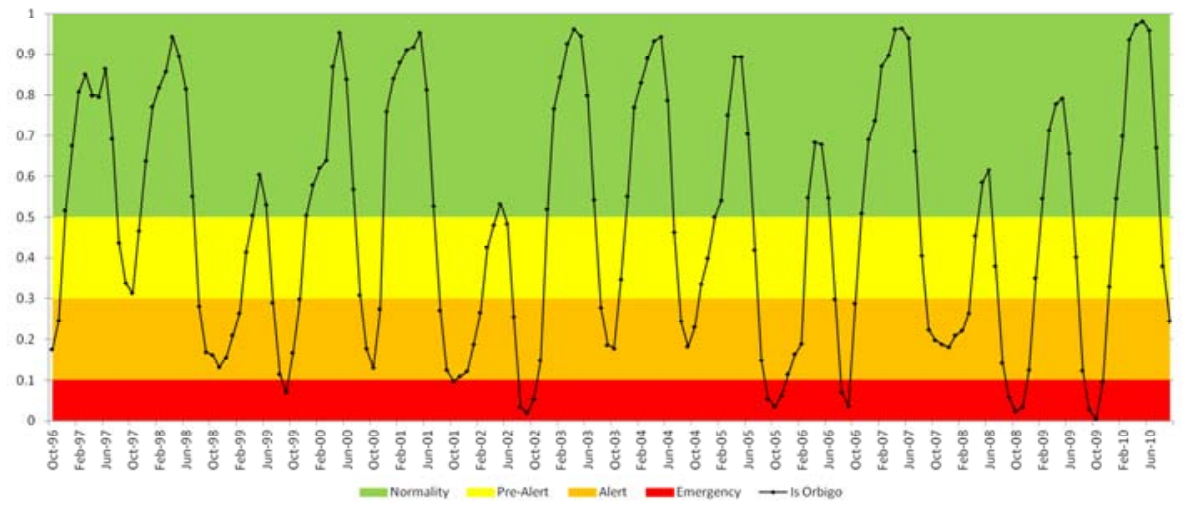

b) Recalculated



Figure 2. State Index for Orbigo River basin for the period 1996/97 to $2009 / 10$ calculated with the current methodology (a) or with the modified one (b) 


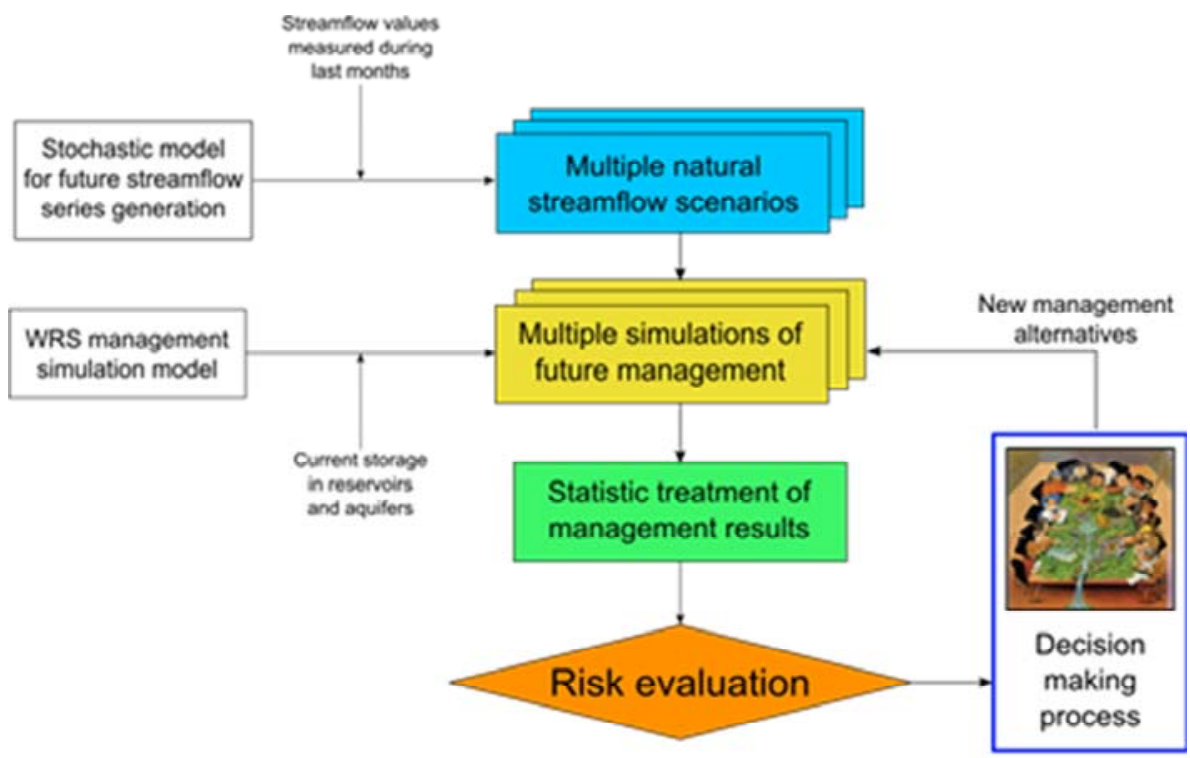

Figure 3. Scheme of the workflow using the SIMRISK methodology 
Probable State Index value evolution

a) Complete time series values
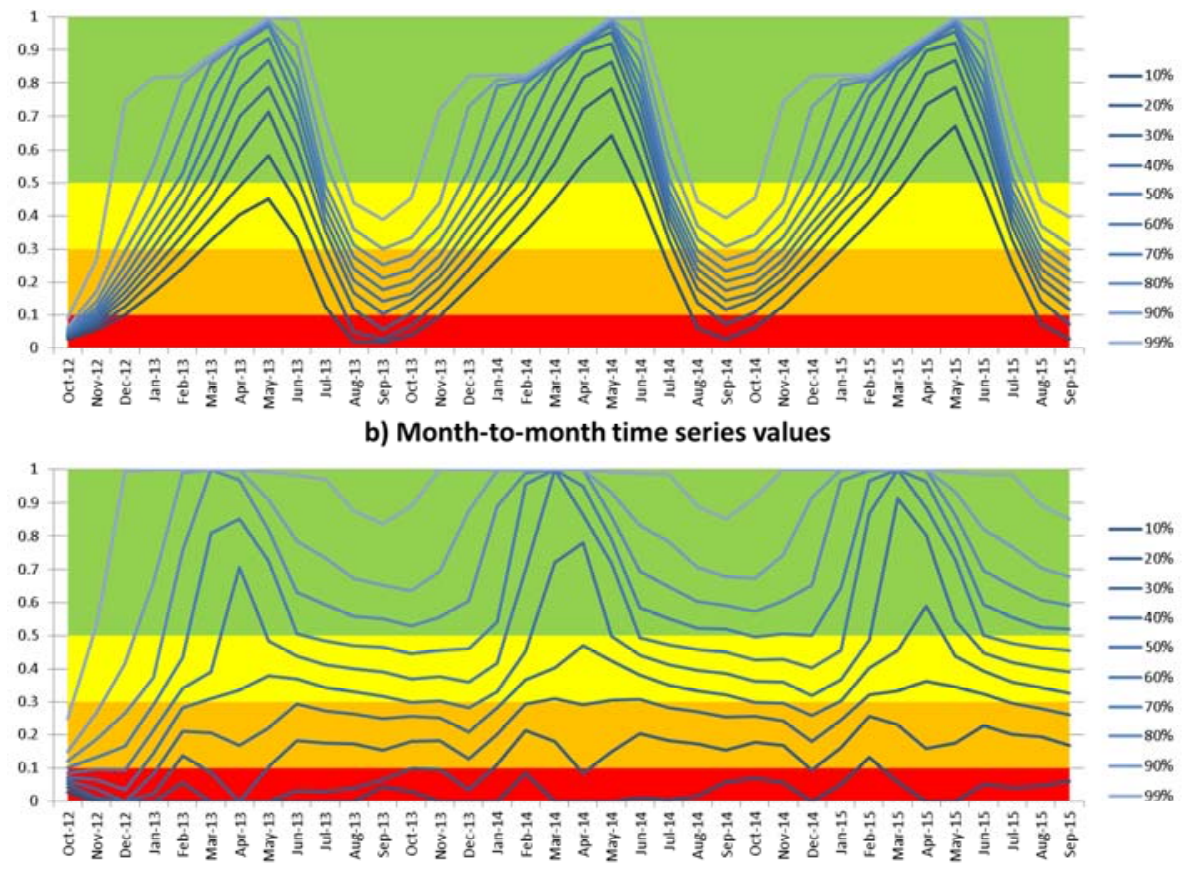

Figure 4. State Index evolution along the three campaigns calculated with the whole time series values (a) and with month-to-month values (b) 
a) End of first campaign 12 months

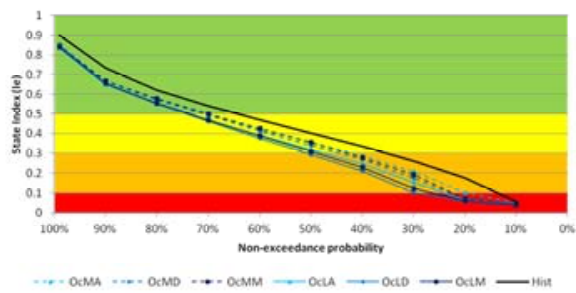

b) End of first campaign 9 months

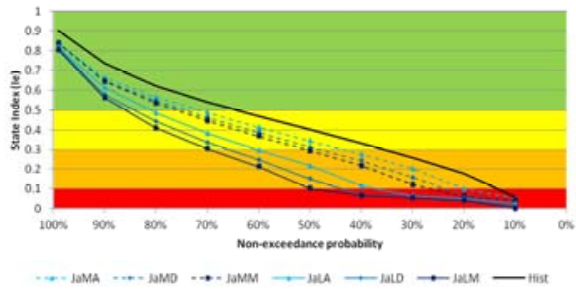

c) End of first campaign 6 months

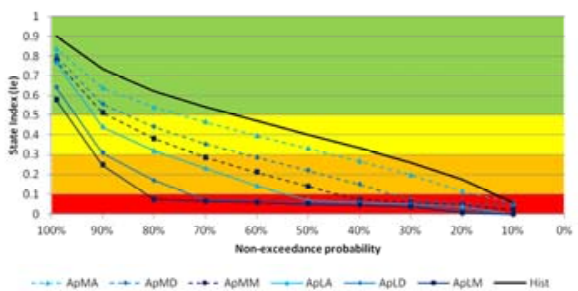

d) End of first campaign 3 months



Figure 5. Probability distributions of state index values at the end of the first campaign (September) for four different anticipation periods

\section{A.2. Participation in conferences}

\section{A.2.1. Incorporating aquifer modeling into a multi- period network flow programming optimization model for water resources management}

Haro D., Solera A., Paredes J., Andreu J.

(Proceedings and Oral communication at HIC 2012, Hamburg)

Aquifers provide a very important source of water in river basins under great surface water stress, and conjunctive use represents sometimes the only way of supplying all the different demands within the basin in drought periods. On the other hand, optimization models help decision makers to depict the operations which should be done in a water resources system in order to maximize the benefits and minimize the costs while keeping a certain supply level and complying with some other constrains. Therefore, including aquifers modeling, and all their surrounding aspects, in a river basin optimization model does not only increase the 
representation of the model itself but also offers the possibility of studying the optimal pumping rules in a similar way as other operation rules are dealt with via the pumping control parameters. This article presents the development and integration of a groundwater module in an already existing water resources optimization model based in network flow programming. Network flow programming is an efficient form of linear programming, hence incorporating aquifer modeling that is a highly nonlinear process supposes a big challenge. Moreover, in order to consider aquifers in a river basin model always implies considering as well some other non-linear related aspects such as seepage from reservoirs, river bed and irrigation schemes, additional pumping and pumping from demands, natural and artificial recharge, and water exchanges between river and aquifer, all aspects that must be incorporated to the network flow in form of new arcs and nodes and be dealt with in the optimization process. All these non-linearities have been approximated through iterations which have shown to be sufficient to yield proficient results in the example cases carried out during the development process. As an addition, different aquifer models have been considered so future modelers can choose among them one that better fits their needs.

\section{INTRODUCTION}

Management of natural resources, one of which is water, is a very important activity in the actual world. Availability and quality of water determine, among other important aspects of quality of life and economy, public health levels and agricultural, industrial and energy production. Inside management, planning is one of the most critical tasks.

Hydrological planning is a legal requirement established with the general objectives of achieving the good status and adequate protection of water masses inside a river basin, fulfillment of water demands and equilibrium and harmonization of regional and sectorial development. These objectives must be achieved increasing water availability, protecting its quality, and economizing its use, rationalizing it in harmony with environment and other natural resources. 
For these objectives attainment, hydrological planning will employ sustainability criteria in the use of water through integrated management and protection to the long term of resources, preventing water state deterioration, improvement of aquatic ecosystems and reduction of pollution. Likewise, hydrological planning should contribute mitigating the effects of floods and droughts.

The development of models which help reaching a higher comprehension of a water resources system and its operation is a common practice in the planning process which serves of great help for the achievement of the objectives previously stated while respecting the imposed criteria. Moreover, system modeling provides a way, perhaps the main one, to predict the future behavior of the system or its possible modifications (Loucks[1]). Water resources systems modeling implies the development of a mathematical or computational framework for describing a particular system and its operation to study, identify and evaluate all the possible solutions to the existing problems in that very system.

When facing a hydrological planning problem, the most usual is having one or more objectives to accomplish under various efficiency measures, or manners of evaluating the achievement of the objectives. Normally, there will be a limited amount of resource and a series of water uses which will compete for it, besides all the different restrictions both physical and environmental. Under this perspective, a water manager will want to know what will be the optimal flow distribution throughout the system so the benefits for water use are maximized while costs are minimized, and all the demands are properly supplied. This problem is usually called "water allocation problem", and the path to follow will involve defining several alternatives and the form of evaluating each of them to finally decide which one of them will be the chosen one. At this point is where an optimization model comes to play to solve the problem.

An optimization model obtains the optimal values of the control variables defined for a certain system (a water resources system in this case), which usually are the circulating flows in it. To do this, the 
optimization model will obtain the best value (maximum or minimum) of a function which components represent both the control variables and the different weight parameters for them, while respecting a series of restrictions limiting the values selection of the control variables. However, as the mathematical optimization process is usually quite complex, optimization models have had a tendency to make important simplifications of the systems studied, what have made them less detailed than the more extended simulation models and therefore less utilized by water managers (Labadie [2]). On the other hand, continuous advances in computing techniques and computing speeds have made that complex mathematical processes, even though are still laborious, can be solved in less and less time. This makes possible to include more complexities in previous simplistic optimization models so they reach a higher degree of representation, what in the end will make their results closer to real systems.

This paper shows how aquifers, a high complexity element inside many water resources systems, have been introduced in the optimization process of a prescriptive model running under network flow programming.

\section{GROUNDWATER IN WATER RESOURCES OPTIMIZATION MODELS}

Global groundwater volume stored beneath the Earth's surface represents 96 percent of the Earth's unfrozen freshwater (Shiklomanov [3]). Groundwater provides useful functions and services to humans and the environment. It feeds springs and streams, supports wetlands, maintains land surface stability in areas of unstable ground, and acts as an overall critical water resource serving our water needs.

IGRAC (International Groundwater Resources Assessment Centre) estimates that about 60 percent of withdrawn groundwater is used to support agriculture in arid and semi-arid climates [4]. Morris et al. [5] report that groundwater systems globally provide 25 to 40 percent of the world's drinking water. Today, half the world's megacities and hundreds of other major cities on all continents rely upon or make significant use of groundwater. Small towns and rural communities particularly rely on it for 
domestic supplies. Even where groundwater provides lower percentages of total water used, it still can serve local areas with relatively low-cost goodquality water where no other accessible supply exists. Finally, groundwater can bridge water supply gaps during long dry seasons and during droughts.

Therefore, aquifers suppose a very important element in water resources planning and management of many river basins. Thanks to aquifers it is possible to supply, or give additional supply, of numerous demands, being agricultural demands the most favored, especially in surface water scarcity periods during which thanks to groundwater pumping many crops can be saved. However, indiscriminate pumping may result in aquifer overexploitation, what would later create several problems for future pumping supply, in rivers connected to the aquifer, and even in zones far from them. Because these reasons, including aquifers in the optimization process should be mandatory when the groundwater utilization in the studied water resources system has certain significance. Doing this would be beneficial allowing, for example, operation rules for pumping from demands or reservoir operation curves taking into account the possibility of additional pumping.

At present, there are few models of general use including the possibility of introducing aquifers as a specific element when developing a water resources scheme for study. These models are mainly for simulation (SIMGES [6], Modsim [7], or WEAP [8]), which solve an optimization problem for each time step in the simulation to obtain the flows through the system. However, any pure optimization model has been found that allows introducing aquifers as a separate element and they are usually dealt with by tricks in the system description using, for example, reservoir elements, what will not show the usual complex behavior of aquifers, although it could be a first approach. Therefore, it has been found interesting to develop a model where this inconvenience is solved and aquifers, and their related features inside the water system, are considered as a specific separate element. To do this, an existing optimization model has been used as a base so focus was exclusively upon the aquifer development. In the following sections describe the optimization model 
used and how an aquifer module has been developed for it together with an example of how it works.

\section{OPTIGES, A NETWORK FLOW PROGRAMMING MODEL FOR WATER RESOURCES SCHEMES OPTIMIZATION}

OPTIGES (Andreu [9]) is a program of general use that allows optimizing a scheme of water resources. It is integrated in the DSS AQUATOOL (Andreu et al. [10]).

For its use, the user must previously make a simplified scheme of the water resources system with the elements considered by the model which are, namely, channels (natural and artificial), nodes (forks, junctions or reservoirs), hydrological inflows and demands (zones where water is used). The user supplies the program with the configuration data of the scheme together with the physical data of the elements (for example maximum capacities of channels, or maximum volume stored in reservoirs), the demands data as well as the data used for fixing priorities between scheme elements and for defining guarantee criteria of demands satisfaction and environmental requirements.

The program works with monthly values and allows optimization periods of at least one year, with a number of periods also fixed by the user. The model results include the values of the stored volumes in reservoirs, circulating flows and supply deficits for each month, as well as a final summary of the whole optimization horizon including average, monthly and yearly values of all variables.

To solve the optimization problem, OPTIGES converts the user scheme with all the introduced data into a minimum cost network flow problem which is afterwards solved with either the Out-of-Kilter algorithm (Ahuja [11]) or the RELAX-IV algorithm (Bersetkas [12]), depending on the choice of the user and being the first one used mainly for schemes created in the initial versions of the program and the second for the later versions. 
OPTIGES is also capable to deal with evaporation from reservoirs and water returns from demands. These two aspects represent nonlinearities which are a priori impossible to solve directly with network flow programming, since it is a form of linear programming. What it is done instead is solving iteratively the minimum cost network flow problem, changing the characteristics of the arcs in the network associated to each of the non-linear elements, after each iteration, until convergence is reached. The iteration routine calculates the evaporation or return flows associated to the solution obtained with the network flow algorithm and compares these values with the ones obtained in the corresponding arcs of the network; if there is a difference between them, the routine modifies the flow limits of the arcs and runs again the algorithm. This is done until the difference between the calculated values and the ones obtained from the algorithm is minimal, or the maximum number of iterations is reached.

\section{AQUIFER MODULE DEVELOPMENT}

When considering aquifers in a water resources system, not only their storage capacity must be taken into account but also all the possible relations they may have with the surface system. This means that infiltration from reservoirs and from river bed must be considered, also pumping from demands or for other uses as well as artificial recharges and last but not least the connection between river and aquifer which sometimes exists. Therefore, the inclusion of an aquifer will require several actions that will affect the optimization model at different levels:

Water resources system schematization

Network flow definition

Iterative process of new non-linear elements (infiltration from reservoirs, loses from rivers and demands...)

Aquifer simulation

Reading of results 
Both, the water resources system schematization and the network flow definition are intimately related. Together with the element "Aquifer" were also included new options for existing elements of the OPTIGES model both as new scheme elements and extra options for existing ones. The new possibilities added to OPTIGES are:

\section{Aquifer elements}

Channel elements, or river reaches, with loses by infiltration

Channel elements, or river reaches, hydraulically connected to the aquifer
Additional pumping elements
Artificial recharge elements
Infiltration from reservoirs
Pumping supply to consumptive demands
Infiltration loses from consumptive demands

Each of these new features will require, when defined by the user, the creation of extra arcs in the network flow, what will noticeable enlarge it adding an extra complexity to the resolution process.

Several of the newly added features correspond to aspects absolutely non-linear. Thus, as it is already done in OPTIGES with the nonlinear aspects considered (evaporation and returns); an iterative solution process will be followed to deal with the new non-linear processes. All the non-linearities include require that the flow circulating through a certain arc is related in some way to the flow circulating through a different arc. For example, in the case of filtration loses from reservoirs, the circulating flow through the arc connecting the reservoir and the aquifer in one month will be related to the flow representing the stored volume following the infiltration law: $\mathrm{F}=\mathrm{a}+\mathrm{bV}^{\mathrm{c}}$, where $\mathrm{F}$ represents the infiltration looses flow, $V$ is the volume stored in the reservoir and $a, b$ and $c$ are three coefficients 
which must have been defined by the user previously. The same procedure is followed for infiltration loses in channels. The infiltration loses from consumptive demands depend from the usage and return factors associated to the demands, which must be defined by the user as well. Finally, the hydraulic connection between the aquifer and the river reaches with had been included in the scheme will depend on the volume balance of the aquifer with its inputs and outputs, as well as the aquifer type considered

All the non-linear flows and affections to the aquifer are calculated first and a call is made to a routine (ACUIFERO); where the aquifer balance is calculated and the flows circulating between aquifer and hydraulically connected river reaches is obtained. The ACUIFERO routine simulates the aquifer behavior for the whole optimization period and checks for impossible water withdrawals from river reaches as well as pumping control parameters. The aquifer simulation yields as a result the connection flow between aquifer and river which is the last non-linearity to be calculated. As explained before, the iteration routine checks for convergence in all the affected arcs of the network and reassigns their limits if necessary, triggering a new run of the resolution algorithm.

The previously commented pumping control parameters are rules for groundwater extraction through wells that are defined by the user and depend of the aquifer status (either the volume stored in the aquifer or the volume circulated between river and aquifer). When the value of any of the two aquifer parameters is below certain threshold, the pumping controlled by that parameter will stop until the value is above the defined threshold.

After convergence has been reached for all the non-linearities, the program will extract the results for the complete optimization period and will write average, monthly and annual summaries, as well as create a results file for graphical output.

APPLICATION IN THE OPTIMIZATION OF A SIMPLE WATER RESOURCES SYSTEM 
To show how the developed module works a simple water resources system scheme was created. The system has a single reservoir which has looses by infiltration, a urban demand which returns part of the supplied water to the river, a rural demand that can extract groundwater for complementing the surface water supply (only half of the total demand is possible to supply from pumping), a unicellular aquifer hydraulically connected to two river reaches and receiving precipitation recharge. The urban demand has priority of supply respect the rural demand.

With the same hydrological inflows for a 60 year period, the scheme was run with the SIMGES [6] simulation model and with the OPTIGES optimization model with the groundwater module included.

The results obtained show how the optimization model allows more pumping for the rural demand since it considers the whole 720 month period while the simulation model only uses the groundwater supply as a complement in months when surface supply is not enough, and allows maintaining a higher storage volume in the reservoir instead of emptying it. Of course, all this means that the deficits in both the urban and the rural demands are reduced. However, the higher exploitation of the aquifer yields, of course, a diminishment in the groundwater storage during the driest periods. Anyway, aquifer overexploitation problems may be avoided by using a pumping control parameter which will prevent water to be extracted from the aquifer if its levels decrease below the value of the parameter.

\section{CONCLUSIONS AND FURTHER WORK}

Optimization is an important task in water resources planning and management. Thus, it is important that the optimization models, even though they are primarily used for alternatives filtering, show a good degree of detail. This should help to make better decisions on the actions to be studied more in deep. Moreover, water resources systems are becoming more and more complex, and water managers require giving more precise 
answers to the principal stakeholders' necessities. Therefore, improving the representation of the optimization models being used is a need to be fulfilled in the short term.

An aquifer module has been developed for an existing optimization model working under network flow programming. The aquifer consideration in the network flow has been made through iterations so the non-linear behavior of the new element and all the new features related to it, which have also been implemented, can be dealt with. The results for simple cases show that the module works fine as the model improves the water availability in the system, reducing the water deficits while saves water for future needs. At the same time, the model makes an efficient use of the aquifer and only extracts water when it is necessary.

However, the module behavior can still be improved. It has been observed that the model withdraws water from the aquifer in the very months that it is needed. Although this is a logical behavior, it is also interesting the possibility of pumping water before it is needed, so the water stored in the reservoir is saved and, at the same time, during dry periods, when the aquifer recharge is lower, the pressures on it are minor, since the water supplied can come from the superficial storage.

Another aspect to be improved is the behavior of the pumping control parameters. At present, this feature works either allowing groundwater pumping at whole capacity or stopping it completely when the threshold is surpassed. A more optimal solution could be obtained if the pumping capacity could be reduced gradually until the parameter was just at its threshold.

These two improvements are being dealt with at the moment and new advances are being done so a proper version of the optimization model is available in the coming time.

\section{REFERENCES}


[1] Loucks D., "Water Resource System Models: Their Role in Planning", Journal of Water Resources Planning and Management, Vol. 118, No. 3, (1992), pp 214-223

[2] Labadie J., "Optimal Operation of Multireservoir Systems: Stateof-the-Art Review", Journal of Water Resources Planning and Management, Vol. 130, No. 2, (2004), pp 93-111

[3] Shiklomanov I.A. and Rodda J.C., "World Water Resources at the Beginning of the $21^{\text {st }}$ Century", Cambridge, UK, Cambridge University Press, (2003)

[4] IGRAC, "Global Groundwater Information System Database" (igrac.nitg.tno.nl/ggis map/start.html IvJan12)

[5] Morris B.L., Lawrence A.R., Chilton P.J., Adams B., Calow R.C. and Klinck B.A., "Groundwater and its Susceptibility to Degradation. A Global Assessment of the Problem and Options for Management". Early Warning and Assessment Report Series, RS. 03-3, UN, (2003)

[6] Andreu J., Solera A., Capilla J. and Ferrer J., "Modelo Simges para Simulación de Cuencas. Manual de Usuario v3.00", Valencia, Spain, Universidad Politécnica de Valencia (2007)

[7] Labadie, J. and R. Larson, "MODSIM: River basin management decision support system, User Manual”, Department of Civil Engineering, Ft. Collins, CO, Colorado State University, (2007)

[8] Yates D., Sieber J., Purkey D. and Hubert-Lee A., "WEAP21 - A Demand-, Priority-, and Preference-Driven Water Planning Model. Part 1: Model Characteristics". Water International, Vol. 30, No. 4, (2005), pp 487500

[9] Andreu J. "Modelo OPTIGES de Optimización de la Gestión de Esquemas de Recursos Hídricos. Manual del Usuario v2.00", Valencia, Spain, Universidad Politécnica de Valencia, (1992) 
[10] Andreu J., Capilla J. and Sanchís E., "AQUATOOL: a generalized decisión support system for water resources planning and operational management". Journal of Hydrology, Vol. 177, (1996), pp 269-291

[11] Ahuja R., Magnanti T. and Orlin J., "Network Flows: theory, algorithms and applications", New York, Prentice Hall, (1993)

[12] Bersetkas D. and Tseng P., "RELAX-IV: A Faster Version of the RELAX code for Solving Minimum Cost Flow Problems", Completion Report for NSF Grant CCR-9103804, Dept. of Electrical Engineering and Computer Science, Massachusetts Institute of Technology, Cambridge, USA, (1994)

\section{A.2.2. Optimal management of the Jucar River and Turia River basins under uncertain drought conditions}

David Haro, Abel Solera, María Pedro-Monzonís, Joaquín Andreu

(Proceedings and Oral communication at WDSA 2014, Bari)

\section{Abstract}

This paper presents a methodology to assess the best behavior achievable for a water resources system, and we apply it to the joint system of the Jucar River and Turia River basins in Spain. The resources of the two rivers are used jointly to meet the different water uses within the region, especially urban demands and environmental requirements. The climate change effects in this area are predicted to be particularly severe in this area [1] with great variability in drought patterns [2]. The results are particularly suitable for evaluating the best performance of the system under uncertain conditions.

\section{Introduction}

Drought is a major concern for water managers in many regulated river basins throughout the world. Especially at those in which the equilibrium between resources availability and water uses is very fragile, making that deviation below normality compromises the capacity of the 
system to cope with all the demands and environmental requirements. Since droughts are not isolated events but instead they develop over time in what could be considered a creeping behavior, it is very difficult to determine when an episode starts and how long will it last. This lack of knowledge makes difficult both long term and short term decision-making processes.

Because of the difficulty at detecting drought episodes occurrence, and forecasting their intensity and duration, the traditional responses to drought have been reactive, adapting the measures to the severity of impacts as long as they were detected in what is called a crisis management. This approach is ineffective, poorly coordinated, and untimely; and does little to reduce the risk associated with drought [6]. Because of this, drought management has evolved in recent years towards a more risk-preventive approach. Drought planning must predict what is predictable and establish strategies of prevention and management of the growing drought risks generated within the current climate change dynamics [7]. To reduce drought risk, there must be an understanding of the hazard using climatology, improved operational monitoring, an analysis of vulnerability to understand what people and sectors may be most affected by drought, why these impacts occur, and if these relationships are changing over time [8]. This new risk management based approach to drought management has been expressed in the necessity of developing drought management plans ([9]) that provide a dynamic framework for an ongoing set of actions to prepare for, and effectively respond to drought, including periodic reviews of the achievements and priorities; readjustments of goals, means and resources; as well as strengthening institutional arrangements, planning, and policy-making mechanisms for drought mitigation.

Following a preventive approach in drought management requires advancing, to a certain extent, the possible impacts a drought episode may have on the water resources system. To do this it is necessary both forecasting drought characteristics and assessing their effects on the system. A common methodology is the use of indicator systems. An 
indicator system for a river basin is formed by a series of variables that describe the basin drought status and include: reservoir storages, groundwater piezometric levels, streamflows, reservoir inflows and precipitation. The different values taken by the indicator define what is the drought status. However, these systems are limited to determine current drought situation based on the comparison of present variables values with the variables occurred in the past. This limits the forecasting capabilities of the indicator systems. Even though they have been calibrated in such a way they can forecast similar past droughts, no drought episode is equal to other and thus it is very unlikely the indicator system is capable of advancing the real consequences of the upcoming event.

This paper introduces a methodology to assess the best behavior of a water resources system in front an uncertain hydrologic situation, as well as to evaluate the best achievable results for any mitigation option managers could envisage. We applied it to the Jucar and Turia Rivers conjunctive water resources system as a complement of the existing indicators system. We will show how the complementary use of both options allows an improved management of the system allowing water managers to optimize the settings of the measures addressed to avoid the drought event develops into a serious threat to the system.

\section{Tools and methods}

To show the applicability of the methodology presented we applied it to the water resources system composed by the Jucar and Turia Rivers. These two rivers suffer from recurrent drought episodes and have developed an indicator system to define the situation of both systems with regard to such events. The reason to choose the two systems instead of just one is the existence of a complex union between them two at their lower courses, with an important amount of different water uses with different priorities and necessities what makes of the management of these two systems a very interesting matter of study. Additionally, the results of recent drought studies revealed the necessity to create an indicator system for the two systems at the same time due to the particular management 
issues of both together [10]. With the proposed methodology it will be possible to forecast which system will be in a worse condition first. This will allow anticipating measures to bring water from one system to the other that minimize the possible effects of drought, if the episode developed worse.

\section{Area of study}

The Jucar and Turia River Basins are located in the eastern part of the Iberian Peninsula in Spain (see figure 1). These two basins are the main of 9 water exploitation systems in the Jucar River Basin Demarcation (DHJ). In the Valencia coastal plain, where Jucar and Turia Rivers have their final parts, and between both mouths, there is a shallow lake called Albufera, with an associated wetland. Both, the lake and the wetland, represent the nexus of union between both systems, as they depend on return flows from irrigation areas belonging to both basins, and also on groundwater flows from the coastal aquifer beneath the plain.

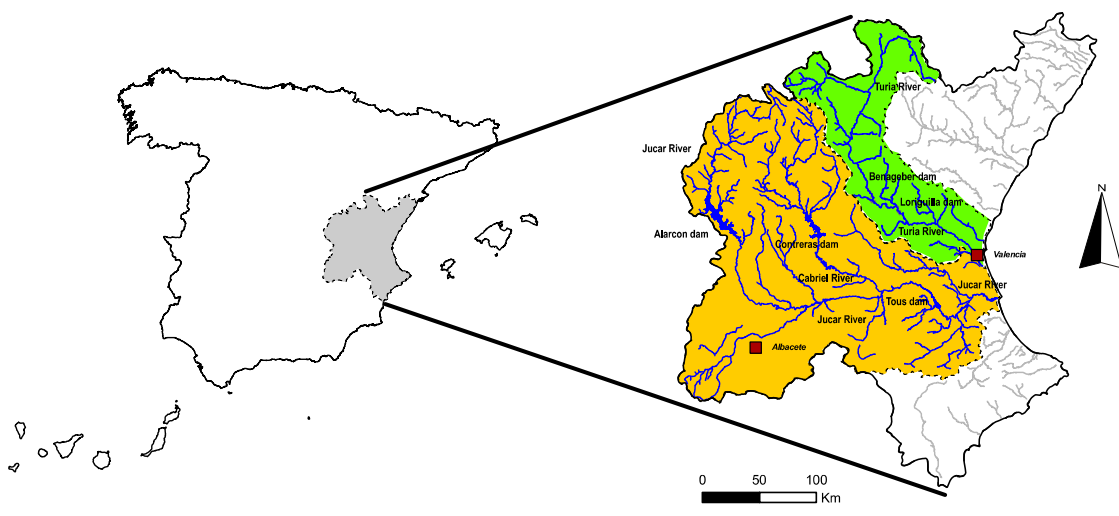

Fig. 1. Location of the Jucar and Turia River Basins in Iberian Peninsula

The Jucar River has a length of $497.5 \mathrm{~km}$, traversing the provinces of Teruel, Cuenca, Albacete and Valencia, having its mouth at the Mediterranean Sea. Additionally, this water exploitation system includes 
the area and services provided by the Jucar-Turia Channel and the littoral sub-basins between the Albufera Lake and around 10 kilometres south from the mouth of the river. It is the most extensive system $(22,261 \mathrm{~km} 2)$ and with more water resources at the Jucar River Basin Agency. On the other hand, the Turia River has a length of $280 \mathrm{~km}$, traversing the provinces of Teruel, Cuenca and Valencia, having its mouth in the city of Valencia at the Mediterranean Sea too. It is the second most extensive system $(6,393 \mathrm{~km} 2)$ and with more water resources at the Jucar River Basin Agency. A brief description of the study area and key issues is presented below, details can be found in [12].

Both rivers are an example of a typical Mediterranean river, characterized by a semi-arid climate consisting of irregular rainfall and seasonal summer scarcity that occurs when irrigation requirements are at their height [14]. Average natural resources reach 1,170 hm3/year for the Jucar River and $295 \mathrm{hm} 3 /$ year for the Turia River. The total population depending on both river basins represents a water demand of 148.5 $\mathrm{hm} 3 /$ year and the water demand for irrigated agriculture reaches 833.7 hm3/year. The supply to urban areas comes mainly from wells and springs, but Albacete, Sagunto and Valencia metropolitan areas use surface water.

Both systems represent one of the most vulnerable areas of the western Mediterranean region, due to high water exploitation indexes, and to environmental and water quality problems when droughts appear. This situation has triggered an increased use of non-conventional resources in recent years, such as reuse of wastewater and drought emergency wells. Also, conjunctive use of surface-ground waters has been historically a very important option in the district to provide robustness against droughts. The integrated use of those three kinds of resources was crucial in adapting to the recent drought occurring between 2005 and 2008 [15]. This situation is especially important in Turia River Basin where Valencian farmers have been able to integrate groundwater, recycled and traditional surface water use in a single system. 
From the above, the Albufera Lake represents the nexus of union between both river basins (see figure 2). Their natural and anthropogenic inputs correspond to [16]: freshwaters, groundwater contributions through a series of springs called "ullals", direct precipitation on the lake, return flows from irrigation areas belonging to both basins and urban or industrial wastewater treatment outflows. It is noteworthy that agricultural activity, contribute to near $60 \%$ of inputs to the Albufera [17].

\section{The SIMRISK-OPTIRISK methodology}

The SIMRISK-OPTIRISK methodology is based in previous works presented in [4], [5] and [18]. Their results were successfully used in the management of previous drought episodes in the two systems studied. We now present an evolution of the previous ones introducing an optimization approach what will allow obtaining the best results achievable in the system and the better rules for the application of the mitigation and prevention measures.

This methodology is summarized in figure 2 and allows evaluating the propensity of the WRS to operative droughts, both on a short and a long-term time scale (from a single campaign to some years depending on the memory of the system). It requires, on a first stage, the identification of the water resources system and its characteristics, both hydrological and physical. From hydrologic characteristics, principally streamflow series, it will be possible to formulate and calibrate a stochastic model with which generating multiple streamflow series equiprobable with the historic series. From the physical characteristics of the system it is possible to develop a scheme that can be later used to run a simulation or an optimization model of the system management. The previously generated series can be used to feed the desired model in multiple runs so multiple different management results of the system are obtained depending on the hydrologic conditions introduced. 


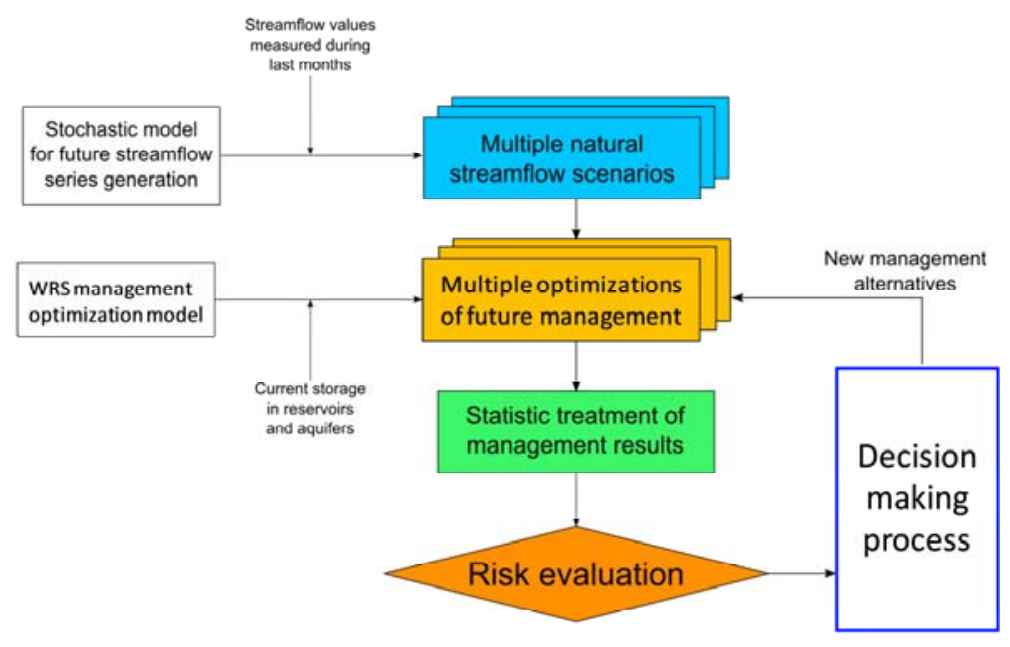

Fig. 2. Flow chart of the OPTIRISK methodology

After the multiple runs are completed, it is possible to calculate several indicators for short-term management, such as: the probability of suffering a monthly shortfall in the supply to a demand or environmental flow; or the probability of being in a certain storage level at a reservoir in one month.

These values provide an estimation of the risk of operative drought in the forthcoming months. If this risk is high, it will be necessary to take measures to mitigate the effects of the possible drought.

If the model of the system used is a simulation model, then the results obtained are with regard to the existing, or newly proposed, management rules of the system. On the other hand, by using an optimization model, like we propose now, the results yielded by the analysis will be with regard to the best achievable management of the system resources. This may help decision makers to know what is the best situation they may encounter after the considered period (for example at the end of the irrigation campaign in the summer), and thus to better define operation rules of the system during drought episodes. It will also 
allow optimizing the timing for additional measures to mitigate drought effects, saving money from their setting and operation costs.

Therefore, to apply this methodology we need a stochastic model for multiple streamflow series generation, an optimization model of the system to study and tools to carry out the probability analyses to obtain management indicators.

\section{Stochastic generation of streamflow series}

For the studied case, we adjusted a multivariate $\operatorname{ARMA}(1,1)$ model using the monthly streamflow series from 1980 to 2008 . With the calibrated model we are now capable of generating any number of time series equiprobable with the historic series. Following the proposed methodology, we generated a high number of series (1000) with initial analysis month April 2014, which corresponds to the beginning of the irrigation campaign, and 18 months length in order to reach the end of the next year irrigation campaign (irrigation campaign normally ends in September).

\section{Water resources system management optimization model OPTIGES}

OPTIGES is a program of general use that allows optimizing a scheme of water resources. It is integrated in the DSS AQUATOOL [19].

For its use, the user must previously create a simplified scheme of the water resources system with the elements considered by the model that are, namely, channels (natural and artificial), nodes (forks, junctions or reservoirs), hydrological inflows and demands (zones where water is used). The user supplies the program with the configuration data of the scheme together with the physical data of the elements (for example maximum capacities of channels, or maximum volume stored in reservoirs), the demands data as well as the data used for fixing priorities between scheme elements and for defining guarantee criteria of demands satisfaction and environmental requirements. Figure 3 shows the scheme of the Jucar and Turia water resources system developed for this study. 


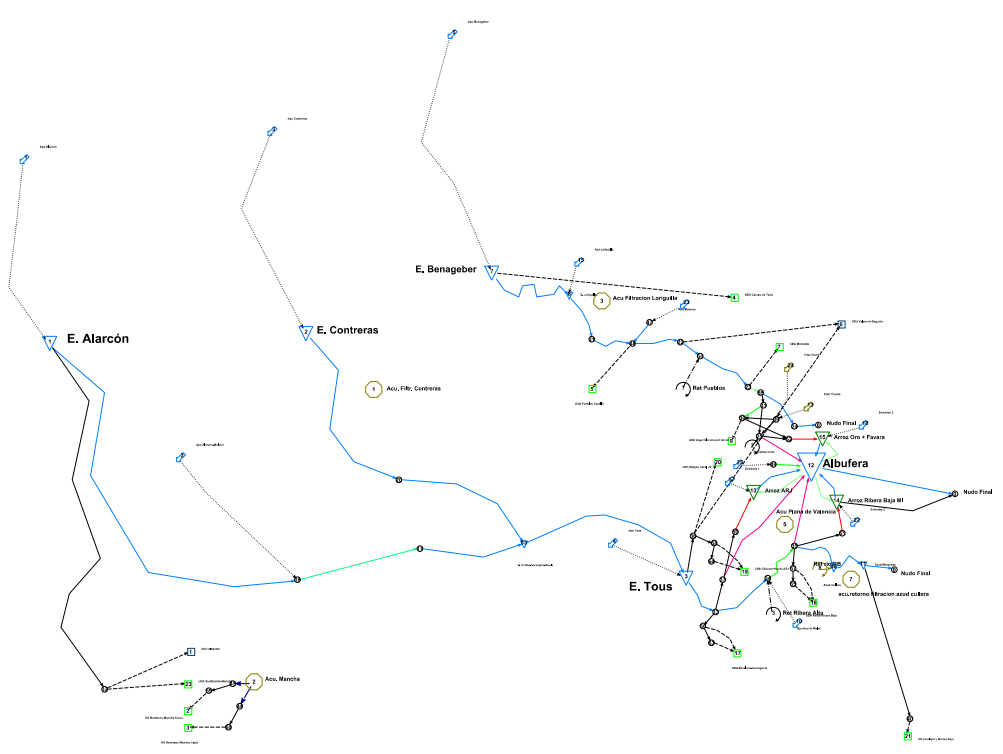

Fig. 3. AQUATOOL scheme of the Jucar and Turia water resources systems

The program works with monthly values and allows optimization periods of at least one year, with a number of periods also fixed by the user. The model results include the values of the stored volumes in reservoirs, circulating flows and supply deficits for each month, as well as a final summary of the whole optimization horizon including average, monthly and yearly values of all variables.

To solve the optimization problem, OPTIGES converts the user scheme with all the introduced data into a minimum cost network flow problem which is afterwards solved with a high performance algorithm.

OPTIGES is also capable to deal with evaporation from reservoirs and water returns from demands. Additionally, it is also capable of considering, to a certain extent, the relation between the surface system and groundwater [20]. The user can make use of several aquifer models and connecting them to the surface system via infiltration losses from 
conductions and reservoirs, hydraulic connected river stretches, pumping from demands and artificial groundwater recharges. All these aspects represent non-linearities that are, a priori, impossible to solve directly with network flow programming, since it is a form of linear programming. What it is done instead is solving iteratively the minimum cost network flow problem, changing the characteristics of the arcs in the network associated to each of the non-linear elements, after each iteration, until convergence is reached. The iteration routine calculates the flows associated to the solution obtained with the network flow algorithm and compares these values with the ones obtained in the corresponding arcs of the network; if there is a difference between them, the routine modifies the flow limits of the arcs and runs again the algorithm. This is done until the difference between the calculated values and the ones obtained from the algorithm is minimal, or the maximum number of iterations is reached.

\section{Results and discussion}

During the last large drought episode suffered in the basin, $\mathrm{CHJ}$ developed a Standardized Operative Drought Monitoring Indicators system (SODMI) [21]. In essence, the SODMI uses real-time information provided by the Automatic Data Acquisition System of $\mathrm{CHJ}$ on the state of reservoirs, aquifers, rivers, and precipitation to produce standardized indexes for some selected elements in the basin. These indexes then are combined into a single standardized index for each basin. Figure 4 shows the evolution of this index along time for the Jucar and Turia Rivers basins.
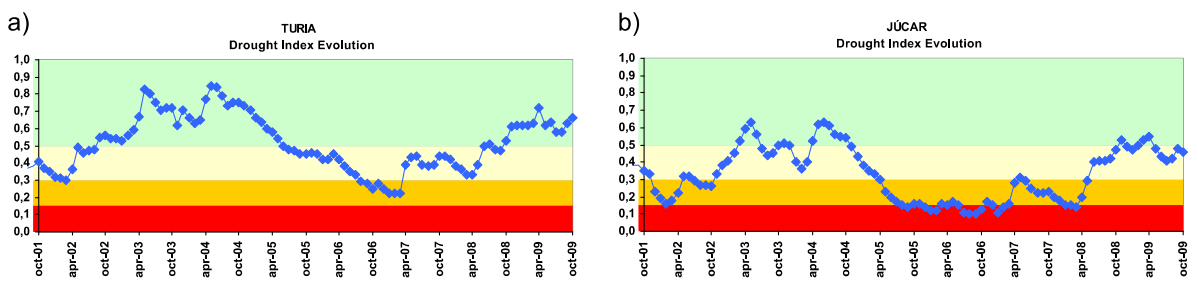

Fig. 4. Evolution of the standardized drought index in the a) Turia and b) Jucar Rivers basins 
SODMI has provided useful information for early warning and action against drought, as well as for risk perception by the public. Yet, in order to manage droughts, a more elaborate and detailed information system is needed to better assess the risk and the effectiveness of the measures that can be used to modify the risks, and to mitigate the effects of the drought on both the established uses and on the environment.

The predictions of OPTIRISK improve with regard the combined indicators of storage and streamflow because they include both previous precipitation and storage data. Additionally, they include the information regarding the physical system what allows obtaining its best management options.

A very important issue with regard to drought risk in a regulated system is the storage level of reservoirs, especially at the end of the irrigation campaign, which coincides with the beginning of the hydrologic year, and thus representing the available volume to confront the next management period. Figure 5 shows the probability of non-exceedance of storage in the reservoirs of the Turia and Jucar Rivers at the end of the two campaigns considered when generating streamflow series. It is possible to observe that there are high chances the Turia River basin ends the current campaign with low storage levels, below $100 \mathrm{hm} 3$, while for the end of the second campaign the situation improves notably. This is due to Turia River basin is regulated in a within-year basis what means its management is mostly driven by hydrology. On the other hand, the Jucar River basin will probably end the current campaign with intermediate-high storage levels and, since it is an over-year operated, the chances that it ends the next campaign with levels above average. The decisions made by the water managers will depend on how serious they consider the risk of shortages, especially in the Turia River basin. 

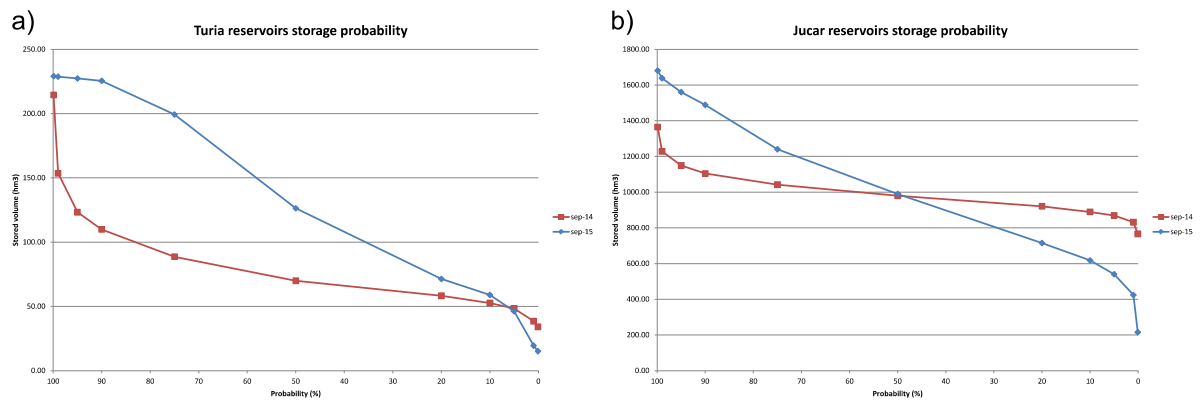

Fig. 5. Probability of non-exceedance of storage in the reservoirs of the a) Turia and b) Jucar Rivers at the end of the 2013-14 and 2014-15 campaigns, calculated in May 2014

\section{Conclusions}

We have presented a methodology for drought risk assessment based on the probabilistic aggregation of optimal management results of a water resources system model when fed with multiple stochastic generated streamflow series. We have applied it to the water resources system of the Jucar and Turia River basins and shown how this analysis improves the quality of the information on the actual situation at the time, since it provides estimations of probability that are not obtainable from the more classical indicators described above, complementing them.

The methodology we presented has a broad range of applications with regard to drought management and preparation, for example: identification and definition of both measures to reduce the propensity to operative droughts (pro-active measures) and short-term operative drought mitigation measures (reactive measures); design of emergency plans against drought; definition of better indicators to identify the risk of suffering an operative drought; and optimizing the implantation of the measures considered to be the most appropriate.

One of the main advantages of the proposed methodology is its capacity for dealing with complex systems, giving an overall picture of the situation in the basin as well as of the individual uses, while most of the previously developed indices are applicable only to a demand or to a group 
of demands. Thus, the proposed method constitutes an authentic early warning system on the arrival of an operative drought.

\section{Acknowledgements}

The authors wish to thank the Confederación Hidrográfica del Júcar (Spanish Ministry of the Environment) for the data provided in developing this study and the Spanish Ministry of Economy and Competitiveness for its financial support through the projects SCARCE (Consolider-Ingenio 2010 CSD2009-00065) and NUTEGES (CGL2012-34978). We also value the support provided by the European Community's Seventh Framework Program in financing the projects DROUGHT-R\&SPI (FP7-ENV-2011, 282769), ENHANCE (FP7-ENV-2012, 308438), WAMCD (EC-DG Environment No. 07.0329/2013/671291/SUB/ENV.C.1) and LIFE ALBUFERA (LIFE12 ENV/ES/000685).

\section{References}

[1] S.R. Lavorel, J. Canadell, S. Rambal, J. Terradas, "Mediterranean terrestrial ecosystems: research priorities on global change effects", Global Ecology and Biogeography, vol. 7, pp. 157-166

[2] S.M. Vicente-Serrano, J.C. González-Hidalgo, M. de Luis, J. Raventós, "Drought patterns in the Mediterranean area: the Valencia región (eastern Spain)", Climate Research, vol. 26, 2004, pp. 5-15

[3] J. Andreu, J. Capilla, E. Sanchis, "AQUATOOL a generalized decisión support system for water resources planning and operational management", Journal of Hydrology, vol. 117, pp. 269-291

[4] S. Sanchez-Quispe et al., Gestión de recursos hídricos con decisiones basadas en estimación del riesgo, Valencia, Universitat Politécnica de València

[5] A. Cancelliere, V. Nicolosi, G. Rossi, "Assessment of drought risk in water supply systems", in A. Iglesias (ed) Coping with drought risk in 
agriculture and water supply systems, Advances in natural and technological hazards, vol. 26

[6] D. Wilhite, M.J. Hayes, C Knutson, K. Helm Smith "Plannign for drought: Moving from crisis to risk management," Journal of the American Water Resources Association 2000; 26: 697-710

[7] P. Arrojo Agudo, "Bases para un documento de directrices en material de prevención y gestión de sequías en la planificación hidrológica", in: E. Cabrera and L. Babiano (Eds.) La sequía en España. Directrices para minimizar su impacto, Ministry of Environment of Spain (2007)

[8] M.J. Hayes, O.V. Wilhelmi, C.L. Knutson, "Reducing Drought Risk: Bridging Theory and Practise," Natural Hazards Review 2004; 5: 106113

[9] D.A. Wilhite, "A Methodology for Drought Preparedness," Natural Hazards 1996; 13: 229-252

[10] CHJ , "Informe Post-Sequía," in Plan especial de alerta y eventual sequía en la confederación hidrográfica del Júcar , 2010

[11] J. Ferrer, M.A. Pérez-Martín, S. Jiménez, T. Estrela and J. Andreu, "GIS-based models for water quantity and quality assessment in the Júcar River Basin, Spain, including climate change effects," Science of the Total Environment 2012; 440: 42-59 http://dx.doi.org/10.1016/j.scitotenv.2012.08.032

[12] M. Ortega-Reig, G. Palau-Salvador, M.J. Cascant, J. BenítezBuelga, D. Badiella and P. Trawick, "The integrated use of surface, ground and recycled waste wáter in adapting to drought in the traditional irrigation system of Valencia," Agricultural Water Management, 2014, 133, pp. 55-64.

[13] P. Carmona and J.M. Ruiz, "El medio físico. El territorio como escenario de los regadios históricos," In: Hermosilla, ESTEPA (Eds.), El patrimonio hidráulico del bajo Turia. L'Horta de Valencia, Volume 9. 
Consellería de Cultura y Deporte de la Generalitat Valenciana, Valencia, 2007, pp. 30-44.

[14] M. Ortega-Reig, G. Palau-Salvador, M.J. Cascant, J. BenítezBuelga, D. Badiella and P. Trawick, "The integrated use of surface, ground and recycled waste wáter in adapting to drought in the traditional irrigation system of Valencia," Agricultural Water Management, 2014, 133, pp. 55-64.

[15] O.L. Usaquén, A. García, A. García, C. Álvarez and J.A. Revilla, "Methodology to assess sustainable management of wáter resources in coastal lagoons with agricultural uses: An application to the Albufera lagoon of Valencia (Eastern Spain)," Ecological Indicators 2012, 13, pp. 129-143.

[16] CHJ, "Contributions to L'Albufera Lake. Supplementary report to the European Investment Bank on the Júcar-Vinalopo." Jucar River Basin District, Valencia (Spain), 2003.

[18] J. Andreu, J. Ferrer-Polo, M.A. Perez, A. Solera and J. Paredes-Arquiola, "Drought Planning and Management in the Júcar River Basin, Spain," in K. Schwabe, J. Albiac, J.D. Connor, R.M. Hassan and L.MesaGonzalez (Eds.) Drought in Arid and Semi-Arid Region. A multidisciplinary and cross-country perpective, Springer 2013, pp 237-249

[19] J. Andreu, J. Capilla and E. Sanchis, "AQUATOOL: A generalized decision support system for water resources planning and operational management," Journal of Hydrology, 177: 269-291

[20] D. Haro, A. Solera, J. Paredes and J. Andreu, "Incorporating aquifer modeling into a multi-period network flow programming optimization model for water resources management," in Understanding Changing Climate and Environment and Finding Solutions, Proceedings of the 10th International Conference on Hydroinformatics - HIC 2012, Eds. Hinkelmann,R., Nasermoaddeli,M.H., Liong,S.Y., Savic,D., Fröhle,P., Daemrich,K.F., Hamburg, 14-18 July,2012, ISBN 978-3-941492-45-5 
[21] T. Estrela, "La gestión de las sequías en España," Ingeniería y Territorio. Catástrofes naturales 74; 52-57

\section{A.2.3. Current and future drought vulnerability assessment in the Jucar River basin (Spain)}

David Haro, Joaquín Andreu, Abel Solera, Javier Paredes

(Abstract and Oral communication at HYPER Droughts - EGU Leonardo 2014, Prague)

Drought occurrence and its related impacts are a major concern in many river basins throughout the world. In the coming times, water managers will confront severe uncertainties within the decision making process, both in the short term (management and operation) and long term (planning), in any water resources system where droughts are very frequent and where water resources are under a massive use. In general, vulnerability is used to characterize the performance of the system and it is a good indicator of the most likely failures. This may help managers especially in the planning phase, in which new measures both technical and operational may be devised to reduce the risk of suffering the effects of a dry spell either in the short or long term.

Decision support tools are a great ally of water managers, especially in situations of high water stress and hydrologic uncertainty, allowing them to in-deep analyze the system and finding the best measures to minimize the risk of a system failure. The use of such systems allows developing and using real time management models able to assess the vulnerability and risk of drought, and the effectiveness of proactive and reactive measures applied on regular basis for the management of river basins. They also represent a powerful tool for participatory processes since the different stakeholders involved in drought planning have a chance to develop and understanding of one another's various points of view, and to generate collaborative solutions. 
The Jucar River basin is one of the most vulnerable areas to drought of the western Mediterranean region due to climate characteristics (mostly semiarid), high water exploitation indexes (water scarcity), and very high space and time variability of precipitation (leading to a highly seasonal, and inter-annual variability in the river flows). Hydrological droughts in this region are frequent, and they can be very intense and with duration of years (frequently more than 3 years). For these reasons, careful risk and vulnerability assessments must be carried out to find and apply the appropriate measures to reduce them. Climate in the Jucar River basin is characterized by great variability, and climate projections only reveal that future resources generation will be characterized by great uncertainty.

In this article, we use a Monte Carlo approach to evaluate current and future vulnerability to drought in the Jucar River basin. First, we will assess the existing drought vulnerability under the present climatic conditions with a simulation model feed with multiple equiprobable series. Since it is not possible to know what will be the future operation of the system, its vulnerability needs to be approached from a different perspective. We will use an optimization model instead to obtain the minimum expected vulnerability of the system. This can help managers to develop future operation rules and enhance participatory processes to show stakeholders what are the least problems they may confront in the future. 